\title{
Electrochemical phosphorus removal and recovery
}

Yang Lei 


\section{Thesis committee}

\section{Promotor}

Prof. Dr C.J.N. Buisman

Professor of Biological Recovery and Re-use Technology

Wageningen University \& Research

\section{Co-promotors}

Dr R.D. van der Weijden

Senior Researcher, Department of Environmental Technology

Wageningen University \& Research

Dr M. Saakes

Theme coordinator

Wetsus, European Centre of Excellence for Sustainable Water Technology

\section{Other members}

Prof. Dr H. Bitter, Wageningen University \& Research

Dr P. van der Marel, North Water, Groingen

Dr P. Wilfert, IPP Ingenieurgesellschaft, Kiel, Germany

Prof. Dr F. Harnisch, Helmholtz Centre for Environmental Research-UFZ, Leipzig, Germany

This research was conducted under auspices of the Graduate School for Socio-Economic and Natural Sciences of the Environment (SENSE) 


\title{
Electrochemical phosphorus removal and recovery
}

\author{
Yang Lei
}

\author{
Thesis \\ submitted in fulfilment of the requirements for the degree of doctor \\ at Wageningen University \\ by the authority of the Rector Magnificius, \\ Prof. Dr A.P.J. Mol, \\ in the presence of the \\ Thesis Committee appointed by the Academic Board \\ to be defended in public \\ on Friday 6 December 2019 \\ at 4 p.m. in the Aula.
}


Yang Lei

Electrochemical phosphorus removal and recovery,

237 pages.

$\mathrm{PhD}$ thesis, Wageningen University, Wageningen, the Netherlands (2019)

With references, with summary in English

ISBN 978-94-6395-047-3

DOI https://doi.org/10.18174/496730 
For my family

谨以此书献给我的家人 


\section{Table of Contents}

Chapter 1. Introduction

Chapter 2. Electrochemical induced calcium phosphate precipitation: importance of local $\mathrm{pH}$

Chapter 3. Interaction of calcium, phosphorus and natural organic matter in electrochemical recovery of phosphate

Chapter 4. Fate of calcium, magnesium and inorganic carbon in electrochemical phosphorus recovery from domestic wastewater

Chapter 5. Is there a precipitation sequence in municipal wastewater induced by electrolysis?

Chapter 6. Energy efficient phosphorus recovery by microbial electrolysis cell induced calcium phosphate precipitation

Chapter 7. Electrochemical removal of phosphate in the presence of calcium at low current density: precipitation or adsorption?

Chapter 8. Electrochemically mediated calcium phosphate precipitation from phosphonates: implications on phosphorus recovery from non-orthophosphate

Chapter 9. Calcium carbonate packed electrochemical precipitation column: new concept of phosphate removal and recovery

Chapter 10. General discussion \& outlook

Summary

References

Acknowledgments

About the author

List of publications 


\section{Chapter 1}

\section{Introduction}




\subsection{Importance of phosphorus}

It is known that greenhouse gases (i.e., $\mathrm{CO}_{2}$ ) are changing the climate, drinking water is becoming increasingly scared, and the world population will reach 10 billion by the middle of the $21^{\text {st }}$ century.

However, the importance of phosphorus is probably not well-recognized [1].

Phosphorus is an essential nutrient-element for all forms of life, accounts for 2-4 weight percent of most dried cells, and plays a vital role in fundamental biochemical reactions (i.e., gene expression) [2]. As humans, our daily requirement of phosphorus can be gained from our diet. It was reported that a single adult consumes an equivalent of $35.2 \mathrm{~kg}$ of phosphate rock per year [3].

Along with the substantial increase in the world population, the demand for food has increased and thus also for phosphorus fertilizer. The global mining of phosphate rock has seen about a fivefold increase over the past half-century, from 14.6 Tg P in 1961 to $68.7 \mathrm{Tg}$ $\mathrm{P}$ in 2013, and this will continue to increase, along with the population growth [4]. Phosphorus fertilizer is widely used, yet it has no substitutes [5]. Without the use of phosphorus fertilizer, humanity could only produce half of the food that it does today. Therefore, the use of phosphorus fertilizer is essential in guaranteeing food production for the increasing global population [1].

Additionally, phosphorus is also used in pharmaceuticals, catalysts, flame retardants, building materials, food preservatives, and many other industries [6]. The non-fertilizer final use of phosphorus has increased from 5.6 Tg in 1991 to $26.5 \mathrm{Tg}$ in 2013 , which is almost a fivefold increase [4].

To conclude, phosphorus is of great importance for society and life itself.

\subsection{The problem: potential phosphorus shortage and eutrophication}

Along with the widespread use of phosphorus fertilizer and many other phosphorus products, two global problems arise: the potential phosphorus shortage crisis and the eutrophication of surface waters $[1,7]$. Although the potential phosphorus shortage might not be as well-known as other issues (i.e., climate change, population increase), it is equally important [1]. After all, humans can live without electronics, vehicles, but without phosphorus, humanity would starve. 
The world population, meanwhile, had seen a significant increase from 1.6 billion in the year 1900 to 7.7 billion in the year 2019 and could reach 10 billion by 2056 [8]. The ability to feed the 10 billion people is a real challenge [9].

Most certainly, the use of phosphorus fertilizer in modern agriculture will continue. In general, phosphorus fertilizer can be produced from mined phosphate rock. Unfortunately, the phosphate rock, as a finite resource, will be subjected to exhaustion [1]. While the exhaustion date of phosphate rock reserves is disputable, there is no doubt that phosphate rock will become a scarce resource, sooner or later, if no actions are taken $[4,10]$.

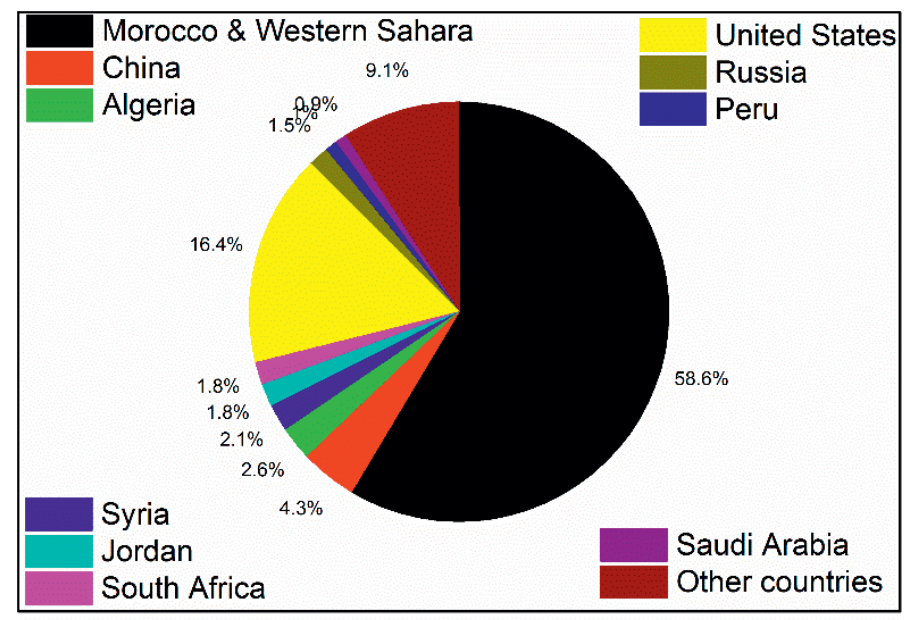

Figure 1.1. World phosphate rock reserves.

Also concerning, as shown in Figure 1.1, phosphate rock resources are only located in a few countries, with Morocco and Western Sahara holding 59\% of the global reserves, followed by the United States, and China [3]. In many countries, including the EU, there is almost no mineable phosphate rock [11]. As a result, those countries rely on importing phosphorus. This could be a big concern when countries set restrictions on their export of phosphorus due to geopolitical tensions or for other reasons [1]. In the past, we have seen a remarkable increase in the phosphate rock price by $800 \%$ in the middle of 2008 . This led to an increase in food price and even to violent riots in some countries [1]. Given the potential phosphorus crisis, both China and the U.S. have reduced the scale of phosphate rock mining, increased tariffs on phosphorus exporting, and tend to import more phosphate from outside their countries than export, for the sake of their long-term food security. 
Ironically, phosphorus, when in excess in water bodies, will harm the environment via eutrophication [4]. An example of eutrophication is shown in Figure 1.2. Eutrophication is a result of an excessive load of limiting nutrients into water bodies leading to harmful algal blooms, which in the end, deplete oxygen in water bodies and release toxic compounds (i.e., microcystin) [12]. Phosphorus is recognized by scientists in many cases as the primary limiting nutrient responsible for the eutrophication of water bodies [4, 13]. The eutrophication of surface waters not only reduces the value of aquatic systems for recreation but also challenges the production of safe and clean drinking water [10]. The estimated economic damages caused by eutrophication in the U.S. alone is approximately $\$ 2.2$ billion annually [14].

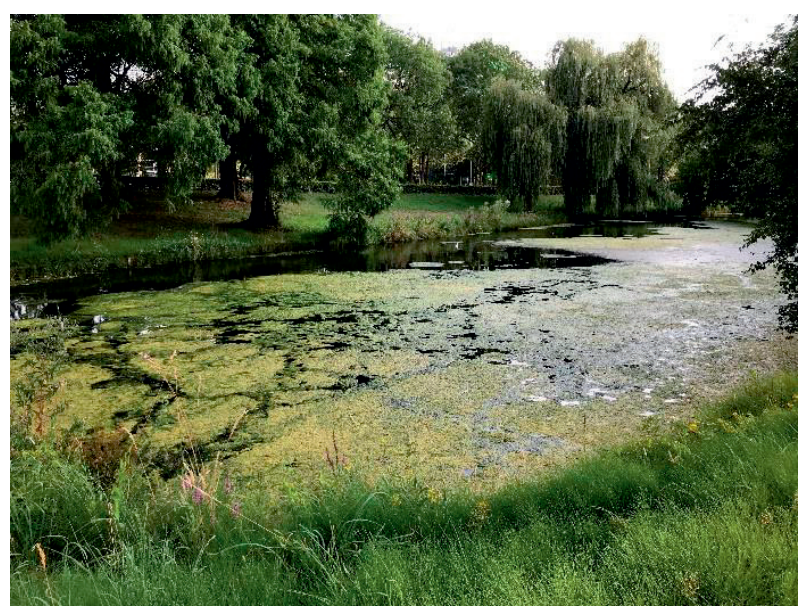

Figure 1.2. An example of eutrophication.

Although eutrophication can be a naturally occurring process, nowadays, eutrophication is mainly associated with human activities [15]. The discharge of not well-treated domestic and industrial wastewaters gives rise to an overload of phosphorus in surface waters. Moreover, the unsustainable management of feces of livestock (i.e., manure) brings phosphorus to natural aquatic systems via leaching, runoff or direct discarding [16]. Furthermore, overfertilization with artificial fertilizer also results in the leaching and runoff of phosphorus from agricultural fields into rivers and eventually the sea. As a consequence, phosphorus accumulates in some aquatic systems, leading to the algal blooms and in some situations, the breakdown of the local eco-system [17]. 


\subsection{The solution: a circular phosphorus economy}

Considering the merits and harms of phosphorus, the most obvious solution to address phosphorus-related social and environmental issues is to work on a circular phosphorus economy $[7,10]$.

Our ancestors have shown their wisdom in how the phosphorus cycle can be best managed. In ancient times, crops were consumed by humans and animals while their excreta were applied as a natural fertilizer to grow crops again. In this simple way, the cycle for phosphorus resource was short and nearly closed. This is still common practice in some rural areas in China. Today, due to the fast expansion of the global population and civilization, it is no longer that easy to close the phosphorus cycle, as our ancestors did in the past. The phosphorus cycle has been broken as a result of changes in civilization [7]. Nowadays, crops are cultivated in the countrysides and transported to cities. The waste associated with food consumption in cities is not returned to the farmlands but to the sewage system, which ends up either in sewage sludge or rivers, lakes, and the sea [1]. Often sewage sludge is incinerated and then landfilled.

Consequently, the cycle of phosphorus has become to some extent a linear process, that is, one-way flow of phosphorus from phosphate rock to landfills and to receiving water bodies, which eventually ends up in the sea [7].

Nonetheless, it is possible to reinvent a modern phosphorus cycle through multiple approaches [18]. Even if it may not be possible to achieve a $100 \%$ closed phosphorus loop, the use of phosphate rock, which is a nonrenewable resource, should be as sustainable as possible.

Obviously, the first approach would be to increase the usage efficiency of phosphorus fertilizer. This can significantly reduce the demand for phosphate rock mining. Today, about $80 \%$ of mined phosphate rock is used as fertilizer. However, less than $21 \%$ of the dosed phosphorus fertilizer is taken up by plants, and only $16 \%$ of used phosphorus fertilizer makes it into food, most of it is lost to soils and water bodies via runoff from agricultural fields [1, $7,10]$.

Independent of the usage efficiency of phosphorus fertilizer, there will be phosphorus discharged to sewage systems. A rough estimation of Yuan et al. suggested that the 
phosphorus in sewage systems could account for as much as $20 \%$ of the global agricultural demand of phosphorus fertilizer [19]. If the phosphorus in such waste streams can be recovered and reused, this would not only avoid/reduce the risk of eutrophication of water bodies but also provide a secondary phosphorus source [10, 20]. This would contribute significantly to close the phosphorus cycle.

In the realm of phosphorus removal and recovery, there are many technologies available. In the next paragraph, a brief introduction of phosphorus removal and recovery technologies will be presented.

\subsection{Phosphorus removal and recovery technologies}

Phosphorus removal has been in practice in wastewater treatment plants (WWTP) since decades in both developed and developing countries, mainly driven by legislative requirements. Indeed, to prevent eutrophication, the phosphorus in wastewaters needs to be removed before discharge into receiving surface waters. In this context, enhanced biological phosphorus removal (EBPR), adsorption, and chemical phosphate removal (CPR) via precipitation have emerged as efficient strategies for phosphorus removal [21, 22].

The modern WWTPs are based on biological processes. Biological processes, due to their broad applicability and low cost, are widely used. However, a single biological process usually cannot achieve efficient phosphorus removal. Therefore, in practice, the biological process is combined with other processes, i.e., chemical precipitation. CPR is a process where chemicals (i.e., iron or aluminum salts) are dosed into wastewaters, forming coagulants or binding directly with phosphate, which results in the removal of phosphate with the wastewater sludge $[23,24]$. Especially iron salts $\left(\mathrm{FeCl}_{2}\right.$ and $\left.\mathrm{FeCl}_{3}\right)$ are widely used for the CPR. Dosing iron is efficient for removing phosphate, yet for recovery, an extra process is needed to extract phosphorus from the sludge [25]. Adsorption is mostly used as a posttreatment strategy to further reduce phosphorus concentration in the effluent when strict discharge limits are implemented [26]. A general comparison of different phosphorus removal and recovery methods is presented in Table 1.1. 
Table 1.1. Merits, drawbacks and target applications of different phosphorus removal and recovery methods

\begin{tabular}{|c|c|c|c|}
\hline methods & advantages & disadvantages & application \\
\hline EBPR & $\begin{array}{c}\text { low cost; robust } \\
\text { operation }\end{array}$ & $\begin{array}{c}\text { relative low stability; } \\
\text { sludge }\end{array}$ & $\begin{array}{c}\text { concentrated } \\
\text { wastewater; full } \\
\text { scale }\end{array}$ \\
\hline adsorption & $\begin{array}{l}\text { high efficiency; } \\
\text { suitable for low } \\
\text { phosphorus- } \\
\text { containing streams }\end{array}$ & $\begin{array}{l}\text { low selectively; } \\
\text { regeneration of } \\
\text { adsorbents }\end{array}$ & $\begin{array}{l}\text { post-treatment; } \\
\text { medium to small } \\
\text { scale }\end{array}$ \\
\hline CPR & $\begin{array}{l}\text { easy operation; } \\
\text { highly efficiency } \\
\text { and stable }\end{array}$ & $\begin{array}{c}\text { dosing chemicals; } \\
\text { pH adjustment; } \\
\text { sludge }\end{array}$ & full scale \\
\hline $\begin{array}{l}\text { electrochemical } \\
\text { approach }\end{array}$ & $\begin{array}{l}\text { no chemical } \\
\text { dosing; less } \\
\text { sludge; }\end{array}$ & high energy cost & $\begin{array}{l}\text { on-site treatment; } \\
\text { medium to small } \\
\text { scale }\end{array}$ \\
\hline
\end{tabular}

While there are many methods addressing the removal of phosphorus, efficient and economically feasible methods for phosphorus recovery are limited. In the last decades, due to increased awareness of phosphorus depletion, pioneers had developed some approaches toward simultaneous removal and recovery of phosphate. In this realm, the struvite $\left(\mathrm{MgNH}_{4} \mathrm{PO}_{4} \cdot 6 \mathrm{H}_{2} \mathrm{O}\right)$ process stood out as one of the most promising ways [27]. One of the merits of struvite process is that phosphate $\left(\mathrm{PO}_{4}-\mathrm{P}\right)$ and ammonium $\left(\mathrm{NH}_{4}-\mathrm{N}\right)$ are removed simultaneously. Additionally, struvite has a higher bioavailability than iron and aluminum phosphate, and hence, it can be applied as a slow-release fertilizer [23].

However, the applicability of the struvite process depends on the water composition. The solution needs a pH between 8.0 and 9.0 and an ideal $\mathrm{Mg} / \mathrm{NH}_{4} / \mathrm{PO}_{4}$ molar ratio close to 1:1:1. Because the $\mathrm{Mg}$ concentration is low relative to $\mathrm{PO}_{4}{ }^{3-}$ and $\mathrm{NH}_{4}{ }^{+}$in most nutrient-rich waste streams, the dosing of a Mg source is required [28]. Therefore, although the struvite process has been tested in practice, this process is not widely adopted [28]. 


\subsection{Calcium phosphate precipitation}

An alternative process for phosphorus removal and recovery is by calcium phosphate precipitation $[29,30]$. In this process, the addition of a Ca source is most likely not necessary, as $\mathrm{Ca}^{2+}$ is an abundant ion in most waste streams [31,32]. It is worth mentioning that even when an external Ca source is required, the cost of dosing $\mathrm{Ca}$ is cheaper than dosing $\mathrm{Mg}$ [33, 34]. Moreover, as calcium phosphate is the key component of mined phosphate rock, it can be used directly as a raw material for the production of phosphorus fertilizer in the existing facilities [22,31]. Last but not least, the recovered product could also be stocked as a valuable phosphorus source for future use [30].

\subsection{Drawbacks of conventional chemical calcium phosphate precipitation}

The precipitation of calcium phosphate species is a complex process [22, 35]. In general, it is determined by the solution $\mathrm{pH}$, the concentrations of calcium and phosphate ions, coexisting components, and the temperature [36]. To trigger calcium phosphate precipitation, the solution needs to be highly saturated. The most common way to create a supersaturated condition is by increasing $\mathrm{pH}$ via the addition of caustic soda $(\mathrm{NaOH})$. However, as most wastewaters have a considerable buffering capacity due to the presence of organic acids and (bi)carbonate, significant dosing of $\mathrm{NaOH}$ is needed, in order to increase the $\mathrm{pH}$ to a certain level that would induce calcium phosphate precipitation in the waste streams. For example, Jaffer et al., reported that the cost relates to $\mathrm{NaOH}$ addition accounted for up to $97 \%$ of the total chemical costs associated with phosphate recovery by struvite formation method [37]. Moreover, in conventional CPR, a large quantity of sludge is generated, which requires further treatment before recycling. Furthermore, the high $\mathrm{pH}$, which is needed to induce calcium phosphate precipitation, needs to be reduced again by dosing acid [38].

\subsection{Electrochemically induced calcium phosphate precipitation}

Electrochemically induced calcium phosphate precipitation opens a door for avoiding such problems. Figure 1.3 illustrates the principle of electrochemically induced calcium phosphate precipitation. In the electrochemical system, a local high $\mathrm{pH}$ close to the cathode can be created by water electrolysis [39-41], as shown in eq 1.1:

$$
\text { Cathode: } 4 \mathrm{H}_{2} \mathrm{O}+4 \mathrm{e}^{-} \rightarrow 4 \mathrm{OH}^{-}+2 \mathrm{H}_{2} \uparrow
$$




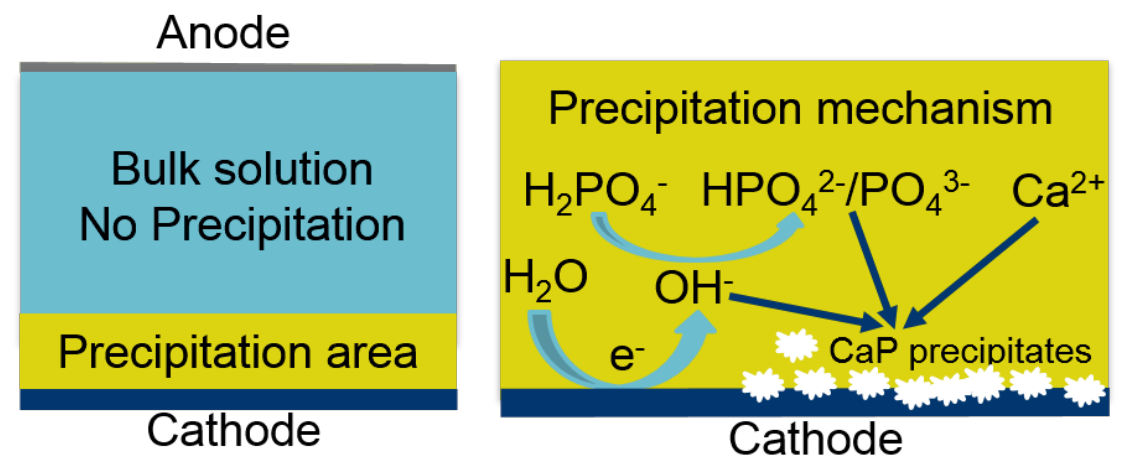

Figure 1.3. Principle of electrochemically induced calcium phosphate precipitation.

The formation of $\mathrm{OH}^{-}$ions will create a $\mathrm{pH}$ gradient between the cathode and the bulk solution. In general, a pH gradient is unwanted in most electrochemical systems. For instance, the $\mathrm{pH}$ gradient will result in a higher overpotential of the hydrogen evolution reaction and therefore increase the energy input [42]. Nonetheless, in terms of calcium phosphate precipitation, the high local $\mathrm{pH}$ can be beneficial. As is well-known, the $\mathrm{pH}$ plays a crucial role in the precipitation of calcium phosphate $[23,36]$. Moreover, the solubility of calcium phosphate minerals is $\mathrm{pH}$-dependent, and a high $\mathrm{pH}$ usually means high thermodynamic driving force for calcium phosphate precipitation.

In the electrochemical system, although the local $\mathrm{pH}$ is increased, the $\mathrm{pH}$ of the bulk solution only changes slightly. This is because an equal number of protons are produced at the anode (see eq 1.2).

$$
\text { Anode: } 2 \mathrm{H}_{2} \mathrm{O} \rightarrow 4 \mathrm{H}^{+}+\mathrm{O}_{2} \uparrow+4 \mathrm{e}^{-}
$$

Moreover, the presence of buffers such as (bi)carbonate in wastewaters may contribute to a stable bulk solution $\mathrm{pH}$. Hence, a post reduction of the $\mathrm{pH}$ of treated wastewater is not necessary. More importantly, since the precipitation reactions only take place in the vicinity of the cathode, the formed precipitates can easily be harvested from the cathode. This means that a solid-liquid separation process that is needed in conventional chemical precipitation, can be avoided. Therefore, in principle, the electrochemical system can achieve simultaneously phosphorus removal and separation from wastewaters without dosing chemicals. 
Electrochemical treatment, in general, is a robust approach and is highly amenable to automation. This makes it especially attractive for onsite-treatment and for rural areas where centralized wastewater treatment facilities are not available [43]. Electrochemical treatment is seen as next-generation wastewater treatment technology and has received increasing interest over the last decade [44]. Additionally, electrochemical approaches also demonstrate excellent potential in resource recovery from waste streams [45]. 


\subsection{Scope and thesis outline}

This thesis aims to contribute in solving issues about phosphorus being scare as a resource (fertilizer) yet abundant as a pollutant (eutrophication) by investigating the potential of electrochemical approaches toward phosphorus removal and recovery.

Specifically, the goal of this $\mathrm{PhD}$ project is to establish a membrane-free electrochemical system for energy-efficient phosphorus removal and recovery in the form of calcium phosphate. We first used synthetic solutions to study the possibility, the efficiency, the mechanism, and the energy consumption of this system. Next, we evaluated the feasibility of this system using real wastewater. We further discussed the associated challenges and potential solutions toward upscaling of the technology.

In the second chapter, we explore the possibility and the mechanism of electrochemically induced calcium phosphate at various $\mathrm{pH}$.

In the third chapter, we investigate the interaction mechanism of natural organic matter (often present in wastewater) with calcium ions and phosphate, discuss its implication on electrochemical phosphorus removal and recovery.

In the fourth chapter, we examine the effects of pre-acidification of wastewater on the purity of recovered product and its implications on the specific removal pathways of phosphorus, calcium, magnesium and inorganic carbon.

In chapter 5, we investigate the electrochemical precipitation sequence of $\mathrm{CaCO}_{3}, \mathrm{Mg}(\mathrm{OH})_{2}$, and calcium phosphate in domestic wastewater and its implications on selectively calcium phosphate precipitation.

In chapter 6, we show that a bioelectrochemical system can serve as an energy-efficient approach for phosphorus removal from domestic wastewater.

In chapter 7, we present the use of a graphite-felt cathode and the operation of the electrochemical system at low current densities can reduce the energy consumption in electrochemical removal of phosphate.

In chapter 8, we show how phosphorus present in a specific organic phosphorus compound can be removed and recovered as calcium phosphate using the electrochemical approach. 
In chapter 9, we propose a new concept, namely a $\mathrm{CaCO}_{3}$ packed electrochemical precipitation column, for efficient removal of phosphate. We discuss the possibility, the efficiency, and the mechanism of this newly system.

In chapter 10, we present a general discussion about the overall findings within this thesis, the limitations of present research and future directions in electrochemical phosphorus removal and recovery. 


\section{Chapter 2}

\section{Electrochemical induced calcium phosphate precipitation: importance of local $\mathrm{pH}$}
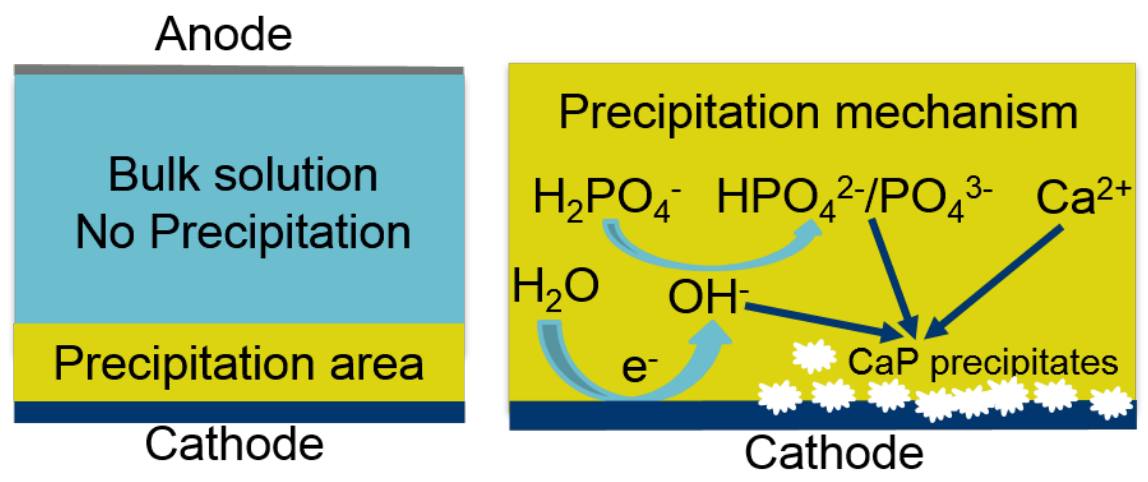

Yang Lei, Bingnan Song, Renata D. van der Weijden, Michel Saakes, Cees J.N. Buisman

This chapter has published as:

Lei, Yang, Bingnan Song, Renata D. van der Weijden, Michel Saakes, and Cees J.N. Buisman. "Electrochemical induced calcium phosphate precipitation: importance of local $\mathrm{pH} . "$

Environmental Science \& Technology 51, no. 19 (2017): 11156-11164. 


\begin{abstract}
Phosphorus (P) is an essential nutrient for living organisms and cannot be replaced or substituted. In this paper, we present a simple yet efficient membrane-free electrochemical system for $\mathrm{P}$ removal and recovery as calcium phosphate $(\mathrm{CaP})$. This method relies on in situ formation of hydroxide ions by electro mediated water reduction at a titanium cathode surface. The in situ raised $\mathrm{pH}$ at the cathode provides a local environment where $\mathrm{CaP}$ will become highly supersaturated. Therefore, homogeneous and heterogeneous nucleation of $\mathrm{CaP}$ occur near and at the cathode surface. Because of the local high $\mathrm{pH}$, the $\mathrm{P}$ removal behavior was not sensitive to bulk solution $\mathrm{pH}$ and therefore, efficient $\mathrm{P}$ removal was observed in three studied bulk solutions with pH of 4.0 (56.1\%), 8.2 (57.4\%), and 10.0 (48.4\%) after $24 \mathrm{~h}$ of reaction time. While P removal efficiencies were not generally affected by the bulk solution $\mathrm{pH}$, the chemical-physical properties of $\mathrm{CaP}$ solids collected on the cathode were still related to the bulk solution $\mathrm{pH}$, as confirmed by structure characterizations. High initial solution $\mathrm{pH}$ promoted the formation of more crystalline products with relatively high atomic $\mathrm{Ca} / \mathrm{P}$ ratio. The atomic $\mathrm{Ca} / \mathrm{P}$ ratio increased from $1.30(\mathrm{pH} 4.0)$ to $1.38(\mathrm{pH} 8.2)$ and further to $1.55(\mathrm{pH}$ 10.0). The formation of $\mathrm{CaP}$ precipitates was a typical crystallization process, with an amorphous phase formed at the initial stage which then transformed to the most stable crystal phase, hydroxyapatite, which was inferred from the increased $\mathrm{Ca} / \mathrm{P}$ atomic ratio from 1.38 (day 1) to the theoretical 1.76 (day 11) and by the formation of needle-like crystals. Finally, we demonstrated the efficiency of this system for real wastewater. This, together with the fact that the electrochemical method can work at low bulk $\mathrm{pH}$, without dosing chemicals and a need for a separation process, highlights the potential application of the electrochemical method for P removal and recovery.
\end{abstract}




\subsection{Introduction}

Phosphorus $(\mathrm{P})$ is an irreplaceable nutrient, but it is also associated with eutrophication [10, $22,46,47]$. On the one hand, a large amount of $\mathrm{P}$ is discharged to surface waters resulting in eutrophication [47]. On the other hand, the quantity and the quality of $\mathrm{P}$ ore has declined in the past decades because of $\mathrm{P}$ rock mining for producing fertilizer [22]. The calculation of Evelyn Desmid that applied the data of U.S geological survey 2012 suggested that natural P reserves will be fully depleted in 372 years if current mining rates are maintained [22]. In addition, considering the uneven distribution of $\mathrm{P}$ rock reserves, there may arise a $\mathrm{P}$ shortage for countries that completely depend on importing P rock in the near future $[10,48]$. The potential P shortage, along with $\mathrm{P}$ discharge associated eutrophication has created increased awareness of the importance of $\mathrm{P}$ recycling [10, 22, 49]. For instance, the Swedish government has set a national goal to recover at least $40 \%$ of $\mathrm{P}$ in wastewater treatment plants [50].

There are many P removal methods available [20, 22, 23, 51], but efficient and economically feasible methods for $\mathrm{P}$ recovery are limited. Among the few methods, struvite $\left(\mathrm{MgNH}_{4} \mathrm{PO}_{4} \cdot 6 \mathrm{H}_{2} \mathrm{O}\right)$ formation and precipitation is regarded as one of the most promising ways [49, 52-54]. Struvite, which is a slow-release fertilizer, shows higher bioavailability than iron and aluminum phosphate [23]. However, it is necessary to supply a Mg source to assist struvite formation $[28,54,55]$, which makes this process less economically attractive because of the low concentration of $\mathrm{Mg}^{2+}$ in wastewaters [28]. Alternatively, calcium phosphate $(\mathrm{CaP})$, which is the mined component in $\mathrm{P}$ rock, would be a better solution [31, 56]. CaP solids can form without adding $\mathrm{Ca}^{2+}$ since there is often already sufficient $\mathrm{Ca}^{2+}$ in water bodies [57]. Therefore, $\mathrm{P}$ recovery via $\mathrm{CaP}$ formation and precipitation is a preferred method and has received a lot of attention $[33,56]$.

$\mathrm{CaP}$ precipitation is a very complex process. In general, the process is controlled by the chemical species in solutions, including $\mathrm{Ca}$ and $\mathrm{P}$ concentrations and $\mathrm{pH}[36,58,59]$. To induce $\mathrm{CaP}$ precipitation, the solution needs to be highly supersaturated. The typical way to create a supersaturated condition is by adding caustic soda to increase solution $\mathrm{pH}$. However, because wastewater normally has a considerable buffering capacity because of the presence of organic acids and (bi)carbonate, significant base addition is needed in order to increase the bulk solution $\mathrm{pH}$ to a certain level that would induce $\mathrm{CaP}$ precipitation. For instance, as 
reported by Jaffer et al. [37], the sodium hydroxide addition is accounted for up to $97 \%$ of the total chemical costs associated with $\mathrm{P}$ recovery by struvite formation method. Furthermore, traditional chemical precipitation based methods produce a large quantity of sludge, which still needs to be treated before recycling [60].

Recently, (bio)electrochemical processes were suggested as next-generation technologies for treating (in)organic polluted water [44] and recognized as an efficient strategy for nutrient removal and recovery from nutrient-rich wastewater [61]. Though (bio)electrochemical reactions are quite complicated processes, they can be simply divided as anode oxidation and cathode reduction. Most environment related electrochemical applications depend on the processes at the anode. The well-established electro-Fenton method for degrading organic pollutants is a good example [62]. By contrast, the role of cathode mediated reduction has just begun to be explored for remediation and recovery by environmental scientists [63]. The (bio)electrochemical induced $\mathrm{P}$ removal and recovery as struvite has been well-documented [64-66]. However, the electrochemical assisted struvite formation, like chemical precipitation, still relies on dosing of costly $\mathrm{Mg}^{2+}$. Moreover, the importance of local $\mathrm{pH}$ at the cathode with respect to electrochemical P recovery has not been recognized yet. Most studies mention that the increased $\mathrm{pH}$ is responsible for the precipitation of phosphate salts, but none, to our knowledge, has investigated the role of the local $\mathrm{pH}$ in detail. This is because it is difficult to measure the local $\mathrm{pH}$ directly, as there still are no reliable $\mathrm{pH}$ sensors for detecting the electrochemically induced local $\mathrm{pH}$ at the electrode surface, though there are some specially designed lab tools $[67,68]$. Moreover, the importance of the local $\mathrm{pH}$ was seemingly ignored. Some researchers equated bulk solution $\mathrm{pH}$ to local $\mathrm{pH}$ and therefore just recorded bulk solution $\mathrm{pH}$ and used it as the $\mathrm{pH}$ for phosphate salts precipitation [64, 69]. Consequently, the reported results with respect to local $\mathrm{pH}$ varied from experiment to experiment. As an example, Wang et al.[64] reported the slight increase of $\mathrm{pH}$ near the cathode from 7.0 to 7.5 as the cause for pure struvite formation in their electrochemical system. However, the local $\mathrm{pH}$ can be much higher than can be measured [68].

To the best of our knowledge, the electrochemically induced $\mathrm{CaP}$ precipitation on the cathode has not been reported, in terms of $\mathrm{P}$ removal and recovery and at various bulk $\mathrm{pH}$. Although $\mathrm{CaP}$ coverage of the cathode might seem unwanted, we see this as an opportunity to separate P from waste streams with low P concentrations. Therefore, the purpose of this study is to 
evaluate the efficiency of a single electrochemical cell without membranes toward P removal and recovery by forming $\mathrm{CaP}$ precipitates. The importance of the local high $\mathrm{pH}$ in the electrochemical cell was demonstrated by evaluating the performance of this system at low, higher and high bulk solution $\mathrm{pH}$ combined with theoretical calculations. Finally, the efficiency and the cost for treatment of real wastewater were addressed.

\subsection{Materials and methods}

\subsubsection{Materials}

All chemicals used here were at least reagent-grade. Disodium monohydrogen phosphate $\left(\mathrm{Na}_{2} \mathrm{HPO}_{4}\right)$ and sodium sulfate anhydrous $\left(\mathrm{Na}_{2} \mathrm{SO}_{4}\right)$ were purchased from VWR (Leuven, Belgium). Calcium nitrate tetrahydrate $\left(\mathrm{Ca}\left(\mathrm{NO}_{3}\right)_{2} \cdot 4 \mathrm{H}_{2} \mathrm{O}\right)$ was received from Merck (Germany). Electrodes were provided by MAGNETO Special Anodes BV (Schiedam, The Netherlands).

\subsubsection{Electrolysis setup}

The electrochemical cell consisted of two compartments, one working cell $(500 \mathrm{~mL})$ for $\mathrm{CaP}$ precipitation and one tank cell $(500 \mathrm{~mL})$ for mixing and sampling. The total solution in the two compartments $(1000 \mathrm{~mL})$ is circulated with a pump at a flow rate of $100 \mathrm{~mL} / \mathrm{min}$. The anode material is platinum-coated $\left(20 \mathrm{~g} / \mathrm{m}^{2}\right)$ titanium mesh with a round shape $(\varnothing 10 \mathrm{~cm}$, thickness $0.1 \mathrm{~cm})$ and it is perpendicularly welded to a $10 \mathrm{~cm}$ long Ti $\operatorname{rod}(\varnothing 0.3 \mathrm{~cm})$. The cathode is a pure titanium plate similarly welded (grade A, Ø $8.2 \mathrm{~cm}$, thickness $0.1 \mathrm{~cm}$ ). A $\mathrm{pH}$ sensor was placed in the sampling tank to record bulk solution $\mathrm{pH}$ change. In some cases, the $\mathrm{pH}$ electrode (Ø $1.2 \mathrm{~cm}$, Endress Hauser, Germany) was also placed near the cathode (about $1.0 \mathrm{~mm}$ ), in order to record the local $\mathrm{pH}$. The $\mathrm{pH}$ sensors were calibrated weekly. The diagram of the setup is shown in Figure S2.1 (Supporting information).

\subsubsection{Electrolysis experiments}

We conducted the electrochemical precipitation experiments with synthetic solutions containing $0.6 \mathrm{mM} \mathrm{P}$ and $1.0 \mathrm{mM}$ Ca under constant current $(20 \mathrm{~mA})$ conditions and at constant ionic strength mediated by $50 \mathrm{mM} \mathrm{Na}_{2} \mathrm{SO}_{4}$. The choice for a sulfate salt was made because it does not interfere with the precipitation of $\mathrm{CaP}$ and does not produce harmful chlorine gas. While the initial Ca concentration is close to its natural concentration, the initial $\mathrm{P}$ concentration was higher compared to real wastewater in order to collect sufficient solid 
samples for further characterization. Where appropriate, the bulk solution $\mathrm{pH}$ was adjusted by concentrated $\mathrm{NaOH}$ or $\mathrm{HNO}_{3}$. Unless specified, the electrolysis process was open to the air and lasted for $24 \mathrm{~h}$ at room temperature. The bulk solution $\mathrm{pH}$ was monitored during the whole process and logged by a computer program (Liquisys M CPM 253, Endress + Hauser, Naarden, The Netherlands).

\subsubsection{Calcium phosphate collection}

After the reaction was stopped at a predetermined time, the solutions in the electro cell were carefully removed with a syringe as to not disturb $\mathrm{CaP}$ precipitates at the cathode surface, for the sake of solid characterization. Then the electrode with precipitates on its surface was airdried at room temperature. After drying, $\mathrm{CaP}$ solids were harvested by light scraping. After sampling, the cathode was immersed in a $1.0 \mathrm{M} \mathrm{HNO}_{3}$ solution to remove any $\mathrm{CaP}$ remains, then thoroughly rinsed with Milli-Q water, and dried again for use.

\subsubsection{Analytical methods}

We analyzed the concentrations of $\mathrm{P}$ and $\mathrm{Ca}$ ions by ICP-AES. We identified the crystal structure (or absence thereof if amorphous) of collected precipitates by X-ray diffraction (XRD). The XRD characterization is performed on a Bruker D8 advanced diffractometer equipped with a Vantec position sensitive detector and with a Co K $\alpha$ radiation $(\lambda=0.179 \mathrm{~nm})$ over a range of $10-70^{\circ}$ in 0.02 step sizes with an integration time of $0.5 \mathrm{~s}$. We obtained Raman spectra of the collected solids using a LabRAM HR Raman spectrometer from Horiba Jobin Yvon. This system is equipped with a mpc3000 laser emitting at $532.2 \mathrm{~nm}$ and an 800 $\mathrm{mm}$ focal length achromatic flat field monochromator (grating of 600 grooves $\cdot \mathrm{mm}^{-1}$ ). The laser beam was focused on the sample with an Olympus Bx41 microscope equipped with a $50 \times$ objective lens, which gives a spot size ca.1-2 $\mu \mathrm{m}$ and resolution of $6 \mathrm{~cm}^{-1}$. The detector is a Synapse multichannel air-cooled $\left(-70^{\circ} \mathrm{C}\right) \mathrm{CCD}$. The applied laser power was between 5 and $50 \mathrm{~mW}$ (using density filters). The measurement time varied 5 to $30 \mathrm{~s}$. Finally, the data were processed with LabSpec software. We examined he morphology of collected products and their elemental compositions by a Scanning Electron Microscope (SEM) coupled with Energy dispersive x-ray spectroscopy (EDS) (JEOL-6480LV, JEOL Ltd., Japan). Samples were coated with gold using a JEOL JFC-1200 Fine coater at $10 \mathrm{~Pa}$ for $30 \mathrm{~s}$. 


\subsubsection{Calculations}

The degree of saturation $(\Omega)$ and saturation index (SI) of a solution regarding a mineral phase, are defined as follows [70]:

$$
\begin{aligned}
& \Omega=\frac{\mathrm{IAP}}{\mathrm{K} s p} \\
& \mathrm{SI}=\log \left(\frac{\mathrm{IAP}}{\mathrm{K} s p}\right)
\end{aligned}
$$

Where IAP refers to the ion activity of the associated lattice ions and Ksp is the thermodynamic solubility product. The computer program visual MINTEQ [71] was applied to calculate SI, as an indication for the potential saturation of possible products. $\mathrm{Ca}$ and $\mathrm{P}$ fractions were acquired by using Hydra-Medusa database [72].

Based on Faraday's law of electrolysis assuming that the electricity consumed was $100 \%$ used for water reduction and meanwhile supposing the produced $\mathrm{OH}^{-}$was not consumed by other occurring reactions and was homogeneously mixed in the local layer, the theoretical maximum local $\mathrm{pH}$, with respect to the thickness of local layer $(\delta, m)$ and electrolysis time $(t, s)$ can be calculated by eqs $2.3,2.4$ and 2.5 :

$$
\begin{aligned}
& M\left(O H^{-}\right)=\frac{I t}{z F} \\
& {\left[O H^{-}\right]=\frac{I t}{250 z F \pi d^{2} \delta}} \\
& p H=14+\log \left(\frac{I t}{250 z F \pi d^{2} \delta}\right)
\end{aligned}
$$

$I$, electricity current (A); $z$, number of electrons transferred per mole hydroxide ions, $z=1$; $F$, Faraday constant $96,485(\mathrm{C} / \mathrm{mol}) ; d$, diameter of cathode $(d=0.082 \mathrm{~m})$. It should be noted here that the real local $\mathrm{pH}$ will be below the theoretically calculated value because the current efficiency is unlikely to reach $100 \%$ and the electrochemically produced $\mathrm{H}^{+}$at anode will react with $\mathrm{OH}^{-}$to a certain extent.

\subsection{Results and discussion}

\subsubsection{Effects of initial bulk $\mathrm{pH}\left(\mathrm{pH}_{0}\right)$}

As a proof of principle, electrochemical removal of $\mathrm{P}$ was evaluated at three $\mathrm{pH}$ values including background solution $\mathrm{pH}\left(\mathrm{pH}_{0} \sim 8.2\right)$ after mixing of all chemicals, weakly acidic 
$\left(\mathrm{pH}_{0} 4.0\right)$ and alkaline $\left(\mathrm{pH}_{0}\right.$ 10.0) conditions. As can be seen from Figure 2.1A, under open circuit conditions, only $20 \%$ of $\mathrm{P}$ was removed in the case of $\mathrm{pH}_{0} 10.0$ and there was no obvious $\mathrm{P}$ removal at $\mathrm{pH}_{0} 4.0$ and 8.2. For $\mathrm{pH}_{0} 4.0$, the solution was undersaturated with respect to hydroxyapatite $(\mathrm{HAP})\left(\mathrm{SI}_{\mathrm{HAP}}=-15.5\right)$ and with respect to any solid calcium species like gypsum (Figure 2.1B).
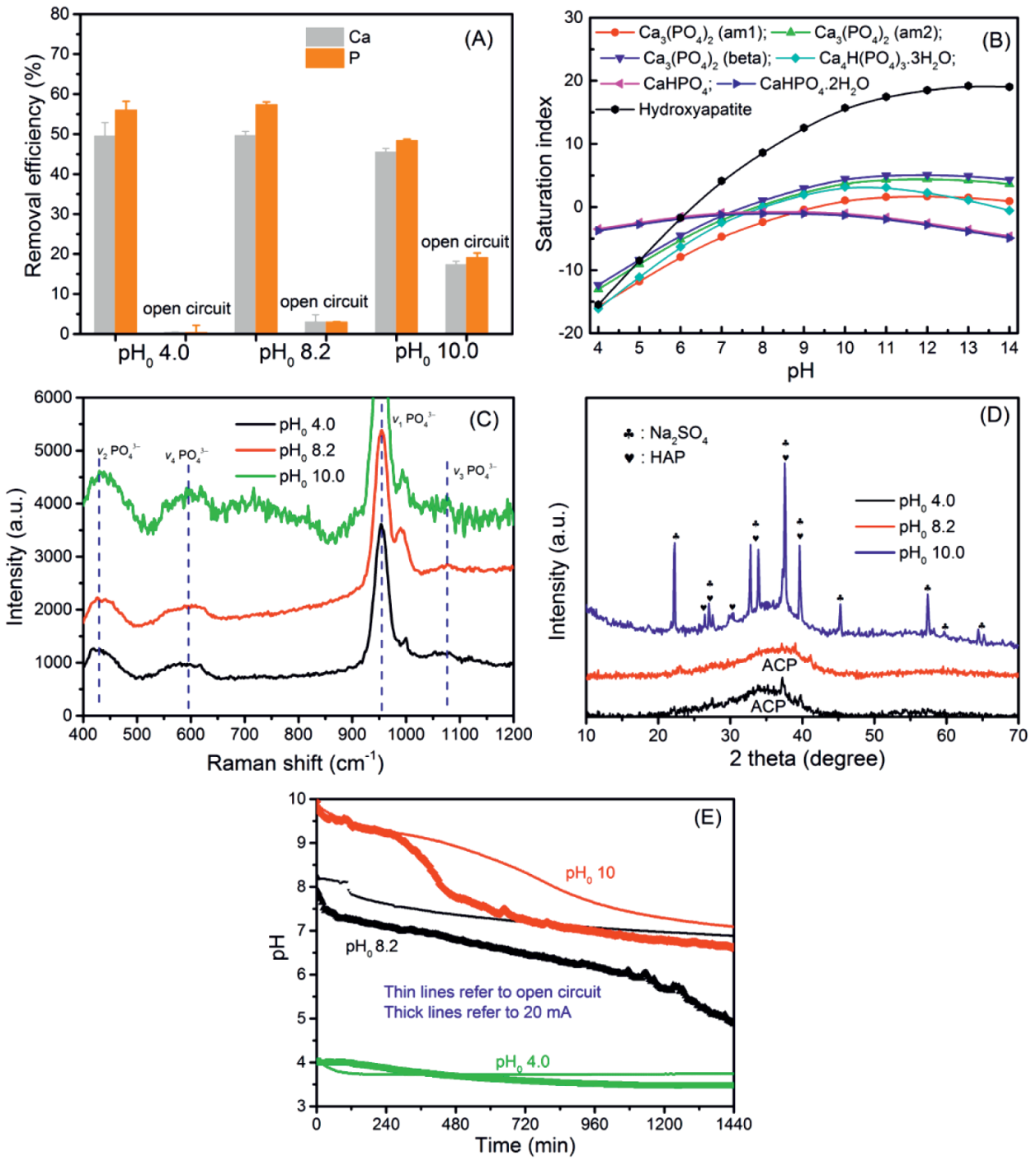

Figure 2.1. (A) Effects of initial $\mathrm{pH}$ on $\mathrm{P}$ and Ca removal efficiency. (B) Supersaturation index calculated from Visual MINTEQ. (C) Raman and (D) XRD patterns of recovered solid products. (E) Change of solution $\mathrm{pH}$ in open and closed circuit. Conditions: $\left[\mathrm{Ca}\left(\mathrm{NO}_{3}\right)_{2} \cdot 4 \mathrm{H}_{2} \mathrm{O}\right]$ $=1.0 \mathrm{mM} ;\left[\mathrm{Na}_{2} \mathrm{SO}_{4}\right]=50 \mathrm{mM} ;\left[\mathrm{Na}_{2} \mathrm{HPO}_{4}\right]=0.6 \mathrm{mM}$; current $=20 \mathrm{~mA}$, time $=24 \mathrm{~h}$. 
In addition, the calculation of the species distribution shows that nearly $87 \%$ of Ca presented as dissolved $\mathrm{CaSO}_{4}$ and $\mathrm{P}$ was almost $100 \%$ present as $\mathrm{H}_{2} \mathrm{PO}_{4}{ }^{-}$(Figure S2.2). Therefore, it is not surprising that no $\mathrm{CaP}$ precipitated from solution at $\mathrm{pH}_{0} 4.0$. At $\mathrm{pH}_{0} 8.2$, while the thermodynamic calculation indicates the solution is supersaturated with respect to HAP $\left(\mathrm{SI}_{\mathrm{HAP}}=8.6\right)$ and the fraction calculation also suggests the formation of HAP (Figure S2.2), no visible precipitates were found in reactors. Actually, many lakes are also supersaturated with respect to HAP without HAP being found in the lake sediments [70]. Indeed, thermodynamic predictions for precipitation of certain solids do not imply that they are kinetically favorable. The precipitation rate may be too slow to be observed and precipitation may progress via the Ostwald Step Rule [73]. Interestingly, it was found that the application of a current of $20 \mathrm{~mA}$ (current density, $3.8 \mathrm{~A} / \mathrm{m}^{2}$ ) makes a big difference. The $\mathrm{P}$ removal efficiencies jumped to over $48 \%$ in all cases: $56.1 \%, 57.4 \%$ and $48.4 \%$ of $\mathrm{P}$ were removed at $\mathrm{pH}_{0} 4.0, \mathrm{pH}_{0} 8.2$ and $\mathrm{pH}_{0} 10.0$ within $24 \mathrm{~h}$, respectively (Figure 2.1A). We found that approximately $50 \%$ of $\mathrm{Ca}$ was removed as well. The simultaneous removal behavior of $\mathrm{Ca}$ and $\mathrm{P}$ indicates their removal as $\mathrm{CaP}$ precipitates. The precipitated solids were characterized by XRD and Raman spectroscopy. The Raman spectrum (Figure 2.1C) of the three samples almost all show internal bands of CaP, including a main $v_{1} \mathrm{PO}_{4}{ }^{3-}$ peak around $955 \mathrm{~cm}^{-1}$ and well isolated $v_{2} \mathrm{PO}_{4}{ }^{3-}\left(\sim 425 \mathrm{~cm}^{-1}\right)$ and $v_{4} \mathrm{PO}_{4}{ }^{3-}\left(\sim 590 \mathrm{~cm}^{-1}\right)$ peaks, which clearly demonstrates the formation of $\mathrm{CaP}[74,75]$.

Interestingly, the XRD patterns (Figure 2.1D) suggest amorphous products are produced in acid and neutral solution as confirmed by the lack of sharp peaks and the presence of a broad peak around $2 \theta=38^{\circ}$. At $\mathrm{pH}_{0} 10.0$, a relatively more crystalline product is formed. The sharp peak around $2 \theta=30^{\circ}$ indicates the presence of more crystalline $\mathrm{CaP}$ phases. However, the product is still dominantly amorphous. Most of the sharp peaks of $\mathrm{pH}_{0} 10.0$ are attributed to $\mathrm{Na}_{2} \mathrm{SO}_{4}$ because the collected solids were air-dried without rinsing.

While it is not surprising that $\mathrm{P}$ was removed in an alkaline solution, the high removal efficiency of $\mathrm{P}$ at $\mathrm{pH}_{0} 4.0$ was not expected. As seen from Figure 2.1B, the solution at $\mathrm{pH}_{0}$ 4.0 is undersaturated for all possible $\mathrm{CaP}$ products. The only factor that can contribute to the increase of SI here could be the increase of $\mathrm{pH}$. However, Figure 2.1E shows the solution $\mathrm{pH}$ decreases largely for $\mathrm{pH}_{0} 8.2$ and $\mathrm{pH}_{0} 10.0$, in which the solution $\mathrm{pH}$ drops to 4.6 and 4.0 respectively. Regarding $\mathrm{pH}_{0} 4.0$, it also declines to 3.4 after $24 \mathrm{~h}$ treatment. It should be noted that under open circuit the solution $\mathrm{pHs}$ also drop to some extent due to equilibration with 
atmospheric $\mathrm{CO}_{2}$ in an open system (Figure 2.1E). In conclusion, it may be reasonable to infer that bulk solution $\mathrm{pH}$ is not that important, in terms of $\mathrm{P}$ removal efficiency.

\subsubsection{Importance of local pH}

A phenomenon that we observed during our experiments is that precipitates just formed at/near the surface of the cathode. This points to different conditions at the cathode surface than in the bulk solution. The possible differences could be $\mathrm{pH}, \mathrm{Ca}$ and $\mathrm{P}$ concentration, which determine the saturation of $\mathrm{CaP}$ species in our system. Indeed, electro migration could transfer negative ions to the anode and positive ions to the cathode. However, because the relatively low concentration of $\mathrm{Ca}^{2+}$ compared to electrolyte $\left(50 \mathrm{mM} \mathrm{Na}_{2} \mathrm{SO}_{4}\right)$, it is unlikely that $\mathrm{Ca}^{2+}$ can be enriched to such an extent that it can increase the saturation state of $\mathrm{CaP}$. In addition, if electro migration plays an important role here, the $\mathrm{P}$ concentration in the vicinity of cathode should decline correspondingly. Therefore, we conclude that electro migration of ions does not play a crucial role in this system. The only possible reason for precipitation should then be attributed to the production of $\mathrm{OH}^{-}$by electrochemically mediated water reduction at the cathode:

$$
2 \mathrm{H}_{2} \mathrm{O}+2 \mathrm{e}^{-} \rightarrow 2 \mathrm{OH}^{-}+\mathrm{H}_{2} \uparrow
$$
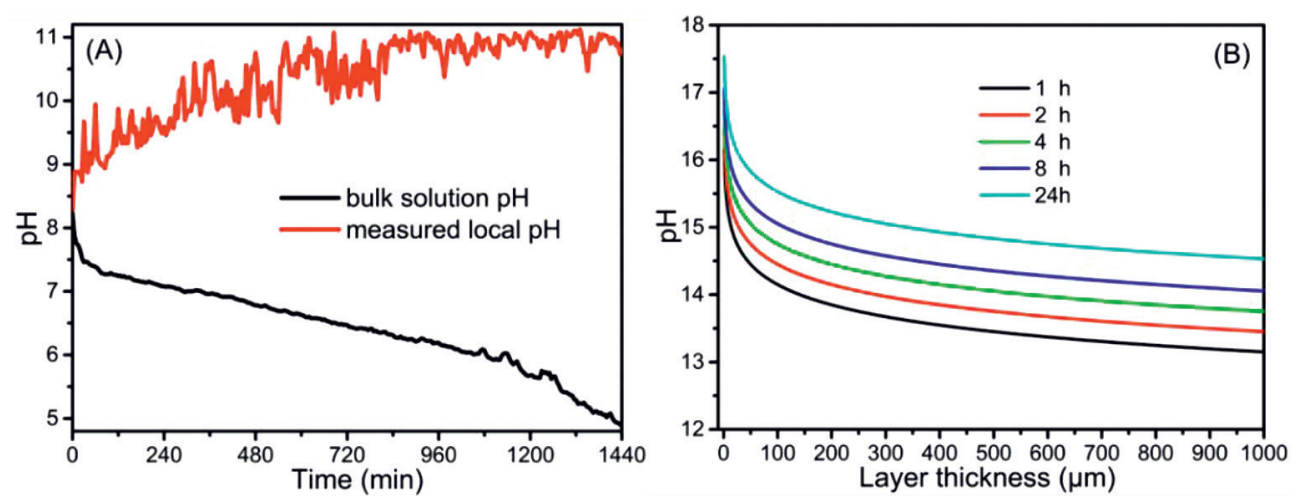

Figure 2.2. (A) The measured and (B) theoretically calculated local pH. Conditions: $\left[\mathrm{Ca}\left(\mathrm{NO}_{3}\right)_{2} \cdot 4 \mathrm{H}_{2} \mathrm{O}\right]=1.0 \mathrm{mM} ;\left[\mathrm{Na}_{2} \mathrm{SO}_{4}\right]=50 \mathrm{mM} ;\left[\mathrm{Na}_{2} \mathrm{HPO}_{4}\right]=0.6 \mathrm{mM}$; current $=20 \mathrm{~mA}$, time $=24 \mathrm{~h}$.

Though the produced $\mathrm{OH}^{-}$will diffuse to the bulk solution and the diffusion rate will increase with the mixing rate, the relatively high $\mathrm{pH}$ in the very vicinity of cathode will not disappear [76]. While we did not have special $\mathrm{pH}$ sensors to record local $\mathrm{pH}$, an attempt was made to 
measure the local $\mathrm{pH}$ by a general $\mathrm{pH}$ sensor. Indeed, we observed a big difference between the bulk solution $\mathrm{pH}$ and the so measured local $\mathrm{pH}$, as shown in Figure 2.2A. For example, in $1 \mathrm{~h}$, while the solution $\mathrm{pH}$ dropped from 8.2 to 7.4 , the local $\mathrm{pH}$ went up to 9.9. However, as the measurement of local $\mathrm{pH}$ by this method is sensitive to the distance between the sensor and the cathode, it is difficult to record a consistent $\mathrm{pH}$. Consequently, the trend of local $\mathrm{pH}$ changes a lot. Although we did not measure the exact thickness of the precipitation layer, it is supposed that the local crystallization zone ranges to less than $1 \mathrm{~mm}$ away from the cathode surface, which was proven by a simple test. When we put a glass plate $(26 \times 26 \times 1 \mathrm{~mm})$ on the cathode surface, covering $12.8 \%$ of the cathode, there were no precipitates initiated from the glass surface. This showed that $\mathrm{CaP}$ precipitation just take places in the local region of the Ti cathode where the surface $\mathrm{pH}$ is much higher than the bulk solution $\mathrm{pH}$ because of the electrochemical production of hydroxide ions. Considering the size of a regular $\mathrm{pH}$ sensor as used in our experiments and the thickness of the reaction zone where a high local $\mathrm{pH}$ is created, it is evident that the local $\mathrm{pH}$ cannot be recorded consistently with a common $\mathrm{pH}$ electrode. Nevertheless, there is no doubt that the local $\mathrm{pH}$ is much higher than the bulk solution $\mathrm{pH}$. In addition to measuring the local $\mathrm{pH}$ directly, we made an attempt to calculate the local $\mathrm{pH}$ theoretically. The production of $\mathrm{OH}^{-}$corresponds to the electricity consumed with time elapse and can be calculated by Faraday's law. The calculation results (Figure 2.2B) suggest that the local $\mathrm{pH}$ decreases with the thickness of local diffusion layer and it can reach $\mathrm{pH}$ values as high as 13.2 and 14.5 theoretically for an assumed maximum thickness of the local diffusion layer of $1 \mathrm{~mm}$ and after, respectively, 1 and $24 \mathrm{~h}$ electrolysis. The local $\mathrm{pH}$ can be even higher if we assume a smaller local diffusion layer. The theoretical calculation, along with the fact that $\mathrm{CaP}$ only forms in the vicinity of and on the cathode surface indicated that the electrochemically induced high local $\mathrm{pH}$ is indeed responsible for the calcium phosphate precipitation.

\subsubsection{Crystallization mechanism.}

As discussed above, the bulk solution $\mathrm{pH}$ in the electrochemical system is not as important as in traditional chemical precipitation processes. This is attributed to the electrochemically created difference between the bulk solution $\mathrm{pH}$ and the local $\mathrm{pH}$ at the vicinity of cathode. We proposed a possible CaP formation and precipitation mechanism based on the increase of local $\mathrm{pH}$. For the first step, the consumption of electrons by cathode mediated water reduction created the high local $\mathrm{pH}$ (see eq 2.6). Meanwhile, dihydrogen phosphate $\left(\mathrm{H}_{2} \mathrm{PO}_{4}^{-}\right)$ 
reacts to monohydrogen phosphate $\left(\mathrm{HPO}_{4}{ }^{2-}\right)$ and phosphate $\left(\mathrm{PO}_{4}{ }^{3-}\right)$ via acid-base reactions in the local area.

In the second step, homogenous nucleation of $\mathrm{CaP}$ occurs because of the increased thermodynamic driving force and the declined solubility of $\mathrm{CaP}$ salts, both resulting from the high local $\mathrm{pH}$. It should be noted that the Ti cathode might also provide a favorable surface for $\mathrm{CaP}$ nucleation in this system. Even so, it takes more than $4 \mathrm{~h}$ to see macroscopic precipitates. These then promote the growth and precipitation of precursor phases of HAP. The formed precipitates were weakly attached to the cathode surface via electrostatic interactions and continued to grow [77]. Gradually, the precipitates covered the cathode surface. One may worry that covering the cathode surface with $\mathrm{CaP}$ precipitates will increase the resistance and will corrupt the local $\mathrm{pH}$ and thus under constant current conditions, the cell potential would increase a lot. However, this phenomenon was not observed in our system, probably because the surface is not completely blocked as a result of the formation of hydrogen bubbles that resulted in small channels through the CaP layer. In addition, because of the design of our electrodes, the bottom side (or even the rod) of the cathode can work equally well when the top of the cathode is covered.

$$
\begin{aligned}
& \mathrm{xCa}^{2+}+\mathrm{yHPO}_{4}{ }^{2-} / \mathrm{PO}_{4}{ }^{3-}+\mathrm{nH}_{2} \mathrm{O} \rightarrow \mathrm{ACP} \downarrow \\
& \mathrm{Ca}^{2+}+\mathrm{HPO}_{4}{ }^{2-}+2 \mathrm{H}_{2} \mathrm{O} \rightarrow \mathrm{DCPD} \downarrow \\
& 8 \mathrm{Ca}^{2+}+4 \mathrm{PO}_{4}{ }^{3-}+2 \mathrm{HPO}_{4}{ }^{2-}+5 \mathrm{H}_{2} \mathrm{O} \rightarrow \mathrm{OCP} \downarrow
\end{aligned}
$$

The possible intermediate phases, including amorphous calcium phosphate (ACP), brushite $\left(\mathrm{CaHPO}_{4} \cdot 2 \mathrm{H}_{2} \mathrm{O}, \mathrm{DCPD}\right)$, and octacalcium phosphate $\left(\mathrm{Ca}_{8}\left(\mathrm{HPO}_{4}\right)_{2}\left(\mathrm{PO}_{4}\right)_{4} \cdot 5 \mathrm{H}_{2} \mathrm{O}, \mathrm{OCP}\right)$ can be involved in the crystallization process (see eqs. 2.7, 2.8 and 2.9). However, we were not able to characterize all possible species mentioned. The associated initial phase in our system was confirmed as ACP by the absence of peaks in the corresponding XRD patterns. The typical broad peak at $2 \theta=38^{\circ}$ confirms the formation of ACP as a precursor (Figure 2.3A). Regarding ACP, there is no defined chemical formula yet but normally the formula of $\mathrm{Ca}_{9}\left(\mathrm{PO}_{4}\right)_{6} \cdot \mathrm{nH}_{2} \mathrm{O}$ is used since Posner and Betts proposed that structure [78]. However, the atomic $\mathrm{Ca} / \mathrm{P}$ ratio $(1.38$, Figure $\mathbf{S 2 . 3})$ in our system is lower than the proposed value and therefore, the formula of $\mathrm{Ca}_{\mathrm{x}} \mathrm{H}_{\mathrm{y}}\left(\mathrm{PO}_{4}\right)_{\mathrm{z}} \cdot \mathrm{nH}_{2} \mathrm{O}$ is suggested. The formation of ACP in our system can be expressed as given in eq 2.7 . 

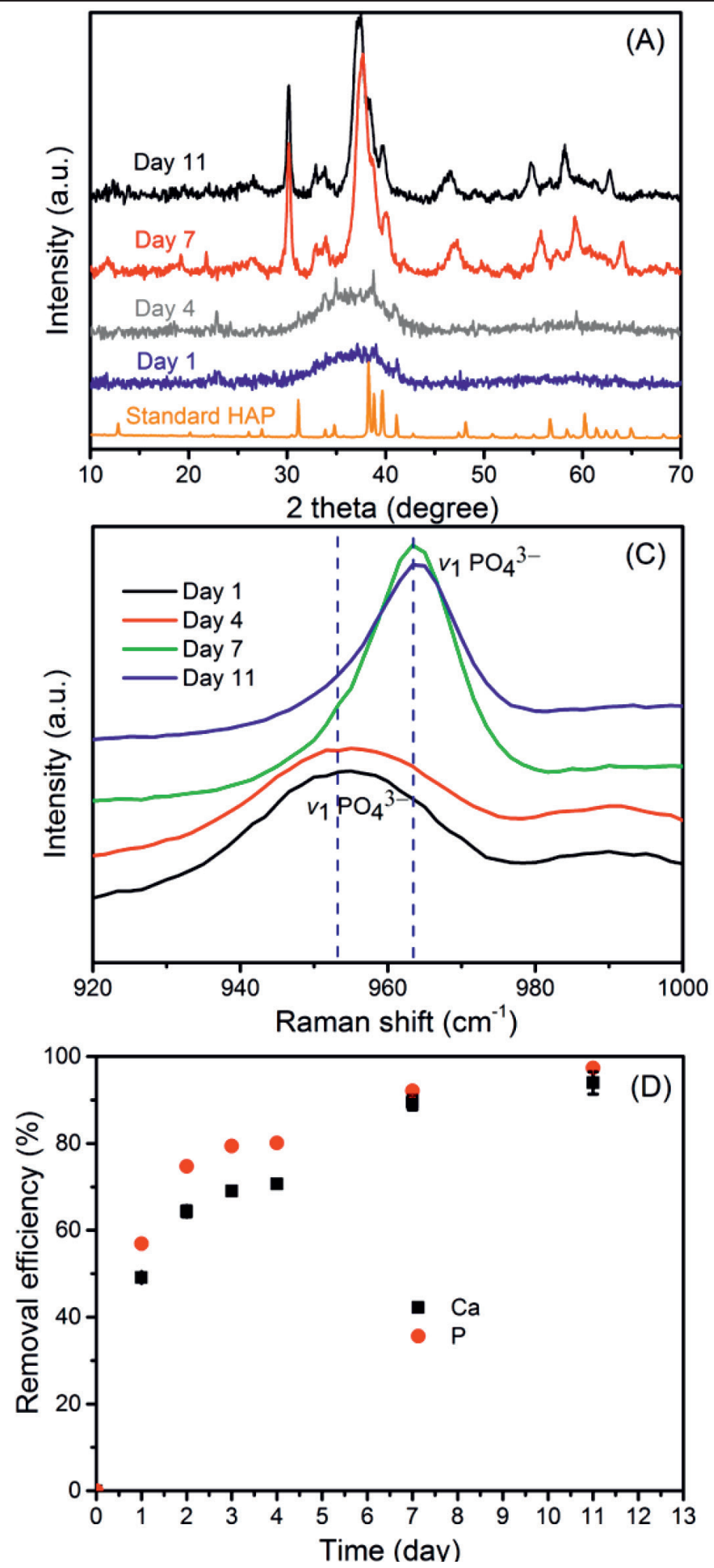


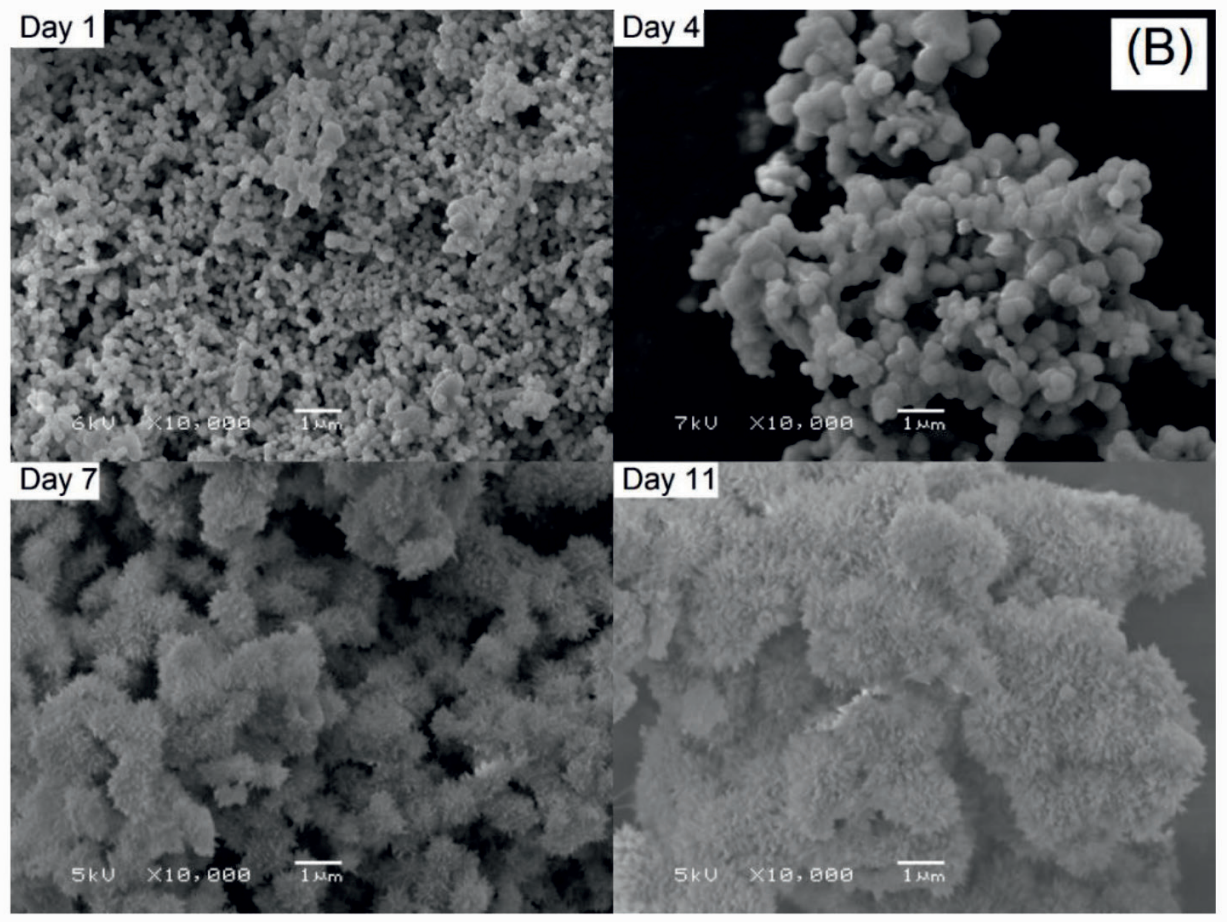

Figure 2.3. (A) XRD patterns, (B) SEM images and (C) Raman spectrum of samples collected at different reaction days. (D) $\mathrm{Ca}$ and $\mathrm{P}$ concentration change with time elapse. Conditions: $\left[\mathrm{Ca}\left(\mathrm{NO}_{3}\right)_{2} \cdot 4 \mathrm{H}_{2} \mathrm{O}\right]=1.0 \mathrm{mM} ;\left[\mathrm{Na}_{2} \mathrm{SO}_{4}\right]=50 \mathrm{mM} ;\left[\mathrm{Na}_{2} \mathrm{HPO}_{4}\right]=0.6 \mathrm{mM}$; current $=20 \mathrm{~mA}, \mathrm{pH}_{0}=8.2 ;$ time $=1$ day to 11 days.

In addition, carbonate, which could originate from atmospheric $\mathrm{CO}_{2}$ under alkaline conditions, might also be incorporated or precipitate as calcium carbonate. However, both $\mathrm{XRD}$ and Raman data do not confirm the presence of $\mathrm{CaCO}_{3}$. The formation of ACP in our system agrees with Ostwald rule [73], which foresees that the crystallization process is initiated by the formation of the least thermodynamically stable phase. Indeed, though thermodynamics predict HAP formation, the direct formation of HAP (eq 2.10) was not observed.

$$
10 \mathrm{Ca}^{2+}+6 \mathrm{PO}_{4}{ }^{3-}+2 \mathrm{OH}^{-} \rightarrow \mathrm{HAP} \downarrow
$$

This is because the formation of HAP is much slower than that of either ACP or OCP, and during simultaneous phase formation, a larger percentage of the kinetically favored species may be observed, even though it has a much smaller thermodynamic driving force [35]. At constant temperature, the transformation kinetics is a function of only $\mathrm{pH}$ because $\mathrm{pH}$ 
regulates both the dissolution of precursor phases and the formation of the early HAP nuclei [35]. In our system, the cathode mediated water reduction regulates the production of $\mathrm{OH}^{-}$. Therefore, when the electrolysis time is increased, the initially formed ACP and other intermediate $\mathrm{CaP}$ phases may transform to HAP via eq 2.11:

$$
\mathrm{OCP} / \mathrm{DCPD} / \mathrm{ACP}+\mathrm{xCa}^{2+}+\mathrm{yOH}^{-} \rightarrow \mathrm{HAP} \downarrow
$$

To check if HAP can form eventually, we increased the electrolysis time up to 11 days. The XRD characterization indicates that even after 4 days, the products were still dominantly amorphous (Figure 2.3A). This indicates that the precursor phase can be maintained for a long period. However, we found that though the phase does not change, the solids particle size increased, as can be seen from SEM images shown in Figure 2.3B. Note that these SEM images have the same magnification factor $(\times 10000)$. In addition to the growth of particles, the corresponding $\mathrm{Ca} / \mathrm{P}$ ratio also increases to 1.44 (Figure S2.3). However, on day 7, both the morphology and phase changed. The XRD data (Figure 2.3A) along with the typical needle-like shape [79] (Figure 2.3B) demonstrates the formation of HAP on the seventh day. The good match with peaks around $13^{\circ}, 30^{\circ}$ and the four peaks in the range of $2 \theta$ from $38^{\circ}$ to $42^{\circ}$ for commercial HAP confirms the transformation to HAP. The atomic $\mathrm{Ca} / \mathrm{P}$ ratio (1.66) on day 7 also agrees well with the theoretical ratio (1.67). On day 11, the particle size increased again and the $\mathrm{Ca} / \mathrm{P}$ ratio reached 1.76 , but the morphology remained needle-like. The phase transformation to HAP can be further supported by Raman data (Figure 2.3C), where the $v_{1} \mathrm{PO}_{4}^{3-}$ band shifted from $955 \mathrm{~cm}^{-1}$ typical for ACP (day 1 and 4) to $963 \mathrm{~cm}^{-1}$ that is for HAP (day 7 and 11) [80]. In addition to solid characterization and analysis, the changes of $\mathrm{Ca}$ and $\mathrm{P}$ concentrations in the bulk solution also support the phase transformation. Figure 2.3C shows the removal trend of $\mathrm{Ca}$ and $\mathrm{P}$ from solution. Both $\mathrm{P}$ and $\mathrm{Ca}$ concentrations decreased with electrolysis time. After 7 days, more than $90 \% \mathrm{P}$ and $\mathrm{Ca}$ precipitated from solution. Specifically, at the end of all reaction periods, the removal efficiency of $\mathrm{P}$ is higher than of $\mathrm{Ca}$, but the difference for 7 days and 11 days $(3.1 \% \pm 0.3)$ is much lower than for day 1 and day $4(9.5 \% \pm 1.0)$. This result suggests that low atomic $\mathrm{Ca} / \mathrm{P}$ ratio products $(\mathrm{ACP})$ are formed initially on day $1(\mathrm{Ca} / \mathrm{P}=1.38)$ and day $4(\mathrm{Ca} / \mathrm{P}=1.44)$ and later transformed into high ratio (1.66 and 1.76 for day 7 and 11 , respectively) product (i.e., HAP), thanks to the continuous production of $\mathrm{OH}^{-}$at the cathode surface. Because the initial molar ratio of $\mathrm{Ca}(1.0 \mathrm{mM})$ to $\mathrm{P}(0.6 \mathrm{mM})$ is 1.67 and therefore the formation of low ratio $\mathrm{Ca} / \mathrm{P}$ products will result in the relatively lower use of $\mathrm{Ca}$. To conclude, the formation of 
HAP in the electrochemical system is identified as a typical crystallization process, starting with an amorphous phase followed by the precursors and finally transformed to the thermodynamically most stable phase (HAP).

\subsubsection{Electrochemical recovery of phosphorus in real wastewater}

Besides studying the efficiency and the precipitation mechanism using simulated solutions with various bulk $\mathrm{pH}$, the efficiency of electrochemical $\mathrm{P}$ precipitation for real wastewater was investigated and compared with conventional chemical precipitation, in terms of efficiency and cost. Detailed information about the wastewater compositions, experimental methods and cost calculation are provided in SI (See Table S2.1, Texts S2.1, S2.2, S2.3 and S2.4).
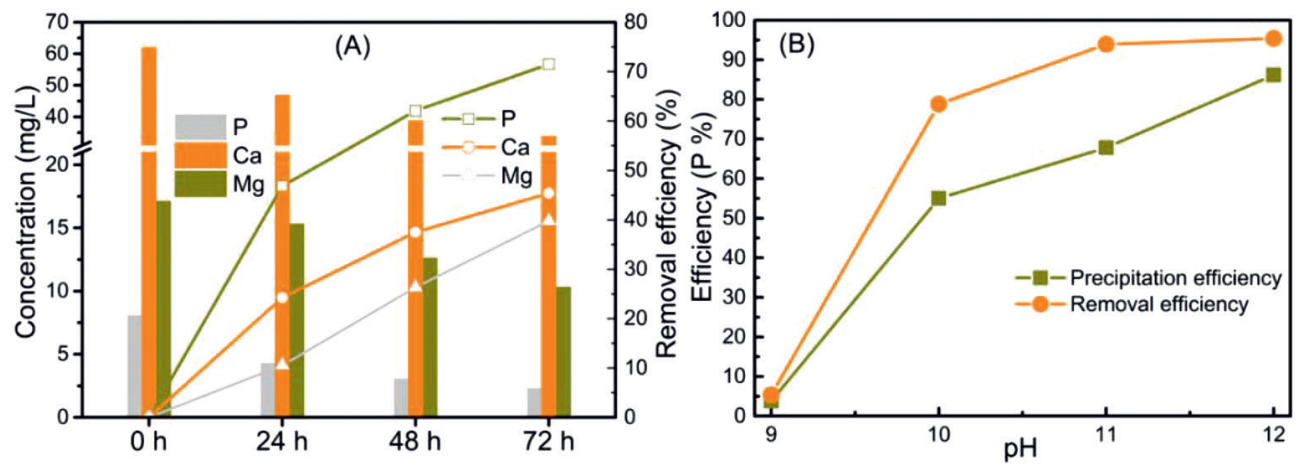

Figure 2.4. (A) Concentration change and removal efficiency of $\mathrm{P}, \mathrm{Ca}$ and $\mathrm{Mg}$ in real wastewater by electrochemical precipitation. (B) Removal efficiency of $\mathrm{P}$ by conventional chemical precipitation under different solution $\mathrm{pH}$ adjusted by sodium hydroxide.

Figure 2.4 gives a summary of the results of electrochemical and chemical precipitation. In electrochemical precipitation system, after a period of 24,48 and $72 \mathrm{~h}$, the $\mathrm{P}$ concentration decreased from 8.0 to $4.3,3.1$ and $2.3 \mathrm{mg} / \mathrm{L}$ respectively. This corresponds to a removal efficiency of $42.8 \%$ in $24 \mathrm{~h}, 62.1 \%$ in $48 \mathrm{~h}$ and $71.5 \%$ in $72 \mathrm{~h}$. Though the wastewater has a complicated matrix (Table S2.1) and a much lower P concentration, the removal efficiency is comparable to the simulated solutions. This is probably due to the role of $\mathrm{Mg}$ and $\mathrm{Ca}$. In the wastewater, the removal of $\mathrm{P}$ may result from both calcium phosphate and magnesium phosphate precipitation. This was concluded from the simultaneous removal of $\mathrm{P}, \mathrm{Ca}$ and $\mathrm{Mg}$ (Figure 2.4A). At the same time, we found the concentration of inorganic carbon also 
decreased from 166 to $115 \mathrm{mg} / \mathrm{L}$ (Figure S2.4). This point to formation and precipitation of $\mathrm{CaCO}_{3}$ and $\mathrm{MgCO}_{3}$ or a mixed phase. The contribution of $\mathrm{CaCO}_{3}$ was also reported on $\mathrm{P}$ removal from wastewater by $\mathrm{CaP}$ precipitation $[31,69]$. In addition to the co-precipitation of carbonate salts, the heavy metal ions in the wastewater, which we did not address in this paper, might be removed via adsorption or incorporation, as reported in a previous study on struvite formation from urine [81]. Hence, for P recycling for use in fertilizer, the behavior of toxic ions in the phosphate recovery process should be investigated in detail. Ideally, heavy metal ions (i.e., $\mathrm{Zn}, \mathrm{Cu}$ ) could be incorporated and work as micronutrients, but their contents should be kept below the standard for P fertilizer. A more in-depth study on the fate and behavior of coexisting components and the corresponding effects on the possible application of products is ongoing.

We also compared the electrochemical $\mathrm{P}$ precipitation with conventional chemical precipitation, in terms of efficiency and cost. Clearly, as shown in Figure 2.4, as expected, chemical precipitation is more efficient than electrochemical precipitation regarding removal efficiency. After adjusting the solution $\mathrm{pH} \geq 10$, over 78.8\% P (Figure 2.4B) was removed from the solution. It should be noted that the P removal refers to the P removal after filtration through $0.45 \mu \mathrm{m}$ membrane and therefore this value is higher than the precipitation efficiency (see Figure 2.4B), as the formed products do not have a good settling rate. For example, the removal efficiency of $\mathrm{P}$ is $93.9 \%$ at $\mathrm{pH} 11$ but the corresponding precipitation efficiency is only $67.8 \%$. Hence, in chemical precipitation process, a follow-up separation process is needed. However, in the electrochemical system, because the precipitation only happens near and on the cathode, removal and separation are simultaneous. The extra separation process is therefore avoided.

For cost comparison, we only considered the electricity cost in the electrochemical system and the caustic soda cost for the chemical precipitation system. After normalizing the cost as $€ / \mathrm{kg} \mathrm{P}$, the cost of electrochemical precipitation is $41 € / \mathrm{kg} \mathrm{P}$, which is comparable to chemical precipitation. The cost of chemical precipitation depends on the solution $\mathrm{pH}$ and varies from 18.9 to $61.1 € / \mathrm{kg}$ P. The lowest cost is achieved at $\mathrm{pH} 10$. As the cost of the two methods is of the same magnitude, we believe optimization of the electrochemical process can make the process economically viable. 


\section{Supporting information}

Text S2.1 Wastewater sampling. We sampled the domestic wastewater from the local wastewater treatment plants (Leeuwarden, The Netherlands). The wastewater is the influent of the treatment plants. The wastewater was pretreated by physical separation to remove obvious solids. The wastewater composition is shown in Table S2.1.

Text S2.2 Experiment methods. We conducted electrochemical precipitation tests by adding 1.0 L wastewater to the electro cells with process conditions equal to the ones for the simulated solutions. We did not add any chemicals except applying a $20 \mathrm{~mA}$ current. We conducted chemical precipitation experiments in a beaker with $500 \mathrm{~mL}$ of the sampled wastewater. We then used analytical sodium hydroxide $(1.0 \mathrm{~mol} / \mathrm{L}$, VWR Chemicals, Belgium) to adjust the $\mathrm{pH}$ of the wastewater to $9,10,11$ and 12 . The used volume of sodium hydroxide was recorded. We then mixed the solutions at $400 \mathrm{rpm}$ for $30 \mathrm{mins}$ and allowed another 30 mins for the precipitates to settle.

Text S2.3 Electrochemical precipitation cost. The electricity price is $0.09 € / \mathrm{kW} \cdot \mathrm{h}$. In electrochemical precipitation system, $3.41 \mathrm{mg} P$ was removed in $24 \mathrm{~h}$ under $20 \mathrm{~mA}$ current. The energy consumption is $0.02 \mathrm{~A} * 3.24 \mathrm{~V} * 24 \mathrm{~h}=1.557 \mathrm{~W} \cdot \mathrm{h}=1.557 * 10^{-3} \mathrm{~kW} \cdot \mathrm{h}$. Then the specific energy consumption is $1.557 * 10^{-3} \mathrm{~kW} \cdot \mathrm{h} / 3.41 \mathrm{mg}$ P. After normalization, the cost is $41 € / \mathrm{kg} \mathrm{P}$.

\section{Text S2.4 Chemical precipitation cost}

The commercial price of $\mathrm{NaOH}$ is $0.4 € / \mathrm{kg}$ [82].

For $\mathrm{pH} 9$, we used $0.825 \mathrm{~mL} \mathrm{NaOH}(1 \mathrm{~mol} / \mathrm{L})$ and removed $0.216 \mathrm{mg} \mathrm{P}$, the corresponding cost is $61.1 € / \mathrm{Kg} \mathrm{P}$.

For $\mathrm{pH} 10$, we added $3.725 \mathrm{~mL} \mathrm{NaOH}$ and removed $3.151 \mathrm{mg}$, the corresponding cost is $18.9 € / \mathrm{kg} \mathrm{P}$.

For $\mathrm{pH} 11$, we added $7.8 \mathrm{~mL} \mathrm{NaOH}$ and removed $3.755 \mathrm{mg}$, the corresponding cost is 33.2 $€ / \mathrm{kg} \mathrm{P}$.

For $\mathrm{pH} 12$, we added $11.4 \mathrm{~mL} \mathrm{NaOH}$ and removed $3.815 \mathrm{mg} \mathrm{P}$, the corresponding cost is $47.8 € / \mathrm{kg} \mathrm{P}$. 
Table S2.1 Wastewater composition of influent in WWTP Leeuwarden, the Netherlands.

\begin{tabular}{cccc}
\hline parameter & value & standard dev. & unit \\
\hline total COD & 197.70 & 25.32 & $\mathrm{mg} / \mathrm{L}$ \\
total organic carbon & 61.2 & 7.15 & $\mathrm{mg} / \mathrm{L}$ \\
inorganic carbon & 166 & 6.38 & $\mathrm{mg} / \mathrm{L}$ \\
$\begin{array}{c}\text { total P- } \mathrm{PO}_{4}{ }^{3-} \\
\text { total N }\end{array}$ & 7.82 & 0.44 & $\mathrm{mg} / \mathrm{L}$ \\
$\mathrm{K}^{+}$ & 64.05 & 0.73 & $\mathrm{mg} / \mathrm{L}$ \\
$\mathrm{Mg}^{2+}$ & 20.8 & 0.27 & $\mathrm{mg} / \mathrm{L}$ \\
$\mathrm{Ca}^{2+}$ & 15.8 & 1.52 & $\mathrm{mg} / \mathrm{L}$ \\
$\mathrm{Cl}^{-}$ & 60.2 & 1.85 & $\mathrm{mg} / \mathrm{L}$ \\
$\mathrm{pH}^{2+}$ & 170.8 & 14.1 & $\mathrm{mg} / \mathrm{L}$ \\
conductivity & 8.12 & 0.14 & $\mathrm{~N} / \mathrm{A}$ \\
& 1.97 & 0.14 & $\mathrm{mS} / \mathrm{cm}$ \\
\hline
\end{tabular}




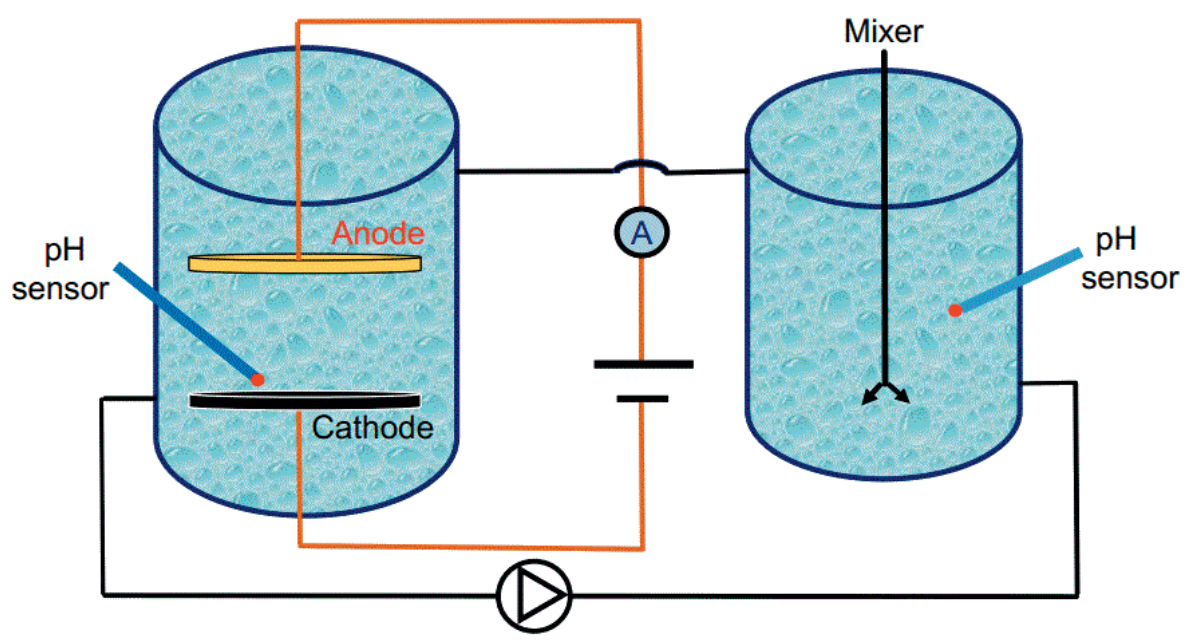

Figure S2.1. Schematic view of the setup. An external tank was connected to the electrochemical phosphorus recovery cell, for the consideration of sampling and analysis. 

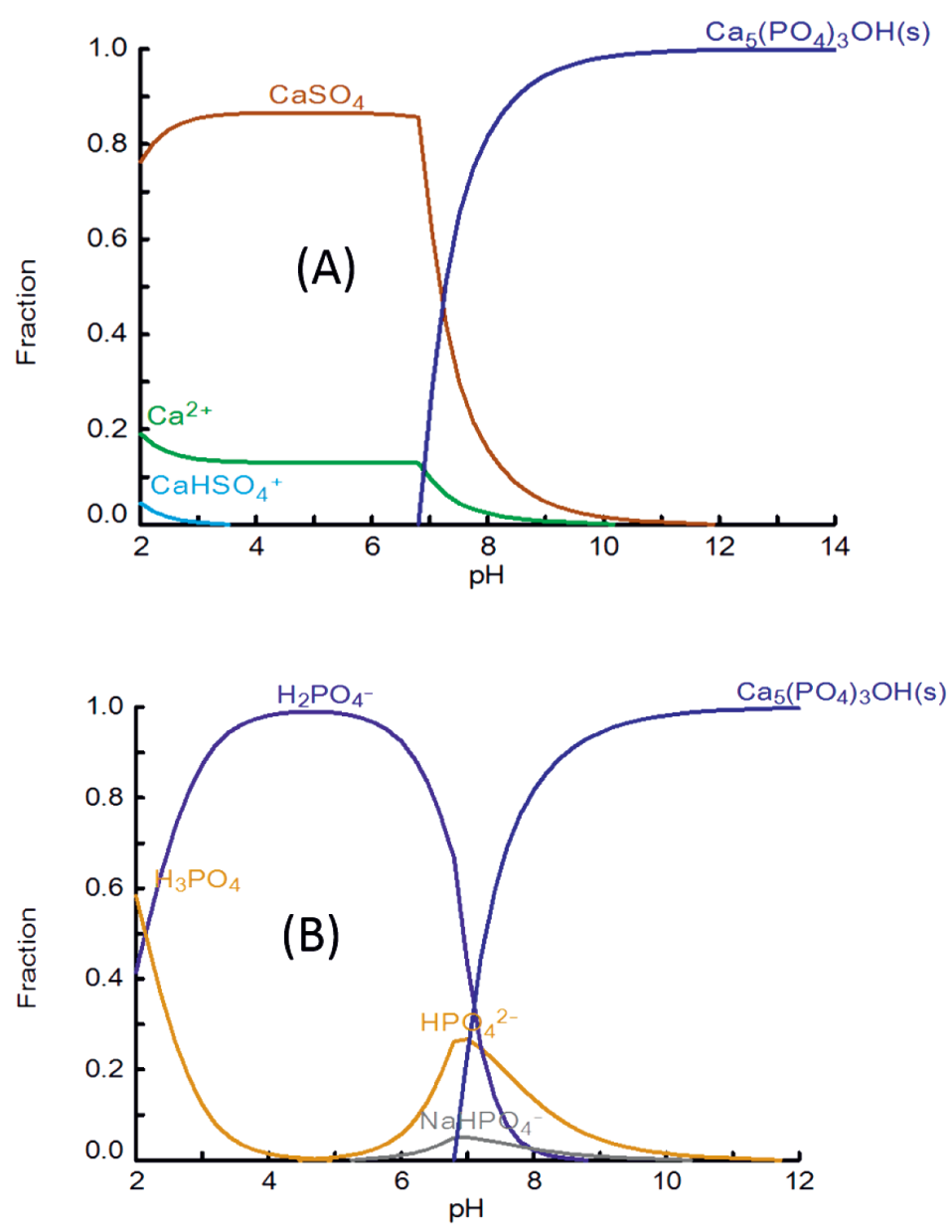

Figure S2.2. (A) Ca and (B) P distribution under different solution $\mathrm{pH}$ calculated with HydraMedusa. Input conditions: $\left[\mathrm{Ca}^{2+}\right]=1.0 \mathrm{mM} ;\left[\mathrm{HPO}_{4}{ }^{2-}\right]=0.6 \mathrm{mM} ;\left[\mathrm{Na}^{+}\right]=111.3 \mathrm{mM} ;\left[\mathrm{SO}_{4}{ }^{2-}\right]$ $=50 \mathrm{mM} ;\left[\mathrm{NO}_{3}^{-}\right]=2.0 \mathrm{mM}$. 


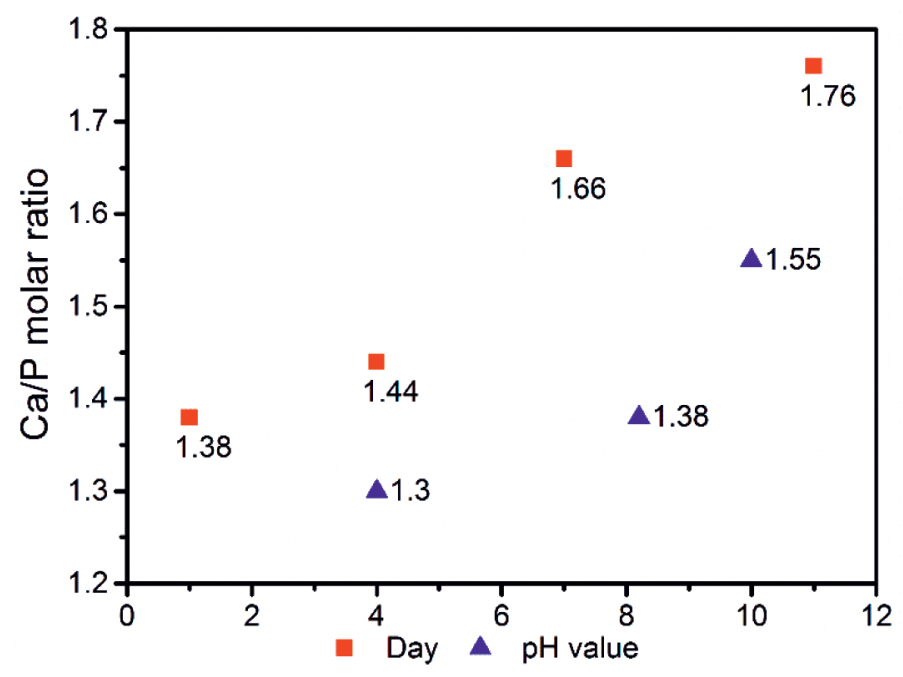

Figure S2.3. The atomic $\mathrm{Ca} / \mathrm{P}$ ratios of the collected calcium phosphate precipitates for different initial solution $\mathrm{pH}$ and different electrolysis time. 


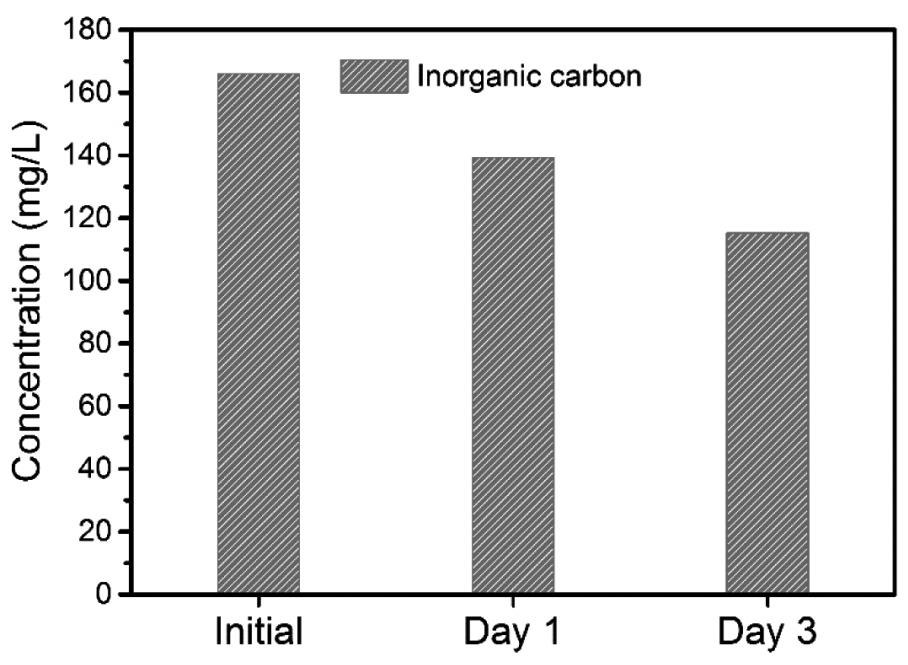

Figure S2.4. Change of inorganic carbon concentration during the electrochemical $P$ precipitation process. Conditions: $20 \mathrm{~mA}$. 


\section{Chapter 3}

\section{Interaction of calcium, phosphorus and natural organic matter in electrochemical recovery of phosphate}

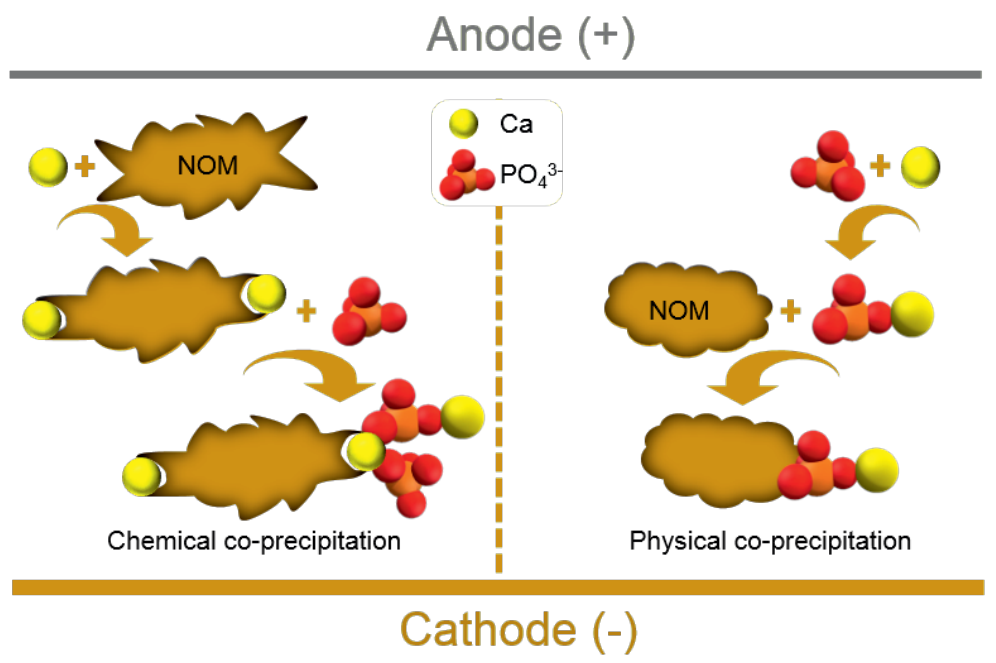

Yang Lei, Bingnan Song, Renata D. van der Weijden, Michel Saakes and Cees J.N. Buisman

This chapter has been published as:

Lei, Yang, Bingnan Song, Michel Saakes, Renata D. van der Weijden, and Cees J.N. Buisman. "Interaction of calcium, phosphorus and natural organic matter in electrochemical recovery of phosphate."

Water Research 142 (2018): 10-17. 


\begin{abstract}
To address the issues of eutrophication and the potential risk of phosphorus $(\mathrm{P})$ shortage, it is essential to remove and recover $\mathrm{P}$ from P-containing streams to close this nutrient cycle. Electrochemical induced calcium phosphate $(\mathrm{CaP})$ precipitation was shown to be an efficient method for P recovery. However, the influence of natural organic matter (NOM) is not known for this treatment. In this paper, the behavior of NOM and its effect on CaP precipitation was studied. In contrast to studies where NOM hindered CaP precipitation, results show that the interaction of NOM with CaP improves the removal of $\mathrm{P}$, independent of the types of NOM. The P removal at the average increased from $43.8 \pm 4.9 \%$ to $58.5 \pm 1.2 \%$ in the presence of $1.0 \mathrm{mg} / \mathrm{L} \mathrm{NOM}$. Based on the yellow color of the CaP product, NOM is co-precipitated. The bulk solution $\mathrm{pH}$ with and without buffers has different effects on the precipitation process. Without buffer, CaP precipitates on the cathode surface in a wide $\mathrm{pH}$ range $(\mathrm{pH}$ 4.0-10.0). However, the precipitation process is completely inhibited when the bulk solution is buffered at $\mathrm{pH} 4.0$ and 6.0. This is probably due to neutralization of $\mathrm{OH}^{-}$by the buffers. Regardless of the presence or absence of $\mathrm{NOM}$ and solution $\mathrm{pH}$, the recovered products are mainly amorphous CaP unless the electrolysis time was increased to seven days with $4.0 \mathrm{~A} / \mathrm{m}^{2}$, in which crystalline $\mathrm{CaP}$ formed. These findings advance our understanding on the interaction of $\mathrm{Ca}, \mathrm{P}$ and NOM species for the application of electrochemical method for P recovery from real wastewater.
\end{abstract}




\subsection{Introduction}

Phosphorus (P) plays an essential role for all living organisms [22]. P fertilizer is also needed to secure food production. However, the diminishing reserves of $\mathrm{P}$ rock are not adapted to the growing demand of $\mathrm{P}[7,83]$. Indeed, on the one hand, $\mathrm{P}$ can be a scarce resource in the future, on the other hand, plenty of $\mathrm{P}$ containing waste streams are discharged to water bodies, resulting in an environmental catastrophe, namely eutrophication [7]. However, if we can recover the lost $\mathrm{P}$ and re-use it as a constituent in fertilizer, this can reduce the risk of $\mathrm{P}$ shortage and alleviate eutrophication problems [10].

Various methods, including enhanced biological phosphorus removal [31, 84], adsorption [85] and chemical precipitation have been applied to remove P from waste streams. Among them, the most common way is chemical precipitation because of its easy operation and efficiency [23]. For the sake of re-use, the chemical precipitation method has shifted from using $\mathrm{Fe}$ and $\mathrm{Al}$ salts, which produce hardly bio-reusable $\mathrm{P}$ salts, to struvite $\left(\mathrm{MgNH}_{4} \mathrm{PO}_{4}\right)$ and calcium phosphate $(\mathrm{CaP})$, which can be used as a slow-release fertilizer or as raw materials for the fertilizer industry, respectively [29, 31, 54]. Previous studies indicate that the concentrations of the associated lattice ions and $\mathrm{pH}$ affect the removal performance of $\mathrm{P}$ since these variables determine the driving force for the precipitation of a species in chemical precipitation process $[36,86]$. On the basis of this, a variety of $\mathrm{Mg}$ or Ca sources, such as natural brucite [28], building waste [87] and steel slag [88] had been applied to achieve efficient and cost-effective $\mathrm{P}$ removal. The advantage of these $\mathrm{Mg}$ or Ca sources is that they not only provide $\mathrm{Mg}^{2+}$ or $\mathrm{Ca}^{2+}$ but also increase solution $\mathrm{pH}$. Particularly, the membrane containing electrochemical system, which can enrich phosphate concentration and increase solution pH simultaneously, receives a lot of attention [49, 55, 56, 69]. However, the associated fouling issues of membranes remain a challenge. The inspiring point, however, is that several studies showed the possibility of a membrane-free system for P removal and recovery $[64,65]$.

Lei et al. recently reported an efficient membrane-free system which induces $\mathrm{CaP}$ precipitation at the cathode surface over a wide $\mathrm{pH}$ range [89]. It was proposed that the production of hydroxide ions on the surface of the titanium cathode through water electrolysis is responsible for P precipitation. In the tests described in Lei et al. [89], calcium nitrate and sodium phosphate in a background matrix of sodium sulfate in MilliQ $(18.2 \mathrm{M} \Omega \cdot \mathrm{cm})$ water 
was used. Further assessment of the applicability of the membrane-free system requires adding other components that could be naturally present and that may interfere with the precipitation of CaP. Previous non-electrochemical studies have shown that both $\mathrm{Mg}^{2+}$ and carbonate inhibit $\mathrm{CaP}$ precipitation by replacing lattice $\mathrm{Ca}$ and decreasing free $\mathrm{Ca}$ by complexation, respectively [90-92]. In particular, it was reported that natural organic matter (NOM) inhibits the precipitation of $\mathrm{CaP}$ by decreasing free aqueous $\mathrm{Ca}$ ions and blocking nucleation sites [93-95]. NOM is a complex matrix of heterogeneous mixture of organic compounds [96] and coexists with $\mathrm{Ca}$ and $\mathrm{P}$ in every aquatic and soil system [95]. The complex structure and functional groups of NOM allows ion exchange and complexation [97], and thereby may interact with lattice ions and thence influence $\mathrm{CaP}$ precipitation. However, the interaction of $\mathrm{NOM}$ on $\mathrm{CaP}$ precipitation in electrochemical systems, to our knowledge, has not been studied, nor the effect of NOM from different sources (or the combined effect of $\mathrm{NOM}$ ) and solution $\mathrm{pH}$ on $\mathrm{CaP}$ precipitation. Electrochemically induced $\mathrm{CaP}$ precipitation depends on the local chemical environment near the cathode surface. It is also known from the literature that though NOM in general shows inhibiting effects on $\mathrm{CaP}$ precipitation in conventional chemical precipitation process, the negative role can be overcome by increasing solution $\mathrm{pH}[93,95]$. Since the electrochemical system can create a high local $\mathrm{pH}$ by $\mathrm{OH}^{-}$production at the vicinity of the cathode, the negative effects of NOM may be eliminated in this system.

The objective of this study is to elucidate the influence of NOM on CaP precipitation in the electrochemical system. Specifically, we studied the effects of NOM from different sources at different $\mathrm{pH}$ conditions. We also investigated the effect of electrolysis time on the electrochemical interaction of $\mathrm{Ca}, \mathrm{P}$ and NOM and the associated impact on chemical and physical properties of precipitates.

\subsection{Materials and methods}

\subsubsection{Materials}

Calcium nitrate tetrahydrate $\left(\mathrm{Ca}\left(\mathrm{NO}_{3}\right)_{2} \cdot 4 \mathrm{H}_{2} \mathrm{O}\right)$ was bought from Merck (Germany). Disodium phosphate $\left(\mathrm{Na}_{2} \mathrm{HPO}_{4}\right)$, sodium sulfate anhydrous $\left(\mathrm{Na}_{2} \mathrm{SO}_{4}\right)$, phthalate $(\mathrm{pH} 4$ buffer), citrate ( $\mathrm{pH} 6$ buffer) and borate ( $\mathrm{pH} 10$ buffer) were obtained from VWR (Leuven, Belgium). Electrodes were provided by MAGNETO Special Anodes BV (Schiedam, The Netherlands). Three types of NOM were purchased from the IHSS (International Humic 
Substances Society) as dry solid extracts: Suwannee River NOM (2R101N, NOM $)$, Nordic Lake NOM (1R108N, NOM $)$ and Pony Lake NOM (1R109F, NOM 3 ). No further purification is performed on these NOMs. All solutions were prepared in MilliQ water (18.2 $\mathrm{M} \Omega \cdot \mathrm{cm})$.

\subsubsection{Setup}

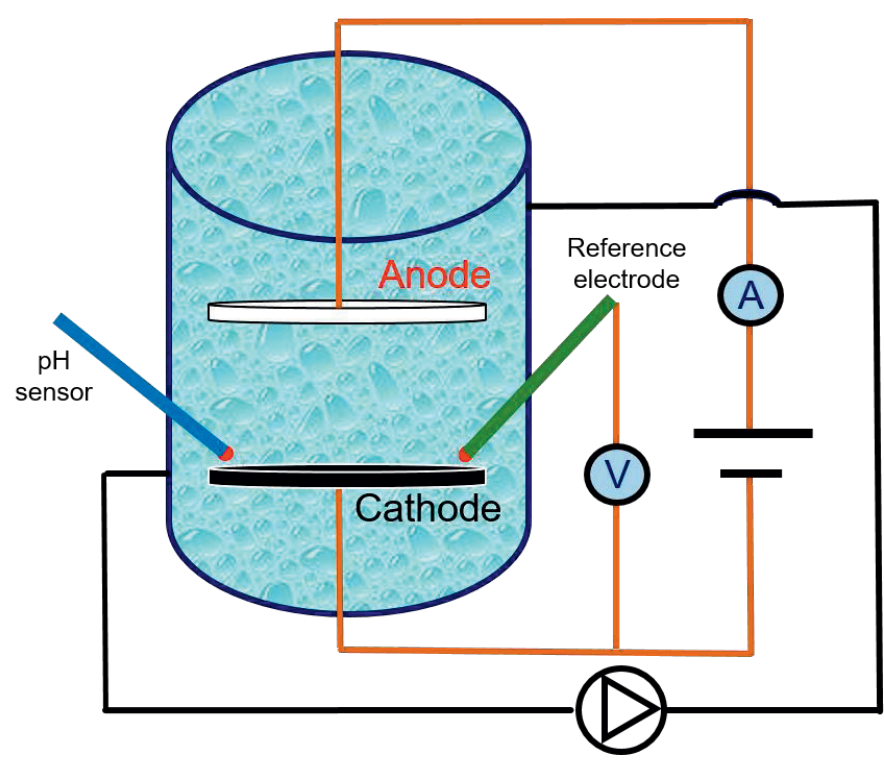

Figure 3.1. Schematic diagram of the setup.

As shown in Figure 3.1, the electrochemical cell consists of a working electrode (cathode), a counter electrode (anode) and an $\mathrm{Ag} / \mathrm{AgCl}$ reference electrode. The constant current condition was provided by a potentiostat (VERTEX, IVIUM Technologies, The Netherlands). The cathode is a pure Ti disc $(\varnothing 8.0 \mathrm{~cm}$, thickness $0.1 \mathrm{~cm}$, grade A) and is perpendicularly welded to a 12-cm long rod $(\varnothing 0.3 \mathrm{~cm})$. The anode has the same design as the cathode and was coated with $10 \mathrm{~g} / \mathrm{m}^{2} \mathrm{Ru}-\mathrm{Ir}$. The total solution in the electrochemical cell $(800 \mathrm{~mL})$ is circulated with a pump at a flow rate of $70 \mathrm{~mL} / \mathrm{min}$.

\subsubsection{Batch experiments}

For the preparation of the test solutions, we used stock solutions of $\mathrm{Ca}^{2+}(0.4 \mathrm{M})$ and $\mathrm{P}-\mathrm{PO}_{4}$ $(0.24 \mathrm{M})$ to obtain final concentrations of $1.0 \mathrm{mM}$ total $\mathrm{Ca}$ and $0.6 \mathrm{mM} \mathrm{P}$. In this paper, we used the term "P" to represent all soluble phosphorus species in the bulk solution. In all batch tests, we added $50 \mathrm{mM} \mathrm{Na}_{2} \mathrm{SO}_{4}$ to maintain the electrolyte conductivity. We first chose 
$\mathrm{NOM}_{1}$ as the typical reference $\mathrm{NOM}$, investigated its effect on $\mathrm{CaP}$ precipitation in the range of 1.0 to $10.0 \mathrm{mg} / \mathrm{L}$, and subsequently studied the effects of NOM sources. We also examined the effects of $\mathrm{pH}$ in buffered and unbuffered solutions on $\mathrm{P}$ recovery. We performed all the electrochemical experiments at a constant current density $\left(4.0 \mathrm{~A} / \mathrm{m}^{2}\right)$ for $24 \mathrm{~h}$ at room temperature. All the tests were at least done in duplicate. The data are shown as mean plus standard deviation. Solids on the cathode surface were collected and dried at room temperature. It should be noted that the solid precipitates were not washed with MilliQ (18.2 $\mathrm{M} \Omega \cdot \mathrm{cm}$ ) water in preventing potential dissolution or recrystallization of precipitates.

\subsubsection{Analysis}

The soluble $\mathrm{Ca}$ and $\mathrm{P}$ concentrations were analyzed by ICP-AES. NOMs were characterized by Liquid Chromatography-Organic Carbon Detection (LC-OCD) (Model 8, DOC-LABOR, Karlsruhe, Germany). Detail information about the analysis of LC-OCD can be found in a previous publication [98]. Prior to the analysis, the samples were filtered with a $0.45 \mu \mathrm{m}$ filter. The phases of collected precipitates were identified by X-ray diffraction (XRD) and collected on a Bruker D8 advanced diffractometer equipped with a Vantec position sensitive detector and with a $\mathrm{Cu} \mathrm{K} \alpha$ radiation $(\lambda=0.154 \mathrm{~nm})$ over a range of $10-70^{\circ}$ in 0.02 step sizes with an integration time of $0.5 \mathrm{~s}$. The XRD data were processed with DIFFRAC.EVA software (Bruker, Germany) and compared with the Crystallography Open Database (COD). The corresponding morphologies were examined by scanning electron microscope (SEM, JEOL-6480LV, JEOL Ltd., Japan). The SEM samples were coated with gold using a JEOL JFC-1200 Fine coater at $10 \mathrm{~Pa}$ for $30 \mathrm{~s}$.

\subsubsection{Calculation}

We used visual Minteq to calculate the supersaturation index (SI) of the possible species in the bulk solution. The SI is defined as:

$$
\mathrm{SI}=\log \left(\frac{\mathrm{IAP}}{\mathrm{Ksp}}\right)
$$

Where Ksp is the thermodynamic solubility product and IAP is the ion activity of the associated lattice ions. 


\subsection{Results and discussion}

\subsubsection{Effect of addition of NOM}

We started our experiments by comparing $\mathrm{P}$ removal in the presence and the absence of $\mathrm{NOM}_{1}$. Figure 3.2A shows the effect of $5.0 \mathrm{mg} / \mathrm{L} \mathrm{NOM}_{1}$ on $\mathrm{Ca}$ and $\mathrm{P}$ removal at an initial $\mathrm{pH}(\sim 8.0$,$) established after all chemicals were added.$
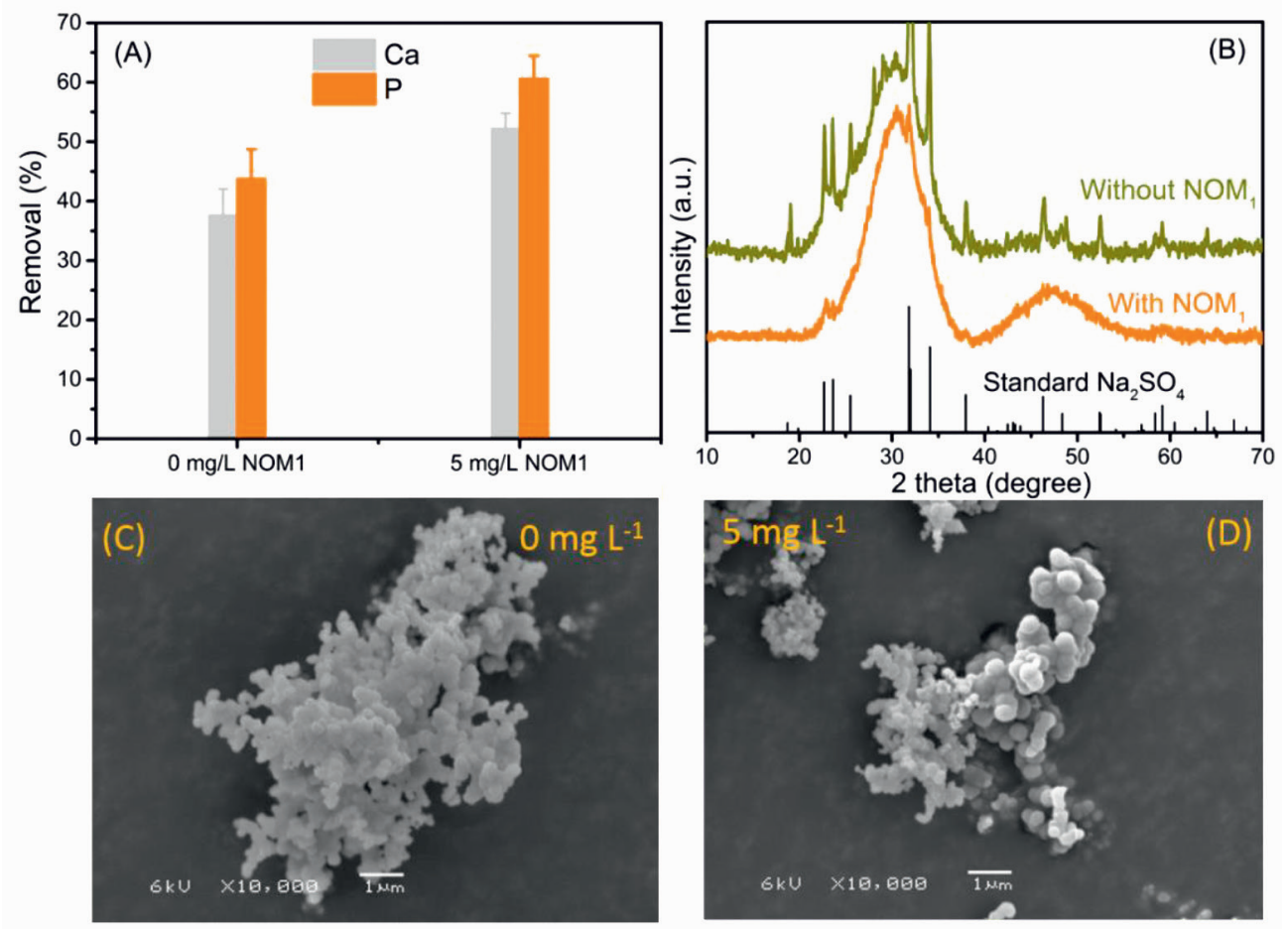

Figure 3.2. (A) Effects of $\mathrm{NOM}_{1}$ on the removal of $\mathrm{Ca}$ and $\mathrm{P},(\mathrm{B}) \mathrm{XRD}$ patterns and $(\mathrm{C}, \mathrm{D})$ SEM images of the precipitates collected in the absence and presence of $\mathrm{NOM}_{1}$. It seems that $\mathrm{NOM}_{1}$ improves the removal of $\mathrm{P}$, but it does not change the morphology of precipitates. Conditions: Suwannee river $\mathrm{NOM}_{1}=5.0 \mathrm{mg} / \mathrm{L} ;\left[\mathrm{Ca}^{2+}\right]=1.0 \mathrm{mM} ;\left[\mathrm{P}-\mathrm{PO}_{4}\right]=0.6 \mathrm{mM} ; \mathrm{pH}_{0}=$ 8.0; electrolysis time $=24 \mathrm{~h}$; current density $4.0 \mathrm{~A} / \mathrm{m}^{2}$; anode: RuIr-Ti; cathode: Ti.

In the presence of $5.0 \mathrm{mg} / \mathrm{L} \mathrm{NOM}_{1}$, the removal efficiency of $\mathrm{Ca}$ and $\mathrm{P}$ increased by $14.6 \%$ and $16.9 \%$, respectively, in comparison to the removal of $\mathrm{Ca}$ and $\mathrm{P}$ in the absence of $\mathrm{NOM}_{1}$. This is in contrast to results found for non-electrochemical $\mathrm{CaP}$ precipitation, where an inhibitory effect of NOM on CaP precipitation was observed $[94,95]$. The lack of inhibition by $\mathrm{NOM}_{1}$ on the removal of $\mathrm{P}$ in our system is probably because the precipitation occurs in 
a local region where the $\mathrm{pH}$ is high enough to overcome the negative influence of $\mathrm{NOM}_{1}$. Indeed, it is known from literature that NOM shows negligible inhibition on both struvite and $\mathrm{CaP}$ precipitation under strongly alkaline conditions $(\mathrm{pH}>9.0)[93,95]$. In the electrochemical system, a local high $\mathrm{pH}$ at the vicinity of the Ti cathode can be created through water reduction; $2 \mathrm{H}_{2} \mathrm{O}+2 \mathrm{e}^{-} \rightarrow 2 \mathrm{OH}^{-}+\mathrm{H}_{2}$. As a result, $\mathrm{Ca}$ and $\mathrm{P}$ ions precipitate as solid CaP phase, even in the presence of $\mathrm{NOM}_{1}$.

This still does not explain why NOM improves the precipitation of $\mathrm{CaP}$ on the cathode. One of the reasons could be that NOM provides binding sites for Ca once NOM co-precipitates with $\mathrm{CaP}$ nuclei which are precursors of stable calcium phosphate particles. NOM, due to its multiple functional groups, such as carboxyl group, can easily adsorb $\mathrm{Ca}^{2+}$. The used $\mathrm{NOM}_{1}$ has a charge density of $11.21 \mathrm{meq} / \mathrm{g}$ carbon at $\mathrm{pH} 8.0$, according to the data provided by IHSS [99]. With $5 \mathrm{mg} / \mathrm{L} \mathrm{NOM}_{1}$ (carbon content 50.7\%), theoretically, only 0.0284 meq could be available for binding $\mathrm{Ca}^{2+}$, which accounts for $1.4 \%$ of $1.0 \mathrm{mM} \mathrm{Ca}^{2+}$. From this perspective, the NOM seemingly not play a role in complexation with $\mathrm{Ca}$. However, the charge density of humic substance increases systematically with $\mathrm{pH}$.

Once being adsorbed to the formed calcium phosphate and in contact with the local high $\mathrm{pH}$, the $\mathrm{NOM}_{1}$ may able to further interact with the phosphate. In this way, the co-precipitated $\mathrm{NOM}_{1}$ enhanced the removal of $\mathrm{P}$. Also, it is reported that NOM can react with electrons from the cathode or with $\mathrm{H}_{2}$ formed at the cathode surface [100]. In our system, the $\mathrm{NOM}_{1}$ may work similarly. Once being adsorbed to the cathode surface, the $\mathrm{NOM}_{1}$ may interact with the $\mathrm{Ca}^{2+}$ and phosphate in the bulk solution and thus enhance the removal of $\mathrm{P}$. Perassi and Borgnino [101] investigated the effect of humic acid on phosphate adsorption by calcite coated montmorillonite. It was found that the order of adding humic acid and phosphate affects the adsorption significantly. When humic acid and phosphate were added simultaneously or humic acid firstly, the adsorption of phosphate on calcite coated montmorillonite was lower, compared to the values observed in the absence of humic acid. However, when phosphate was added first, the adsorption of phosphate on $\mathrm{CaCO}_{3}-\mathrm{M}$ increases when humic acid was added [101]. It was proposed that humic acid improves the adsorption of $\mathrm{P}$ onto calcite coated montmorillonite by preventing precipitation of $\mathrm{CaP}$ in bulk solution. The same mechanism may apply to our system as well. 
Indeed, NOM may prevent $\mathrm{CaP}$ precipitation in the bulk solution through complexation with $\mathrm{Ca}$ and enhance the removal of $\mathrm{P}$. In the presence of $1.0 \mathrm{mM} \mathrm{Ca}$ and $0.6 \mathrm{mM}$ phosphate, at $\mathrm{pH}$ 8.0, the solution is already supersaturated, though no visible precipitation can be noticed. Table S3.1 shows in the absence of $\mathrm{NOM}_{1}$ at least four calcium phosphate species are saturated, including amorphous calcium phosphate $(\mathrm{ACP}, \mathrm{SI}=0.382)$, beta $\mathrm{Ca}_{3}\left(\mathrm{PO}_{4}\right)_{2}(\mathrm{SI}=$ 1.052), $\mathrm{Ca}_{4} \mathrm{H}\left(\mathrm{PO}_{4}\right)_{3} \cdot 3 \mathrm{H}_{2} \mathrm{O}(\mathrm{SI}=0.046)$ and hydroxyapatite (HAP, $\left.\mathrm{SI}=8.634\right)$. This suggests that the Ca may already form metastable phase with phosphate, but due to kinetic reasons or surface tension that needs to be overcame did not precipitate. The formation of such complex will decrease the availability of lattice ions in the bulk solution, so as the diffusion of lattice ions toward the cathode. However, in the presence of $5 \mathrm{mg} / \mathrm{L} \mathrm{NOM}, \mathrm{Ca}_{4} \mathrm{H}\left(\mathrm{PO}_{4}\right)_{3} \cdot 3 \mathrm{H}_{2} \mathrm{O}(\mathrm{SI}$ $=-0.049$ ) is not saturated and the SI of the rest species also decreased. The decrease of SI may increase the free phosphate in the bulk solution and so as the diffusion of phosphate toward the cathode.

The increased removal of $\mathrm{P}$ in the presence of $\mathrm{NOM}_{1}$ did not change the structure of $\mathrm{CaP}$, as shown by XRD (Figure 3.2B). There are no crystalline CaP phases that can be identified in the XRD patterns. Most of the sharp peaks in the absence of $\mathrm{NOM}_{1}$ turn out to be $\mathrm{Na}_{2} \mathrm{SO}_{4}$ resulting from the background electrolyte. The consistent broad peak around $30^{\circ}$ can be assigned to ACP. This is further supported by the unchanged morphology of $\mathrm{CaP}$, as shown in the SEM images (Figure 3.2C). Whether in the absence or presence of $\mathrm{NOM}_{1}$, the precipitates appear as small spherical particles, which is typical for ACP.

\subsubsection{Effect of NOM1 concentration}

After recognizing the promoting effect of $\mathrm{NOM}_{1}$ on electrochemical CaP precipitation, we studied the influence of $\mathrm{NOM}_{1}$ concentration. Figure 3.3A shows the removal of $\mathrm{P}$ slightly increased from $43.8 \pm 4.9 \%(0 \mathrm{mg} / \mathrm{L})$ to $58.5 \pm 1.2 \%(1.0 \mathrm{mg} / \mathrm{L})$ and further to $62.5 \pm 1.9 \%$ in the presence of $10 \mathrm{mg} / \mathrm{L} \mathrm{NOM}_{1}$. In addition, we found that the addition of $\mathrm{NOM}_{1}$ changes the color of the recovered products (Figure 3.3B). Without $\mathrm{NOM}_{1}$, the precipitate has the typical white color of $\mathrm{CaP}$. However, the color of precipitates changes to light yellow in the presence of $1.0 \mathrm{mg} / \mathrm{L} \mathrm{NOM}_{1}$. The color intensity of precipitates increases with increasing $\mathrm{NOM}_{1}$ dosage (Figure 3.3B), probably because of the amount of adsorbed/co-precipitated $\mathrm{NOM}_{1}$ increases. The increased adsorption/co-precipitation of NOM on CaP may hinder the further adsorption of phosphate on initially precipitated CaP. It was documented that the 
simultaneous addition of humic acid and phosphate lowers the adsorption of phosphate on calcite coated montmorillonite [101].
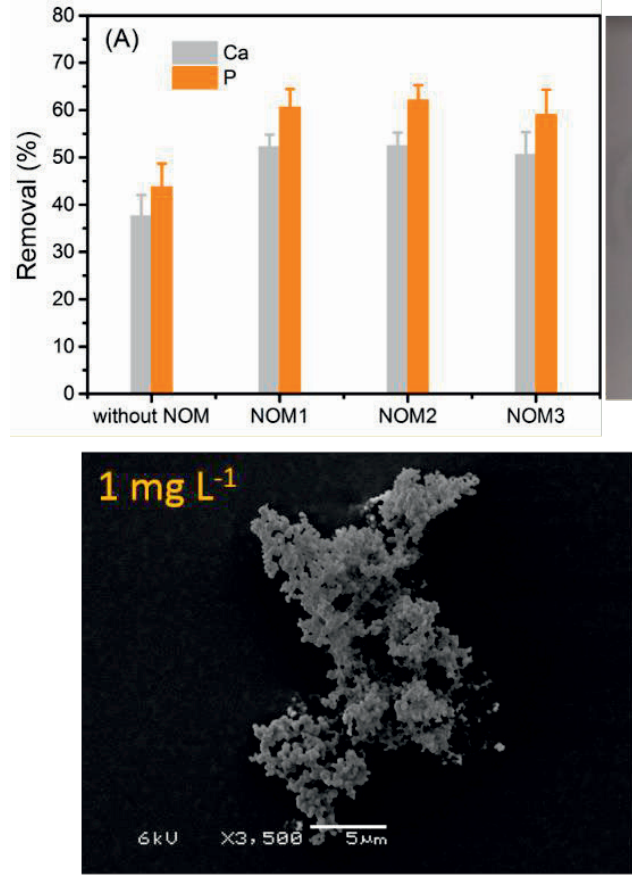

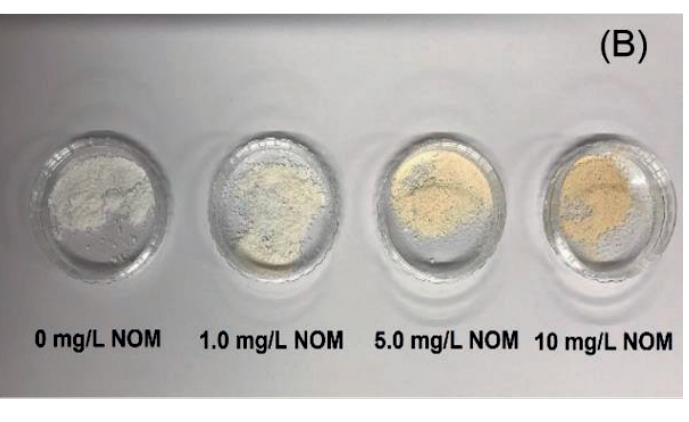

(C)

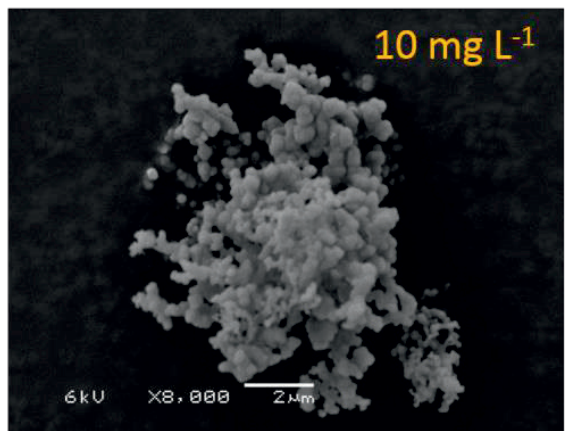

Figure 3.3. (A) Removal efficiencies of $\mathrm{Ca}$ and $\mathrm{P}$, (B) the color of precipitates and (C) SEM images as a function of $\mathrm{NOM}_{1}$ dosage. SEM images in the absence of $\mathrm{NOM}_{1}$ and in the presence of $5 \mathrm{mg} / \mathrm{L} \mathrm{NOM}_{1}$ can be found in Figure 3.2. $\mathrm{NOM}_{1}$ improves the precipitation of calcium phosphate and the higher the $\mathrm{NOM}_{1}$ concentration, the higher the P removal, but the enhancement is quite small. The presence of $\mathrm{NOM}_{1}$ also changes product color by coprecipitation with CaP. Conditions: $\left[\mathrm{Ca}^{2+}\right]=1.0 \mathrm{mM} ;\left[\mathrm{P}_{-} \mathrm{PO}_{4}\right]=0.6 \mathrm{mM}$; electrolysis time $=$ $24 \mathrm{~h} ; \mathrm{pH}_{0}=8.0$; current density $=4.0 \mathrm{~A} / \mathrm{m}^{2}$; anode: $\mathrm{RuIr}-\mathrm{Ti}$; cathode: Ti.

Overall, the small increase of $\mathrm{P}$ removal with increasing $\mathrm{NOM}_{1}$ concentration in our system is because $\mathrm{NOM}_{1}$, on the one hand, promotes $\mathrm{CaP}$ precipitation on the surface of cathode, on the other hand, at a later stage, the co-precipitated $\mathrm{NOM}_{1}$ may hinder the further adsorption of phosphate on the initially precipitated CaP. Moreover, the complexation of $\mathrm{NOM}_{1}$ with $\mathrm{Ca}^{2+}$ may not only decrease the free $\mathrm{Ca}$ in the bulk solution but also the availability of $\mathrm{Ca}$ in the local region at a high $\mathrm{NOM}_{1}$ concentration (i.e., $10 \mathrm{mg} / \mathrm{L}$ ). This negative effect may cancel out the positive effect of $\mathrm{NOM}_{1}$ on $\mathrm{CaP}$ precipitation at the surface of the cathode. In conclusion, the effect of $\mathrm{NOM}_{1}$ on $\mathrm{CaP}$ precipitation in the electrochemical system is dictated 
by the balance between the positive role and negative role. As a result, the increase in both $\mathrm{P}$ and $\mathrm{Ca}$ removal is small with increasing $\mathrm{NOM}_{1}$ concentration.

Regardless of the dosage of $\mathrm{NOM}_{1}$, the morphology of the precipitates is consistent, all in special shape (Figure 3.3C), which is often seen for ACP. It is widely reported that the presence of NOM will inhibit the transfer of ACP to crystalline CaP [102]. As the precipitates collected in the absence of $\mathrm{NOM}_{1}$ is ACP, it is not surprising that the precipitates remain in the amorphous phase in the presence of $\mathrm{NOM}_{1}$. Apparently, the co-precipitation of $\mathrm{NOM}_{1}$ with $\mathrm{CaP}$ will lower the purity of product as $\mathrm{CaP}$. However, in terms of the value of $\mathrm{CaP}$ either as a raw fertilizer or as a direct $\mathrm{P}$ fertilizer, the co-precipitation may be desirable. According to the study of Delgado et al. [103] and Perassi and Borgnino [101], the presence of organic matter can increase the bioavailability of $\mathrm{P}$ in $\mathrm{CaP}$ for plants. This point out the potential of producing organic containing $\mathrm{CaP}$ fertilizer by precipitating $\mathrm{Ca}, \mathrm{P}$ and $\mathrm{NOM}$ simultaneously by applying the electrochemical phosphorus recovery system.

\subsubsection{Co-precipitation mechanism}

Although we found that NOM co-precipitates with $\mathrm{CaP}$ and improves the removal of $\mathrm{P}$ in the electrochemical system, we are not yet able to clarify the precipitation mechanism. We assume that the co-precipitation can be either as direct physical precipitation or an indirect chemical co-precipitation or a combination of both, as illustrated in Figure 3.4.

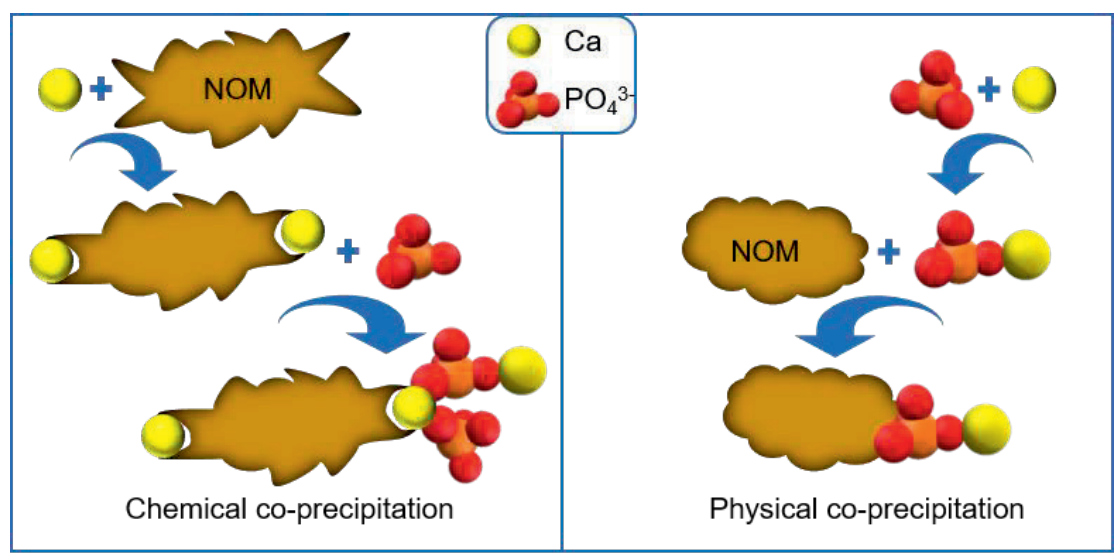

Figure 3.4. Two plausible pathways for the co-precipitation of NOM with $\mathrm{Ca}$ and $\mathrm{P}$ in the electrochemical P recovery system. 
For the chemical co-precipitation pathway, $\mathrm{Ca}^{2+}$ forms a binary complex with NOM (NOM$\mathrm{Ca}^{+}$) initially and then diffuses to the cathode and forms insoluble P-Ca-NOM complex. The crucial step of chemical co-precipitation is the diffusion of $\mathrm{NOM}-\mathrm{Ca}^{+}$toward the cathode. However, given the big molecular size of NOM-Ca ${ }^{+}$, the diffusion rate of $\mathrm{NOM}-\mathrm{Ca}^{+}$should be much slower than free $\mathrm{Ca}^{2+}$, and therefore it is unlikely that the $\mathrm{NOM}-\mathrm{Ca}^{+}$complex participates in the precipitation of $\mathrm{CaP}$ directly. The most likely co-precipitation mechanism is the adsorption of NOM on ACP (Figure 3.4). In this process, the formation of ACP by $\mathrm{Ca}^{2+}$ and phosphate is the first step. Due to the good adsorption ability of the initially formed ACP and its unstable structure [93], NOM can be easily adsorbed to the surface of ACP. Zhou et al. [104] reported similar physical adsorption of NOM on the surface of struvite crystals. The adsorbed $\mathrm{NOM}_{1}$ (negatively charged) may then interact with the $\mathrm{Ca}^{2+}$ through electrostatic interaction, forming NOM-Ca ${ }^{+}$. Also, it is reported that NOM can react with electrons from the cathode or with $\mathrm{H}_{2}$ formed at the cathode surface [100]. This may contribute to the formation of NOM-Ca ${ }^{+}$as well. Subsequently, the NOM-Ca+ may able to interact with the phosphate chemically, leading to the formation of insoluble NOM-Ca-P.

In the same way, NOM and Ca interaction enhances the fouling of membranes in the nanofiltration process [105]. Therefore, it is suggested that the physical adsorption of NOM by ACP is the dominant co-precipitation pathway in the initial stage also because only a very small amount of $\mathrm{Ca}^{2+}$ can complex with NOM. In a later stage, both physical and chemical adsorption may contribute to the enhanced removal of $\mathrm{P}$ in the presence of NOM in the electrochemical P recovery system.

\subsubsection{Effect of NOM type}

Figure 3.5 shows that there is no significant difference for $\mathrm{Ca}$ and $\mathrm{P}$ removal among the three types of NOM, though the three NOMs are supposed to have different behaviors in $\mathrm{CaP}$ precipitation due to their variation in molecular size and functional groups. 

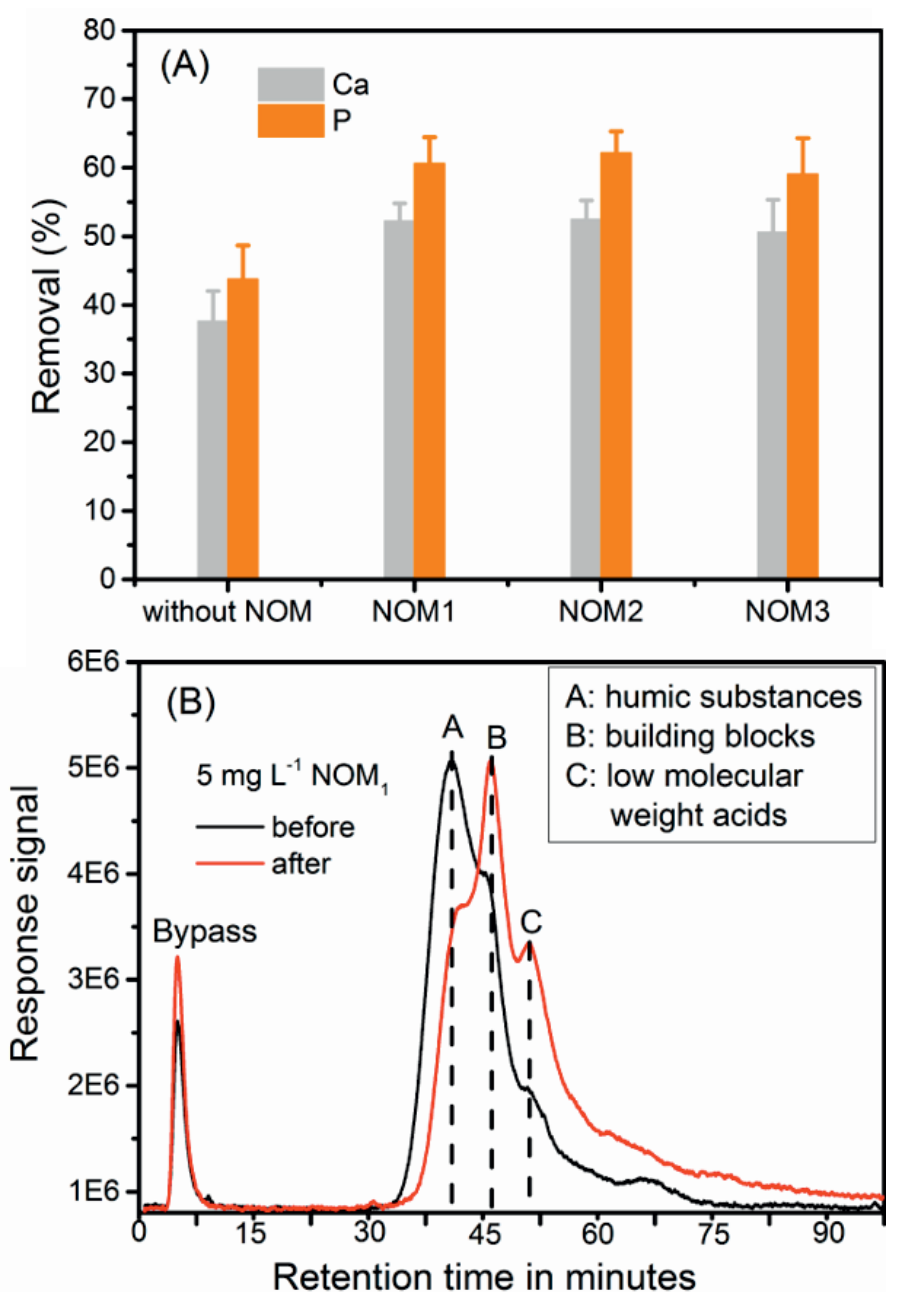

Figure 3.5. (A) Effect of NOM types on the removal of $\mathrm{Ca}$ and $\mathrm{P}$, (B) LC-OCD chromatogram of $\mathrm{NOM}_{1}$ before and after treatment. No significant differences of $\mathrm{Ca}$ and $\mathrm{P}$ removal efficiencies among the three types of NOM. Conditions: $\left[\mathrm{Ca}^{2+}\right]=1.0 \mathrm{mM}$; $\left[\mathrm{P}-\mathrm{PO}_{4}\right]$ $=0.6 \mathrm{mM}$; electrolysis time $=24 \mathrm{~h}$; current density $=4.0 \mathrm{~A} / \mathrm{m}^{2} ;\left[\mathrm{NOM}_{1}\right]=\left[\mathrm{NOM}_{2}\right]=\left[\mathrm{NOM}_{3}\right]$ $=5.0 \mathrm{mg} \mathrm{L}^{-1} ; \mathrm{pH}_{0}=8.0$; anode: RuIr-Ti; cathode: Ti.

$\mathrm{NOM}_{1}$ has a larger molecular weight and is regarded as a natural anionic polyelectrolyte. $\mathrm{NOM}_{2}$ is a mixture of hydrophilic non-humic with hydrophobic humic matter, while $\mathrm{NOM}_{3}$ is the representative of fulvic acid with a low molecular weight [98]. The characterization of the three NOMs by LC-OCD (Figure S3.1) suggests that the order of humic acids-carbon 
$(\mathrm{HA}-\mathrm{C})$ content is $\mathrm{NOM}_{1}(1.78 \pm 0.09 \mathrm{mg} / \mathrm{L})>\mathrm{NOM}_{3}(1.49 \pm 0.04 \mathrm{mg} / \mathrm{L})>\mathrm{NOM}_{2}(1.03 \pm$ $0.03 \mathrm{mg} / \mathrm{L})$, all in the same dosage $(5 \mathrm{mg} / \mathrm{L})$.

The charge density of the NOMs is also different. $\mathrm{NOM}_{1}$ has a charge density of $11.21 \mathrm{meq} / \mathrm{g}$ carbon, while the value for $\mathrm{NOM}_{3}$ is 7.09 [99]. Note that the charge density of $\mathrm{NOM}_{2}$ is not provided by IHSS, but it probably lies in the range of 7.09 to $11.21 \mathrm{meq} / \mathrm{g}$ carbon, if considering the HA-C content. Efforts were made to relate the composition of the NOMs with the $\mathrm{P}$ and $\mathrm{Ca}$ removal, but no solid conclusions could be drawn. Though it is evident that all NOMs improve the removal of $\mathrm{P}$ (Figure 3.5A), there is no significant variation between these NOMs. The small difference might be because the NOMs were degraded by the anode or an anode mediated oxidation, which results in the breakdown of NOM molecules. The breakdown of NOM was confirmed by the decreased humic substances, increased building blocks and the low molecular-weight acids, which is shown in the LC-OCD chromatogram (Figure 3.5B).

The color of recovered products is different (Figure S3.2). The precipitates with $\mathrm{NOM}_{3}$ is in light yellow and even close to the color of samples collected in the absence of NOM. However, the precipitates collected in the presence of $\mathrm{NOM}_{1}$ and $\mathrm{NOM}_{2}$ are yellow-brown. The difference in the color of precipitates is caused by the initial color of NOMs. This again confirms the involvement of NOM in the CaP solids. On top of this, the small difference of $\mathrm{P}$ removal in response to the different types of NOM may highlight the dominant coprecipitation mechanism of NOM as physical precipitation. NOM participates in the precipitation process mostly in the second step by adsorption to the surface of $\mathrm{CaP}$. The initial formation of $\mathrm{CaP}$ at the cathode surface may be not affected by the presence of NOM nor by the NOM type. Therefore, the change of NOM type did not result in significant changes in $\mathrm{CaP}$ precipitation and the associated NOM co-precipitation. However, the complexity of this system makes it difficult to give a solid conclusion on the role of NOM on CaP precipitation in the electrochemical system.

\subsubsection{Effect of solution pH}

In a previous study, it was shown that the electrochemical system works efficiently in a wide $\mathrm{pH}$ range in the absence of NOM and in non-buffered solutions [89]. To investigate the performance of this system in the presence of NOM, the role of $\mathrm{pH}$ with and without buffer 
was studied. In unbuffered solutions, as without NOM, the system shows efficient $\mathrm{P}$ and $\mathrm{Ca}$ removal over a wide $\mathrm{pH}$ range ( $\mathrm{pH}$ 4.0-10.0) (Figure 3.6).

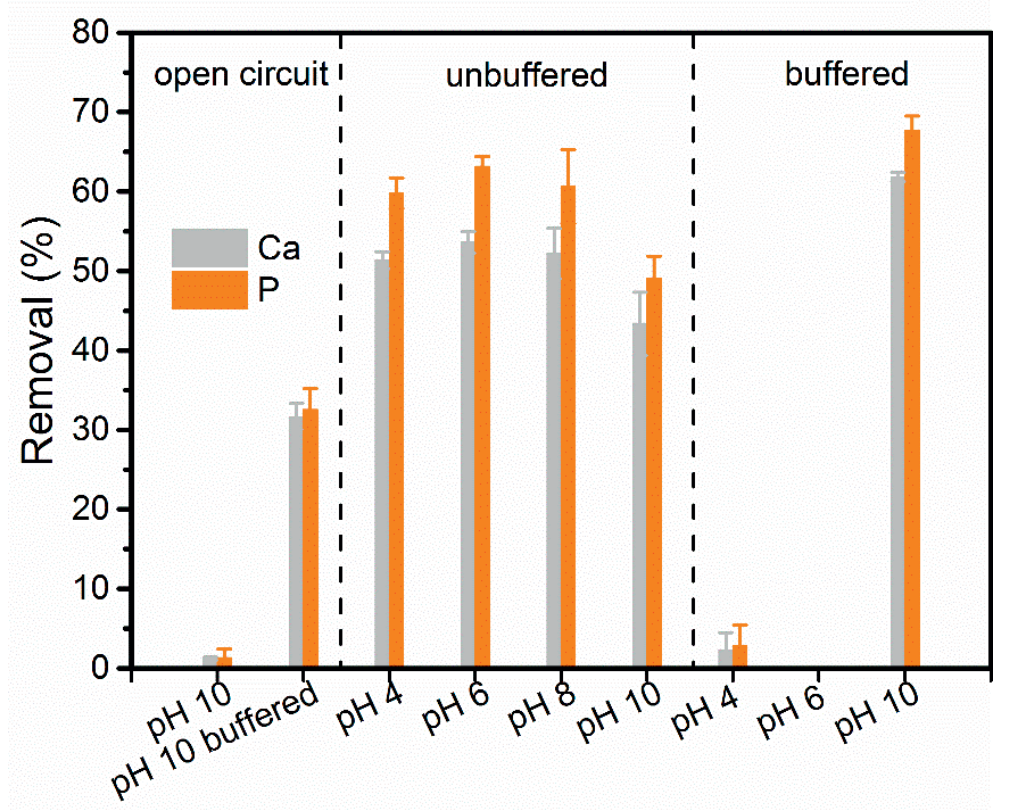

Figure 3.6. Effect of solution $\mathrm{pH}$ on the precipitation of calcium phosphate in presence of $\mathrm{NOM}_{1}$. There is no significant difference among different initial solution $\mathrm{pH}$, but the presence of buffers at $\mathrm{pH} 4.0$ and 6.0 totally blocks calcium phosphate precipitation, with almost no $\mathrm{Ca}$ and $\mathrm{P}$ removed from solution. Conditions: $\left[\mathrm{Ca}^{2+}\right]=1.0 \mathrm{mM} ;\left[\mathrm{P}-\mathrm{PO}_{4}\right]=0.6 \mathrm{mM} ;\left[\mathrm{NOM}_{1}\right]$ $=5.0 \mathrm{mg} / \mathrm{L} ;[$ phthalate $]=250 \mathrm{~g} / \mathrm{L}(\mathrm{pH} 4.0) ;[$ citrate $]=250 \mathrm{~g} / \mathrm{L}(\mathrm{pH} 6.0) ;[$ borate $]=250 \mathrm{~g} / \mathrm{L}$ $(\mathrm{pH} 10.0)$; electrolysis time $=24 \mathrm{~h}$; current density $=4.0 \mathrm{~A} / \mathrm{m}^{2}$; anode: RuIr-Ti; cathode: Ti.

Overall, there is no big difference among different initial bulk solution $\mathrm{pH}$ values and the obtained P removal ( $\sim 60 \%$ ). However, at $\mathrm{pH} 10.0$ approximately $10 \%$ less $\mathrm{P}$ was removed from the solution. This is in line with a previous study in the absence of NOM that a low bulk solution $\mathrm{pH}$ results in slightly higher P removal [89]. However, in buffered solutions, the precipitation of $\mathrm{Ca}$ and $\mathrm{P}$ was reduced. Specifically, the presence of buffers at $\mathrm{pH} 4.0$ and 6.0 blocks CaP precipitation completely, with almost no $\mathrm{Ca}$ and $\mathrm{P}$ removed from the solution. This is because the strong buffers inhibit the increase of local $\mathrm{pH}$ by consuming the produced $\mathrm{OH}^{-}$at the surface of cathode, which was already documented $[68,106]$. For instance, Honda et al. reported that the addition of glycine buffer $(0.2 \mathrm{M})$ drops the local $\mathrm{pH}$ from 12.5 to 2.5 [68]. For the solution buffered at $\mathrm{pH}$ 10.0, though borate buffer may hinder the increase of 
local $\mathrm{pH}$ as well, the system still forms $\mathrm{CaP}$ precipitates in the vicinity of cathode. This is because at $\mathrm{pH} 10.0$, the solution is already highly supersaturated with respect to $\mathrm{CaP}$. This is supported by the $32.5 \% \mathrm{P}$ and $31.6 \% \mathrm{Ca}$ removal in open circuit in $24 \mathrm{~h}$ (Figure 3.6). Indeed, we found precipitates on the surface of cathode, anode and the bottom of the electrochemical cell in open circuit. However, under the same solution conditions, in closed circuit, most precipitates form at the surface of cathode. It seems that in the electrochemical system in addition to the production of $\mathrm{OH}^{-}$ions, the migration of $\mathrm{Ca}^{2+}$ toward the Ti cathode is enhanced by the applied current. Due to the self-driven and electrochemical-driven precipitation of $\mathrm{CaP}$ in $\mathrm{pH} 10.0$ (buffered), the highest $\mathrm{P}$ removal (67.7\%) was achieved.

\subsubsection{Effects of electrolysis time}

The time dependence of $\mathrm{P}$ removal was evaluated by extending reaction time up to seven days in the presence of $5.0 \mathrm{mg} / \mathrm{L} \mathrm{NOM}_{1}$ at background solution $\mathrm{pH}$ (about 8.0). Generally, the removal of both $\mathrm{Ca}$ and $\mathrm{P}$ was improved by a longer electrolysis time. In the first day, $60.0 \% \mathrm{P}$ and $52.2 \% \mathrm{Ca}$ precipitate from the solution (Figure 3.7A). The removal percentage increases to $80.5 \%$ and $68.3 \%$ for $\mathrm{P}$ and Ca respectively on the second day. This is because the increase of electrolysis time not only produces more $\mathrm{OH}^{-}$but also provides more time for the diffusion of $\mathrm{Ca}$ and $\mathrm{P}$ toward the reaction zone (near cathode). However, the further increase of electrolysis time does not increase the removal substantially.

The removal of $\mathrm{Ca}$ and $\mathrm{P}$ increased only by about $10 \%$ even the electrolysis time was extended to seven days. This is probably due to the decrease of concentrations of $\mathrm{Ca}$ and $\mathrm{P}$ ions in the bulk solution. After two days' reaction, the concentrations of $\mathrm{Ca}$ and $\mathrm{P}$ decreased to 12.7 and $3.6 \mathrm{mg} / \mathrm{L}$, respectively. The decrease of lattice ions concentration in the bulk solution will drop the availability of lattice ions in the local region where precipitation happens and so as the removal rate of lattice ions. 

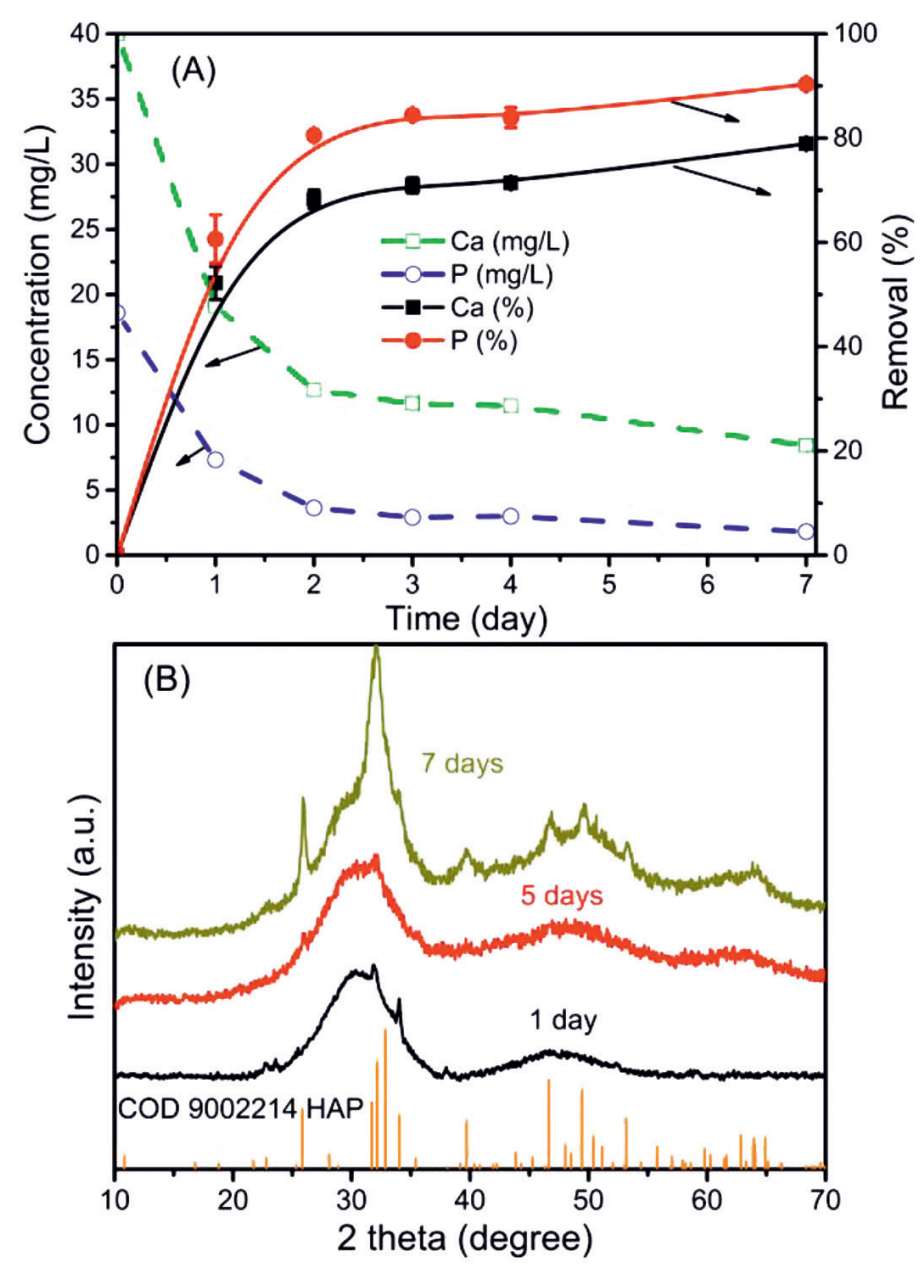

Figure 3.7. (A) Effects of electrolysis time on the removal efficiencies. (B) XRD patterns of calcium phosphate products collected under different electrolysis time. Conditions: $\left[\mathrm{Ca}^{2+}\right]=$ $1.0 \mathrm{mM} ;\left[\mathrm{P}_{-} \mathrm{PO}_{4}\right]=0.6 \mathrm{mM} ;\left[\mathrm{NOM}_{1}\right]=5 \mathrm{mg} / \mathrm{L}$; current density = $4.0 \mathrm{~A} / \mathrm{m}^{2}$; anode: RuIr-Ti; cathode: Ti.

Moreover, the initially precipitated $\mathrm{CaP}$ occupied most of the Ti surface. The space for further $\mathrm{CaP}$ precipitation was limited. Consequently, the removal of $\mathrm{P}$ only increased slightly with increasing the electrolysis time. Interestingly, the removal percentage of $\mathrm{P}$ is always about $10 \%$ higher than $\mathrm{Ca}$ during the whole precipitation process. Mass balance calculations show that the $\mathrm{Ca} / \mathrm{P}$ molar ratio in the precipitates, is 1.44 (first day), 1.41 (second day), 1.40 (fourth day) and 1.42 (seventh day). This is different from the $\mathrm{Ca} / \mathrm{P}$ molar ratio in the absence of 
$\mathrm{NOM}$, where the $\mathrm{Ca} / \mathrm{P}$ ratio gradually increased from 1.43 in the first day to 1.66 on the seventh day [89].

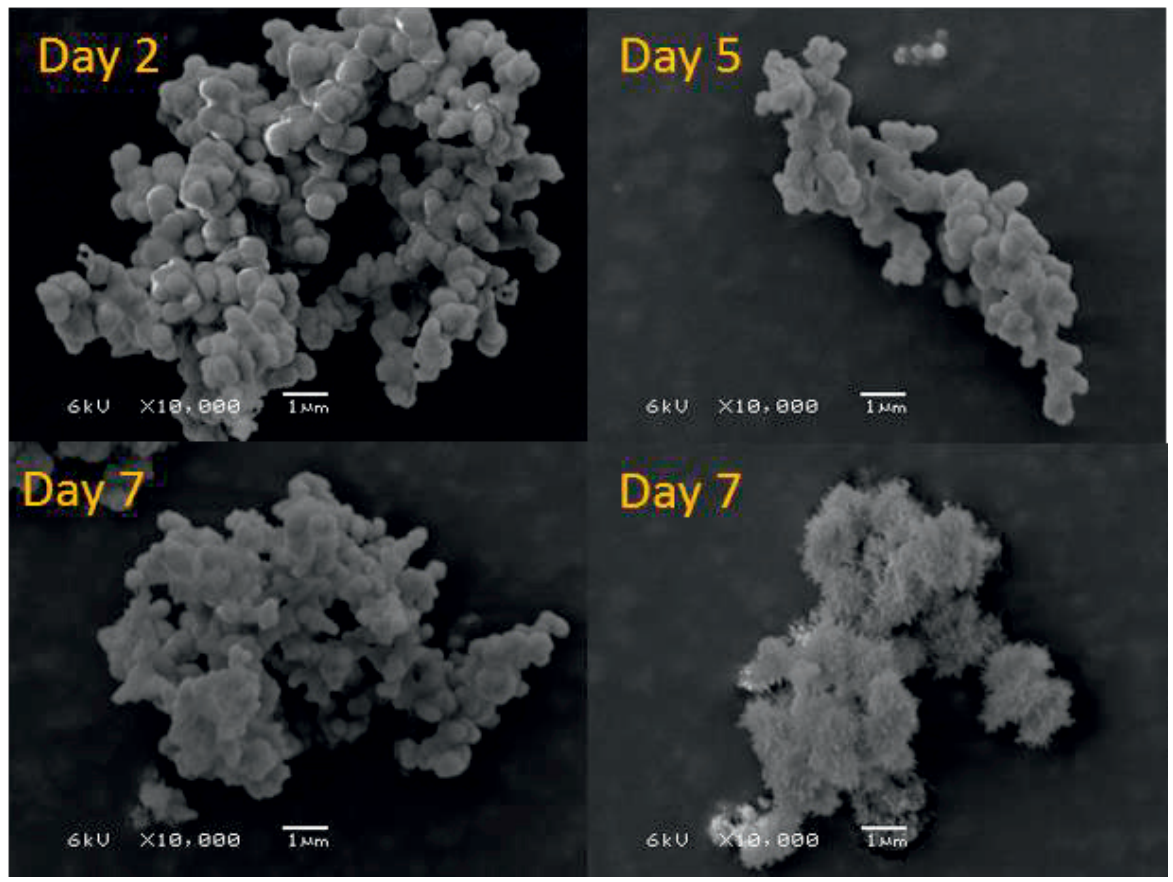

Figure 3.8. Effects of electrolysis time on the morphologies of calcium phosphate products. SEM image of solids collected on the first day can be found in Figure 3.2.

The difference is likely caused by the presence of NOM. As discussed previously, NOM was adsorbed to the surface of ACP on the cathode. The transfer of initially formed ACP to crystalline CaP (i.e., HAP) will be hindered/delayed in the presence of NOM [102]. Indeed, as shown by the SEM images (Figure 3.8), the collected particles are spherical which is typical for ACP till day seven when needle-like shape (HAP) co-exists with the spherical shape. Therefore, the precipitates collected after one day, five and seven days were subjected to XRD characterization (Figure 3.7B). As shown in Figure 3.7B, in $24 \mathrm{~h}$ and 5 days, the corresponding XRD spectrum shows only broad peaks around $30^{\circ}$ and $47^{\circ}$. This suggests that the samples are dominantly ACP. However, within seven days, in addition to the same broadened peaks, there are also some sharp peaks which match the reference HAP (COD 9002214), suggesting the presence of HAP in the precipitates. Though in the presence of $\mathrm{NOM}$, the crystallization process is delayed, ACP can still transfer to crystalline species, depending on reaction time and $\mathrm{pH}$. 


\subsection{Conclusions}

To conclude, we confirmed, for the first time, that the presence of NOM improves CaP precipitation mainly via physical co-precipitation with $\mathrm{CaP}$ in the electrochemical phosphorus recovery system. However, the co-precipitation of NOM on CaP surface delays the transfer of ACP to HAP and results in the formation of low $\mathrm{Ca} / \mathrm{P}$ molar ratio species. Still, part of the ACP recrystallized to HAP when the electrolysis time was extended to 7 days. Interestingly, the initial bulk solution $\mathrm{pH}$ does not have dramatic effects on the interaction of $\mathrm{Ca}, \mathrm{P}$ and NOM because the precipitation process is induced by the high local $\mathrm{pH}$ at the cathode. However, high concentrations of acidic buffer inhibit the precipitation of $\mathrm{CaP}$ and the accompanied co-precipitation of NOM because buffers hinder the increase of local $\mathrm{pH}$ at the cathode. 


\section{Supporting information}

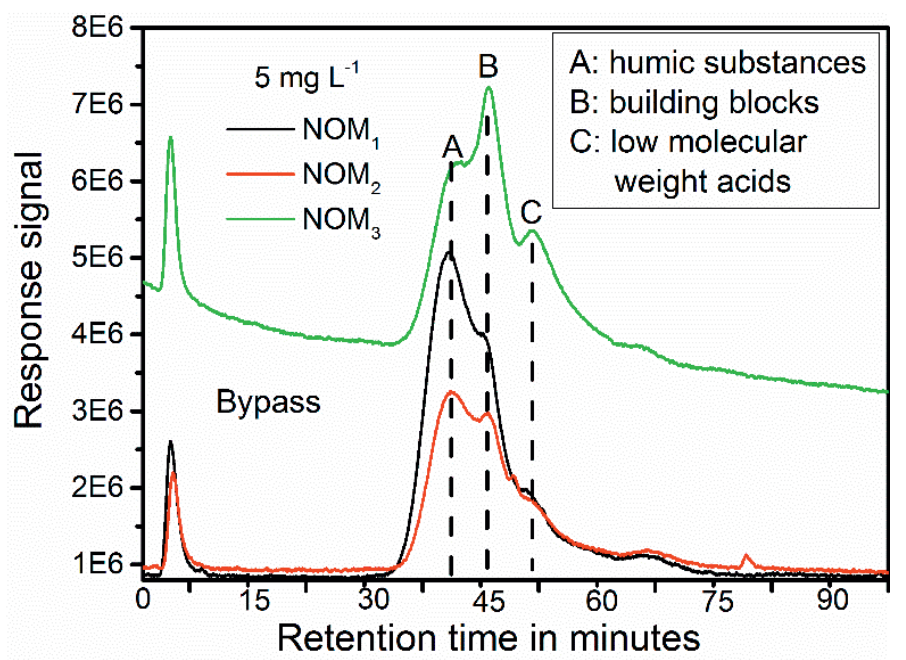

Figure S3.1. LC-OCD chromatography of the three NOMs.

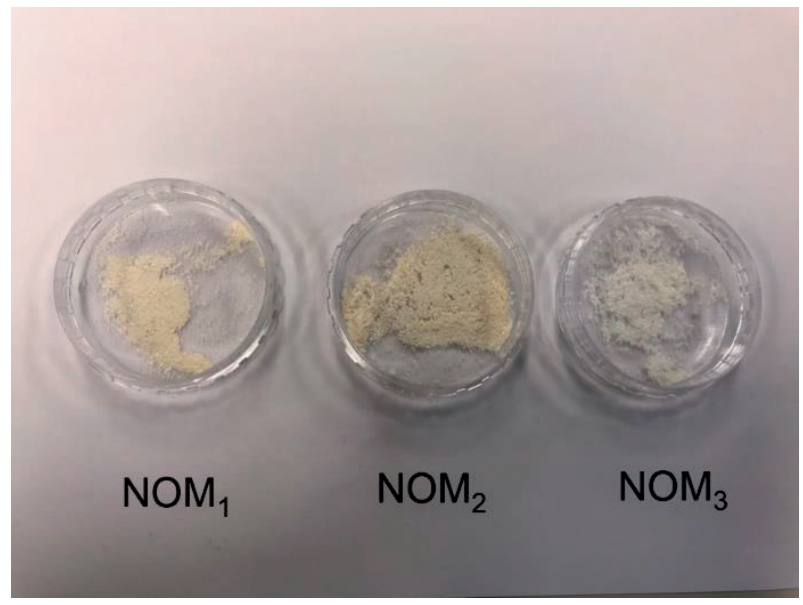

Figure S3.2. Color of precipitates collected in the presence of different types of NOM. Conditions: $\left[\mathrm{Ca}^{2+}\right]=1.0 \mathrm{mM}$; $\left[\mathrm{P}-\mathrm{PO}_{4}\right]=0.6 \mathrm{mM}$; electrolysis time $=24 \mathrm{~h}$; current density $=$ $4.0 \mathrm{~A} / \mathrm{m}^{2} ;\left[\mathrm{NOM}_{1}\right]=\left[\mathrm{NOM}_{2}\right]=\left[\mathrm{NOM}_{3}\right]=5.0 \mathrm{mg} / \mathrm{L} ; \mathrm{pH}_{0}=8.0 ;$ anode: RuIr-Ti; cathode: Ti. 
Table S3.1. Supersaturation index of possible calcium phosphate species in the bulk solution. $1.0 \mathrm{mM} \mathrm{Ca}{ }^{2+}, 0.6 \mathrm{mM} \mathrm{P}, \mathrm{pH}$ 8.0. ACP (amorphous calcium phosphate, $\left.\mathrm{Ca}_{3}\left(\mathrm{PO}_{4}\right)_{2}\right)$, HAP (hydroxyapatite, $\left.\mathrm{Ca}_{5}\left(\mathrm{PO}_{4}\right)_{3} \cdot \mathrm{OH}\right)$.

\begin{tabular}{ccccc}
\hline conditions & ACP & HAP & $\begin{array}{c}\text { Beta } \\
\mathbf{C a}_{3}\left(\mathbf{P O}_{4}\right)_{2}\end{array}$ & $\mathbf{C a}_{4} \mathrm{H}_{(}\left(\mathbf{P O}_{4}\right)_{3} \cdot \mathbf{3 H}_{2} \mathbf{O}$ \\
& & & 1.052 & \\
\hline without NOM & 0.382 & 8.634 & 0.046 \\
$\mathbf{5} \mathbf{~ m} / \mathbf{L ~ N O M}$ & 0.289 & 8.45 & 0.959 & -0.049 \\
\hline
\end{tabular}




\section{Chapter 4}

\section{Fate of calcium, magnesium and inorganic carbon in electrochemical phosphorus recovery from domestic wastewater}
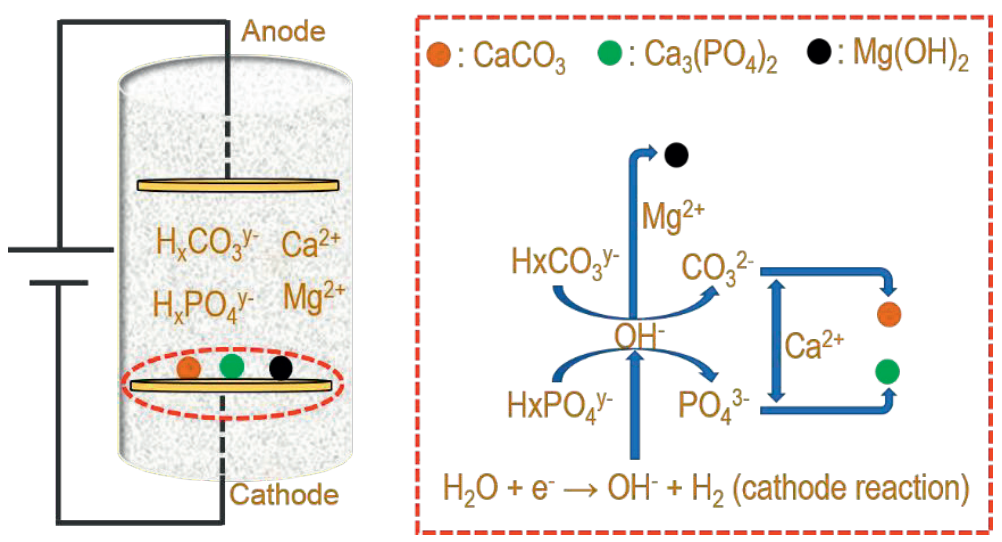

Yang Lei, Ipan Hidayat, Michel Saakes, Renata van der Weijden, and Cees J.N. Buisman

This Chapter has been published as:

Lei, Yang, Ipan Hidayat, Michel Saakes, Renata D. van der Weijden, Cees J.N. Buisman. "Fate of calcium, magnesium and inorganic carbon in electrochemical phosphorus recovery from domestic wastewater." Chemical Engineering Journal 362 (2019): 453-459. 


\begin{abstract}
Calcium (Ca), magnesium $(\mathrm{Mg})$, phosphate and (bi)carbonate are removed simultaneously in electrochemical recovery of phosphorus (P) from sewage. However, the fate of these ions is not completely understood yet. In this paper, through wastewater acidification and current density altering, we clarified the precipitation process and electrochemical interaction of phosphate and coexisting ions. The removal of $\mathrm{P}$ is attributed to amorphous calcium phosphate (ACP) formation, whereas the removal of bicarbonate is mainly due to calcite $\left(\mathrm{CaCO}_{3}\right)$ formation and acid-base neutralization. While both ACP and calcite results in $\mathrm{Ca}$ removal, Ca predominantly ends up in calcite. For $\mathrm{Mg}$, it is exclusively removed as brucite $\left(\mathrm{Mg}(\mathrm{OH})_{2}\right)$. Regardless of the acidification, $53 \pm 2 \% \mathrm{P}$ and $32 \pm 1 \% \mathrm{Mg}$ were removed in $24 \mathrm{~h}$ at $8.3 \mathrm{~A} / \mathrm{m}^{2}$. By contrast, in response to the acidification, the removal of $\mathrm{Ca}$ dropped from $42 \%$ to $19 \%$. The removal of $\mathrm{Mg}$ depends on the current density, with less than $5 \%$ removed at $1.4 \mathrm{~A} / \mathrm{m}^{2}$ but $70 \%$ at $27.8 \mathrm{~A} / \mathrm{m}^{2}$ in $24 \mathrm{~h}$. Based on the precipitation mechanisms, the formation of calcite and brucite can be reduced by acidification and operating at a relatively low current density, respectively. Accordingly, we achieved the lowest $\mathrm{Ca} / \mathrm{P}$ molar ratio (1.8) and the highest relative abundance of ACP in the precipitates (75\%) at bulk pH 3.8 with a current density of $1.4 \mathrm{~A} / \mathrm{m}^{2}$.
\end{abstract}




\subsection{Introduction}

Phosphorus (P) is a crucial and irreplaceable element for all forms of life [47]. Today, the use of $\mathrm{P}$ fertilizer is essential in securing food production for the growing world population $[1,10]$. Unfortunately, the globally unsustainable use of $\mathrm{P}$ products has not only resulted in the substantial decrease of $\mathrm{P}$ reserves in both quality and quantity but also to an increase of $\mathrm{P}$ content in rivers, lakes and coastal seas [22]. The enrichment of $\mathrm{P}$ in receiving water bodies is recognized as the primary cause of eutrophication $[1,7]$.

To reconcile the shortage of mined $\mathrm{P}$ and the overabundance of $\mathrm{P}$ in waste streams, the $\mathrm{P}$ in wastewaters needs to be captured and reused $[1,7,10]$. $\mathrm{P}$ in domestic wastewater is an important source for $\mathrm{P}$ recycling and reclamation [47, 107, 108]. During past decades, biological [19, 31, 109], physicochemical [107, 110-112] and combined process [109, 113, 114] have been proposed for extracting $P$ from domestic wastewater and other types of waste streams. In this context, calcium phosphate $(\mathrm{CaP})$ based treatment techniques have emerged as promising ways for $\mathrm{P}$ recovery, as $\mathrm{CaP}$ is a preferred form for the fertilizer industry [29, $31,113,114]$.

In recent years, the use of an electrochemical process has gained attention for effective wastewater treatment and resources recovery $[44,61,115,116]$. In a typical electrochemical wastewater treatment process, the reduction of water molecules occurs at the surface of the cathode. This results in an increase of $\mathrm{pH}$ in the vicinity of the cathode [117]. By making use of the local high $\mathrm{pH}$, electrochemical removal of hardness [41, 118] and electrochemical $\mathrm{P}$ recovery as struvite [64] had been proposed. Based on the same principle, electrochemical P recovery as $\mathrm{CaP}$ was proven with synthetic solutions [89]. It was found that electrochemical treatment could induce $\mathrm{CaP}$ precipitation on the cathode surface. In particular, no precipitation of $\mathrm{CaP}$ was seen in the bulk solution [89, 119]. As such, there is no need for an extra separation process to separate precipitates from the bulk solution. The efficiency of electrochemical P recovery from toilet wastewater [110] and domestic wastewater [32] was demonstrated as well. However, the main issue of electrochemical P recovery from real wastewater is that other solids are formed in addition to $\mathrm{CaP}$, due to the complex wastewater matrices. The formation of other solids will lower the amount of $\mathrm{CaP}$ in the precipitates and the value of the recovered products. 
The dominant byproduct was found to be calcium carbonate [32]. An obvious way to increase the $\mathrm{CaP}$ content in products is to reduce the bicarbonate concentration through preacidification of the wastewater. However, the acidification of wastewater may also affect the $\mathrm{CaP}$ precipitation, as the $\mathrm{pH}$ and the buffering capacity of the wastewater change with the acidification. We previously showed that electrochemically induced $\mathrm{CaP}$ precipitation depends on the local $\mathrm{pH}$ and therefore, the system performs well in a wide $\mathrm{pH}$ range [89]. However, it was also found that in the presence of a strong buffer, the system only works in neutral and alkaline conditions [120]. Therefore, the efficiency of electrochemical CaP precipitation in acidified wastewater needs to be investigated.

Another way of influencing product and byproduct formation is to choose a suitable current density. Lei et al. reported that the removal extent of associated ions in the electrochemical wastewater treatment process could be adjusted by the applied current density [32]. Therefore, in this study, we combined acidification with current density optimization, to determine how to increase the relative abundance of $\mathrm{CaP}$ in recovered products and the amount of $\mathrm{P}$ in the product, and in particular, to understand the ions interaction mechanisms in the electrochemical system. While the previous study indicated that $\mathrm{Ca}, \mathrm{Mg}, \mathrm{P}$ and bicarbonate ions were simultaneously removed during electrochemical phosphorus recovery [32], it is not completely clear how these ions interact with each other. For example, theoretically, $\mathrm{Mg}^{2+}$ can precipitate with phosphate, carbonate and hydroxide ions. $\mathrm{Mg}^{2+}$ can even together precipitate with $\mathrm{Ca}^{2+}$ and carbonate, forming dolomite $\left(\mathrm{CaMg}\left(\mathrm{CO}_{3}\right)_{2}\right)$.

The objective of this study is to understand the formation mechanisms of product and byproducts and to present with a solution to reduce the formation of byproducts in electrochemical phosphate recovery from domestic wastewater. Insights in this study could be applied in further optimization of electrochemical P recovery.

\subsection{Materials and methods}

\subsubsection{Materials}

The wastewater was untreated influent collected from the local WWTP (Leeuwarden, The Netherlands). After sampling, the wastewater was sieved with a $250 \mu \mathrm{m}$ sieve to remove suspended solids and stored in $4{ }^{\circ} \mathrm{C}$ fridge to maintain the wastewater composition. The main composition of the wastewater is shown in Table $\mathbf{S 4 . 1}$. The acid $\left(\mathrm{HNO}_{3}\right.$, reagent grade) used 
Fate of $\mathrm{Ca}, \mathrm{Mg}$ and inorganic carbon in electrochemical phosphorus recovery from domestic wastewater

for acidification was purchased from VWR Chemicals (France). The electrodes were provided by Magneto Special Anodes BV (Schiedam, The Netherlands).

\subsubsection{Experimental setup}

The electrochemical reactor was made of a transparent glass cell $(1000 \mathrm{~mL})$. The electrodes were placed horizontally where the cathode was positioned below the anode at a distance of $30 \mathrm{~mm}$. The wastewater in the reactor was mixed with a peristaltic pump $(60 \mathrm{~mL} / \mathrm{min})$. The anode was platinum-coated $\left(20 \mathrm{~g} / \mathrm{m}^{2}\right)$ titanium $(\varnothing 80 \mathrm{~mm}$, thickness $1 \mathrm{~mm})$. The cathode was a square titanium plate $\left(36 \mathrm{~cm}^{2}\right.$, thickness $1 \mathrm{~mm}$, grade A). The anode and cathode were perpendicularly welded with a Pt-coated Ti rod (Ø $30 \mathrm{~mm}$, length $120 \mathrm{~mm}$ ) and pure Ti rod, respectively. The rods were connected to a power supply (ES 015-10, Delta Electronics, The Netherlands) so that electrical current was applied.

\subsubsection{Batch experiments}

We prepared $1000 \mathrm{~mL}$ of the sampled wastewater with a volumetric flask and used nitric acid $(1.0 \mathrm{~mol} / \mathrm{L})$ to acidify the wastewater from its initial $\mathrm{pH}$ value $(7.5)$ to $\mathrm{pH} 6.5, \mathrm{pH} 6.0, \mathrm{pH}$ 5.5, $\mathrm{pH} 5.0, \mathrm{pH} 4.5$ and $\mathrm{pH} 3.8$. After acidification, the wastewater was transferred to the reactor. The electrochemical treatment was then performed under constant current $(30 \mathrm{~mA}$, $\left.8.3 \mathrm{~A} / \mathrm{m}^{2}\right)$ for $24 \mathrm{~h}$ at room temperature $\left(23 \pm 1^{\circ} \mathrm{C}\right)$. Furthermore, we also conducted tests with lower current $\left(5 \mathrm{~mA}, 1.4 \mathrm{~A} / \mathrm{m}^{2}\right)$ and higher current $\left(100 \mathrm{~mA}, 27.8 \mathrm{~A} / \mathrm{m}^{2}\right)$ to identify the effects of current density on ions removal efficiency and product purity. Typically, samples were taken before $(0 \mathrm{~h})$ and after $(24 \mathrm{~h})$ batch experiments. We used a daily-calibrated $\mathrm{pH}$ meter (Metter Toledo, Switzerland) to measure the wastewater $\mathrm{pH}$. Unless specified, all experiments were performed in triplicate, and the data are shown as the mean with standard deviation.

\subsubsection{Precipitates collection}

At the end of batch experiments, the precipitates on the cathode were dried at room temperature for $24 \mathrm{~h}$. After drying, the solids were collected by light scraping as not to destroy the structure of the precipitates. After harvesting, the cathode was cleaned by first soaking into acidic solution $\left(1.0 \mathrm{~mol} / \mathrm{L} \mathrm{HNO}_{3}\right)$ and then rinsing with deionized water. 


\subsubsection{Analytical methods}

We applied inductively coupled plasma atomic emission spectrometry (ICP-AES, Optima $5300 \mathrm{DV}$, PerkinElmer) to quantify the concentration of $\mathrm{Ca}, \mathrm{P}$, and $\mathrm{Mg}$ before and after treatment. The detection limits for $\mathrm{Ca}, \mathrm{P}$ and $\mathrm{Mg}$ are 50, 20 and $1 \mu \mathrm{g} / \mathrm{L}$, respectively. We measured anions (chloride, phosphate and sulfate) and cations (ammonium and sodium ions) by ion chromatography (Compact IC 761, Metrohm), equipped a Metrohm Metrosep A Supp 4/5 Guard pre-column, a Metrohm Metrosep A Supp 5 (150/4.0 $\mathrm{mm})$ column, and a conductivity detector. All samples were filtrated through $0.45 \mu \mathrm{m}$ filter before the analysis. We checked the concentration of inorganic carbon by a TOC analyzer (Shimadzu). We quantified the structure of collected precipitates by X-ray Powder Diffraction (XRD) that equipped with Bruker D8 advanced diffractometer with a copper $\operatorname{K} \alpha$ radiation $(\lambda=0.154 \mathrm{~nm})$ at the range of $10-70^{\circ}$ in 0.02 step sizes with $0.5 \mathrm{~s}$ integration time.

\subsubsection{Calculation}

The fraction of species in response to the acidification was calculated by Visual Minteq (available at https://vminteq.lwr.kth.se/). The number of moles (M) of theoretically produced $\mathrm{H}^{+}$and $\mathrm{OH}^{-}$by water electrolysis was calculated based on Faraday's law, using eq 4.1 [89]:

$$
\mathrm{M}=\frac{\mathrm{It}}{\mathrm{zF}}
$$

Where I is the electrical current (A); $t$ is the electrolysis time (s); $z$ is the number of transferred electrons in the reaction for the formation of per $\mathrm{mol} \mathrm{H}^{+}$or $\mathrm{OH}^{-}(\mathrm{z}=1)$, F is Faraday constant $96,485(\mathrm{C} / \mathrm{mol})$.

In this study, we found that amorphous calcium phosphate $(\mathrm{ACP})$, calcite $\left(\mathrm{CaCO}_{3}\right)$ and brucite $\left(\mathrm{Mg}(\mathrm{OH})_{2}\right)$ were formed as precipitates. The molecular weight of calcite and brucite are 100 and $58.3 \mathrm{~g} / \mathrm{mol}$, respectively. For ACP, it is widely accepted that ACP has a $\mathrm{Ca} / \mathrm{P}$ molar ratio 1.5 and $\mathrm{Ca}_{3}\left(\mathrm{PO}_{4}\right)_{2} \cdot \mathrm{nH}_{2} \mathrm{O}$ is the typically applied formula [35]. For easy calculation, we defined the formula as $\mathrm{Ca}_{3}\left(\mathrm{PO}_{4}\right)_{2} ; 310 \mathrm{~g} / \mathrm{mol}$. The amount of precipitated $\mathrm{ACP}(\mathrm{g})$ can be calculated by eq $\mathbf{4 . 2}$ :

$$
\mathrm{m}(\mathrm{ACP})=310 \frac{\mathrm{g}}{\mathrm{mol}} * \frac{1}{2} \mathrm{M}(\mathrm{P})
$$

Where $\mathrm{M}(\mathrm{P})$ is the removed amount of $\mathrm{P}$ in mol. Similarly, the mass of calcite and brucite can be calculated as follows (eq 4.3 and eq 4.4): 


$$
\begin{aligned}
& \mathrm{m}(\text { Calcite })=100 \frac{\mathrm{g}}{\mathrm{mol}} *(\mathrm{M}(\mathrm{Ca})-1.5 \mathrm{M}(\mathrm{P})) \\
& \mathrm{m}(\text { Brucite })=58.3 \frac{\mathrm{g}}{\mathrm{mol}} * \mathrm{M}(\mathrm{Mg})
\end{aligned}
$$

The relative abundance (RA) of ACP can be calculated by eq 4.5:

$$
\mathrm{RA}(\%)=\frac{\mathrm{m}(\mathrm{ACP})}{\mathrm{m}(\mathrm{ACP})+\mathrm{m}(\text { Calcite })+\mathrm{m}(\text { Brucite })} * 100
$$

It should be noted here that the co-precipitation of organic contents was not taken into consideration.

\subsection{Results and discussion}

\subsubsection{Effects of acidification.}

The acidification significantly affects the distribution of species in the wastewater, as shown in Figure S4.1. Without acidification, $\mathrm{P}$ mainly is present as $\mathrm{HPO}_{4}{ }^{2-}(55 \%), \mathrm{H}_{2} \mathrm{PO}_{4}{ }^{-}(18 \%)$, aqueous $\mathrm{CaHPO}_{4}(14 \%)$ and $\mathrm{MgHPO}_{4}(8 \%)$. The fraction of $\mathrm{H}_{2} \mathrm{PO}_{4}^{-}$increases to $84 \%$ whereas the fraction of $\mathrm{HPO}_{4}{ }^{2-}$ drops to $8 \%$ at $\mathrm{pH} 6.0$. At $\mathrm{pH} 3.8,94 \%$ of the $\mathrm{P}$ is in the form of $\mathrm{H}_{2} \mathrm{PO}_{4}^{-}$. While the acidification also affects the fractions of both $\mathrm{Ca}$ and $\mathrm{Mg}$, the influence is relatively small. Both $\mathrm{Ca}$ and $\mathrm{Mg}$ are dominantly present ( $>87 \%)$ as free ions, regardless of the acidification. Regarding inorganic carbon, the calculation of species fraction indicates that the dominant species changes from bicarbonate $(92 \%$ at $\mathrm{pH} 7.5)$ to aqueous $\mathrm{H}_{2} \mathrm{CO}_{3}(66 \%$ at $\mathrm{pH}$ 6.0). At $\mathrm{pH}<5.0$, more than $95 \%$ of the inorganic carbon is in the form of $\mathrm{H}_{2} \mathrm{CO}_{3}$. More importantly, the acidification significantly reduces the available inorganic carbon in the wastewater (Figure 4.1A). 

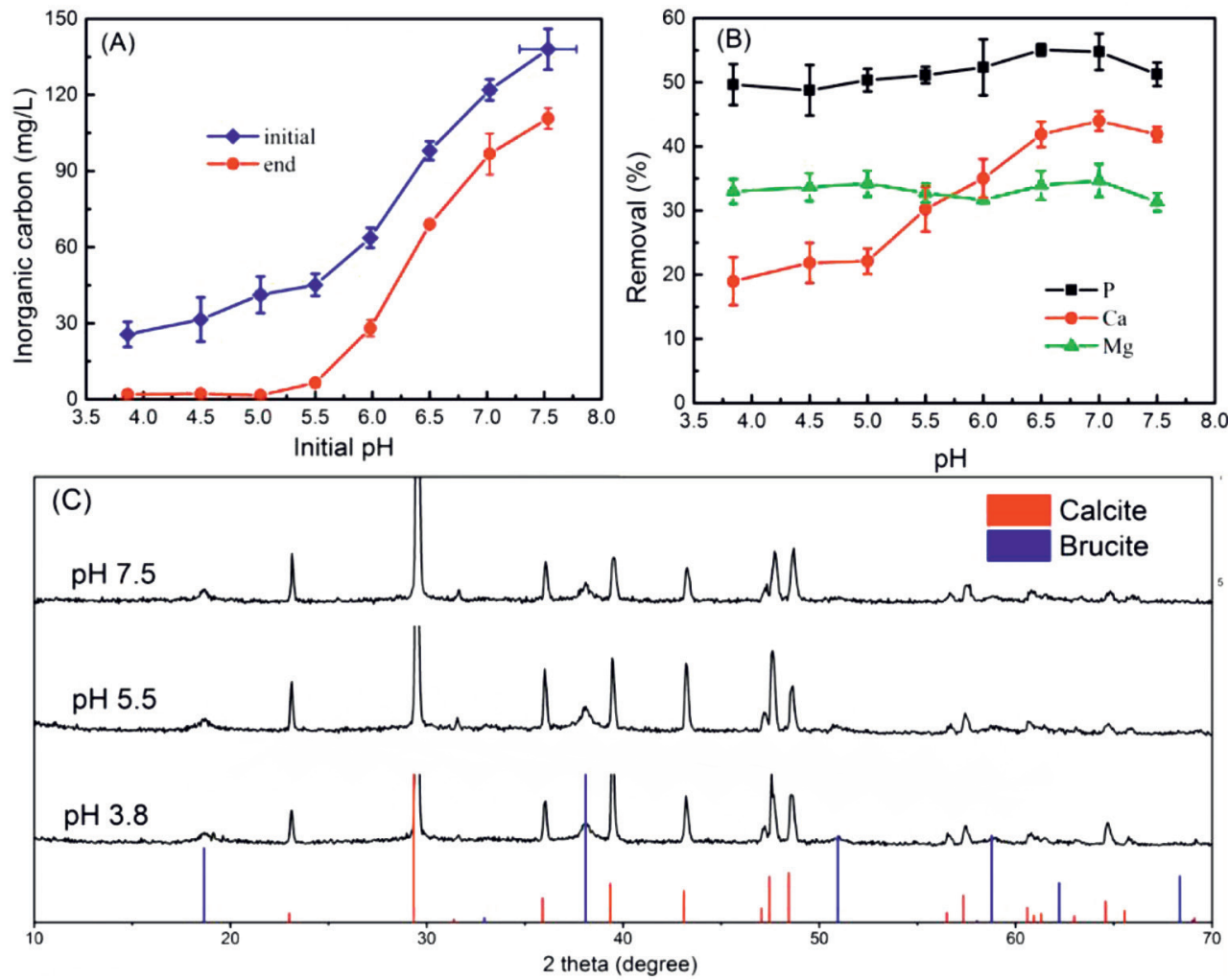

Figure 4.1. (A) Change of wastewater $\mathrm{pH}$ and inorganic carbon concentration before and after electrochemical treatment, (B) Variation of ions removal percentage in response to the acidification, (C) XRD spectrum of solids harvested at $\mathrm{pH}$ 3.8, 5.5 and 7.5. Conditions: 30 $\mathrm{mA}\left(8.3 \mathrm{~A} / \mathrm{m}^{2}\right)$, electrolysis time $=24 \mathrm{~h}$; anode: Pt coated Ti; cathode: Ti $\left(36 \mathrm{~cm}^{2}\right)$; electrode distance $=3 \mathrm{~cm}$.

Despite these changes, we did not observe a noticeable increase in $\mathrm{P}$ removal (Figure 4.1B). In the $\mathrm{pH}$ range of 7.5 to $3.8, \mathrm{P}$ removal efficiency varied from a maximum of $55 \%$ to a minimum of $49 \%$. Overall, the removal efficiency of $\mathrm{P}$ was not much affected by the acidification. This is consistent with our previous finding that electrochemical $\mathrm{P}$ recovery process works comparable in acidic, neutral and basic solutions [89].

The Ca removal efficiency decreased significantly with the acidification. For example, at $\mathrm{pH}$ $7.5,42 \%$ of Ca was removed from the wastewater in $24 \mathrm{~h}$. However, this value dropped drastically to $19 \%$ at $\mathrm{pH} 3.8$. As the removal of $\mathrm{P}$ was relatively stable around $50 \%$, the decrease in Ca removal could only be explained by the reduced $\mathrm{CaCO}_{3}$ formation because of 
the acidification. In contrast to $\mathrm{Ca}$, the removal of $\mathrm{Mg}$ was not affected by the acidification. Regardless of $\mathrm{pH}$ (7.5 to 3.8), the Mg removal efficiency was around $32 \pm 1 \%$. Such trend indicates the removal of $\mathrm{Mg}$ is not connected with (bi)carbonate, which means there is probably no $\mathrm{MgCO}_{3}$ and dolomite formation in our system. Otherwise, the removal of $\mathrm{Mg}$ would decrease as it does for $\mathrm{Ca}$. Therefore, the most obvious way for $\mathrm{Mg}$ removal is $\mathrm{Mg}(\mathrm{OH})_{2}$ formation and precipitation. Indeed, the high local $\mathrm{pH}$ and the electromigration of $\mathrm{Mg}^{2+}$ (positively charged) to the cathode (negatively charged) favors the formation of brucite $\left(\mathrm{Mg}(\mathrm{OH})_{2}\right)$.

Analysis of the solid precipitates with XRD confirmed two crystalline phases: calcite $\left(\mathrm{CaCO}_{3}\right)$ and brucite $\left(\mathrm{Mg}(\mathrm{OH})_{2}\right)$ (Figure 4.1C). This indeed supports our assumption that calcite and brucite are the primary byproducts being formed in the electrochemical P recovery process. However, we did not find any patterns for crystalline CaP because the removed $\mathrm{P}$ and $\mathrm{Ca}$ form ACP instead of crystalline $\mathrm{CaP}$ on the cathode surface. Also, when comparing the XRD spectrum of solids collected after acidification (Figure 4.1C), we can conclude that the acidification does not affect the crystalline phases in the precipitates. Regardless of the bulk $\mathrm{pH}$, the spectrum matches well with patterns of calcite and brucite. In light of these results, a detailed ions interaction mechanism was proposed in Figure 4.2.

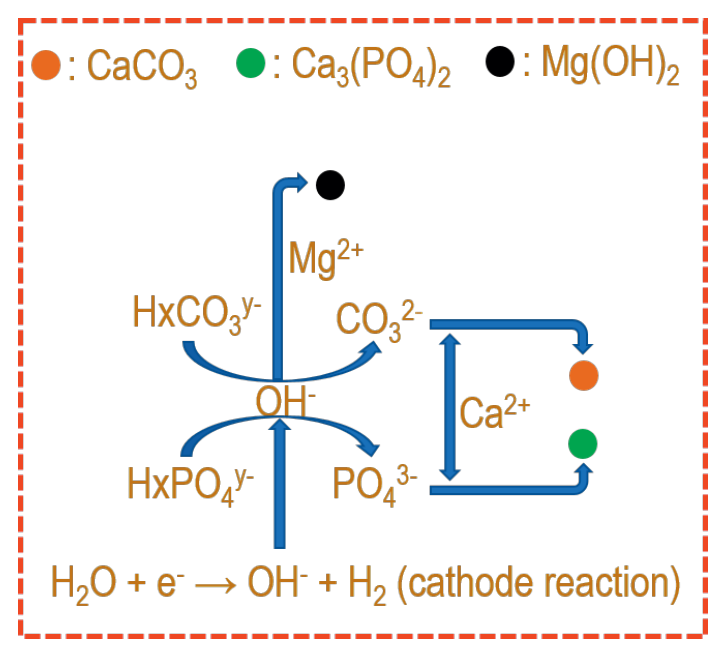

Figure 4.2. Proposed ions interaction mechanism in electrochemical phosphorus recovery from domestic wastewater. 
Initially, the production of hydroxide ions at the cathode drives the deprotonation of phosphate and bicarbonate. In the meantime, due to mass diffusion and electromigration, $\mathrm{Ca}^{2+}$ and $\mathrm{Mg}^{2+}$ were enriched close to the cathode. Due to thermodynamic and kinetic reasons [32], Ca precipitates with phosphate as $\mathrm{ACP}$ (eq 4.6). As the $\mathrm{Ca} / \mathrm{P}$ molar ratio in the wastewater (8.5) is way higher than the required ratio (1.5), the extra $\mathrm{Ca}$ forms calcite with carbonate in the local region (eq 4.7). Mg exclusively precipitates with hydroxide ions as brucite (eq 4.8).

$$
\begin{aligned}
& 3 \mathrm{Ca}^{2+}+2 \mathrm{PO}_{4}{ }^{3-} \rightarrow \mathrm{Ca}_{3}\left(\mathrm{PO}_{4}\right)_{2} \\
& \mathrm{Ca}^{2+}+\mathrm{CO}_{3}{ }^{2-} \rightarrow \mathrm{CaCO}_{3} \\
& \mathrm{Mg}^{2+}+2 \mathrm{OH}^{-} \rightarrow \mathrm{Mg}(\mathrm{OH})_{2}
\end{aligned}
$$

In terms of $\mathrm{P}$ recovery, the formation of calcite and brucite will reduce the $\mathrm{P}$ content of recovered product from the point of the $\mathrm{RA}$ of $\mathrm{CaP}$ in the collected solids. We evaluated the product's $\mathrm{P}$ content by calculating the $\mathrm{Ca} / \mathrm{P}$ molar ratio and the RA of ACP in the solids. As can be seen from Figure S4.2, the removed $\mathrm{Ca} / \mathrm{P}$ molar ratio decreased from 6.7 to 3.2 when the wastewater was acidified from $\mathrm{pH} 7.5$ to 3.8. The typical atomic $\mathrm{Ca} / \mathrm{P}$ ratio for pure $\mathrm{CaP}$ species lies in the range of 1.0 to 1.67 [35]. Clearly, even at $\mathrm{pH} \mathrm{3.8,} \mathrm{the} \mathrm{Ca} / \mathrm{P}$ ratio (3.2) is still much higher than the theoretical ratio (1.5), which indicates $\mathrm{CaCO}_{3}$ is still present in the precipitates. This is supported by the XRD spectrum, where consistent calcite patterns were seen for $\mathrm{pH} 3.8$ and 7.5 (Figure 4.1C).

The calculation of RA (Figure 4.3) suggests that the RA of calcite in the precipitates decreased from $66 \%$ ( $\mathrm{pH} 7.5$ ) to $38 \%$ ( $\mathrm{pH} 3.8$ ). This is due to the decreased $\mathrm{CaCO}_{3}$ formation with acidification. Accordingly, the RA of brucite was doubled from $14 \%$ at $\mathrm{pH} 7.5$ to $28 \%$ at $\mathrm{pH} 3.8$, although the removal efficiency of $\mathrm{Mg}$ was very stable (Figure 4.1A). Similarly, the RA of ACP was enhanced from $20 \%$ at $\mathrm{pH} 7.5$ to $34 \%$ at $\mathrm{pH} 3.8$. 


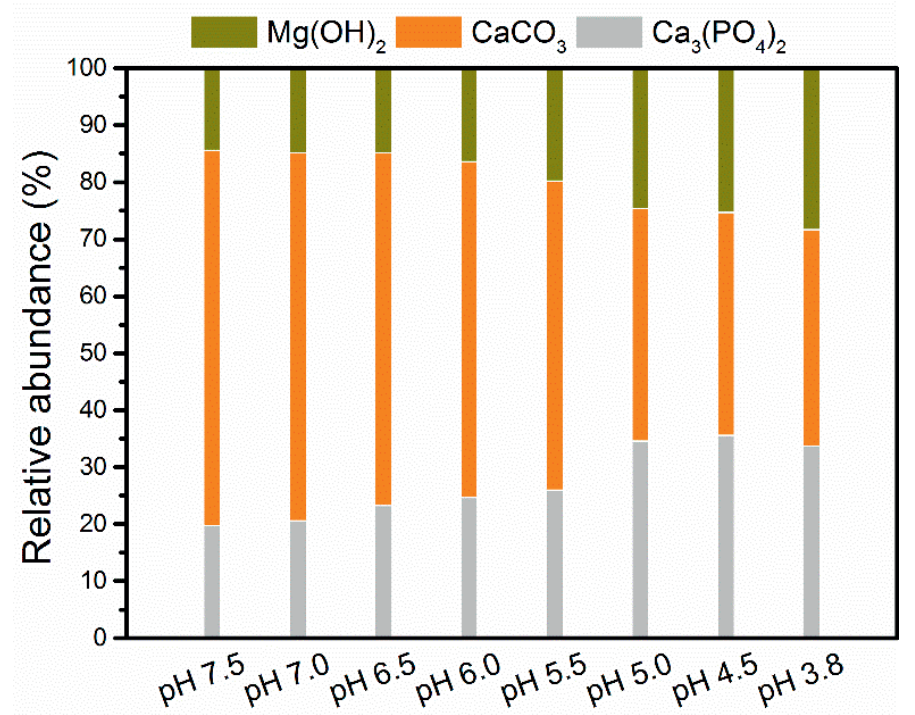

Figure 4.3. Relative abundance of amorphous calcium phosphate (ACP), calcite and brucite in the collected precipitates in response to the acidification. Conditions: $30 \mathrm{~mA}\left(8.3 \mathrm{~A} / \mathrm{m}^{2}\right)$, electrolysis time $=24 \mathrm{~h}$; anode: Pt coated Ti; cathode: Ti $\left(36 \mathrm{~cm}^{2}\right)$; electrode distance $=3 \mathrm{~cm}$.

\subsubsection{Final bulk solution $\mathrm{pH}$}

Figure S4.3 shows the change of $\mathrm{pH}$ of wastewater after electrochemical treatment as a function of acidification. When the initial $\mathrm{pH}$ of the wastewater was acidified below 6.0, the wastewater $\mathrm{pH}$ decreased after treatment. For example, at $\mathrm{pH} 5.0$, the bulk $\mathrm{pH}$ decreased to 3.2 after $24 \mathrm{~h}$ treatment. However, when the initial $\mathrm{pH}$ of the wastewater was higher than 6.0, the bulk $\mathrm{pH}$ increased. For instance, at $\mathrm{pH} 6.5$, the bulk $\mathrm{pH}$ increased to 7.5 after treatment. The difference is likely caused by the decrease of inorganic carbon concentration (Figure 4.1A) and the change of inorganic carbon species (Figure S4.1) resulting from the acidification.

The increase of $\mathrm{pH}$ means the accumulation of $\mathrm{OH}^{-}$in the bulk solution, whereas the decrease of $\mathrm{pH}$ means the accumulation of $\mathrm{H}^{+}$. The change of $\mathrm{pH}$ is a result of a series of reactions, which produce or consume $\mathrm{H}^{+}$and $\mathrm{OH}^{-}$ions. In the electrochemical system, $\mathrm{H}^{+}$and $\mathrm{OH}^{-}$are produced equally at the anode (eq 4.9) and the cathode (eq 4.10), respectively. The recombination of $\mathrm{H}^{+}$with $\mathrm{OH}^{-}$(eq 4.11) will consume an equal amount of each ion and therefore this reaction will not result in the change of $\mathrm{pH}$. However, in our system, there are other reactions will affect the concentration of $\mathrm{H}^{+}$and $\mathrm{OH}^{-}$. While for $\mathrm{H}^{+}$, the only 
consumption pathway is its reaction with bicarbonate and phosphate, $\mathrm{OH}^{-}$can be consumed by $\mathrm{Mg}^{2+}$ (forming $\mathrm{Mg}(\mathrm{OH})_{2}$ ) and all the buffers in the wastewater including, e.g. $\mathrm{NH}_{4}^{+}$, $\mathrm{H}_{2} \mathrm{PO}_{4}^{-} / \mathrm{HPO}_{4}{ }^{2-}$ and $\mathrm{HCO}_{3}{ }^{-} / \mathrm{H}_{2} \mathrm{CO}_{3}$.

$$
\begin{aligned}
& \text { Anode: } 2 \mathrm{H}_{2} \mathrm{O} \rightarrow 4 \mathrm{H}^{+}+\mathrm{O}_{2} \uparrow+4 \mathrm{e}^{-} \\
& \text {Cathode: } 4 \mathrm{H}_{2} \mathrm{O}+4 \mathrm{e}^{-} \rightarrow 4 \mathrm{OH}^{-}+2 \mathrm{H}_{2} \uparrow \\
& \mathrm{H}^{+}+\mathrm{OH}^{-} \rightarrow \mathrm{H}_{2} \mathrm{O}
\end{aligned}
$$

However, because the concentration of inorganic carbon $(11.5 \mathrm{mM})$ in the raw wastewater is much higher than the other species, the depletion of uncombined $\mathrm{OH}^{-}$and $\mathrm{H}^{+}$should be mostly done by inorganic carbon via eq 4.12 and eq 4.13 .

$$
\begin{aligned}
& \mathrm{HCO}_{3}{ }^{-}+\mathrm{OH}^{-} \rightarrow \mathrm{H}_{2} \mathrm{O}+\mathrm{CO}_{3}{ }^{2-} \\
& \mathrm{HCO}_{3}{ }^{-}+\mathrm{H}^{+} \rightarrow \mathrm{H}_{2} \mathrm{CO}_{3}
\end{aligned}
$$

As such, both the concentration of $\mathrm{H}^{+}$and $\mathrm{OH}^{-}$are mostly influenced by bicarbonate. To buffer the produced $\mathrm{H}^{+}$and $\mathrm{OH}^{-}, \mathrm{HCO}_{3}{ }^{-}$in the bulk solution needs to be close to the anode and cathode, respectively. In this content, the diffusion of $\mathrm{HCO}_{3}{ }^{-}$to the electrodes plays an important role. In principle, electromigration of $\mathrm{HCO}_{3}{ }^{-}$(anion) to the anode (positively charged) is more favorable than to the cathode (negatively charged). Also, the reaction rate constant of eq $4.12\left(6 \times 10^{9} \mathrm{~kg} \mathrm{~mol}^{-1} \mathrm{~s}^{-1}\right)$ is lower than eq $4.13\left(4.7 \times 10^{10} \mathrm{~kg} \mathrm{~mol}^{-1} \mathrm{~s}^{-1}\right)$ [121]. As a result, $\mathrm{H}^{+}$is depleted faster than $\mathrm{OH}^{-}$by $\mathrm{HCO}_{3}{ }^{-}$.

Theoretically, $2.7 \times 10^{-2} \mathrm{~mol} \mathrm{H} \mathrm{H}^{+}$and the same amount of $\mathrm{OH}^{-}$are produced in $24 \mathrm{~h}$ electrolysis at $30 \mathrm{~mA}$. Though this is higher than the inorganic carbon $\left(1.15 \times 10^{-2} \mathrm{~mol}\right)$ in the wastewater, the recombination of $\mathrm{H}^{+}$with $\mathrm{OH}^{-}$(eq 4.11) which is one of the fastest reactions known in aqueous solution (rate constant $1.4 \times 10^{11} \mathrm{~kg} \mathrm{~mol}^{-1} \mathrm{~s}^{-1}$ ) [121], should consume a large proportion of the produced $\mathrm{H}^{+}$and $\mathrm{OH}^{-}$. Therefore, in practice, the required inorganic carbon to buffer the uncombined $\mathrm{H}^{+}$and $\mathrm{OH}^{-}$is much lower than the theoretical produced $\mathrm{H}^{+}$and $\mathrm{OH}^{-}$from water electrolysis. Figure $\mathbf{S 4 . 3}$ shows the turning point of $\mathrm{pH}$ is $\mathrm{pH} 6.0$ where the initial concentration of inorganic carbon is $5.3 \pm 0.3 \mathrm{mM}$. In light of the turning point, we concluded that inorganic carbon of $5.3 \pm 0.3 \mathrm{mM}$ is able to buffer the uncombined $\mathrm{H}^{+}$and $\mathrm{OH}^{-}$at $30 \mathrm{~mA}$. However, at a $\mathrm{pH}$ lower than 6.0, the concentration of inorganic carbon after acidification is not enough to buffer uncombined $\mathrm{H}^{+}$and $\mathrm{OH}^{-}$. Moreover, most of the inorganic carbon $(>66 \%)$ is present as aqueous $\mathrm{H}_{2} \mathrm{CO}_{3}$ at $\mathrm{pH}<6.0$ 
(See Figure S4.1). Unlike $\mathrm{HCO}_{3}{ }^{-}, \mathrm{H}_{2} \mathrm{CO}_{3}$ is only able to deplete $\mathrm{OH}^{-}$(eq 4.6). Furthermore, $\mathrm{OH}^{-}$will also be consumed by $\mathrm{Mg}^{2+}$ and $\mathrm{NH}_{4}^{+}$. As a result, $\mathrm{H}^{+}$will be accumulated in the bulk solution, resulting in a decrease of bulk solution $\mathrm{pH}$.

\subsubsection{Combined effects of acidification and current density}

As discussed, with acidification, the highest ACP abundance in the precipitates is $36 \%$ (Figure 4.3), which is still low. The current density plays a vital role in the performance of our electrochemical system. We, therefore, performed the electrochemical P recovery with three different current densities, including low $\left(1.4 \mathrm{~A} / \mathrm{m}^{2}\right)$, medium $\left(8.3 \mathrm{~A} / \mathrm{m}^{2}\right)$ and high $(27.8$ $\mathrm{A} / \mathrm{m}^{2}$ ) current densities, to see how the ions behaved when the current density was changed.
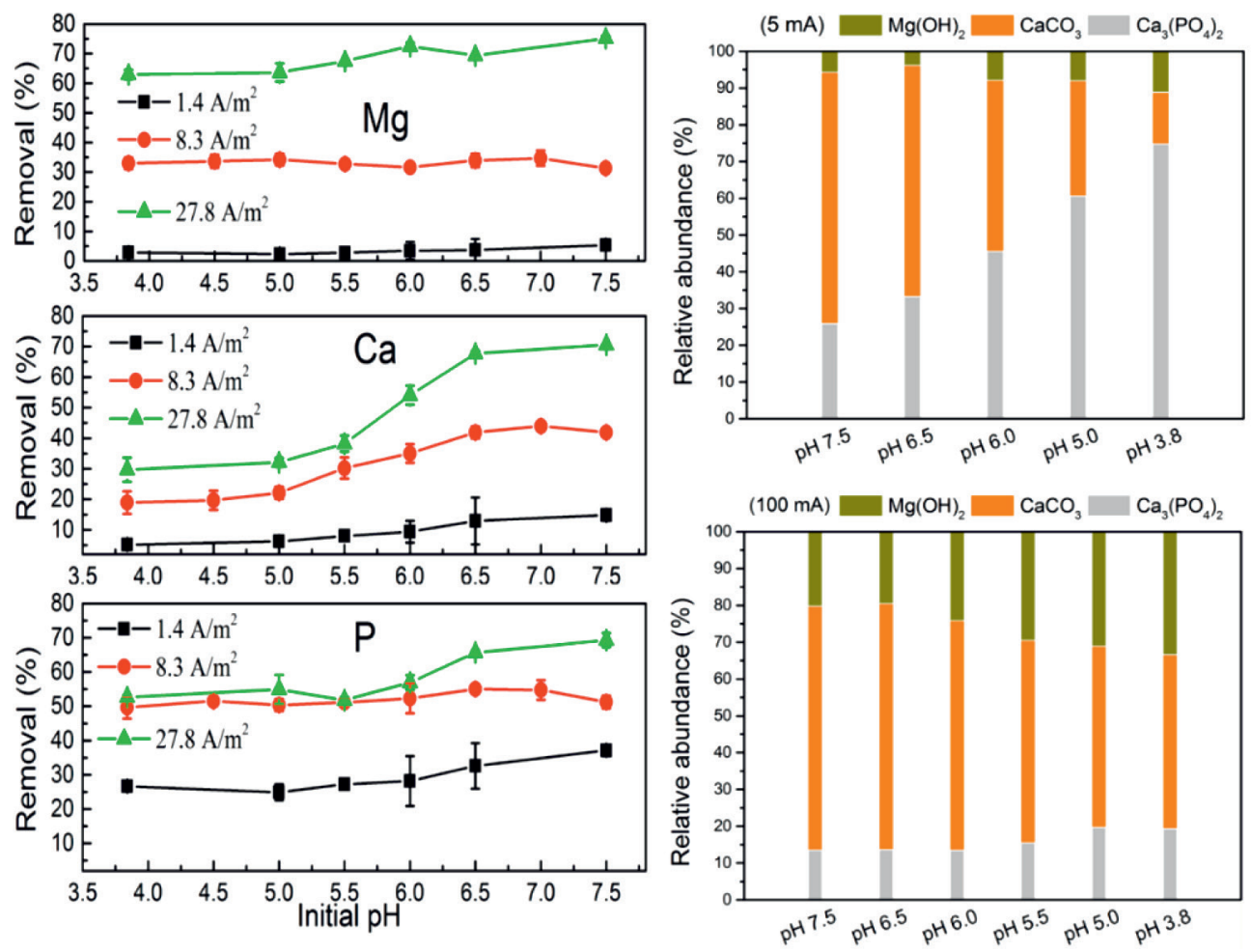

Figure 4.4. The line graphs (left side) show the variation of $\mathrm{Mg}, \mathrm{Ca}$ and $\mathrm{P}$ removal percentages in response to the acidification at different current densities. The column graphs (right side) show the relative abundance of ACP, calcite, and brucite in the solids under electrochemical treatment at $5 \mathrm{~mA}\left(1.4 \mathrm{~A} / \mathrm{m}^{2}\right)$ and $100 \mathrm{~mA}\left(27.8 \mathrm{~A} / \mathrm{m}^{2}\right)$. Conditions: electrolysis time $=24 \mathrm{~h}$; anode: Pt coated Ti; cathode: $\mathrm{Ti}\left(36 \mathrm{~cm}^{2}\right)$; electrode distance $=3 \mathrm{~cm}$. 
Figure 4.4 clearly shows that the removal percentage of $\mathrm{P}$ at $1.4 \mathrm{~A} / \mathrm{m}^{2}$ is considerably lower than at $8.3 \mathrm{~A} / \mathrm{m}^{2}$ and indeed at $27.8 \mathrm{~A} / \mathrm{m}^{2}$. At $1.4 \mathrm{~A} / \mathrm{m}^{2}$, the P removal efficiency lies in the range of $27 \%$ to $37 \%$ in $24 \mathrm{~h}$. At $8.3 \mathrm{~A} / \mathrm{m}^{2}$, the average removal efficiency increases to $53 \pm$ $2 \%$. However, the further increase of current density to $27.8 \mathrm{~A} / \mathrm{m}^{2}$ does not give a noticeable increase of $\mathrm{P}$ removal, especially at $\mathrm{pH}<6.0$, which indicates that the current density is not the limiting factor here. The most likely limiting factor is the diffusion of phosphate toward the cathode, either because a layer has built up at the cathode or because the $\mathrm{P}$ concentration is too low in solution after being removed by some extent.

The removal of Ca shows a similar trend for all current densities namely that the removal efficiencies decrease with the acidification. This is explained previously as the concentration of inorganic carbon decreases with the acidification (Figure 4.1A). However, with the same degree of acidification, the removal of $\mathrm{Ca}$ increases with the increase of current density. This is mostly due to the increased $\mathrm{CaCO}_{3}$ formation instead of ACP, which can be justified by the removal of $\mathrm{Ca}$ and $\mathrm{P}$ under $\mathrm{pH}<6.0$ with different current density. While there was no noticeable increase for P removal when the current density was increased from 8.3 to 27.8 $\mathrm{A} / \mathrm{m}^{2}$ at $\mathrm{pH}<6.0$, the Ca removal efficiency still increased by 11 to $20 \%$.

As explained in the case of $8.3 \mathrm{~A} / \mathrm{m}^{2}$, the removal of $\mathrm{Mg}$ is not much affected by the acidification. Consistently, this is also seen at the low and high current densities. In contrast to the acidification, the change of current density shows a significant effect on the removal of $\mathrm{Mg}$, as shown in Figure 4.4. At $1.4 \mathrm{~A} / \mathrm{m}^{2}$, less than $5 \%$ of $\mathrm{Mg}$ was removed. The removal efficiency jumped to $32 \%$ at $8.3 \mathrm{~A} / \mathrm{m}^{2}$ and further to $70 \%$ at $27.8 \mathrm{~A} / \mathrm{m}^{2}$. The similar removal trend of $\mathrm{Mg}$ as a function of current density was also reported by Zeppenfeld [118]. The increased removal of $\mathrm{Mg}$ is due to the enhanced $\mathrm{Mg}(\mathrm{OH})_{2}$ formation and precipitation, which can be explained by the increased availability of both $\mathrm{OH}^{-}$and $\mathrm{Mg}^{2+}$ in the vicinity of the cathode. Firstly, the production of $\mathrm{OH}^{-}$depends on the current density and therefore, with higher current density, the local concentration of $\mathrm{OH}^{-}$will be higher [41]. Secondly, as a positive ion, the transfer of $\mathrm{Mg}^{2+}$ to the cathode should be enhanced with increasing current density.

The variation of current density affects not only the removal of Ca and $\mathrm{P}$, but also $\mathrm{Mg}$. Hence, it is possible to improve the purity of the $\mathrm{CaP}$ product by combining wastewater acidification and adjusting the current density. As shown in Figure S4.2, through the combined influence 
of acidification and a decrease in current density, the $\mathrm{Ca} / \mathrm{P}$ molar ratio decreases from 9.1 to 1.8. Consistently, the RA of ACP increases to $75 \%$ at $\mathrm{pH} 3.8$ with a current density of 1.4 $\mathrm{A} / \mathrm{m}^{2}$ (Figure 4.4). From the perspective of purity and energy consumption, high current density is not recommended. Due to the complex wastewater compositions, with increased current density, a higher percentage of $\mathrm{CaCO}_{3}$ and $\mathrm{Mg}(\mathrm{OH})_{2}$ is produced in the precipitates. Indeed, we see from Figure 4.4 that at $100 \mathrm{~mA}\left(27.8 \mathrm{~A} / \mathrm{m}^{2}\right)$, the increase of ACP abundance is low in response to the acidification. The lowest $\mathrm{Ca} / \mathrm{P}$ ratio is 5.3 and the highest $\mathrm{RA}$ of ACP is just $19 \%$ at $27.8 \mathrm{~A} / \mathrm{m}^{2}$. However, at $1.4 \mathrm{~A} / \mathrm{m}^{2}$, the increase of ACP abundance is apparent. Based on these results, we can conclude that the best strategy to form the targeted product $(\mathrm{ACP})$ is with relatively low current density $\left(1.4 \mathrm{~A} / \mathrm{m}^{2}\right)$ and at low $\mathrm{pH}(3.8)$.

\subsubsection{Effects of current density on final solution pH}

As discussed, the final $\mathrm{pH}$ of the bulk solution is determined by the concentration of inorganic carbon in the bulk solution. As shown in Figure 4.5, the applied current density also has a strong effect on the $\mathrm{pH}$ of treated wastewater.

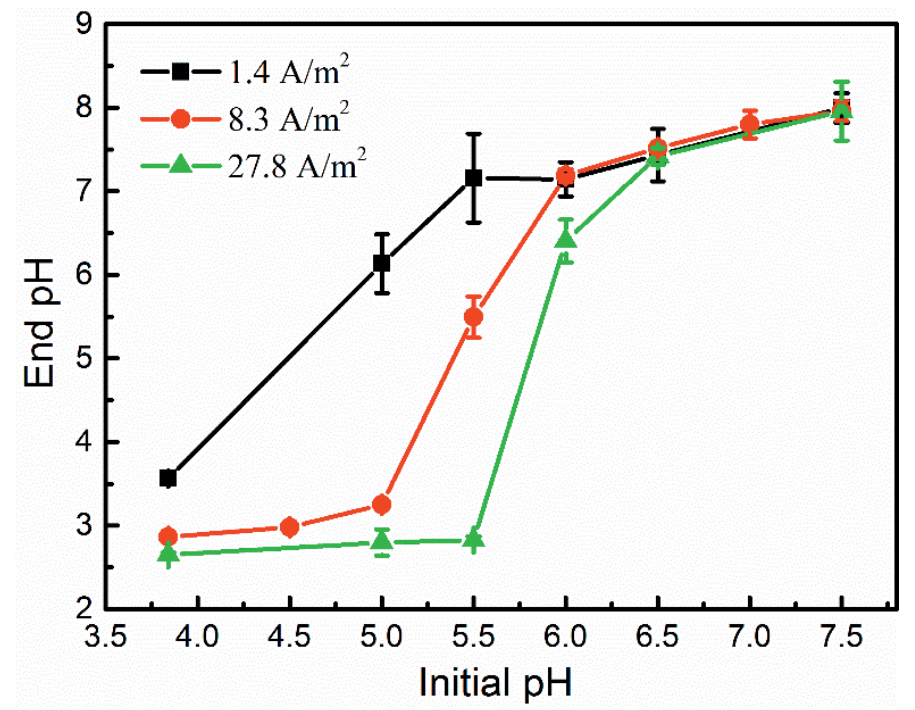

Figure 4.5. Change of wastewater $\mathrm{pH}$ in response to different current densities. Overall, high current density results in a low final $\mathrm{pH}$ after treatment. Conditions: electrolysis time $=24 \mathrm{~h}$; anode: Pt coated Ti; cathode: $\operatorname{Ti}\left(36 \mathrm{~cm}^{2}\right)$; electrode distance $=3 \mathrm{~cm}$.

Overall, the final $\mathrm{pH}$ of the wastewater treated at higher current density is lower than treated at lower current density. For example, at $\mathrm{pH} 5.5$, the end $\mathrm{pH}$ increased to 7.2 at $1.4 \mathrm{~A} / \mathrm{m}^{2}$, but 
for $27.8 \mathrm{~A} / \mathrm{m}^{2}$, the final $\mathrm{pH}$ dropped to 2.8 . The big difference is probably caused by the variation of $\mathrm{H}^{+}$and $\mathrm{OH}^{-}$production. At low current density, the production of $\mathrm{H}^{+}$in $24 \mathrm{~h}$ is relatively low $\left(4.5 \times 10^{-3} \mathrm{~mol}\right)$, the theoretical required inorganic carbon to buffer the uncombined $\mathrm{H}^{+}$should be lower as well, in comparison to a higher current density. The concentration of inorganic carbon in the wastewater, even after acidification, may be high enough to buffer the uncombined $\mathrm{H}^{+}$. As a result, $\mathrm{OH}^{-}$accumulates in the bulk solution. Indeed, at $1.4 \mathrm{~A} / \mathrm{m}^{2}$, the final $\mathrm{pH}$ after electrochemical treatment is higher than its initial $\mathrm{pH}$ (Figure 4.5), except at $\mathrm{pH} 3.8$ where the final $\mathrm{pH}$ is 3.6. By contrast, at high current density, the formation of $\mathrm{H}^{+}$is high $\left(9.0 \times 10^{-2} \mathrm{~mol}\right)$. Therefore, more inorganic carbon is needed to buffer the $\mathrm{H}^{+}$that is present. However, with acidification, the availability of inorganic carbon was decreased. This explains the decrease of $\mathrm{pH}$ after treatment at $27.8 \mathrm{~A} / \mathrm{m}^{2}$ at $\mathrm{pH}<6.0$ (Figure 4.5).

\subsubsection{Importance of continuous current supply}

Consistently, the results here suggest that the electrochemical system works comparable well in acidic conditions, which is in line with our previous finding that electrochemically induced phosphate precipitation depends on the local high $\mathrm{pH}$. However, at low $\mathrm{pH}$ (i.e., $\mathrm{pH}$ 3.8), the dissolution of solids may coincide with the precipitation process. The film of precipitates on the surface of the cathode, on the one hand, is in contact with the cathode surface (high $\mathrm{pH}$ ), while on the other side, it faces the bulk solution. This allows the dissolution of precipitates that face the bulk solution with a low $\mathrm{pH}$. To check this, we performed simple control tests, which first let the electrochemical system run at $8.3 \mathrm{~A} / \mathrm{m}^{2}$ for $24 \mathrm{~h}$ and subsequently at 0 $\mathrm{A} / \mathrm{m}^{2}$ for $48 \mathrm{~h}$. The result is summarized in Figure 4.6. 

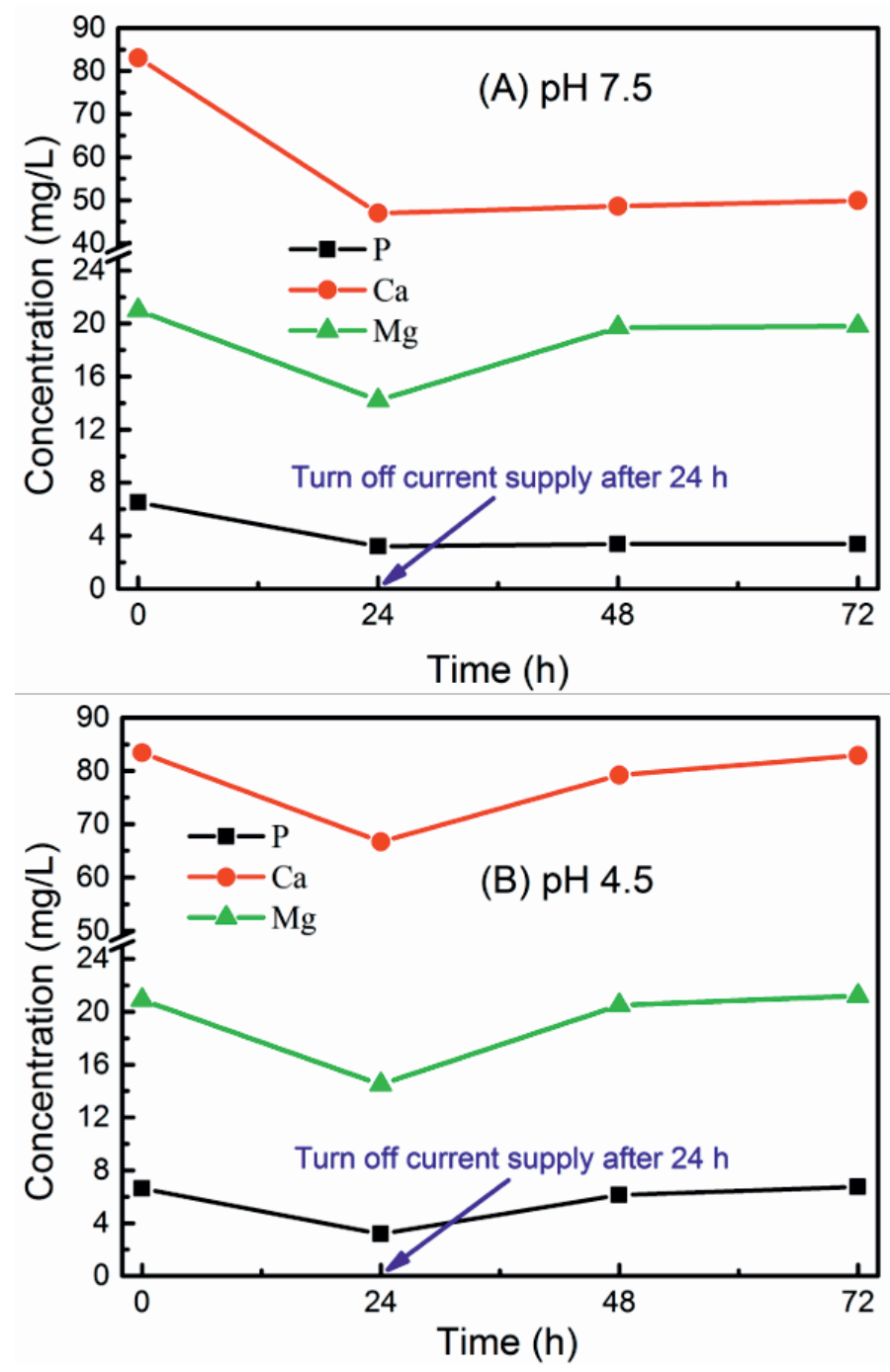

Figure 4.6. Behavior of precipitates after turning off the current supply at (A) pH 7.5 and (B) $\mathrm{pH}$ 4.5. The change of ions concentration suggests that precipitates dissolve in low $\mathrm{pH}$. Conditions: initial $24 \mathrm{~h}$ in closed circuit $\left(8.3 \mathrm{~A} / \mathrm{m}^{2}\right)$, followed by $48 \mathrm{~h}$ in open circuit $\left(0 \mathrm{~A} / \mathrm{m}^{2}\right)$. Initially, with an applied current density of $8.3 \mathrm{~A} / \mathrm{m}^{2}$ at both $\mathrm{pH} 4.5$ and 7.5 , the concentration of $\mathrm{P}, \mathrm{Ca}$ and $\mathrm{Mg}$ decreased at almost the same degree. However, after turning off the current, at $\mathrm{pH} 7.5$, the concentrations of $\mathrm{Ca}$ and $\mathrm{P}$ ions in the bulk solution did not change, while the concentration of $\mathrm{Mg}^{2+}$ increased from 14.2 to $19.8 \mathrm{mg} / \mathrm{L}$ after $48 \mathrm{~h}$ in open circuit. Differently, in the case of $\mathrm{pH} 4.5$, the concentrations of $\mathrm{Ca}, \mathrm{P}$ and $\mathrm{Mg}$ increased to their initial values after 
$48 \mathrm{~h}$ treatment in open circuit. This means that the precipitated solids were dissolved, backing into the bulk solution. The different behavior of precipitates suggests that the dissolution and precipitation may co-occur at acidic $\mathrm{pH}$. This may also explain the relatively low removal of $\mathrm{Mg}^{2+}$ and $\mathrm{P}$ at low $\mathrm{pH}$ in comparison to the high $\mathrm{pH}$ (Figure 4.4).

\subsection{Conclusions}

We investigated the fate of $\mathrm{Ca}, \mathrm{Mg}, \mathrm{P}$ and inorganic carbon in electrochemical phosphate recovery from domestic wastewater. We found that phosphate was removed as ACP with Ca. For $\mathrm{Ca}$, although both ACP and calcite result in its removal, its removal is dominated by the later species. Mg was removed mostly as brucite. In view of the precipitation mechanisms, the formation of calcite and brucite can be reduced by acidification and adjusting the current density, as they affected the concentration of inorganic carbon and the availability of hydroxide ions. We achieved the highest ACP abundance (75\%) when the wastewater was acidified to $\mathrm{pH} 3.8$ and treated at $1.4 \mathrm{~A} / \mathrm{m}^{2}$. However, in real applications, the acidification of wastewater by acid dosing is considered unrealistic because of the massive volume of wastewater and the need of post-treatment to increase wastewater $\mathrm{pH}$ after treatment. The most promising way to reduce inorganic carbon seems to rely on the local low $\mathrm{pH}$ near the anode. In a typical electrochemical system, local high and low $\mathrm{pH}$ can be achieved at the cathode and the anode, respectively. Ideally, on the one hand, we use the local low $\mathrm{pH}$ in the vicinity of the anode to get rid of bicarbonate and on the other hand, we use the local high $\mathrm{pH}$ to induce calcium phosphate precipitation. Through this kind of acidification, we may be able to eliminate the adverse effect of inorganic carbon without dosing external acid. 


\section{Supporting information}
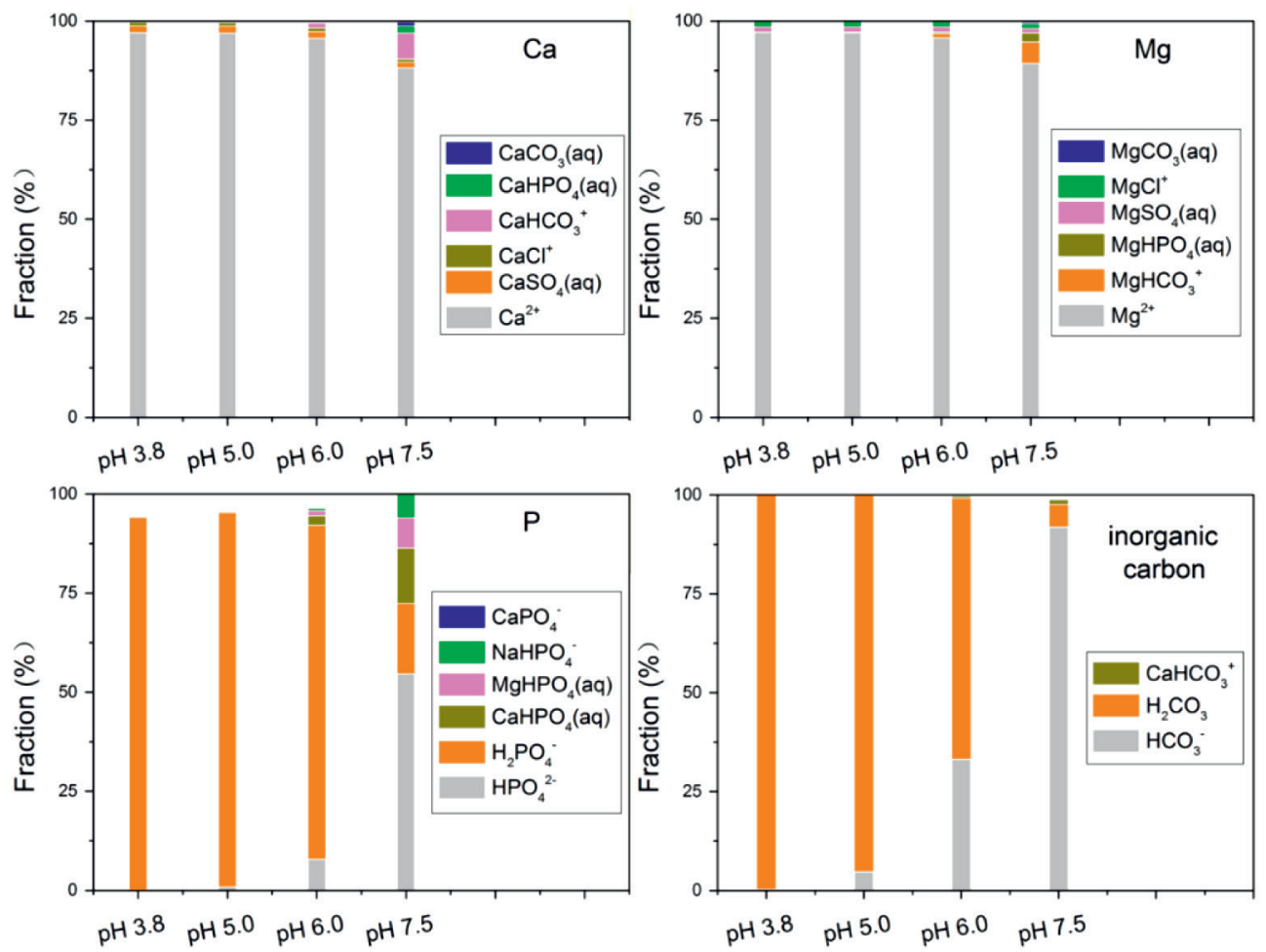

Figure S4.1. Species fraction of $\mathrm{Ca}, \mathrm{P}, \mathrm{Mg}$ and inorganic carbon at $\mathrm{pH} 3.8, \mathrm{pH} 5.0, \mathrm{pH} 6.0$ and $\mathrm{pH}$ 7.5, calculated with Visual Minteq. Input was based on the wastewater composition after acidification (see Table S4.1). 


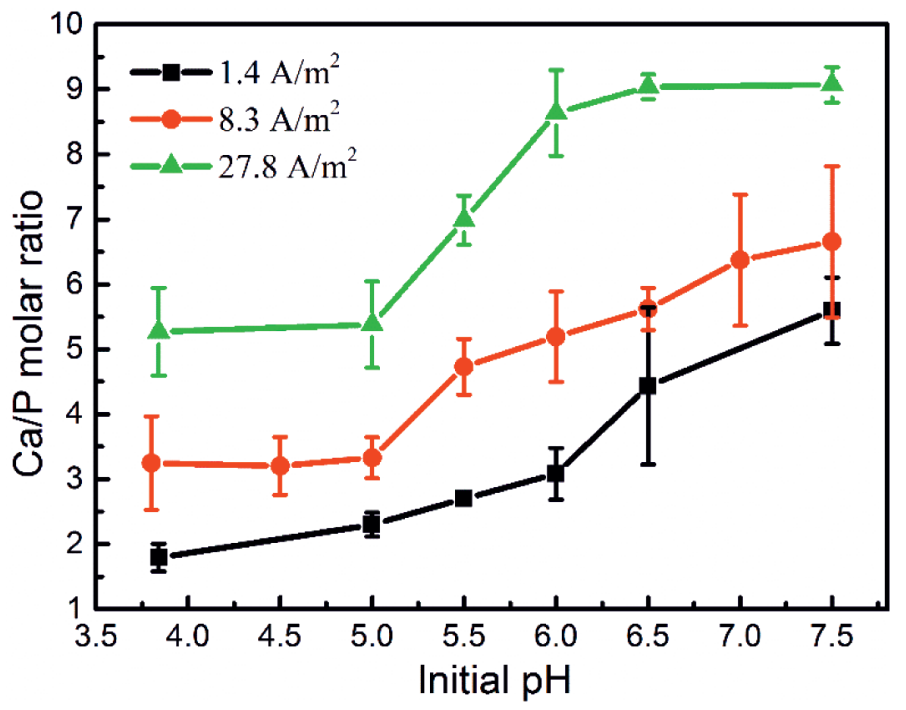

Figure S4.2. Calculated $\mathrm{Ca} / \mathrm{P}$ molar ratio in the collected precipitates.

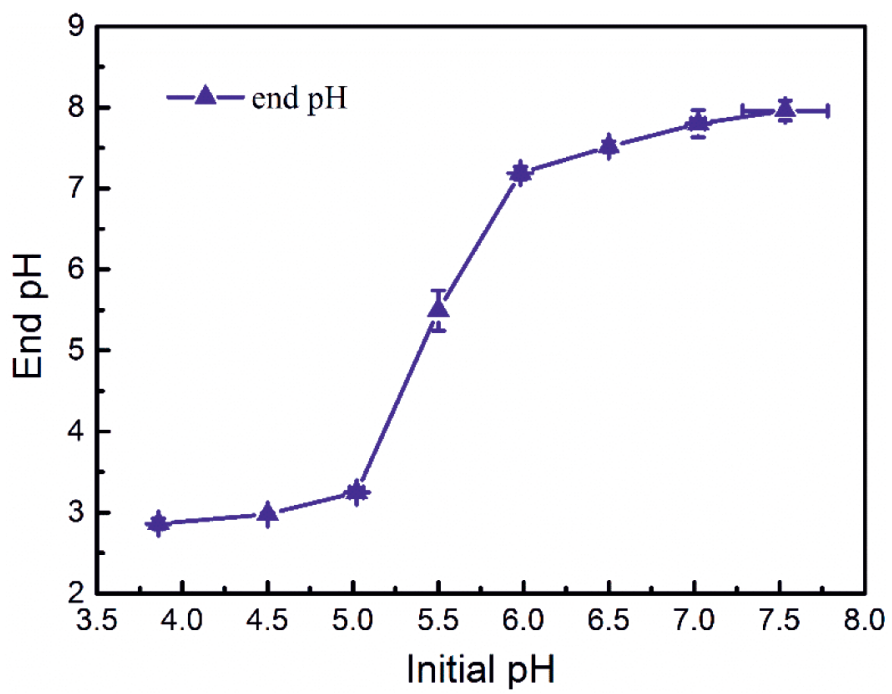

Figure S4.3. Initial and end $\mathrm{pH}$ of the wastewater after electrochemical treatment. Conditions: $30 \mathrm{~mA}\left(8.3 \mathrm{~A} / \mathrm{m}^{2}\right)$, electrolysis time $=24 \mathrm{~h}$; anode: Pt coated Ti; cathode: Ti $\left(36 \mathrm{~cm}^{2}\right)$; electrode distance $=3 \mathrm{~cm}$. 
Table S4.1. Main compositions of the raw wastewater (influent) in WWTP Leeuwarden, the Netherlands.

\begin{tabular}{cccc}
\hline parameter & value & standard dev. & unit \\
\hline inorganic carbon & 138 & 8.1 & $\mathrm{mg} / \mathrm{L}$ \\
$\mathrm{Ca}^{2+}$ & 81.2 & 4.9 & $\mathrm{mg} / \mathrm{L}$ \\
$\mathrm{Mg}^{2+}$ & 19.4 & 2.0 & $\mathrm{mg} / \mathrm{L}$ \\
$\mathrm{P}^{-\mathrm{PO}_{4}{ }^{3-}}$ & 7.5 & 0.4 & $\mathrm{mg} / \mathrm{L}$ \\
$\mathrm{NH}_{4}^{+}$ & 58.9 & 1.3 & $\mathrm{mg} / \mathrm{L}$ \\
$\mathrm{K}^{+}$ & 21.1 & 0.2 & $\mathrm{mg} / \mathrm{L}$ \\
$\mathrm{Na}^{+}$ & 253 & 5.2 & $\mathrm{mg} / \mathrm{L}$ \\
$\mathrm{SO}_{4}^{2-}$ & 26.2 & 0.6 & $\mathrm{mg} / \mathrm{L}$ \\
$\mathrm{Cl}^{-}$ & 223 & 9.9 & $\mathrm{mg} / \mathrm{L}$ \\
$\mathrm{pH}^{2}$ & 7.5 & 0.2 & $\mathrm{~N} / \mathrm{A}$ \\
\hline
\end{tabular}




\section{Chapter 5}

\section{Is there a precipitation sequence in municipal wastewater induced by electrolysis?}

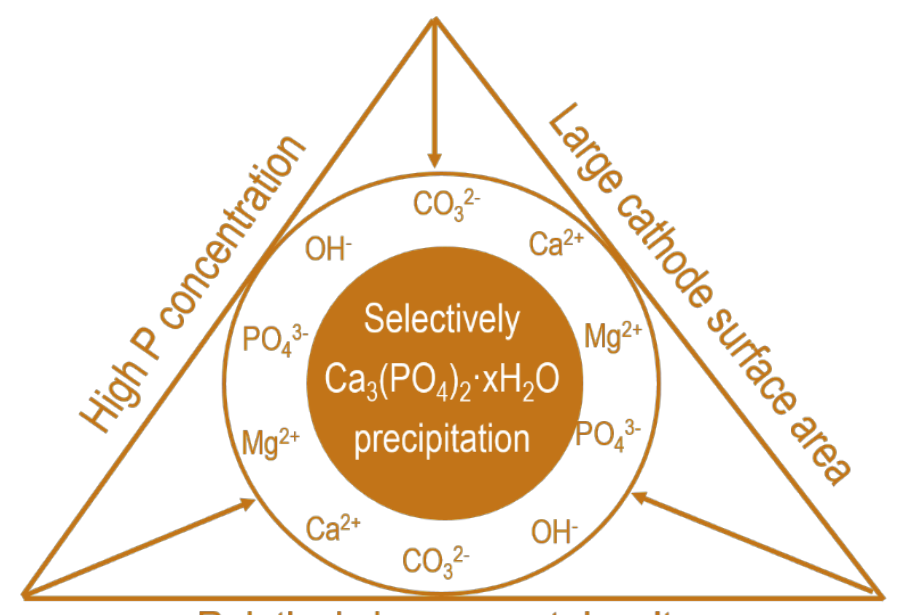

Relatively low current density

Yang Lei, Jorrit Christiaan Remmers, Michel Saakes, Renata D. van der Weijden and Cees J.N. Buisman

This chapter has been published as:

Lei, Yang, Jorrit Christiaan Remmers, Michel Saakes, Renata D. van der Weijden, and Cees JN Buisman. "Is there a precipitation sequence in municipal wastewater induced by electrolysis?."

Environmental Science \& Technology 52, no. 15 (2018): 8399-8407. 


\begin{abstract}
Electrochemical wastewater treatment can induce calcium phosphate precipitation on the cathode surface. This provides a simple yet efficient way for extracting phosphorus from municipal wastewater without dosing chemicals. However, the precipitation of amorphous calcium phosphate (ACP) is accompanied by the precipitation of calcite $\left(\mathrm{CaCO}_{3}\right)$ and brucite $\left(\mathrm{Mg}(\mathrm{OH})_{2}\right)$. To increase the content of ACP in the products, it is essential to understand the precipitation sequence of ACP, calcite and brucite in electrochemical wastewater treatment. Given the fact that calcium phosphate (i.e., hydroxyapatite) has the lowest thermodynamic solubility product and highest saturation index in the wastewater, it has the potential to precipitate first. However, this is not observed in electrochemical phosphate recovery from raw wastewater, which is probably because of the very high $\mathrm{Ca} / \mathrm{P}$ molar ratio (7.5) and high bicarbonate concentration in the wastewater resulting in the formation of calcite. In the case of decreased $\mathrm{Ca} / \mathrm{P}$ molar ratio (1.77) by spiking external phosphate, most of the removed $\mathrm{Ca}$ in the wastewater was used for ACP formation instead of calcite. The formation of brucite, however, was only affected when the current density was decreased or the size of the cathode was changed. Overall, the removal of $\mathrm{Ca}$ and $\mathrm{Mg}$ is much more affected by current density than the surface area of the cathode, whereas for P removal, the reverse is true. Because of these dependencies, though there is no definite precipitation sequence among ACP, calcite and brucite, it is still possible to influence the precipitation degree of these species by relatively low current density and high surface area or by targeting phosphorus-rich wastewaters.
\end{abstract}




\subsection{Introduction}

Municipal wastewater is a significant source of contaminants but can be an important source of nutrients as well, i.e., phosphorus (P) [46, 47, 113]. $\mathrm{P}$ often is considered to be the principal stimulant of eutrophication. However, it is also a limited and essential resource [10]. To bridge the gap of $\mathrm{P}$ being abundant as a pollutant and scare as a resource, it is suggested to remove and reuse $\mathrm{P}$ from wastewater $[7,10]$.

Phosphate can be removed from the wastewater by precipitation as useful P products, such as struvite $\left(\mathrm{MgNH}_{4} \mathrm{PO}_{4} \cdot 6 \mathrm{H}_{2} \mathrm{O}\right)$ and calcium phosphate $[23,29,33,54]$. The most stable phase of calcium phosphate is hydroxyapatite $\left(\mathrm{Ca}_{5}\left(\mathrm{PO}_{4}\right)_{3} \mathrm{OH}, \mathrm{HAP}\right)$, which owns the highest atomic $\mathrm{Ca} / \mathrm{P}$ ratio (1.67) [35]. The typical Ca concentration in domestic wastewater is $20-120 \mathrm{mg} / \mathrm{L}$ [122], whereas the $\mathrm{P}-\mathrm{PO}_{4}$ concentration varies from less than $1.0 \mathrm{mg} / \mathrm{L}$ (effluent) to $10 \mathrm{mg} / \mathrm{L}$ (influent). The P concentration in the downstream wastewater from an anaerobic digestion system can be even higher [123]. In most cases, the aqueous Ca concentration is high enough to precipitate the coexisting phosphate in the wastewater.

However, to achieve efficient precipitation, the wastewater $\mathrm{pH}$ needs to be raised above 10 $[89,124]$. The most simple way of increasing wastewater $\mathrm{pH}$ is by adding sodium hydroxide $[28,65]$. However, this method has some drawbacks. First, the products achieved by conventional chemical precipitation have poor settle ability. Moreover, after precipitation the $\mathrm{pH}$ of the wastewater needs to be reduced by dosing acid, as the typical $\mathrm{pH}(>10)$ required for chemical precipitation is higher than the discharge standard $(6<\mathrm{pH}<9)$.

Electrochemical induced calcium phosphate precipitation opens a door for avoiding such problems. In electrochemical systems, a local high $\mathrm{pH}$ near cathode can be achieved by water electrolysis [89, 106, 125], as shown in eq 5.1:

$$
\text { Cathode: } 4 \mathrm{H}_{2} \mathrm{O}+4 \mathrm{e}^{-} \rightarrow 4 \mathrm{OH}^{-}+2 \mathrm{H}_{2} \uparrow
$$

The formation of $\mathrm{OH}^{-}$ions will create $\mathrm{pH}$ gradients between the cathode and the bulk solution. While the pH gradients are not wanted in most electrochemical systems [106], in terms of calcium phosphate precipitation, the high local $\mathrm{pH}$ can be very useful. As is well-known, the solution $\mathrm{pH}$ plays a crucial role in the precipitation of calcium phosphate $[23,36]$. Moreover, the solubility of calcium phosphate minerals is $\mathrm{pH}$ dependent and a high $\mathrm{pH}$ usually means high thermodynamic driving force for calcium phosphate precipitation [36]. 


$$
\text { Anode: } 2 \mathrm{H}_{2} \mathrm{O} \rightarrow 4 \mathrm{H}^{+}+\mathrm{O}_{2} \uparrow+4 \mathrm{e}^{-}
$$

In the electrochemical system, although the local $\mathrm{pH}$ is increased, the change of $\mathrm{pH}$ in the bulk solution is small. This is because an equal number of $\mathrm{H}^{+}$and $\mathrm{OH}^{-}$are produced at the anode and cathode, respectively (eq 5.1 and eq 5.2). Moreover, the presence of buffers such as inorganic carbon in wastewater may contribute to a stable bulk solution $\mathrm{pH}$ [119]. Hence, a post reduction of $\mathrm{pH}$ of the bulk solution is not needed. Furthermore, as the precipitation only takes place in the vicinity of the cathode and the formed precipitates can easily be collected from the cathode [89], a post-separation of precipitates from the bulk solution is avoided as well. Therefore, in principle, $\mathrm{P}$ can be removed and separated simultaneously from the wastewater without dosing chemicals in the electrochemical system.

Proof of principle of electrochemically induced phosphate precipitation has been demonstrated by using well-defined solutions for both struvite [64] and calcium phosphate [89]. Our previous study indicated that $\mathrm{P}$ could precipitate as calcium phosphate on the cathode in a wide $\mathrm{pH}$ range, even under acidic conditions (i.e., $\mathrm{pH}$ 4.0) [89]. The effects of essential operation conditions and water matrices on this process were studied as well [119, 120]. It was found that the presence of natural organic matter is beneficial to the removal of $\mathrm{P}[120]$. However, the efficiency of this system in raw wastewater is not fully addressed yet. Given the complexity of wastewater composition, it is more likely that other species than calcium phosphate will precipitate. To reduce the formation of unwanted species, we need to understand the precipitation mechanism, not only of calcium phosphate but also of associated byproducts. Particularly, the relative precipitation tendency among products and byproducts is of great importance. If such precipitation sequence exists, we may be able to selectively precipitate $\mathrm{P}$. In case of simultaneous precipitation and the absence of a precipitation sequence, pretreatment may be needed.

The objective of this study is to evaluate the performance of electrochemical P removal and recovery in raw wastewater. Specifically, we focus on understanding the precipitation sequence of all possible solids that may precipitate in the wastewater, which can be important in preventing or reducing the formation of unwanted byproducts and recovering $\mathrm{P}$ as useful products. 


\subsection{Materials and methods}

\subsubsection{Materials}

The anode was a Pt-coated Ti disc $(\varnothing 80 \mathrm{~mm}$, thickness $1 \mathrm{~mm})$. A square Ti plate with sizes of $6 \times 6 \mathrm{~cm}, 4 \times 4 \mathrm{~cm}$ and $2 \times 2 \mathrm{~cm}$ was used as the cathode. The anode and the cathode were perpendicularly welded to a Pt-coated Ti rod and pure Ti rod (Ø $3 \mathrm{~mm}$, length $120 \mathrm{~mm}$ ), respectively. Both electrodes were acquired from MAGNETO Special Anodes BV (Schiedam, The Netherlands).

\subsubsection{Wastewater sampling and processing.}

Raw domestic wastewater was collected from the influent of a local wastewater treatment plant (Leeuwarden, The Netherlands). After sampling, all the wastewater was physically filtered through a combined sieve filter $(325 \mu \mathrm{m})$ and stored at $4^{\circ} \mathrm{C}$ in a fridge.

\subsubsection{Wastewater electrolysis}

We conducted all experiments in an undivided glass type electrochemical cell with a volume of $1.0 \mathrm{~L}$. The electrodes were horizontally located, with the anode at the top and the cathode at the bottom of the cell. The distance between electrodes was $30 \mathrm{~mm}$. Unless specified otherwise, the electrolysis current density was held constant at $8.3 \mathrm{~A} / \mathrm{m}^{2}$ using a power supply (ES 015-10, Delta Electronika, The Netherlands). After each test, the cathode was removed and dried in air at room temperature for 1 day. The next day, the precipitates on the electrode surface were collected by light scraping and then the cathode was cleaned by immersion into acidic solution (1.0 $\mathrm{M} \mathrm{HNO}_{3}$ ) for another day. After acid washing, the cathode was rinsed with deionized water. The anode was also cleaned by acid weekly.

\subsubsection{Analytical methods}

We measured the concentration of cations $\left(\mathrm{Na}^{+}, \mathrm{NH}_{4}{ }^{+}\right)$and anions $\left(\mathrm{SO}_{4}{ }^{2-}, \mathrm{Cl}^{-}, \mathrm{NO}_{3}{ }^{-}\right)$using ion chromatography (Compact IC 761, Metrohm). We quantified concentrations of $\mathrm{Ca}, \mathrm{Mg}$, $\mathrm{K}$ and $\mathrm{P}$ by ICP-AES. We accessed the inorganic carbon and total organic carbon (TOC) concentration by a TOC analyzer (Shimadzu). Given that $98 \%$ of the inorganic carbon was present as bicarbonate at $\mathrm{pH} 8.0$ (see Figure S5.1), the initial concentration of bicarbonate was expressed as inorganic carbon concentration. We analyzed the wastewater $\mathrm{pH}$ was by a daily calibrated $\mathrm{pH}$ meter (Metter Toledo). We characterized the morphologies of precipitates and the corresponding element composition by scanning electron microscopy (SEM, JEOL- 
6480LV) combined with energy dispersive spectroscopy (EDS, Oxford Instruments). The samples for SEM-EDS analysis were coated with gold and detected using carbon film as the background. Because of this, the carbon and gold contents were excluded from the element composition. We examined the solid phases of precipitates by X-ray diffraction (XRD, Bruker). We performed the phase quantification of solid species in the precipitates by using HighScore Plus program.

\subsubsection{Calculations}

We used Visual MINTEQ 3.1 (available at https://vminteq.lwr.kth.se/download/) and HydraMedusa (available at https://www.kth.se/che/medusa/) to calculate the supersaturation index (SI) of potential precipitates and the fractions of $\mathrm{Ca}, \mathrm{Mg}, \mathrm{P}$ and $\mathrm{N}$ in the wastewater versus $\mathrm{pH}$, respectively. The SI is defined as eq 5.3:

$$
\mathrm{SI}=\log \left(\frac{\mathrm{IAP}}{\mathrm{Ksp}}\right)
$$

Where IAP and Ksp refer to the ion activity of the associated lattice ions and the thermodynamic solubility product, respectively.

\subsection{Results and discussion}

\subsubsection{Thermodynamic insights}

We previously confirmed that the electrochemically induced calcium phosphate precipitation was due to the high $\mathrm{pH}$ near the cathode surface [89]. While the local $\mathrm{pH}$ was not recorded, we assumed the local $\mathrm{pH}$ near the cathode could range from the bulk solution $\mathrm{pH} 8.0$ to as high as 12.0. Such a high local $\mathrm{pH}$ was recorded in a biofilm by using a micro $\mathrm{pH}$ sensor [125]. Based on the wastewater composition (Table S5.1), at least 16 precipitates including calcium phosphate, magnesium precipitates, and carbonate precipitates may form and precipitate from the wastewater in response to high local $\mathrm{pH}$, as indicated by the SI of these species (Table 5.1). 
Table 5.1. Supersaturation index (SI) of potential precipitates in the raw wastewater in response to different bulk solution $\mathrm{pH}$ of $8,9,10,11$ and $12^{a}$

\begin{tabular}{|c|c|c|c|c|c|c|}
\hline Mineral & Formula & $\mathrm{pH} 8$ & $\mathrm{pH} 9$ & $\mathrm{pH} 10$ & $\mathrm{pH} 11$ & $\mathrm{pH} 12$ \\
\hline $\mathrm{ACC}$ & $\mathrm{CaCO}_{3} \cdot \mathrm{xH}_{2} \mathrm{O}$ & 0.3 & 0.6 & 1.0 & 1.0 & 1.0 \\
\hline vaterite & $\mathrm{CaCO}_{3}$ & 0.5 & 1.3 & 1.7 & 1.8 & 1.8 \\
\hline aragonite & $\mathrm{CaCO}_{3}$ & 0.9 & 1.8 & 2.2 & 2.2 & 2.2 \\
\hline calcite & $\mathrm{CaCO}_{3}$ & 1.1 & 1.9 & 2.3 & 2.4 & 2.4 \\
\hline $\mathrm{ACP}(\mathrm{am} 1)$ & $\mathrm{Ca}_{3}\left(\mathrm{PO}_{4}\right)_{2}$ & -0.7 & 0.9 & 1.3 & 1.4 & 1.4 \\
\hline $\mathrm{ACP}(\operatorname{am} 2)$ & $\mathrm{Ca}_{3}\left(\mathrm{PO}_{4}\right)_{2}$ & 2.1 & 3.6 & 4.1 & 4.2 & 4.2 \\
\hline TCP & $\mathrm{Ca}_{3}\left(\mathrm{PO}_{4}\right)_{2}$ & 2.9 & 4.4 & 4.8 & 4.9 & 4.9 \\
\hline $\mathrm{OCP}$ & $\mathrm{Ca}_{4} \mathrm{H}\left(\mathrm{PO}_{4}\right)_{3} \cdot 3 \mathrm{H}_{2} \mathrm{O}$ & 2.3 & 3.6 & 3.4 & 2.7 & 1.7 \\
\hline hydroxyapatite & $\mathrm{Ca}_{5}\left(\mathrm{PO}_{4}\right)_{3}(\mathrm{OH})$ & 11.7 & 14.9 & 16.4 & 17.4 & 18.4 \\
\hline brucite & $\mathrm{Mg}(\mathrm{OH})_{2}$ & -4.4 & -2.5 & -0.7 & 1.1 & 2.9 \\
\hline artinite & $\mathrm{Mg}_{2}(\mathrm{OH})_{2} \mathrm{CO}_{3} \cdot 3 \mathrm{H}_{2} \mathrm{O}$ & -4.6 & -1.7 & 0.6 & 2.5 & 4.1 \\
\hline magnesite & $\mathrm{MgCO}_{3}$ & -0.2 & 0.7 & 1.3 & 1.4 & 1.2 \\
\hline hydromagnesite & $\mathrm{Mg}_{5}\left(\mathrm{CO}_{3}\right)(\mathrm{OH})_{2} \cdot 4 \mathrm{H}_{2} \mathrm{O}$ & -9.2 & -3.6 & 0.3 & 2.5 & 3.4 \\
\hline dolomite $^{b}$ & $\mathrm{CaMg}\left(\mathrm{CO}_{3}\right)_{2}$ & 1.4 & 3.2 & 4.1 & 4.3 & 4.1 \\
\hline dolomite $^{c}$ & $\mathrm{CaMg}\left(\mathrm{CO}_{3}\right)_{2}$ & 2.0 & 3.8 & 4.7 & 4.9 & 4.6 \\
\hline huntite & $\mathrm{Mg}_{3} \mathrm{Ca}\left(\mathrm{CO}_{3}\right)_{4}$ & -0.5 & 3.1 & 5.1 & 5.5 & 4.9 \\
\hline
\end{tabular}

$\overline{{ }^{a} \text { ACC: amorphous calcium carbonate; ACP: amorphous calcium phosphate; TCP: tricalcium }}$ phosphate; OCP: octacalcium phosphate; ${ }^{b}$ : ordered; ${ }^{c}$ : disordered.

It should be noted that for the calculations of SI and ion fractions the organic contents were not considered. However, it is worth mentioning the formation of struvite is not favorable according to the thermodynamic calculations, as struvite is undersaturated (SI $<0$, Table S5.2). Therefore, $P$ removal and recovery as struvite probably is not feasible in raw municipal wastewater without dosing external $\mathrm{Mg}$ and/or phosphate. 
Among these possible precipitates, amorphous calcium phosphate (ACP), beta tricalcium phosphate, octacalcium phosphate, and HAP can contribute to the removal of $\mathrm{P}$. The other precipitates including calcium carbonate, magnesium carbonate, brucite, and dolomite may form as byproducts but will not result in the direct removal of P. However, these potential precipitates may still contribute to the removal of $\mathrm{P}$ indirectly, either as adsorbents, coagulants or seeds.
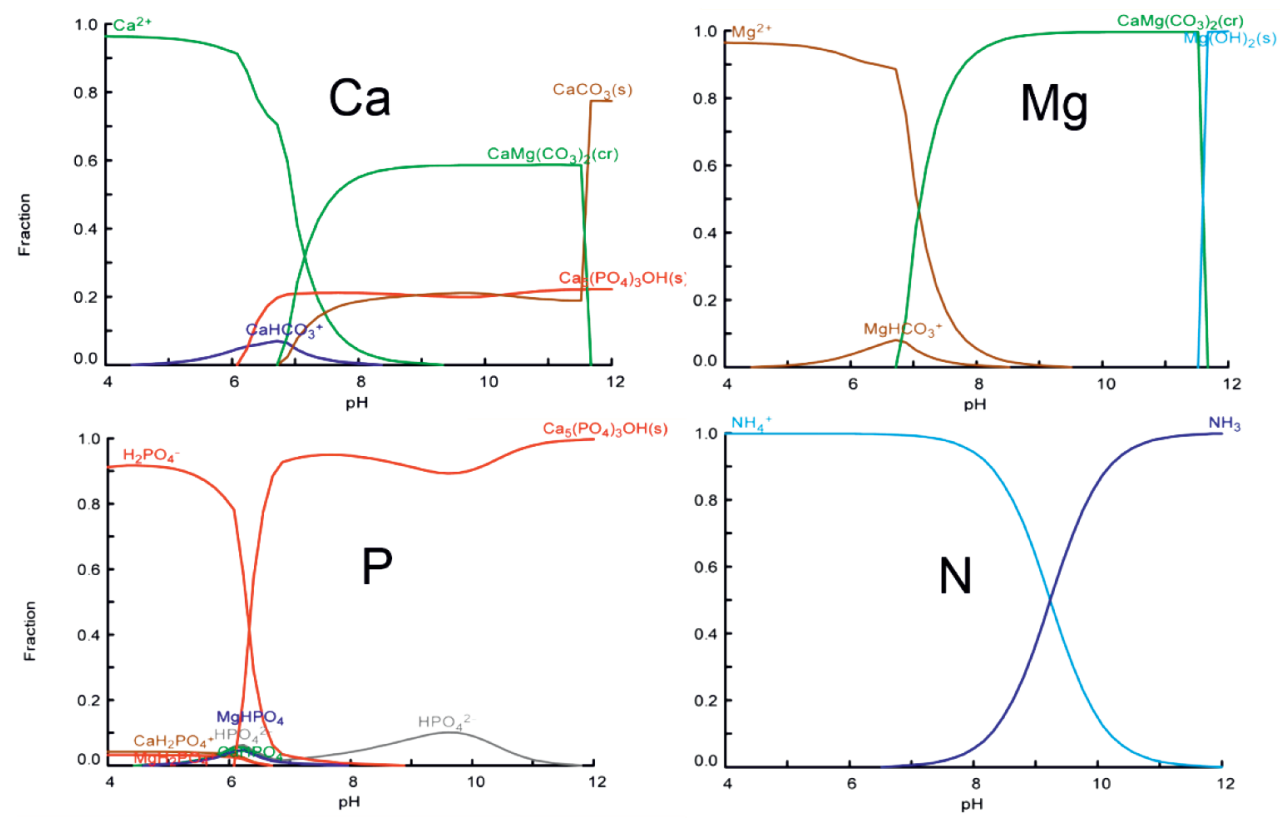

Figure 5.1. Fractions of $\mathrm{Ca}, \mathrm{P}, \mathrm{Mg}$ and $\mathrm{N}$ with respect to varied solution $\mathrm{pH}(4.0-12)$, calculated with using Hydra-Medusa software. Input was based on the main wastewater composition, $\left[\mathrm{Ca}^{2+}\right]=1.87 \mathrm{mM} ;\left[\mathrm{Mg}^{2+}\right]=1.10 \mathrm{mM} ;\left[\mathrm{NH}_{4}^{+}\right]=3.06 \mathrm{mM} ;\left[\mathrm{K}^{+}\right]=0.60 \mathrm{mM}$; $\left[\mathrm{HPO}_{4}{ }^{2-}\right]=0.25 \mathrm{mM} ;\left[\mathrm{HCO}_{3}{ }^{-}\right]=11.45 \mathrm{mM} ;\left[\mathrm{SO}_{4}{ }^{2-}\right]=0.31 \mathrm{mM} ;\left[\mathrm{Cl}^{-}\right]=9.51 \mathrm{mM}$.

For the ions that may be involved in the precipitates, the fraction of these ions was calculated with respect to solution $\mathrm{pH}$ (Figure 5.1). Overall, the fractions' distribution suggests that struvite will not be formed. Nitrogen element is present either as $\mathrm{NH}_{4}{ }^{+}$or as soluble $\mathrm{NH}_{3}$. Magnesium is present as free $\mathrm{Mg}^{2+}$, magnesium carbonate, dolomite, and brucite, with the last being formed when the $\mathrm{pH}$ is higher than 10. Similarly, $\mathrm{Ca}$ is present in both phosphate and carbonate salts. For $\mathrm{P}$, the calculation indicates that $\mathrm{P}$ will precipitate as HAP completely when the solution $\mathrm{pH}$ is above 7.0. The $\mathrm{Ca} / \mathrm{P}$ molar ratio in the wastewater is 7.5 , which is much higher than the required ratio (1.67). This indicates that the $\mathrm{Ca}$ in the wastewater is 
high enough to precipitate with the $\mathrm{P}$ in the wastewater. However, it should be mentioned that the fraction calculations refer to thermodynamic equilibrium conditions of the potential species. Kinetically, the metastable intermediate phases (i.e., ACP) may form as well. To verify the theoretical calculations, batch experiments were performed.

\subsubsection{Proof of principles}

As can be seen from Figure 5.2A, there is no $\mathrm{P}$ removal/precipitation in open circuit in $24 \mathrm{~h}$, though the solution is supersaturated for $\mathrm{ACP}\left(\mathrm{SI}_{\mathrm{ACP} 2}=2.1\right)$ and $\mathrm{HAP}\left(\mathrm{SI}_{\mathrm{HAP}}=11.7\right)$ at $\mathrm{pH}$ 8.0. This indicates that the driving force for precipitation from the bulk solution is not able to induce phosphate precipitation (form nuclei) in the wastewater. This also applies to calcium carbonate and dolomite. Both are saturated in the wastewater but do not precipitate. However, in the closed circuit $\left(8.3 \mathrm{~A} / \mathrm{m}^{2}\right), 46.5 \% \mathrm{P}$ was removed from the wastewater in 24 $\mathrm{h}$, accompanied by the removal of inorganic carbon (24.3\%), $\mathrm{Ca}(42.2 \%)$ and $\mathrm{Mg}(24.3 \%)$.

In principle, both $\mathrm{Mg}$ and $\mathrm{Ca}$ can form precipitates with phosphate ions. However, the thermodynamic calculations suggest that $\mathrm{Mg}_{3}\left(\mathrm{PO}_{4}\right)_{2}$ and $\mathrm{MgHPO}_{4} \cdot 3 \mathrm{H}_{2} \mathrm{O}$ formation is not feasible in our system ( $\mathrm{SI}<0$, Table S5.2). Therefore, the removal of $\mathrm{Mg}$ did not result in the removal of P. In our system, the only way for direct P removal is calcium phosphate formation and precipitation, either as amorphous phase or crystalline solids or a mixture of both. The removal of $\mathrm{Mg}$ relates to dolomite, huntite, magnesite and brucite, while the formation of the last one requires a $\mathrm{pH}$ higher than 10 , according to the thermodynamic and fraction calculations (See Table S5.2 and Figure 5.1). Based on the precipitation pathway of $\mathrm{Ca}$ and $\mathrm{Mg}$, the removal of inorganic carbon is due to calcium carbonate and magnesium carbonate formation. However, according to the mass balance calculation, the absolute amount of removed inorganic carbon $(2.86 \pm 0.15 \mathrm{mM})$ cannot be balanced by the removed $\mathrm{Ca}(0.83 \pm 0.05 \mathrm{mM})$ and $\mathrm{Mg}(0.44 \pm 0.01 \mathrm{mM})$. This suggests that the removal of inorganic carbon may result from other reactions. Indeed, inorganic carbon could also be removed by gas stripping in our system due to $\mathrm{H}_{2}$ and $\mathrm{O}_{2}$ production. Moreover, the local low $\mathrm{pH}$ (eq 5.2) near the anode might allow $\mathrm{CO}_{2}$ production (eq 5.4) which could also contribute to the removal of inorganic carbon [126].

$$
\mathrm{HCO}_{3}{ }^{-}+\mathrm{H}^{+} \rightarrow \mathrm{H}_{2} \mathrm{O}+\mathrm{CO}_{2} \uparrow
$$




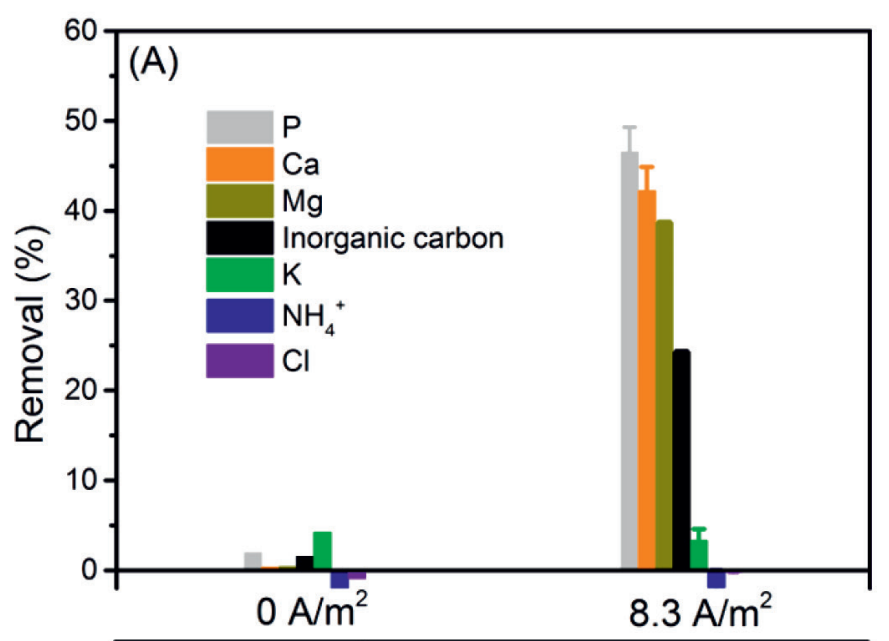

Figure

5.2. (A)

Electrochemical treatment results in the removal of not only $\mathrm{Ca}$ and $\mathrm{P}$ ions but also $\mathrm{Mg}^{2+}$ and inorganic carbon. XRD pattern of the collected precipitates (B) before and (C) after heating treatment at $600{ }^{\circ} \mathrm{C}$ for 1 h. Conditions: electrolysis time $=24 \mathrm{~h}$; current density $=8.3$ $\mathrm{A} / \mathrm{m}^{2}$; anode: $\mathrm{Pt}-\mathrm{Ti}$; cathode: $\mathrm{Ti}\left(36 \mathrm{~cm}^{2}\right)$; electrode distance $=3 \mathrm{~cm}$.
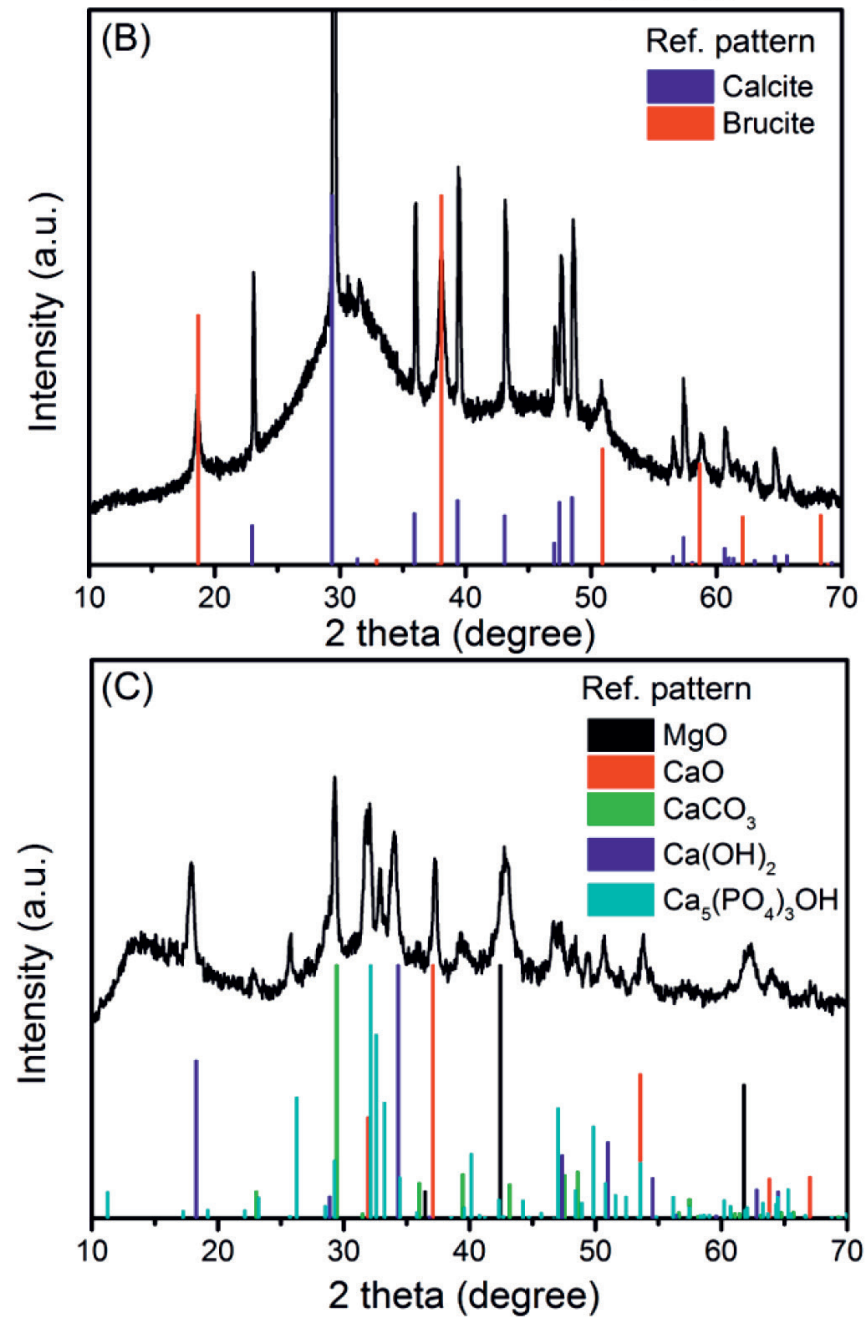
To further clarify the removal mechanism of $\mathrm{Ca}, \mathrm{Mg}, \mathrm{P}$, and inorganic carbon, it is crucial to quantify the species in the precipitates. Therefore, the recovered products were subjected to XRD and SEM-EDS analysis.

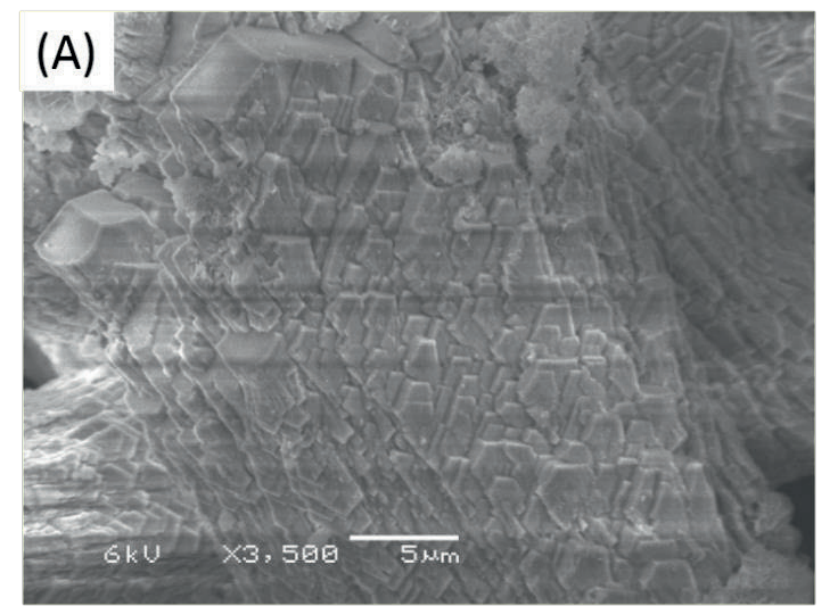

EDS Layered Image 3
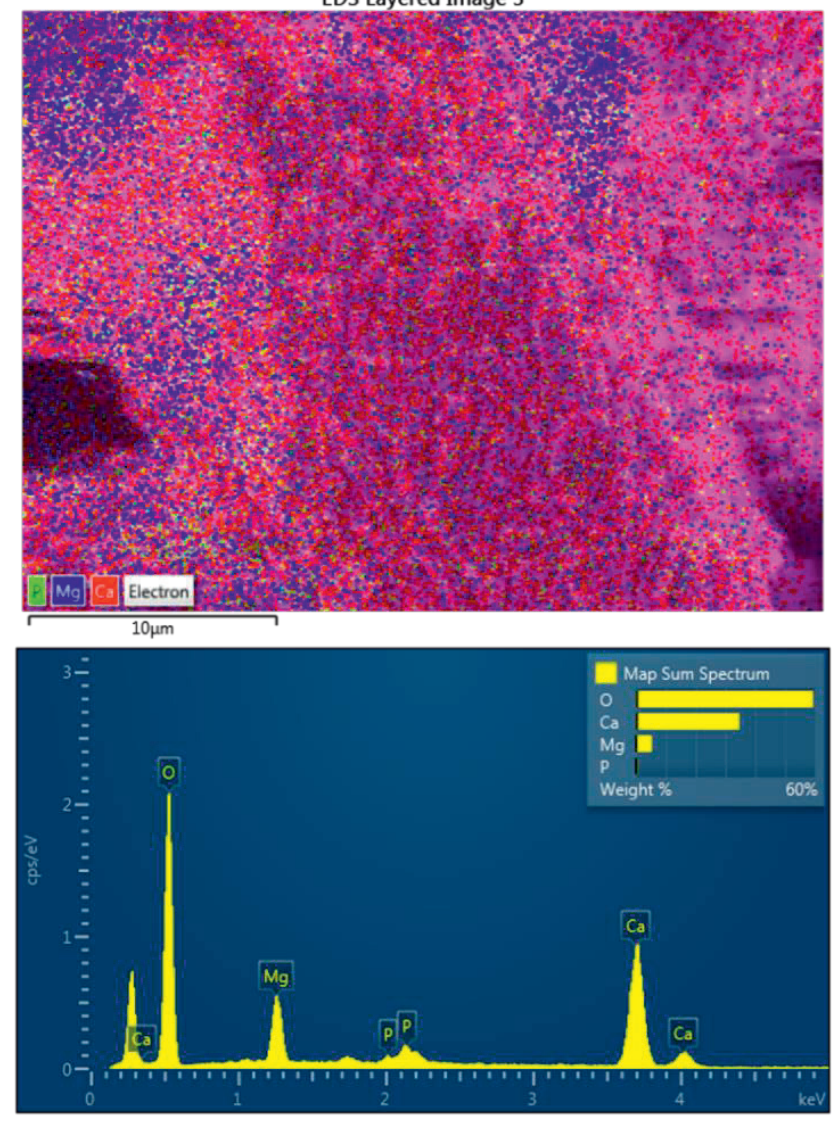

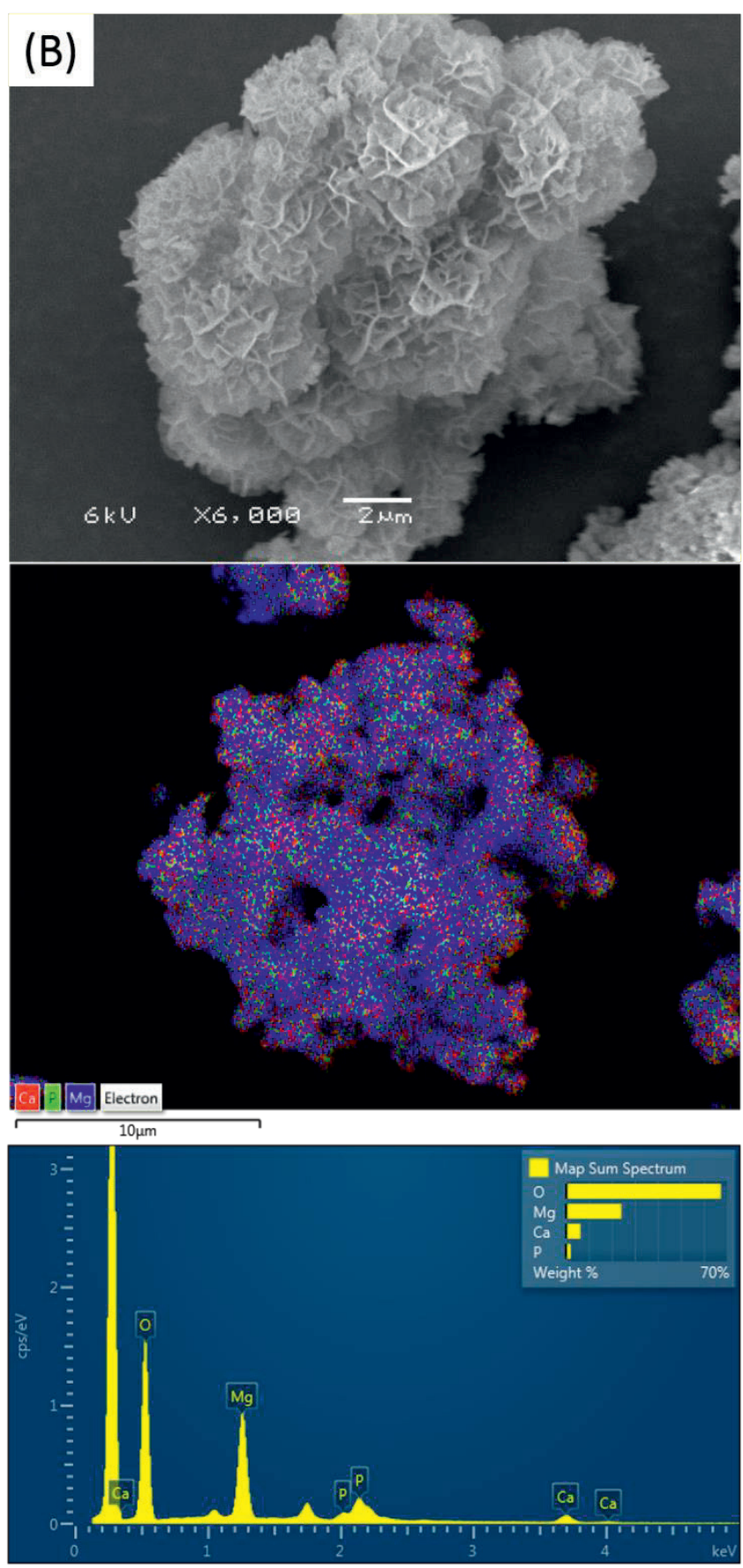


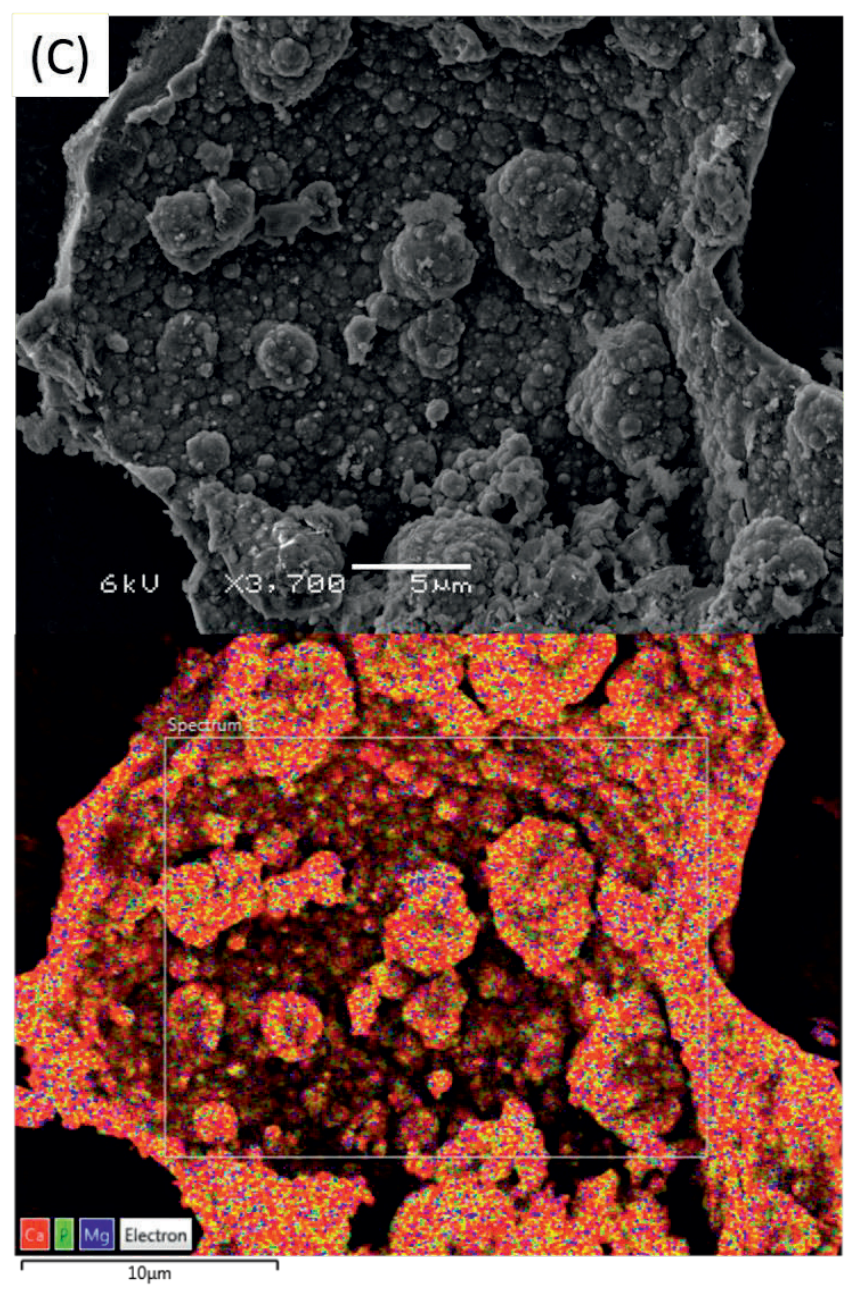

Figure 5.3. SEM images indicate there are three types of morphology in the precipitates. Element analysis (EDS) reveals very different $\mathrm{Ca}, \mathrm{Mg}$ and $\mathrm{P}$ distribution in these morphologies. The irregular rhombohedral shape (A) has the highest $\mathrm{Ca}$ but negligible $\mathrm{P}$ and $\mathrm{Mg}$, whereas the lamellalike shape (B) and the spherical shape (C) contain the highest $\mathrm{Mg}$ and $\mathrm{P}$, respectively. Note the SEM image and the EDS mapping were performed at different voltage and spot size.

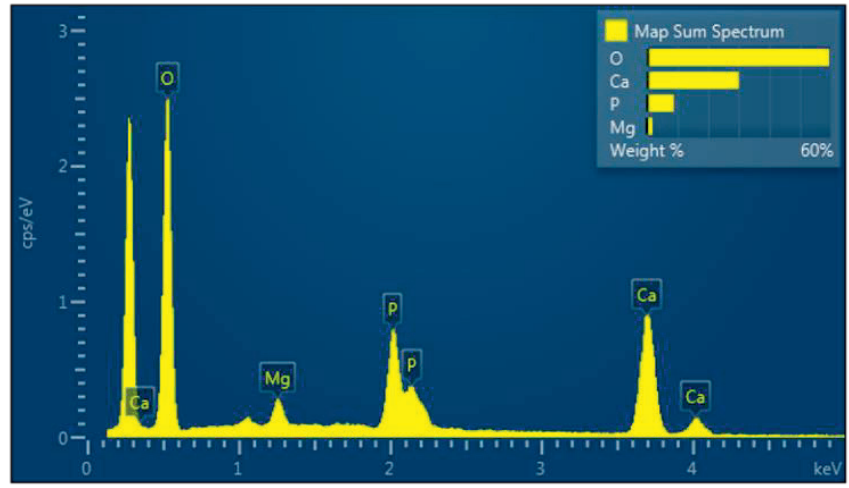


From SEM images, we find three types of morphologies. The irregular rhombohedral (Figure 5.3A) shape is one of the typical morphologies for calcium carbonate [127, 128]. EDS analysis reveals the relative Ca content (\%) in this type of morphology accounts for $34.7 \%$ whereas $\mathrm{Mg}$ and $\mathrm{P}$ only account for $5.3 \%$ and $0.6 \%$, respectively. The lamella-like shapes (Figure 5.3B) are mostly seen for magnesium salts. Indeed, the associated EDS data highlights $\mathrm{Mg}$ as the second richest element (24.1\%), followed by $\mathrm{Ca}(6.3 \%)$ and $\mathrm{P}(2.1 \%)$. The spherical shape (Figure 5.3C) is probably connected with ACP that we have seen in our previous study [89]. Again, this is supported by the relevant element distribution. The spherical shape consists of $30 \% \mathrm{Ca}, 8.8 \% \mathrm{P}$, and negligible $\mathrm{Mg}(1.7 \%)$. The variation of element distributions in the three morphologies suggests the presence of different dominant species. The phases of the solids were further characterized by XRD. The XRD pattern of the precipitates matches with references for calcite and brucite (Figure 5.2B). However, we did not find any sharp peaks for HAP or any other crystalline calcium phosphate. The lack of definite calcium phosphate patterns may be because calcium and phosphate precipitated mainly as ACP which cannot be identified by XRD. Indeed, the broad peak around $30^{\circ}$ can be an indication for ACP. The sample was therefore heated at $600{ }^{\circ} \mathrm{C}$ for $1 \mathrm{~h}$ and then subjected to XRD analysis again. During the heating treatment, the amorphous phase may transfer to the crystalline phase. Indeed, after the heating procedure, as shown in Figure 5.2C, the broad peak around $30^{\circ}$ disappeared. Instead, new sharp peaks were observed. These newly appeared sharp peaks match with reference HAP. Also, patterns of $\mathrm{CaO}$ and $\mathrm{MgO}$ can be found. Under heating treatment, $\mathrm{CaCO}_{3}$ and $\mathrm{Mg}(\mathrm{OH})_{2}$ may decompose to $\mathrm{CaO}$ and $\mathrm{MgO}$, respectively. The formation of $\mathrm{Ca}(\mathrm{OH})_{2}$ might be due to the hydration of $\mathrm{CaO}$ during the XRD testing process.

The concentration of $\mathrm{NH}_{4}{ }^{+}$did not change over the electrolysis process (Figure 5.2A), again confirming the lack of struvite formation. This indeed is in accordance with the theoretical calculation that struvite formation is not thermodynamically feasible. It is also worth mentioning that the chloride concentration did not change (Figure 5.2A), indicating there is no chlorine gas production in our system. This is very important for practical application. Chlorine, once produced, can lead to the formation of toxic chlorinated organic byproducts [129]. The unchanged chloride concentration also explains the negligible ammonium reduction in the electrochemical treatment process. The primary mechanism of ammonium oxidation in electrochemical treatment is chlorination $[129,130]$. Therefore, if there is no 
chlorine formation and in the absence of struvite formation, the direct anode oxidation of ammonium can be neglected, and therefore the ammonium concentration did not change.

To conclude, the solution chemistry together with the theoretical calculation and the characterization of the solids support the formation of three species including ACP, calcite, and brucite in the electrochemical wastewater treatment process.

\subsubsection{Effects of current density}

The electrochemical $\mathrm{P}$ precipitation and byproduct formation are induced by water electrolysis, and more specifically, the increase of $\mathrm{pH}$ near the cathode surface. The extent of $\mathrm{pH}$ increase is regulated by the current density. The current density in our system is defined by the ratio of current and the surface area of the cathode, and therefore, it can be altered by changing either the applied current or the size of the cathode. When the cathode was fixed at $36 \mathrm{~cm}^{2}$, the removal of all ions increased with increasing the current density (Figure 5.4).

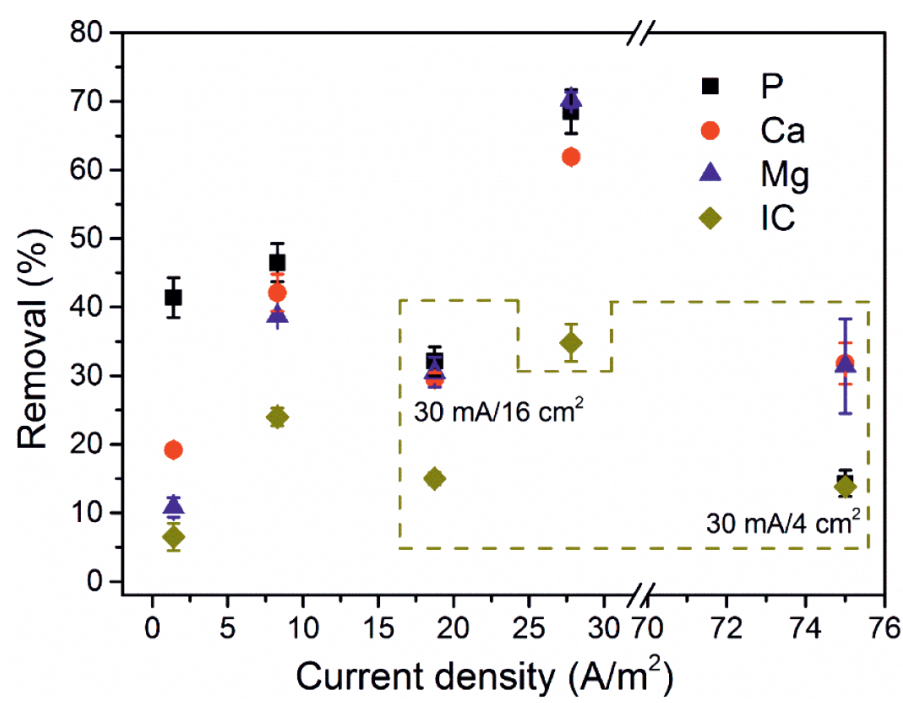

Figure 5.4. Effects of current and cathode surface area on ions removal in the electrochemical phosphorus recovery from domestic wastewater. The circulated data were performed using $16 \mathrm{~cm}^{2}$ and $4 \mathrm{~cm}^{2}$ cathode, the current was $30 \mathrm{~mA}$. The rest was done with using typical 36 $\mathrm{cm}^{2}$ cathode, current was $5 \mathrm{~mA}, 30 \mathrm{~mA}$ and $100 \mathrm{~mA}$. Conditions: electrolysis time $=24 \mathrm{~h}$; anode: Pt-Ti; cathode: Ti; electrode distance $=3 \mathrm{~cm}$.

The removal of P rose from $41.4 \%$ at $1.4 \mathrm{~A} / \mathrm{m}^{2}$ to $46.5 \%$ at $8.3 \mathrm{~A} / \mathrm{m}^{2}$ and further to $68.5 \%$ at $27.8 \mathrm{~A} / \mathrm{m}^{2}$, all recorded in $24 \mathrm{~h}$. The removal of $\mathrm{Ca}$ and $\mathrm{Mg}$ in the three different current 
densities were $19.2 \%, 42.1 \%$ and $61.9 \%$ for $\mathrm{Ca}$ and $10.8 \%, 38.7 \%$ and $70.2 \%$ for $\mathrm{Mg}$, respectively. Clearly, the increase of current density results in relatively more removal of $\mathrm{Ca}$ and $\mathrm{Mg}$ than $\mathrm{P}$.

When the surface area of the cathode was varied at fixed current, the removal of P increased with cathode size but decreased regarding current density. At the highest current density (30 $\mathrm{mA}, 4 \mathrm{~cm}^{2}$ ), only $14.3 \% \mathrm{P}$ was removed. Such removal is even lower than with the lowest current density $\left(1.4 \mathrm{~A} / \mathrm{m}^{2}\right)$ achieved at $5 \mathrm{~mA}$ using the regular $36 \mathrm{~cm}^{2}$ electrode. However, in contrast to $\mathrm{P}$, the corresponding removal of $\mathrm{Ca}$ and $\mathrm{Mg}$ at $75 \mathrm{~A} / \mathrm{m}^{2}$ is much higher than at 1.4 $\mathrm{A} / \mathrm{m}^{2}$ and slightly lower than at $8.3 \mathrm{~A} / \mathrm{m}^{2}\left(30 \mathrm{~mA}, 36 \mathrm{~cm}^{2}\right)$ but close to the removal at 18.8 $\mathrm{A} / \mathrm{m}^{2}\left(30 \mathrm{~mA}, 16 \mathrm{~cm}^{2}\right)$.

It seems that the removal of $\mathrm{Mg}$ and $\mathrm{Ca}$ is more affected by the current density but for $\mathrm{P}$, it is more affected by the cathode size. In an electric field, typically, electromigration will drive anions and cations to anode and cathode, respectively. This means that the diffusion of cations $\left(\mathrm{Ca}^{2+}\right.$ and $\left.\mathrm{Mg}^{2+}\right)$ and anions toward cathode may be enhanced and reduced, respectively. However, bicarbonate, as a buffer, tends to react with the produced $\mathrm{OH}^{-}$to lower the $\mathrm{pH}$ gradients (eq 5.5) [106]:

$$
\mathrm{HCO}_{3}^{-}+\mathrm{OH}^{-} \rightarrow \mathrm{H}_{2} \mathrm{O}+\mathrm{CO}_{3}^{2-}
$$

Therefore, carbonate may still be enriched near the cathode. Phosphate might behave similarly, but its concentration may be too low to affect the local environment near the cathode. Therefore, the formation of calcium carbonate and magnesium hydroxide is still efficient at high current density even if the surface area is small, as the local $\mathrm{pH}$ and the availability of lattice ions are favorable. However, for calcium phosphate, the mass diffusion of $\mathrm{P}$ and the surface area of the cathode, instead of the local $\mathrm{pH}$, are the limiting factors that govern its formation and precipitation. Indeed, we can see from Figure 5.4 that when the current was fixed at $30 \mathrm{~mA}$, the removal of $\mathrm{P}$ increased from $14.3 \%\left(4 \mathrm{~cm}^{2}, 75 \mathrm{~A} / \mathrm{m}^{2}\right)$ to $32.1 \%$ $\left(16 \mathrm{~cm}^{2}, 18.8 \mathrm{~A} / \mathrm{m}^{2}\right)$ and further to $46.5 \%\left(36 \mathrm{~cm}^{2}, 8.3 \mathrm{~A} / \mathrm{m}^{2}\right)$. The $\mathrm{P}$ removal therefore correlated to the increase of the cathode surface area. Though the removal of $\mathrm{P}$ also increased with the current density when fixing the electrode area at $36 \mathrm{~cm}^{2}$ (Figure 5.4), this increase is small. For instance, the nearly 20 times increase of current density from 1.4 to $27.8 \mathrm{~A} / \mathrm{m}^{2}$ only enhanced the removal percentage of $\mathrm{P}$ by $28.1 \%$. It is therefore concluded that increasing cathode size is more efficient than increasing current density in improving the removal of $\mathrm{P}$. 
On top of the removal of ions, we checked the phases of precipitates at different current densities with XRD characterization. Regardless of the current density, the XRD patterns are dominated by calcite and brucite (Figure S5.2). This contrasts with our previous study using synthetic solutions which do not contain magnesium and carbonate. In that case, we found the calcium phosphate shifts from ACP to HAP with increasing current density [89]. The difference may be caused by the coexisting $\mathrm{Mg}^{2+}$ and the organic matters in the domestic wastewater, which could inhibit the recrystallization of ACP to HAP [35, 90, 120].

\subsubsection{Precipitation sequence}

While the removal performance of $\mathrm{P}, \mathrm{Ca}$, and $\mathrm{Mg}$ with respect to current density and surface area was discussed, the underlying mechanism needs to be explored. From the point of resource recovery, calcium phosphate is the most interesting product. However, in practice, other solids including calcite and brucite precipitate as well. To make the electrochemical P recovery process more selective, it is necessary to understand the precipitation sequence of the solids. For this purpose, we monitored ion concentrations during the precipitation process. The concentrations of $\mathrm{Ca}, \mathrm{Mg}, \mathrm{P}$, and inorganic carbon as a function of reaction time are shown in Figure 5.5. It is clear that these ions were removed simultaneously, suggesting there is no removal sequence for $\mathrm{Ca}, \mathrm{Mg}, \mathrm{P}$ and inorganic carbon.
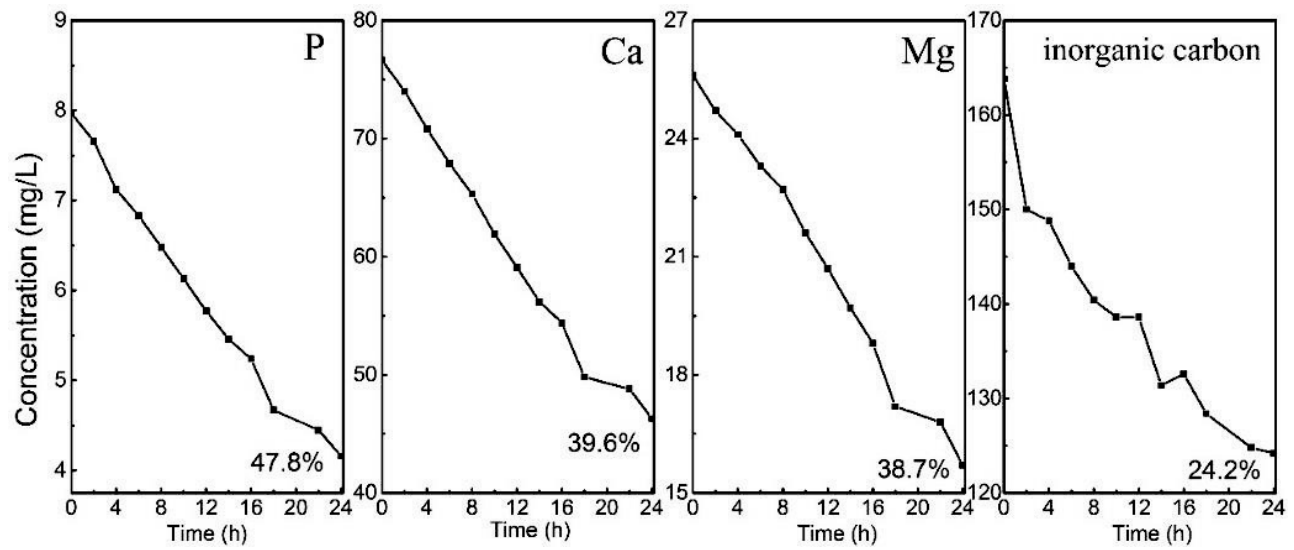

Figure 5.5. Change of ions concentration during electrochemical treatment. Conditions: electrolysis time $=24 \mathrm{~h}$; current density $=8.3 \mathrm{~A} / \mathrm{m}^{2}$; anode: $\mathrm{Pt}-\mathrm{Ti}$; cathode: $\mathrm{Ti}\left(36 \mathrm{~cm}^{2}\right)$; electrode distance $=3 \mathrm{~cm}$. 
To explain the experimental data, it is essential to understand the driving force for the precipitation of salts. Typical precipitation reactions are driven by the concentration of lattice ions, $\mathrm{pH}$, temperature and the thermodynamic ion activity product of the species [36]. In our system, the precipitation temperature and $\mathrm{pH}$ are equal for all species. Then we need to consider the concentrations of lattice ions and the thermodynamic products.

Basically, $\mathrm{Ca}, \mathrm{Mg}, \mathrm{P}, \mathrm{OH}^{-}$ions and (bi)carbonate are involved in the precipitation process. Among these ions, $\mathrm{P}$ only has one main driving force toward the vicinity of the cathode where precipitation reaction happens, which is mass diffusion. However, for cations and (bi)carbonate, in addition to mass diffusion, electromigration and buffer reactions may also contribute to their diffusion to the cathode, respectively. Among the three-identified species, ACP $\left(K \mathrm{sp}=10^{-26}\right)[88]$ has much lower thermodynamic solubility product than calcite $(K \mathrm{sp}$ $\left.=10^{-9}\right)[127]$ and brucite $\left(K \mathrm{sp}=10^{-10.9}\right)$ [28]. It should be noted that HAP $\left(K \mathrm{sp}=10^{-114}\right)$ [88] has the lowest thermodynamic solubility product. In addition, given the wastewater composition, HAP has the highest SI. For instance, at pH 10, the SI of HAP, calcite and brucite are 16.4, 2.3, and -0.7, respectively (Table 5.1 and Table S5.2). Therefore, ACP, as the intermediate species during HAP formation, may precipitate first, but of course, this is subject to solution conditions. The problem is, however, the $\mathrm{Ca} / \mathrm{P}$ molar ratio in the raw wastewater is too high. As a result, the $\mathrm{P}$ in the wastewater only uses a small amount of the $\mathrm{Ca}$ present, and therefore a lot $\mathrm{Ca}$ is still available for byproduct formation. This together with the fact that cations and carbonate can be enriched at the cathode surface explains the formation of $\mathrm{Mg}(\mathrm{OH})_{2}$ and $\mathrm{CaCO}_{3}$, giving simultaneous removal of all ions.

It seems that the low phosphate concentration opens the door for byproduct formation, especially for calcite. Actually, even with extra phosphate in the wastewater, the associated ions were still removed at the same time, as confirmed by the decrease of all ions concentration as a function of time (Figure 5.6). In the presence of $1.15 \mathrm{mM} \mathrm{P}$, under same conditions, the removal of $\mathrm{Ca}$ and $\mathrm{P}$ increased by about $12 \%$, reaching $54.4 \%(\mathrm{Ca})$ and $56.1 \%$ (P). The removal of $\mathrm{Mg}(37.0 \%)$ and inorganic carbon (18.1\%) did not change a lot. 


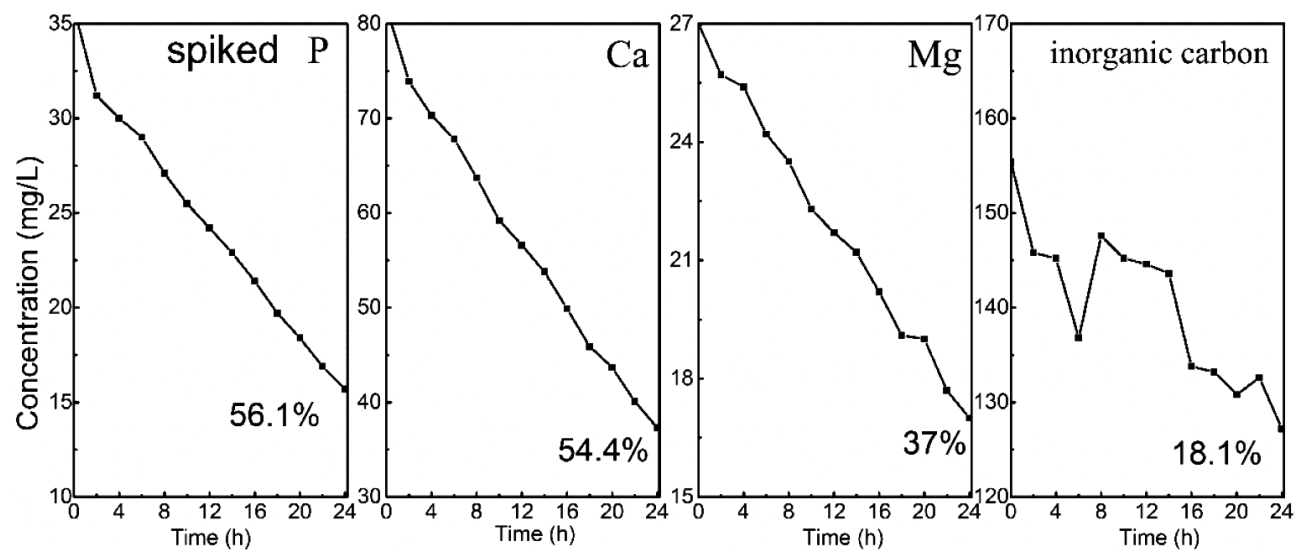

Figure 5.6. Change of ions concentration during electrochemical treatment with spiking extra $\mathrm{P}$ in the wastewater. Conditions: electrolysis time $=24 \mathrm{~h}$; current density $=8.3 \mathrm{~A} / \mathrm{m}^{2}$; anode: $\mathrm{Pt} / \mathrm{Ti}$; cathode: $\mathrm{Ti}\left(36 \mathrm{~cm}^{2}\right)$; electrode distance $=3 \mathrm{~cm},[\mathrm{P}]=1.15 \mathrm{mM}$.

While from the point of removal percentage, there is no significant difference in comparison to the case with low $\mathrm{P}$ concentration, the absolute amount of removed $\mathrm{P}$ is more significant, $0.648(1.15 \mathrm{mM})$ vs $0.119 \mathrm{mM}(0.25 \mathrm{mM})$. The corresponding $\mathrm{Ca} / \mathrm{P}$ molar ratio in precipitates also dropped from 7.0 to 1.7. This indicates that much more $\mathrm{Ca}$ was used for $\mathrm{P}$ precipitation instead of carbonate precipitation with increased phosphate concentration. Still, the calcium phosphate appears as ACP, as inferred from its XRD pattern (Figure S5.3). No pattern for calcite and brucite can be found in the XRD spectra. This indicates that the increase in $\mathrm{P}$ concentration does inhibit the formation of calcite and brucite. Indeed, in response to the spike of extra $\mathrm{P}$, the SI of calcium phosphate increased whereas the SI of calcium carbonate decreased. For instance, at $\mathrm{pH} 10$, while the $\mathrm{SI}$ of $\mathrm{ACP}_{1}$ increased from $1.3(0.25 \mathrm{mM} \mathrm{P})$ to 2.4 (1.15 mM P), the SI of calcite decreased from 2.3 to 2.2. For brucite, it is not saturated in both conditions $(\mathrm{SI}<0)$. The change of SI by increasing phosphate as to achieve a better stoichiometry favors the precipitation of calcium phosphate instead of calcium carbonate. In this way, the formation of calcite is inhibited dramatically. Therefore, if we deal with a specific type of wastewater (i.e., wastewater from the food industry) that has high $\mathrm{P}$ concentration, we may be able to precipitate more calcium phosphate selectively. Figure S5.4 summarizes the preliminary results in electrochemical P recovery from food wastewater. In comparison to the domestic wastewater, the food wastewater has a much high $\mathrm{P}(1.64 \mathrm{mM})$ but less $\mathrm{Ca}(1.34 \mathrm{mM})$. Because of the low Ca concentration, the removal of $\mathrm{P}$ 
was slightly lower: $32 \%$ (food wastewater) vs $46.5 \%$ (domestic wastewater). However, the absolute amount of recovered $\mathrm{P}$ is much higher: $0.53 \mathrm{mM}$ vs $0.12 \mathrm{mM}$. This gives a $\mathrm{Ca} / \mathrm{P}$ molar ratio of 1.1 in the recovered solids.

Still, the research question is whether $\mathrm{P}$ can be selectively precipitated in raw municipal wastewater at low concentration. As discussed, the formation of ACP occurs because of the lowest thermodynamic solubility product and the highest SI, whereas the precipitation of brucite and calcite is due to the high local $\mathrm{pH}$ and the high availability of lattice ions due to electromigration and buffer reactions. The local $\mathrm{pH}$ can be adjusted by the current density: the higher the current density, the higher the local $\mathrm{pH}$. Besides, the electromigration of ions can be influenced by the current density as well. Consequently, at low current density, we may be able to reduce the formation of calcite and brucite. Indeed, as shown in Figure 5.4, at the lowest current density $\left(1.4 \mathrm{~A} / \mathrm{m}^{2}\right), 41.4 \% \mathrm{P}$ was removed, whereas only $19.2 \% \mathrm{Ca}$ and $10.8 \% \mathrm{Mg}$ were removed. In contrast, at the highest current density $\left(75 \mathrm{~A} / \mathrm{m}^{2}\right)$, while $31.8 \%$ $\mathrm{Ca}$ and $31.4 \% \mathrm{Mg}$ were removed, only $14.3 \% \mathrm{P}$ was removed.

Clearly, although all ions do precipitate simultaneously, the extent of removed ions can be regulated by the applied current density. This gives direction for selectively precipitating calcium phosphate instead of precipitating all ions by increasing the cathode surface and by applying a relatively low current density. In conclusion, though there is no precise precipitation sequence in raw wastewater induced by electrolysis, it is still possible to selectively precipitate calcium phosphate and avoid/reduce the formation of byproducts by choosing suitable operating conditions.

\subsubsection{Implications}

Electrochemical induced phosphate precipitation was proven to be a feasible way to remove and recover $\mathrm{P}$ from real domestic wastewater in a lab-scale study. However, due to the complicated wastewater composition, both product and unwanted byproducts are formed. We showed in this paper that it is possible to selectively precipitate more calcium phosphate (product) than the byproducts. Moreover, the electrochemical P recovery is very adaptable to wastewater compositions. Our preliminary tests on food wastewater also demonstrate the possibility of electrochemical $\mathrm{P}$ recovery from other waste streams. For phosphorus-rich waste streams, selective precipitation of calcium phosphate will be even more possible, as we already showed in this study. One thing that we did not address here is that we found that 
the electrochemical P recovery also contributes to the removal of color, turbidity, and COD of wastewater. This will alleviate the burden of subsequent biological treatment. In addition, the produced $\mathrm{O}_{2}$ and $\mathrm{H}_{2}$ could also be used by the biological process. The remaining challenge, however, is how to integrate the electrochemical system with the conventional wastewater treatment process. Our ideal is to locate the electrochemical $\mathrm{P}$ recovery system in the wastewater treatment system. Our goal is to extract about $50 \%$ of the P from the influent and leave the rest $50 \%$ for biomass reproduction which will be removed by the excess sludge. On top of this, it is even possible to combine the electrochemical system with conventional biological wastewater treatment by developing a bioelectrochemical system, in which efficient wastewater treatment and phosphorus recovery can be achieved simultaneously. 


\section{Supporting information}

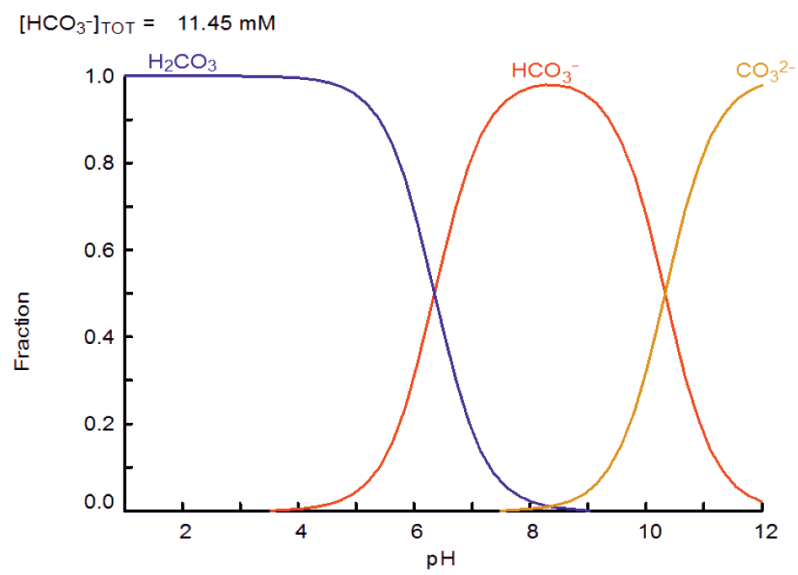

Figure S5.1. The fraction of inorganic carbon species as a function of $\mathrm{pH}$. This is a simplified system where the complexation of inorganic carbon with $\mathrm{Ca}$ was not considered.

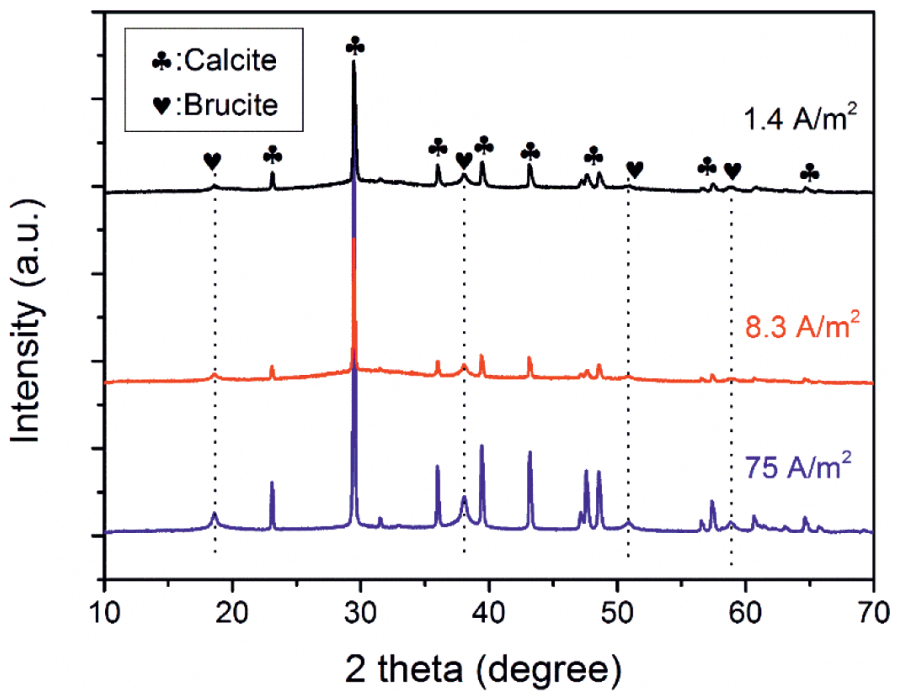

Figure S5.2. XRD patterns of precipitates collected with low, medium and high current densities. Regardless of the current density, the precipitates are dominated by calcite and brucite. 


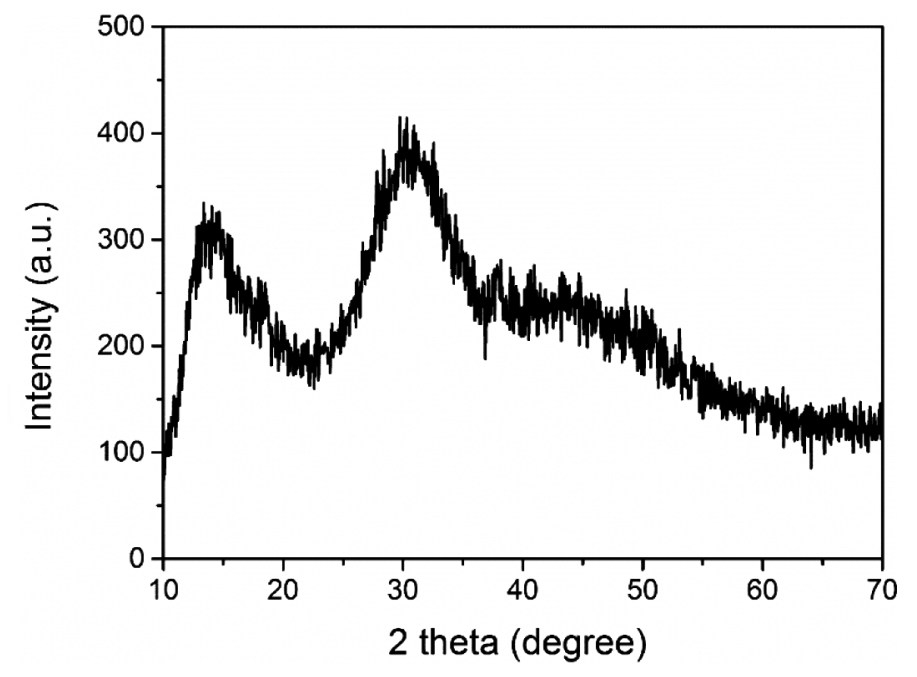

Figure S5.3. XRD pattern of precipitates collected with high P concentration (1.15 mM). The broaden peaks indicate the formation of amorphous calcium phosphate. 


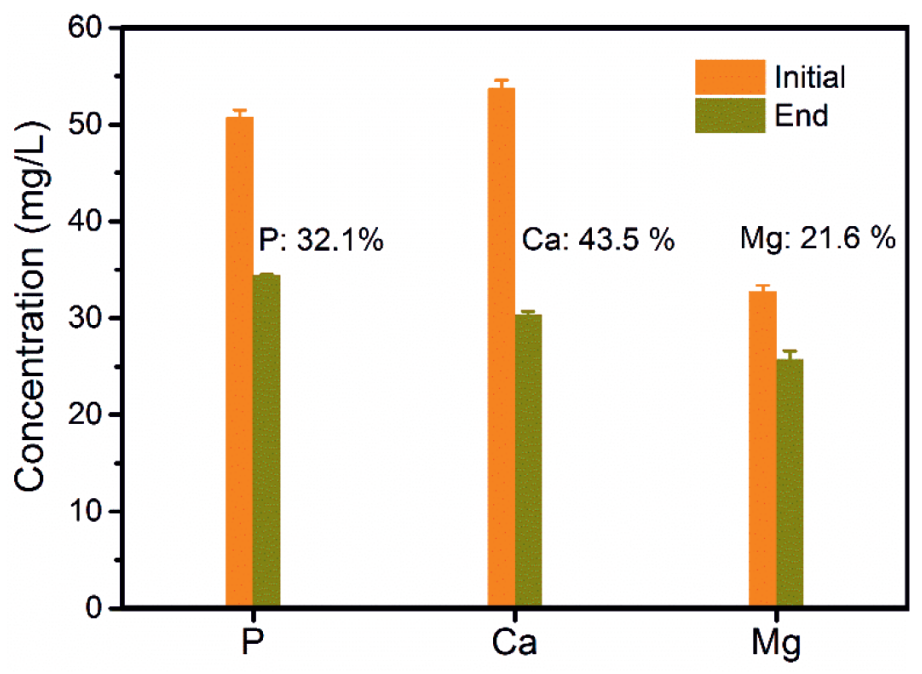

Figure S5.4. The removal of $\mathrm{P}, \mathrm{Ca}$ and $\mathrm{Mg}$ in electrochemical phosphorus recovery from food wastewater. The wastewater was from a potato processing company. Conditions: electrolysis time $=24 \mathrm{~h}$; current density $=8.3 \mathrm{~A} / \mathrm{m}^{2}$; anode: $\mathrm{Pt}-\mathrm{Ti}$; cathode: $\mathrm{Ti}\left(36 \mathrm{~cm}^{2}\right)$; electrode distance $=3 \mathrm{~cm}$. 
Table S5.1. Main composition of the raw wastewater (influent) in WWTP Leeuwarden, the Netherlands.

\begin{tabular}{ccccc}
\hline parameter & value & standard dev. & unit & $\mathbf{m M}$ \\
\hline inorganic carbon & 137.4 & 5.8 & $\mathrm{mg} / \mathrm{L}$ & 11.5 \\
organic carbon & 39.9 & 3.8 & $\mathrm{mg} / \mathrm{L}$ & 3.3 \\
$\mathrm{Ca}^{2+}$ & 75 & 1.1 & $\mathrm{mg} / \mathrm{L}$ & 1.87 \\
$\mathrm{Mg}^{2+}$ & 26.8 & 0.4 & $\mathrm{mg} / \mathrm{L}$ & 1.1 \\
$\mathrm{NH}_{4}^{+}$ & 66.4 & 1.8 & $\mathrm{mg} / \mathrm{L}$ & 3.69 \\
$\mathrm{Na}^{+}$ & 299 & 2.8 & $\mathrm{mg} / \mathrm{L}$ & 13 \\
$\mathrm{~K}^{+}$ & 23.6 & 0.6 & $\mathrm{mg} / \mathrm{L}$ & 0.6 \\
$\mathrm{P}_{-} \mathrm{PO}_{4}{ }^{3-}$ & 7.7 & 0.3 & $\mathrm{mg} / \mathrm{L}$ & 0.25 \\
$\mathrm{SO}_{4}^{2-}$ & 29.7 & 1.0 & $\mathrm{mg} / \mathrm{L}$ & 0.31 \\
$\mathrm{NO}_{3}^{-}$ & $<0.1$ & $\mathrm{~N} / \mathrm{A}$ & $\mathrm{mg} / \mathrm{L}$ & $\mathrm{N} / \mathrm{A}$ \\
$\mathrm{NO}_{2}^{-}$ & $<0.1$ & $\mathrm{~N} / \mathrm{A}$ & $\mathrm{mg} / \mathrm{L}$ & $\mathrm{N} / \mathrm{A}$ \\
$\mathrm{Cl}^{-}$ & 337.7 & 5.0 & $\mathrm{mg} / \mathrm{L}$ & 9.5 \\
$\mathrm{pH}^{-}$ & 8.1 & 0.1 & $\mathrm{~N} / \mathrm{A}$ & $\mathrm{N} / \mathrm{A}$ \\
\hline
\end{tabular}


Table S5.2. Supersaturation index (SI) of unsaturated species in the raw wastewater in response to different bulk solution $\mathrm{pH}$ of $8-12$.

\begin{tabular}{ccccccc}
\hline \multirow{2}{*}{ mineral } & formula & \multicolumn{5}{c}{$\mathrm{pH}$} \\
\cline { 3 - 6 } & & 8 & 9 & 10 & 11 & 12 \\
\hline brushite & $\mathrm{CaHPO}_{4} \cdot 2 \mathrm{H}_{2} \mathrm{O}$ & -0.5 & -0.7 & -1.3 & -2.2 & -3.1 \\
monetite & $\mathrm{CaHPO}_{4}$ & -0.3 & -0.4 & -1.0 & -1.9 & -2.9 \\
struvite & $\mathrm{MgNH}_{4} \mathrm{PO}_{4} \cdot 6 \mathrm{H}_{2} \mathrm{O}$ & -1.0 & -0.3 & -0.3 & -1.1 & -2.2 \\
bobierrite & $\mathrm{Mg}_{3}\left(\mathrm{PO}_{4}\right)_{2}$ & -3.5 & -1.8 & -0.9 & -0.8 & -1.3 \\
newberyite & $\mathrm{MgHPO}_{4} \cdot 3 \mathrm{H}_{2} \mathrm{O}$ & -1.6 & -1.7 & -1.7 & -3.0 & -4.2 \\
\hline
\end{tabular}




\section{Chapter 6}

\section{Energy efficient phosphorus recovery by microbial electrolysis cell induced calcium phosphate precipitation}

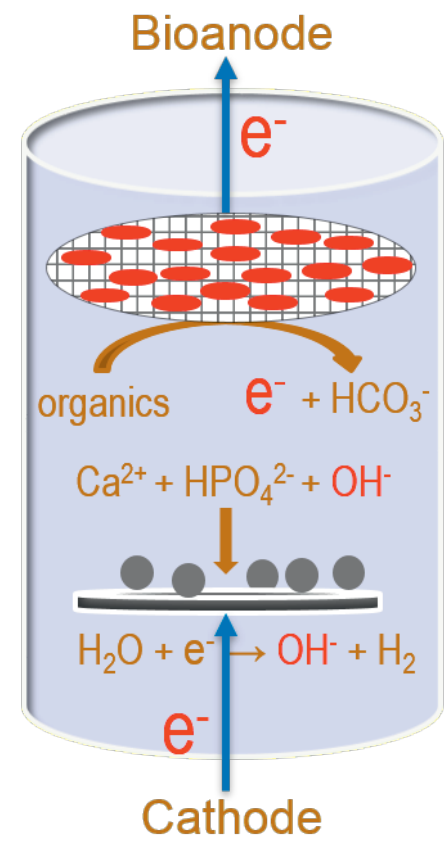

Yang Lei, Mengyi Du, Philipp Kuntke, Michel Saakes, Renata van der Weijden, and Cees J.N. Buisman

This chapter has been published as:

Lei, Yang, Mengyi Du, Philipp Kuntke, Michel Saakes, Renata D. van der Weijden, and Cees J.N. Buisman. "Energy efficient phosphorus recovery by microbial electrolysis cell induced calcium phosphate precipitation" ACS Sustainable Chemistry \& Engineering, 7, no. 9 (2019): 8860-8867. 


\begin{abstract}
Phosphorus (P) removal and recovery from waste streams is essential for a sustainable world. Here, we upgraded a previously developed abiotic electrochemical P recovery system to a bioelectrochemical system. The anode was inoculated with electroactive bacteria (electricigens) which are capable of oxidizing soluble organic substrates and releasing electrons. These electrons are then used for the reduction of water at the cathode, resulting in an increase of $\mathrm{pH}$ close to the cathode. Hence, phosphate can be removed with coexisting calcium ions as calcium phosphate at the surface of the cathode with a much lower energy input. Depending on the available substrate (sodium acetate) concentration, an average current density from $1.1 \pm 0.1$ to $6.6 \pm 0.4 \mathrm{~A} / \mathrm{m}^{2}$ was achieved. This resulted in a P removal of $20.1 \pm 1.5 \%$ to $73.9 \pm 3.7 \%$, a Ca removal of $10.5 \pm 0.6 \%$ to $44.3 \pm 1.7 \%$ and a $\mathrm{Mg}$ removal of $2.7 \pm 1.9 \%$ to $16.3 \pm 3.0 \%$. The specific energy consumption and the purity of the solids were limited by the relative low $\mathrm{P}$ concentration $(0.23 \mathrm{mM})$ in the domestic wastewater. The relative abundance of calcium phosphate in the recovered product increased from $23 \%$ to $66 \%$ and the energy consumption for recovery was decreased from $224 \pm 7 \mathrm{kWh} / \mathrm{kg}$ P to just $56 \pm$ $6 \mathrm{kWh} / \mathrm{kg} \mathrm{P}$ when treating wastewater with higher P concentration $(0.76 \mathrm{mM})$. An even lower energy demand of $21 \pm 2 \mathrm{kWh} / \mathrm{kg} \mathrm{P}$ was obtained with a platinized cathode. Our results highlight the promising potential of bioelectrochemical P recovery from P-rich waste streams.
\end{abstract}


Energy efficient phosphorus recovery by microbial electrolysis cell induced calcium phosphate precipitation

\subsection{Introduction}

Use of phosphorus fertilizer is crucial for securing food production for the increasing world population [1]. However, due to the linear flow of phosphorus from ore, fertilizer products to farms, lakes, and many types of waste streams [7], there is an increasing concern about the potential shortage of phosphorus resources [1,22]. At the same time, the discharge of phosphorus containing streams results in the eutrophication of receiving water bodies $[7,10]$. This broken cycle of phosphorus calls for phosphorus removal and recovery [10]. In this context, enhanced biological phosphorus removal, adsorption and chemical precipitation have emerged as efficient ways for phosphorus removal [22]. In all processes, insoluble or less soluble phosphate salts are recovered as the product. Among these phosphate products, calcium phosphate, which is similar in composition to phosphate rock, can be used as a new raw material for the fertilizer industry [29].

Phosphorus recovery as calcium phosphate has been studied in a large variety of wastewater, but mostly in concentrated phosphorus streams [31, 69, 114, 131]. Few studies deal with wastewater that has a medium or low concentration of phosphorus, for example, domestic wastewater [132]. We recently showed that during electrochemical treatment, the coexisting cations (i.e., $\mathrm{Ca}^{2+}$ ) and anions (i.e., phosphate) in the domestic wastewater form precipitates on the surface of cathode, without adding any chemicals to the system [32]. This provided an excellent way for extracting phosphorus from sewage. Though the concentration of phosphorus in the influent of WWTP is relatively low $\left(5-10 \mathrm{mg} \mathrm{L}^{-1}\right)$, the volume of sewage is huge (135-150 L per capital per day) and therefore, phosphorus in domestic wastewater can be an important source for phosphorus recycling [47]. The added benefits of electrochemical phosphorus recovery are that COD, turbidity and color of the wastewater were simultaneously reduced as well. The disadvantage, however, is that this process is energy intensive.

In this regard, bioelectrochemical systems appear as promising alternatives for the abiotic electrochemical systems [133]. In a typical bioelectrochemical system, electroactive microbes grow as firm biofilms on the anode and serve as biocatalysts [133-135]. Electrons are released during the oxidation of organics by the electroactive bacteria and transferred to the anode $[134,135]$. The electrons can be used to reduce water molecules at the cathode, resulting in an increase of local $\mathrm{pH}$ near the cathode surface $[65,66,136,137]$. It was reported 
that the $\mathrm{pH}$ in the vicinity of cathode increases to 10 while bulk $\mathrm{pH}$ is 7 [138]. Due to the increase of local $\mathrm{pH}$, the soluble calcium phosphate species becomes supersaturated and forms a solid species on the surface of the cathode, as in abiotic electrochemical systems [32, 89].

The advantages of using a bioanode are substantial. First, the energy needed for electrochemical phosphorus recovery is significantly reduced $[40,65,66,136,137]$. The oxidation potential for sodium acetate $(\mathrm{NaAc})$, which is a typical substrate used in bioelectrochemical systems, is $-0.278 \mathrm{~V}$ (vs NHE), which is $1.1 \mathrm{~V}$ lower than abiotic water oxidation (0.817 V, vs NHE), under standard conditions [139]. Second, the use of a bioanode avoids the formation of chlorine at the anode which is an issue in abiotic electrochemical systems [44]. Chlorine, once produced, can result in the formation of chlorinated organic compounds that are extremely toxic $[44,140]$.

Bioelectrochemical systems have been widely used in wastewater treatment for resource recovery and energy production $[61,133,141,142]$. The early work of Ichihashi and Hirooka $[136,137]$ and Roland et al. [66] proved the possibility of bioelectrochemical phosphorus recovery, relying on either artificial wastewater or on concentrated phosphate streams and ion selective membranes. The first simple chamber microbial electrolysis cell (MEC) for phosphorus recovery was developed and tested with artificial wastewater by Roland and Logan [65]. Yuan and Kim [40] extended the application of MEC in a simple cell with improved cathode configurations, yet still in concentrated solutions. In addition, all the reported studies focused on struvite $\left(\mathrm{MgNH}_{4} \mathrm{PO}_{4} \cdot 6 \mathrm{H}_{2} \mathrm{O}\right)$ as the product. In this context, due to the lack of magnesium $(\mathrm{Mg})$ in the wastewater relative to phosphate and ammonium [28], the supply of $\mathrm{Mg}$ source was essential in all these studies. This hinders the further adoption of bioelectrochemical phosphorus recovery, though it shows great potential. We are not aware of any study with MEC focusing at producing calcium phosphate as the recovered product.

Inspired by the successful demonstration of electrochemical phosphorus recovery as calcium phosphate $[89,110,119,120]$, we studied the possibility of energy reduction by upgrading the abiotic electrochemical system to a bioelectrochemical system. This proof of principle, the efficiency of bioelectrochemical system and its relation to substrate concentration and the composition of recovered products were systematically investigated. 


\subsection{Materials and methods}

\subsubsection{Electrodes}

The bioanode was made of a platinum coated $\left(20 \mathrm{~g} \mathrm{~m}^{-2}\right)$ Ti mesh in the form of a disk (Pt $-\mathrm{Ti}, 80 \mathrm{~mm} \varnothing$ ) and a piece of graphite felt (thickness of $3 \mathrm{~mm}$, FMI Composites Ltd., Galashiels, Scotland) connected to the Pt-Ti disk. We used Pt wire to fix the graphite felt to the mesh $\mathrm{Pt}$-Ti disk. On top of the bioanode, a $120 \mathrm{~mm}$-long Pt - Ti rod (3 mm Ø) was welded to the center of the bioanode. The cathode was made of Ti plate (grade one, $6 \times 6$ $\mathrm{cm})$. The $\mathrm{Pt}-\mathrm{Ti}$ current collector and the Ti cathode were provided by MAGNETO Special Anodes BV (The Netherlands).

\subsubsection{Reactor design, start-up and operation}

The reactor has the same design as the abiotic electrochemical cell that we used previously [120]. The difference is that we replaced the abiotic anode with a bioanode. Figure 6.1 illustrates the configuration of the MEC.

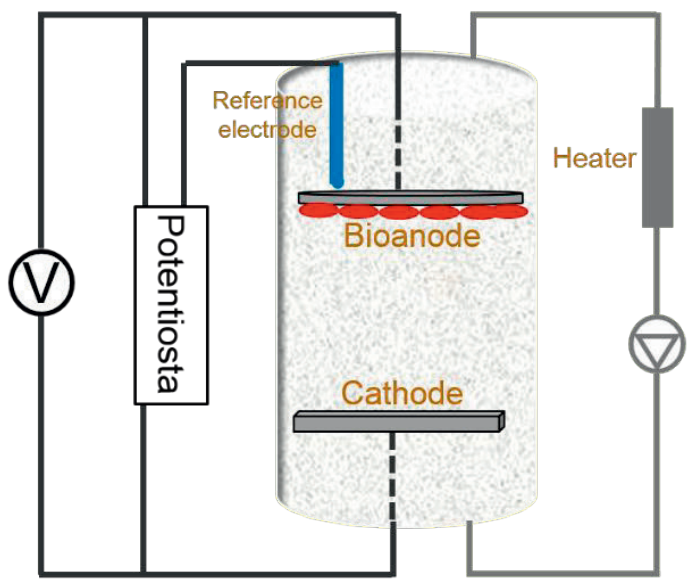

(A)

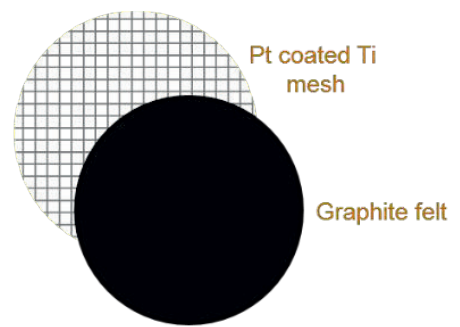

(B)

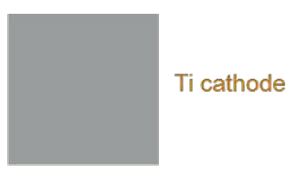

(C)

Figure 6.1. (A) Configuration of the microbial electrolysis cell, (B) components and the materials of the bioanode and (C) cathode. Both electrodes were welded to (platinum coated) titanium rods for connection. The graphite felt and the platinum-coated titanium mesh were fixed with platinum wire.

The MEC is operated in a three-electrode system, with the bioanode as the working electrode and the cathode as the counter electrode. A reference electrode $(\mathrm{Ag} / \mathrm{AgCl}, 0.210 \mathrm{~V}$ vs SHE, 
QM713X, ProSense B.V.) was placed close to the bioanode. The bioanode potential was controlled at $-0.35 \mathrm{~V}$ by a potentiostat (Vertex, Ivium Technologies, The Netherlands), which is slightly higher than the oxidation potential of $\mathrm{NaAc}(>100 \mathrm{mV}$ overpotential under typical experimental conditions) to provide electroactive bacteria with a competitive advantage over methanogens [143]. The average overpotential was about $190 \mathrm{mV}$ under the applied condition at the start of the experiments. In this paper, all potentials were reported related to the $\mathrm{Ag} / \mathrm{AgCl}$ reference electrode. The bioanode and the cathode were located on the top and bottom of the electrochemical cell at a distance of $10 \mathrm{~mm}$. The reactor temperature was maintained at $29.5 \pm 0.5^{\circ} \mathrm{C}$ using a thermostat. Initially, the electrochemical cell was inoculated with artificial wastewater, containing $1 \mathrm{~mL} / \mathrm{L}$ trace element solution and the following: $0.82 \mathrm{~g} / \mathrm{L} \mathrm{CH}_{3} \mathrm{COONa}, 0.74 \mathrm{~g} / \mathrm{L} \mathrm{KCl}, 0.58 \mathrm{~g} / \mathrm{L} \mathrm{NaCl}, 3.4 \mathrm{~g} / \mathrm{L} \mathrm{KH}_{2} \mathrm{PO}_{4}, 4.35 \mathrm{~g} / \mathrm{L}$ $\mathrm{K}_{2} \mathrm{HPO}_{4}, 0.28 \mathrm{~g} / \mathrm{L} \mathrm{NH}_{4} \mathrm{Cl}, 0.1 \mathrm{~g} / \mathrm{L} \mathrm{MgSO}_{4} \cdot 7 \mathrm{H}_{2} \mathrm{O}$ and $0.1 \mathrm{~g} / \mathrm{L} \mathrm{CaCl}_{2} \cdot 2 \mathrm{H}_{2} \mathrm{O}$ [144]. The biomass used for inoculation was collected from an active microbial rechargeable battery cell [145]. The reactor was operated in fed-batch mode with regular replacement of substrate (typically every $24 \mathrm{~h}$ ). The working volume of the bioreactor was $900 \mathrm{~mL}$. The solution in the reactor was mixed by a peristaltic pump at a flow rate of $60 \mathrm{~mL} \mathrm{~min}{ }^{-1}$. After inoculation within 3 days, the system started to produce a positive current. After 2 weeks, the bioanode was completely covered by a visible red biomass. In the meantime, reproducible current was recorded (see Figure 6.2). Then, experiments with real domestic wastewater (with additional $\mathrm{NaAc}$ ) were performed. The wastewater was sampled from a local wastewater treatment plant (Leeuwarden, The Netherlands). The main composition of the wastewater is shown in Table S6.1. Each experiment lasted for $24 \mathrm{~h}$. In this period, the current and the cell voltage between the working and the counter electrode were recorded. Liquid samples before and after $24 \mathrm{~h}$ treatment were taken for analysis. In some cases, the time was extended to 48 and $72 \mathrm{~h}$ and samples were also taken. At least four repetitions were performed, and the mean and standard deviation of the collected data are reported.

\subsubsection{Analysis}

We used ICP-AES (Optima 5300 DV, PerkinElmer) to quantify the concentration of soluble calcium $(\mathrm{Ca})$, phosphorus $(\mathrm{P})$, and magnesium $(\mathrm{Mg})$. We applied the standard cuvette test (LCK114, Hach Company) to measure the concentration of chemical oxygen demand (COD). We quantified the concentrations of cations $\left(\mathrm{Na}^{+}, \mathrm{NH}_{4}^{+}\right)$and anions (chloride, sulfate, nitrate, and nitrite) with ion chromatography (IC, Compact IC 761, Metrohm). We analyzed the total 
organic carbon and inorganic carbon by a TOC-LCPH analyzer equipped with an ASI-L auto sampler (Shimadzu). Prior to ICP-AES and IC analysis, samples were filtered with $0.45 \mu \mathrm{m}$ membrane filter. The qualification of solid phases was achieved with $\mathrm{X}$-ray Powder Diffraction (XRD, Bruker) using $\mathrm{Cu} \mathrm{K} \alpha$ radiation. Details about the information on XRD can be found in a previous publication [120].

\subsubsection{Calculations.}

The average produced current and cell voltage in each experiment for different $\mathrm{NaAc}$ concentration was calculated with MATLAB. Prior to the calculations, the curve fitting for both the recorded current and the cell voltage were performed to meet the prerequisite of integral. The MATLAB function "spline" was used to fit the curves and the "integral" function was applied to solve integral through area measurement. The current density $\left(\mathrm{A} \mathrm{m}^{-2}\right)$ was defined by the average current and the projected surface area of the cathode $\left(36 \mathrm{~cm}^{2}\right)$.

The Coulombic efficiency (CE) was defined as the ratio between the produced charge and the theoretical charge released by the oxidation of substrate (eq 6.1):

$$
\mathrm{CE}(\%)=100 \times \frac{8 \int \mathrm{Idt}}{\mathrm{FV} \Delta \mathrm{COD}}
$$

I is the electric current (A), $\mathrm{F}$ is the Faraday constant $\left(96485 \mathrm{C} \mathrm{mol}^{-1}\right), \mathrm{V}$ is the volume of the reactor $(0.9 \mathrm{~L}), \Delta \mathrm{COD}(\mathrm{g} / \mathrm{L})$ is the removed COD in one fed-batch cycle, the factor 8 is the quotient from the molecular weight of oxygen $\left(32 \mathrm{~g} \mathrm{~mol}^{-1}\right)$ and amount of electrons transferred per mole of oxygen (4).

The electric energy consumption $\left(W_{\mathrm{E}}\right)$ was calculated by eq $\mathbf{6 . 2}$ :

$$
W_{E}=\int_{0}^{\mathrm{t}} I U \mathrm{dt}
$$

Where $U$ is the recorded cell voltage $(\mathrm{V})$.

The anode overpotential was calculated as the difference between the applied anode potential and the theoretical anode potential $\left(\eta_{\text {anode }}=E_{\text {anode, measured }}-E_{\text {anode, theoretical }}\right)$ [135]. 


\subsection{Results and discussion}

\subsubsection{Current production and COD conversion.}

Before evaluating the efficiency of bioelectrochemical system, it is necessary to check if the MEC could work properly, which can be evaluated by the produced current. Figure 6.2 shows the current production in relation to the NaAc concentration in the MEC.

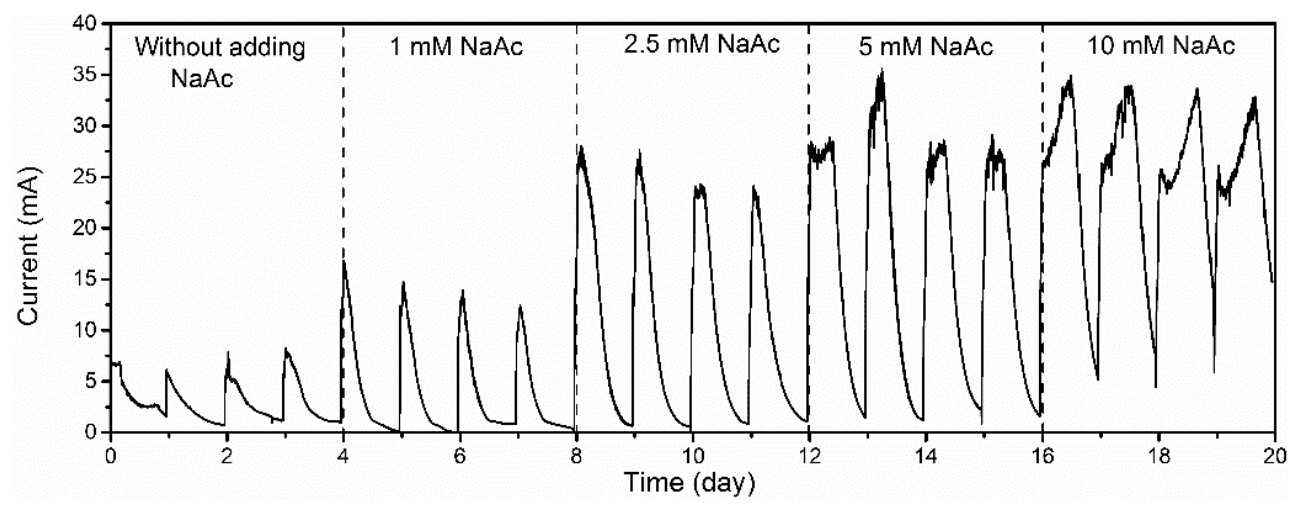

Figure 6.2. Current production as a function of sodium acetate $(\mathrm{NaAc})$ concentration. Overall, the current curve was reproducible among the four fed batch cycles. Conditions: bioanode potential, $-0.35 \mathrm{~V}$, distance between electrodes, $1 \mathrm{~cm}$, batch cycle time, $24 \mathrm{~h}$.

Without adding external substrate, the MEC produces positive current, which suggests that the bioanode can oxidize the organics in the domestic wastewater and produce electricity. The average current in $24 \mathrm{~h}$ produced without adding $\mathrm{NaAc}$ is $3.0 \pm 0.2 \mathrm{~mA}$, corresponding to a current density of $0.84 \pm 0.1 \mathrm{~A} \mathrm{~m}^{-2}$. It should be noted that without adding additional substrate the domestic wastewater should be fresh domestic wastewater. With stored wastewater, the current density recorded was very low. This is because the easily biodegradable COD was consumed by the microbes originating from the wastewater even though we stored the wastewater in a $4{ }^{\circ} \mathrm{C}$ fridge. In Figure S6.1, the initial COD decrease over the storage period is shown. Because of this, additional COD (as NaAc) was added at the start of each experiment.

Figure S6.2 summarizes the removal of COD, current density and Coulombic efficiency in relation to $\mathrm{NaAc}$ concentration. With $1 \mathrm{mM} \mathrm{NaAc}$ added to the stored raw wastewater, the initial COD is $128 \pm 8 \mathrm{mg} \mathrm{L}^{-1}$, and with $10 \mathrm{mM} \mathrm{NaAc}$, the initial COD increases to $640 \pm 34$ $\mathrm{mg} \mathrm{L}^{-1}$. The removal of COD also increases from $45.7 \pm 3.4 \%$ at $1.0 \mathrm{mM} \mathrm{NaAc}$ to the highest 
$(79.8 \pm 2.0 \%)$ at $10 \mathrm{mM} \mathrm{NaAc}$. In response to the increased NaAc dosage and COD conversion, the current production also increases. As can be seen from Figure 6.2, the current curve is reproducible for the four tests. At the beginning the current starts to increase immediately after we turn on the potentiostat and the peak current occurs within $1 \mathrm{~h}$ and then starts to slowly decrease, resulting from the decrease of available substrate. With increasing $\mathrm{NaAc}$ concentration, the observed current peak shifts in time, for instance, at a concentration of $10 \mathrm{mM} \mathrm{NaAc}$, the current peak was observed at $12 \mathrm{~h}$. The calculated average current density in $24 \mathrm{~h}$ is $1.1 \pm 0.2 \mathrm{~A} \mathrm{~m}^{-2}$ with $1.0 \mathrm{mM} \mathrm{NaAc}$. The value increases to $2.7 \pm 0.3$ with $2.5 \mathrm{mM} \mathrm{NaAc}$ and further to $4.4 \pm 0.2$ with $5.0 \mathrm{mM} \mathrm{NaAc}$, reaching the highest current density of $6.6 \pm 0.4 \mathrm{~A} \mathrm{~m}^{-2}$ at $10 \mathrm{mM} \mathrm{NaAc}$. However, in terms of CE, an overall decreasing trend was observed with increasing NaAc concentration from $54.7 \pm 12.9 \%$ at $2.5 \mathrm{mM}$ to $36.4 \pm 2.5 \%$ at $10 \mathrm{mM}$. Such a trend was seen previously [146]. There are multiple reasons for the low CE. First of all, the presence of alternative electron acceptors (i.e., sulfate or $\mathrm{O}_{2}$ ) will lower the Coulombic efficiency. Indeed, in the presence of $10 \mathrm{mM} \mathrm{NaAc}$, we found that the sulfate concentration decreased by $62.3 \pm 6.3 \%$. This is accompanied by the formation of dark precipitates in the circulation tubes, which may be due to metal sulfide formation. Secondly, methanogens may compete with the electricigens to produce methane, especially in excess of $\mathrm{NaAc}[143]$.

\subsubsection{Bioelectrochemical phosphorus removal}

Associated with the current production in the MEC, the concentration of soluble phosphorus decreased and the higher the NaAc concentration, the higher the removal of phosphorus (P) and also calcium $(\mathrm{Ca})$ and magnesium $(\mathrm{Mg})$. The $\mathrm{P}$ removal was dependent on the substrate conversion to electricity, since precipitation was induced by the increase of local $\mathrm{pH}$, as we confirmed in the abiotic system [89]. The reduction of water molecules at the cathode of the $\mathrm{MEC}$, resulting in hydrogen production, led to a local high $\mathrm{pH}$ compared to the bulk solution. We have also seen the increase in $\mathrm{P}$ removal with increasing current density in our previous experiments with the abiotic system [119]. 


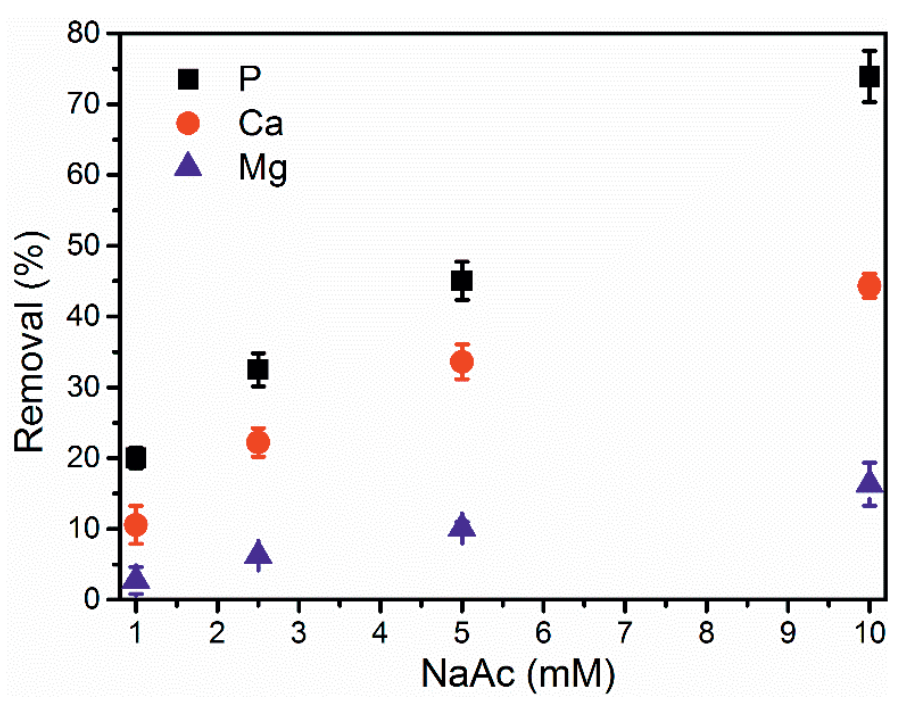

Figure 6.3. Removal percentage of $\mathrm{Ca}, \mathrm{Mg}$ and $\mathrm{P}$ as a function of sodium acetate (NaAc) concentration in the microbial electrolysis cell. Conditions: bioanode potential, $-0.35 \mathrm{~V}$; distance between electrodes, $1 \mathrm{~cm}$; electrolysis time, $24 \mathrm{~h}$.

During experiments with the MEC, the removal efficiency of $\mathrm{P}$ was around $20 \%$ with 1.0 $\mathrm{mM}$ NaAc added (Figure 6.3). At the same time, 11\% Ca and 3\% $\mathrm{Mg}$ were removed. With $2.5 \mathrm{mM} \mathrm{NaAc}$, the P removal efficiency increased by $12 \%$, which was accompanied by an increase of $10 \%$ for $\mathrm{Ca}$ and $3 \%$ for $\mathrm{Mg}$. Likewise, the removal of $\mathrm{P}, \mathrm{Ca}$, and $\mathrm{Mg}$ increased proportionally with $5.0 \mathrm{mM} \mathrm{NaAc}$. At $10 \mathrm{mM} \mathrm{NaAc}$, nearly $74 \% \mathrm{P}, 44 \% \mathrm{Ca}$, and $16 \% \mathrm{Mg}$ were removed from the wastewater. The P recovery performance was poor (about 9\%) without adding $\mathrm{NaAc}$ even with fresh wastewater (data not shown). This is because, although the initial total COD of fresh wastewater is $271 \pm 8.6 \mathrm{mg} / \mathrm{L}$, the soluble COD $(100 \pm 1.2 \mathrm{mg} / \mathrm{L})$ is low. As a result, the average current density generated with fresh wastewater is just $0.84 \pm$ $0.1 \mathrm{~A} \mathrm{~m}^{-2}$ which is lower than that of adding $1.0 \mathrm{mM} \mathrm{NaAc}\left(1 \pm 0.2 \mathrm{~A} \mathrm{~m}^{-2}\right)$.

In response to the removal of ions in the bulk solution, precipitates were seen on the counter electrode (cathode), as seen in the abiotic electrochemical system [32, 89, 119]. The precipitates were characterized with XRD (Figure 6.4A) to determine the solid phases. 


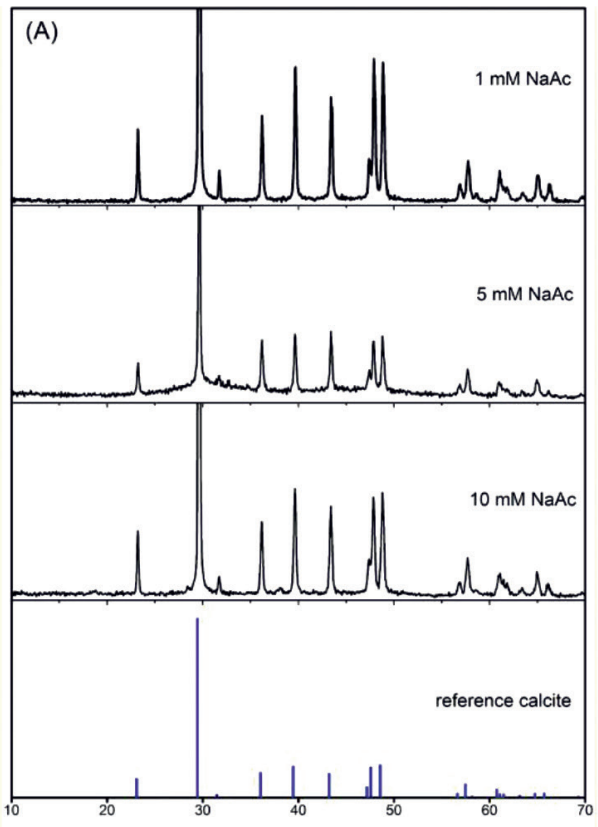

(B)

Heated precipitates

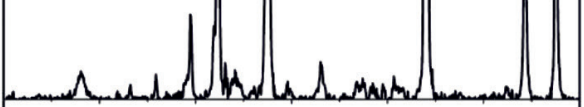

$\mathrm{CaO}$
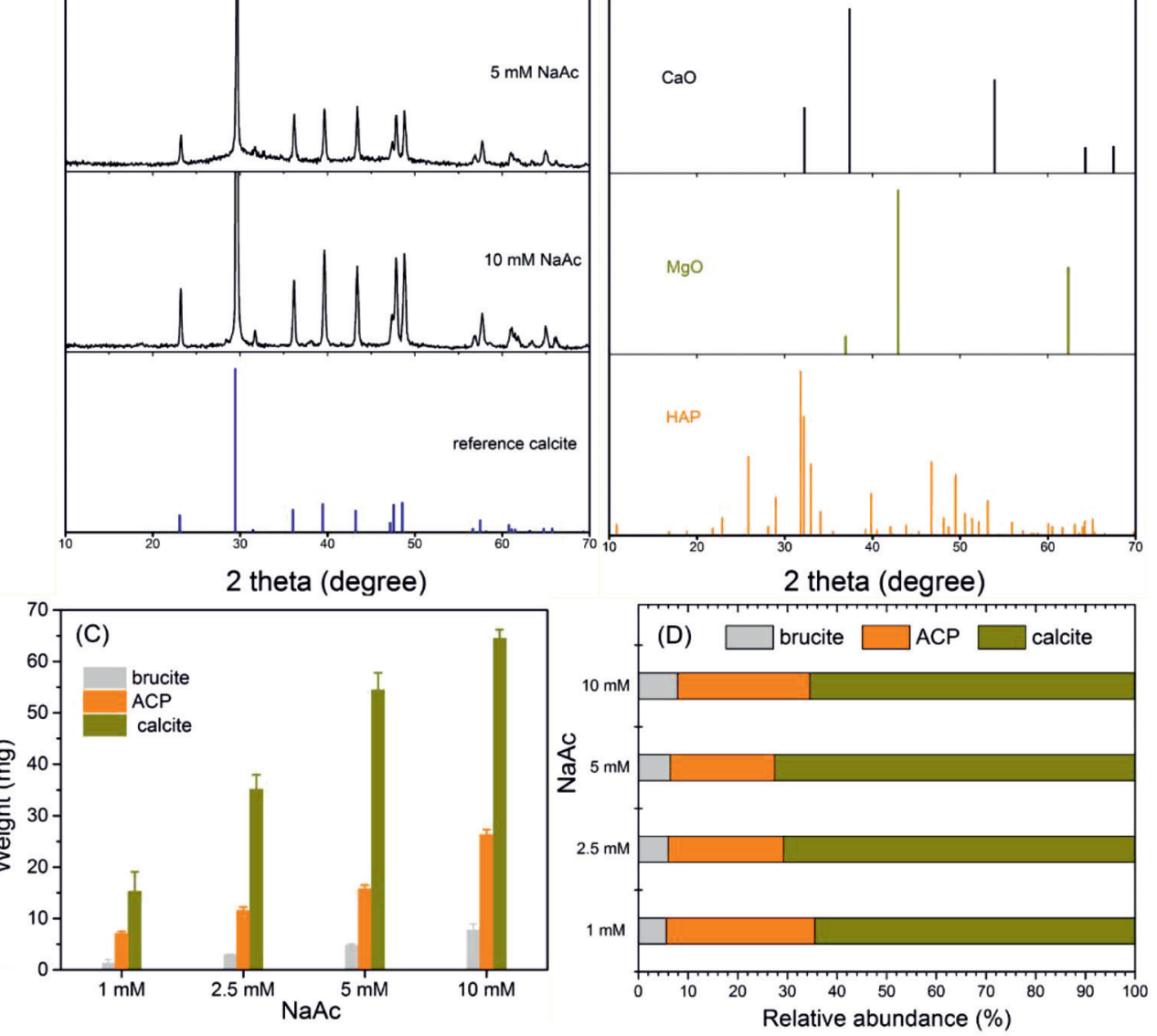

Figure 6.4. (A) XRD pattern of solids collected in the presence of different sodium acetate (NaAc) concentration, (B) XRD pattern of selected samples after heating treatment, the heated samples were collected in the presence of $10 \mathrm{mM} \mathrm{NaAc},(\mathrm{C})$ amount and (D) the relative abundance of brucite $\left(\mathrm{Mg}(\mathrm{OH})_{2}\right)$, amorphous calcium phosphate (ACP) and calcite $\left(\mathrm{CaCO}_{3}\right)$.

For the precipitates formed under different NaAc dosing, all XRD spectra show a good match with calcite $\left(\mathrm{CaCO}_{3}\right)$. This indicates that the precipitates were predominantly $\mathrm{CaCO}_{3}$, while the calcium phosphate was in an amorphous phase [32]. The removal of $\mathrm{Mg}$ as brucite $\left(\mathrm{Mg}(\mathrm{OH})_{2}\right)$, which could also be formed, is highly dependent on the current density [32]. At 
low concentration of $\mathrm{NaAc}(1-5 \mathrm{mM})$, the XRD pattern of brucite cannot be identified in the samples taken from the bioelectrochemical system. The removal efficiency of $\mathrm{Mg}$ was just $2.7 \pm 1.9 \%$ with $1 \mathrm{mM} \mathrm{NaAc}\left(1.1 \pm 0.2 \mathrm{~A} \mathrm{~m}^{-2}\right)$. After we increased the dosage of NaAc to $10 \mathrm{mM}$, the generated current increased, and this resulted in an increase in $\mathrm{Mg}$ removal. Nearly $16 \% \mathrm{Mg}$ was removed in the presence of $10 \mathrm{mM} \mathrm{NaAc}\left(6.6 \pm 0.4 \mathrm{~A} \mathrm{~m}^{-2}\right)$. In this case, typical peaks of brucite at $2 \theta=38^{\circ}$ and $18.6^{\circ}$ were found in the XRD pattern (Figure 6.4A). To investigate the amorphous calcium phosphate (ACP) content, the precipitates collected in the presence of $10 \mathrm{mM} \mathrm{NaAc}$ were heated at $550{ }^{\circ} \mathrm{C}$ for $2 \mathrm{~h}$ and then characterized with XRD. In this way, the organic substances can be removed, and the amorphous phase may recrystallize to a crystalline phase. Indeed, as shown in Figure 6.4B, the XRD pattern of the heated samples matched with hydroxyapatite (HAP), $\mathrm{MgO}$, and $\mathrm{CaO}$. The XRD characterization of solids before and after heating treatment confirmed the precipitates as a mixture of ACP, calcite, and brucite, which is consistent with the composition of solids recovered in the abiotic electrochemical system [32].

Based on our previous calculation approach [147], we estimated the different quantities of precipitates (Figure 6.4C) and the relative abundance of the three species in the products (Figure 6.4D) as a function of NaAc concentration. The amount of all three species increased with the increase of NaAc concentration. Nonetheless, regardless of the NaAc dosage, the precipitates consisted of more than $65 \%$ of calcite and the relative abundance of ACP was just around $20 \%$. The low content of ACP is explained by the much lower phosphorus concentration in comparison to bicarbonate which results in the dominant calcite formation [32].

\subsubsection{Phosphorus removal in one fed-batch test with extended time}

In the abiotic system, we saw a clear increase of phosphorus removal efficiency with the increase of electrolysis time. However, in the biotic system, the removal efficiency of phosphorus decreased with extended microbial electrolysis time. In the presence of $10 \mathrm{mM}$ $\mathrm{NaAc}$, the concentration of phosphorus decreased from $7.0 \pm 0.1$ to $1.7 \pm 0.3 \mathrm{mg} \mathrm{L}^{-1}$ in $24 \mathrm{~h}$ (Figure 6.5A). Then, the $\mathrm{P}$ concentration increased to $3.6 \pm 0.1 \mathrm{mg} \mathrm{L}^{-1}$ within $48 \mathrm{~h}$ and further increased to $5.6 \pm 0.1 \mathrm{mg} \mathrm{L}^{-1}$ in $72 \mathrm{~h}$. 
Energy efficient phosphorus recovery by microbial electrolysis cell induced calcium phosphate precipitation
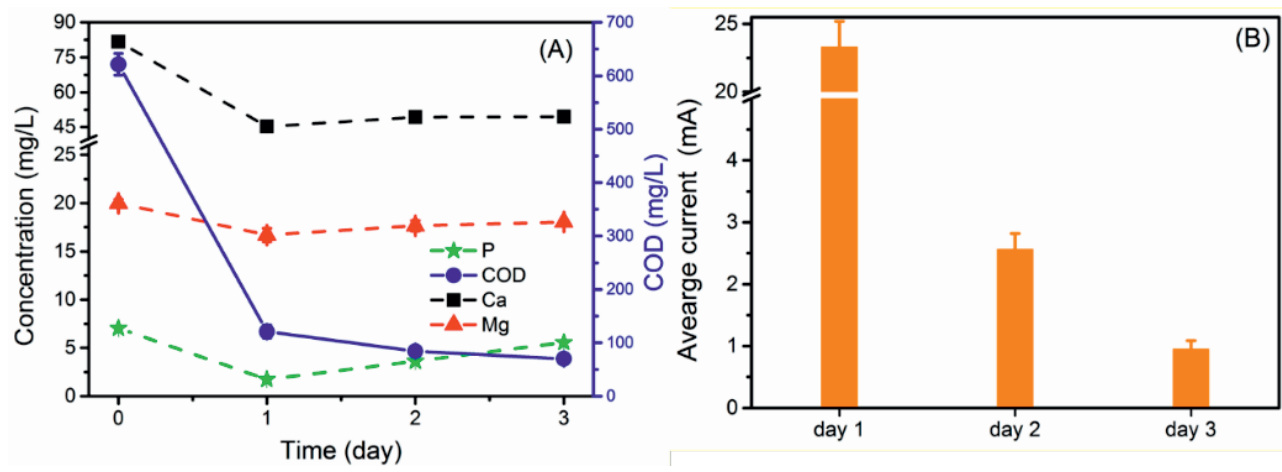

Figure 6.5. (A) Concentrations of $\mathrm{Ca}, \mathrm{P}$, and $\mathrm{Mg}$ and (B) the average current each day over a three-day batch test. Conditions: $10 \mathrm{mM} \mathrm{NaAc}$; bioanode potential, $-0.35 \mathrm{~V}$; distance between electrodes, $1 \mathrm{~cm}$.

We also observed similar trends for $\mathrm{Ca}$ and $\mathrm{Mg}$, but these were less obvious. This was probably due to the dissolution of initial precipitates, which results in the increase of $\mathrm{P}, \mathrm{Ca}$, and $\mathrm{Mg}$ concentrations in the bulk solution. These changes of ions concentration in the wastewater were connected to the depletion of COD in the wastewater and the associated decrease in current density during operation of the bioelectrochemical system over the three days experimental period. The COD decreased from $622 \pm 20$ to $121 \pm 12 \mathrm{mg} \mathrm{L}^{-1}$ within 24 h (Figure 6.5A). Due to the degradation of COD, the output current of the MEC decreased significantly (Figure 6.5B). While the average current on the first day was $23.3 \pm 2.0 \mathrm{~mA}$ $\left(6.5 \pm 0.5 \mathrm{~A} \mathrm{~m}^{-2}\right)$, the average current in the second day and the third day were just $2.6 \pm 0.3$ $\mathrm{mA}\left(0.71 \pm 0.07 \mathrm{~A} \mathrm{~m}^{-2}\right)$ and $1.0 \pm 0.1 \mathrm{~mA}\left(0.26 \pm 0.04 \mathrm{~A} \mathrm{~m}^{-2}\right)$. The precipitation of calcium phosphate and other solid species on the cathode surface is induced by the local high $\mathrm{pH}$ resulting from the (microbial) electrolysis process. Therefore, when the available organic substances were depleted by the electroactive bacteria, the microbial electrolysis process will come to a halt. As a result, the local high $\mathrm{pH}$ cannot be maintained. Therefore, the precipitates will dissolve, accompanied by the increase of ions concentration in the bulk solution. We previously tested the dissolution of precipitates in open circuit in abiotic systems [147]. It was found that only when the bulk solution $\mathrm{pH}$ was acidic, the initial precipitates dissolve. Under alkaline conditions, the precipitates did not dissolve. We measured the bulk solution $\mathrm{pH}$ after $24 \mathrm{~h}, 48 \mathrm{~h}$ and $72 \mathrm{~h}$, which are 7.7, 8.1 and 8.0, respectively. Overall, the bulk solution $\mathrm{pH}$ in the MEC was quite stable. This was due to the presence of bicarbonate, which 
acts as buffer in the wastewater. In addition, the degradation of $\mathrm{NaAc}$ also results in the formation of bicarbonate (eq 6.3).

$$
\mathrm{CH}_{3} \mathrm{COO}^{-}+4 \mathrm{H}_{2} \mathrm{O} \rightarrow 2 \mathrm{HCO}_{3}^{-}+9 \mathrm{H}^{+}+8 \mathrm{e}^{-}
$$

From the point of bulk solution $\mathrm{pH}$, the precipitates should not dissolve. The different behavior of solids in the abiotic system and the biotic system may be explained in several ways. First of all, though the precipitates are a mixture of calcite, brucite and ACP in both systems (biotic and abiotic), the exact composition may still be different. The collected ACP in the biotic system might have a different structure compared to the ACP from the abiotic system, which might lead to a different stability of the amorphous phase. Preliminary leaching tests (Figure S6.4) indicate a higher P concentration in the bulk media $\left(1.28 \mathrm{mg} \mathrm{L}^{-1}\right.$ ) from the biotic precipitates than that of the abiotic precipitates $\left(0.294 \mathrm{mg} \mathrm{L}^{-1}\right)$ when the solids were mixed with deionized water. Furthermore, the presence of organic matters might also influence the stability of initial precipitates [148]. These mechanisms might explain the dissolution of precipitates when the substrate concentration was not able to maintain the high local $\mathrm{pH}$. However, we do not have solid conclusions at this moment, and this interesting difference between abiotic and biotic systems calls for further investigation.

\subsubsection{Phosphorus removal at increased phosphate concentration}

As discussed earlier, the relative abundance of ACP in the precipitates was low. Calcite accounts for the largest proportion in the precipitates. This was probably due to the excess of bicarbonate in the wastewater $(10.1 \mathrm{mM}$ vs $0.23 \mathrm{mM} \mathrm{P})$. In addition, the consumption of $\mathrm{NaAc}$, as mentioned earlier, will add bicarbonate to the system. We previously showed in abiotic systems that a high concentration of phosphorus can enhance calcium phosphate precipitation and inhibit calcium carbonate precipitation [32]. In order to investigate the performance of bioelectrochemical system toward wastewaters with higher P content, we performed tests by spiking extra phosphate (in the form of $\mathrm{Na}_{2} \mathrm{HPO}_{4}$ ) to raise the $\mathrm{P}$ concentration to $0.76 \mathrm{mM}$. The COD removal, the generation of current, and the removal efficiency of ions were similar to the case without spiking phosphorus (Table 6.1). 
Table 6.1. Comparison of COD conversion, ions removal and current density in low and high phosphorus concentration.

\begin{tabular}{|c|c|c|c|c|c|c|}
\hline \multicolumn{2}{|c|}{ concentration $(\mathrm{mM})$} & \multicolumn{4}{|c|}{ removal (\%) } & \multirow{2}{*}{$\begin{array}{l}\text { aver current density } \\
\qquad\left(\mathrm{A} / \mathrm{m}^{2}\right)\end{array}$} \\
\hline phosphorus & NaAc & COD & $\mathbf{C a}$ & Mg & $\mathbf{P}$ & \\
\hline 0.23 & 5 & $\begin{array}{c}74.8 \pm \\
2.8\end{array}$ & $\begin{array}{c}33.6 \pm \\
2.4\end{array}$ & $\begin{array}{c}10.1 \pm \\
0.9\end{array}$ & $\begin{array}{c}45.1 \pm \\
2.7\end{array}$ & $4.4 \pm 0.2$ \\
\hline 0.76 & 5 & $\begin{array}{c}74.9 \pm \\
1.5\end{array}$ & $\begin{array}{c}31.9 \pm \\
1.3\end{array}$ & $\begin{array}{c}16.2 \pm \\
1.3\end{array}$ & $\begin{array}{c}43.8 \pm \\
1.3\end{array}$ & $4.0 \pm 0.2$ \\
\hline
\end{tabular}

However, the characterization of solids by XRD indicated that the relative contribution of components shifted. The XRD spectrum of solids collected in the presence of $0.76 \mathrm{mM} \mathrm{P}$ was dominated by a broad peak around $30^{\circ}$ (Figure S6.3) instead of a clear pattern for calcite (Figure 6.4A). The broad peak is typically seen for ACP $[89,120]$. Similar to the case of $0.23 \mathrm{mM} P$ (without spiking), the raw XRD pattern fails to identify the presence of brucite due to the small amount of brucite in the precipitates. When the solids were subjected to heating treatment, the new XRD pattern was dominated by hydroxyapatite (Figure S6.3), which supports the assumption that the initial form was mostly ACP.

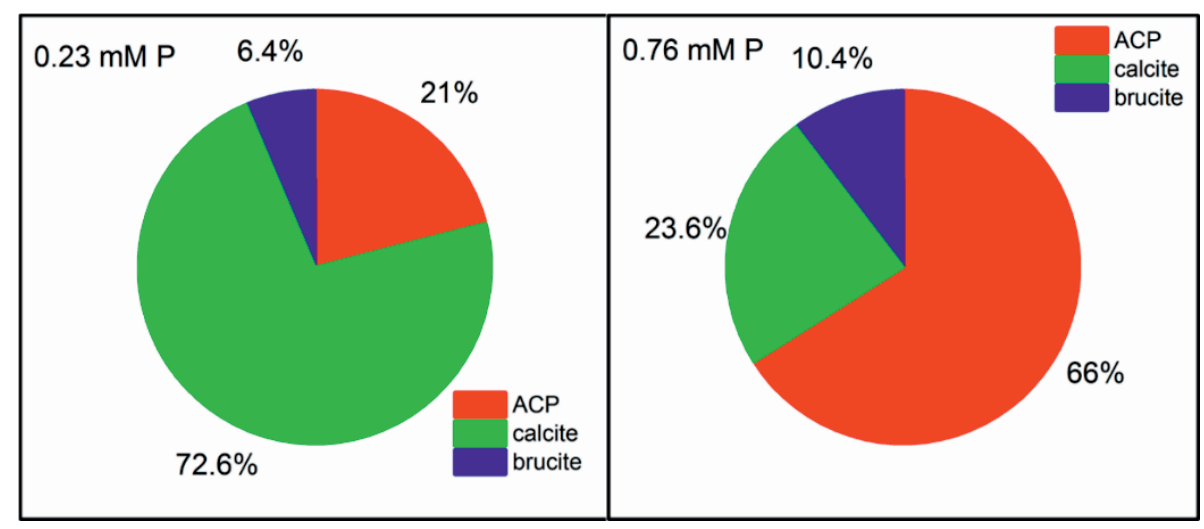

Figure 6.6. Relative abundance of calcite, brucite, and amorphous calcium phosphate (ACP) in the presence of $0.23 \mathrm{mM}$ and $0.76 \mathrm{mM}$ phosphorus. 
Figure 6.6 shows the relative abundance of ACP, calcite, and brucite in the solids obtained from the wastewater with $0.76 \mathrm{mM}$ P. In comparison to the wastewater with lower $\mathrm{P}$ concentration $(0.23 \mathrm{mM} \mathrm{P})$, the relative abundance of ACP increased from $21 \%$ to $66 \%$, whereas the relative abundance of calcite decreased from $73 \%$ to $24 \%$. Without supplying extra $\mathrm{P}$, only $22 \%$ of the removed Ca formed precipitates with phosphate. At a concentration of $0.76 \mathrm{mM} \mathrm{P}, 73 \%$ of the removed Ca was used for ACP formation. This indicated that the increase of phosphate concentration reduced calcium carbonate formation in the bioelectrochemical system, which is in line with the results in the abiotic system [32].

Thermodynamically, calcium phosphate species are less soluble than calcium carbonate, and in the wastewater, the precipitation of calcium phosphate has a higher driving force than calcium carbonate [32]. However, in the wastewater, the $\mathrm{Ca} / \mathrm{P}$ molar ratio was too high; therefore, there was $\mathrm{Ca}$ available for calcium carbonate formation. When extra phosphate was supplied, more Ca was used for ACP formation. While it is unrealistic to dose phosphate to the wastewater, there are other types of wastewater that contain high concentrations of phosphate, for instance, food wastewater [114]. Therefore, it might be possible to produce high purity calcium phosphate from phosphorus-rich waste streams with bioelectrochemical phosphorus recovery process.

\subsubsection{Energy consumption}

We found the bioelectrochemical system has good potential to recover phosphorus from waste streams at relatively low energy cost depending on the phosphorus concentration, availability of substrate, and electrode material. The specific energy cost (as $\mathrm{kWh} / \mathrm{kg} \mathrm{P}$ ) increased with the added NaAc concentration. With $1 \mathrm{mM} \mathrm{NaAc}$, although the P removal efficiency was relatively low ( $20 \%$ ), the cell voltage was low as well, due to the low output current density. The low cell voltage compensates for the low $\mathrm{P}$ removal and results in the lowest energy consumption of $69 \pm 14 \mathrm{kWh} / \mathrm{kg}$ P (Figure 6.7), with the regular cathode (Ti) and regular $\mathrm{P}$ concentration $(0.23 \mathrm{mM})$. 


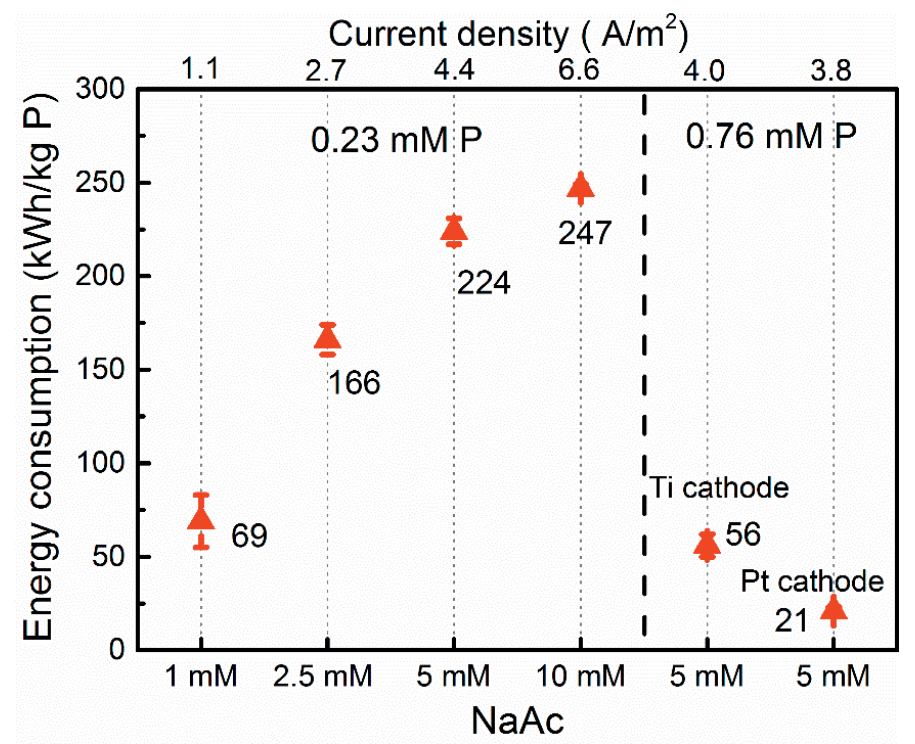

Figure 6.7. Specific energy consumption as a function of sodium acetate (NaAc) concentration, phosphorus concentration and electrode material, expressed in $\mathrm{kWh}$ per $\mathrm{kg}$ phosphorus.

This energy consumption was comparable to a fluidized bed cathode MEC that had a cathode and bioanode compartment separated by membranes, which was $65 \pm 5 \mathrm{kWh} / \mathrm{kg} \mathrm{P}$ [66]. In comparison to the single cell that was reported by Yuan and Kim [40], which had an energy consumption of $109 \mathrm{kWh} / \mathrm{kg}$ P with the addition of NaAc (calculated from the reported 13.8 $\mathrm{kWh} / \mathrm{kg}$ struvite), our energy consumption was relatively low. However, with increased NaAc concentration, the specific energy cost increased, reaching the highest $(247 \pm 2 \mathrm{kWh} / \mathrm{kg}$ $\mathrm{P})$ at $10 \mathrm{mM} \mathrm{NaAc}$. This suggests the increased current production was not matched by $\mathrm{P}$ removal [66]. It should be emphasized that the previous reported results produced struvite from phosphorus-rich solutions (1.5-4.5 mM P) [40, 141]. In our system, with $5 \mathrm{mM} \mathrm{NaAc}$ and increased phosphorus concentration $(0.76 \mathrm{mM})$, the energy consumption dropped from $224 \pm 7$ to just $56 \pm 6 \mathrm{kWh} / \mathrm{kg}$ P. In principle, the energy input of the (bio)electrochemical system is affected by the internal resistance, the half reaction at working electrode and the counter electrode. The use of a bioanode can reduce the minimum required cell voltage for hydrogen production, due to the lower equilibrium voltage of the bioelectrochemial system $(0.14 \mathrm{~V})$ compared to the electrochemical system (1.23 V) [135]. The most energy intensive loss here, if we did not consider the ionic losses, is the overpotential of water reduction at the 
cathode. By using a Pt-coated Ti cathode, the average cell voltage was reduced from $1.56 \pm$ $0.05 \mathrm{~V}$ for the regular cathode (Ti plate) to $0.82 \pm 0.01 \mathrm{~V}$. Due to the decrease of cell voltage, the energy cost further decreased from $56 \pm 6 \mathrm{kWh} / \mathrm{kg}$ P to $21 \pm 2 \mathrm{kWh} / \mathrm{kg}$ P. If we assume an electricity price of $0.09 € / \mathrm{kWh}$, the P recovery cost would be $1.92 \pm 0.21 € / \mathrm{kg}$ P. Such low cost would make this process very competitive, even compared to mined phosphorus, which lies in $1-2 € / \mathrm{kg} P$ [149].

\subsection{Outlook}

We demonstrated that phosphorus in domestic wastewater $(\mathrm{P}=0.23 \mathrm{mM})$ and wastewaters with higher $\mathrm{P}$ up to $0.76 \mathrm{mM}$ can be recovered as calcium phosphate in an energy-efficient way by applying MEC. In line with the abiotic system, ACP, brucite, and calcite were formed as precipitates on the cathode surface. However, the removal of $\mathrm{Mg}$ was relatively low compared to the abiotic electrochemical system, since the current density obtained was much lower compared to the current density applied in our abiotic system. Therefore, the use of a bioelectrochemical system can reduce the formation of brucite. However, to reduce $\mathrm{CaCO}_{3}$ content in the solids, it is necessary to target a wastewater that has relative high phosphorus concentration. Both the purity and the energy consumption were substantially reduced at higher levels of phosphate, simulated by spiking $\mathrm{P}$ to the domestic wastewater. We found that the formed precipitates dissolved when the output current decreases, due to the depletion of substrate, while in the abiotic system they remained. Yet, we are unable to provide a clear explanation for this. We propose further research on understanding the difference between abiotic and biotic precipitates and avoiding the dissolution of initial precipitates. 


\section{Supporting information}

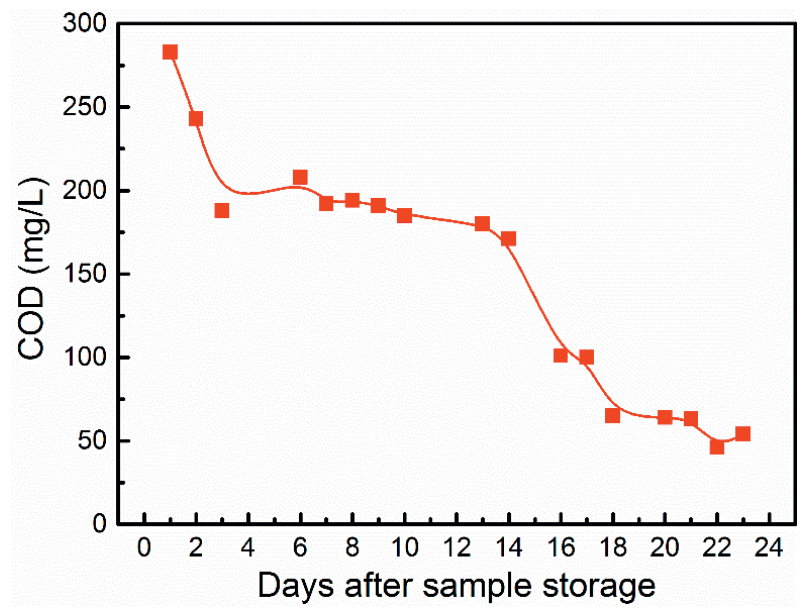

Figure S6.1. Monitoring of wastewater COD indicated the wastewater COD decreased during the storage at $4{ }^{\circ} \mathrm{C}$. Therefore, the experiments were performed after 3 weeks of storage when the COD is relative stable and sodium acetate in different concentrations was added as COD source.
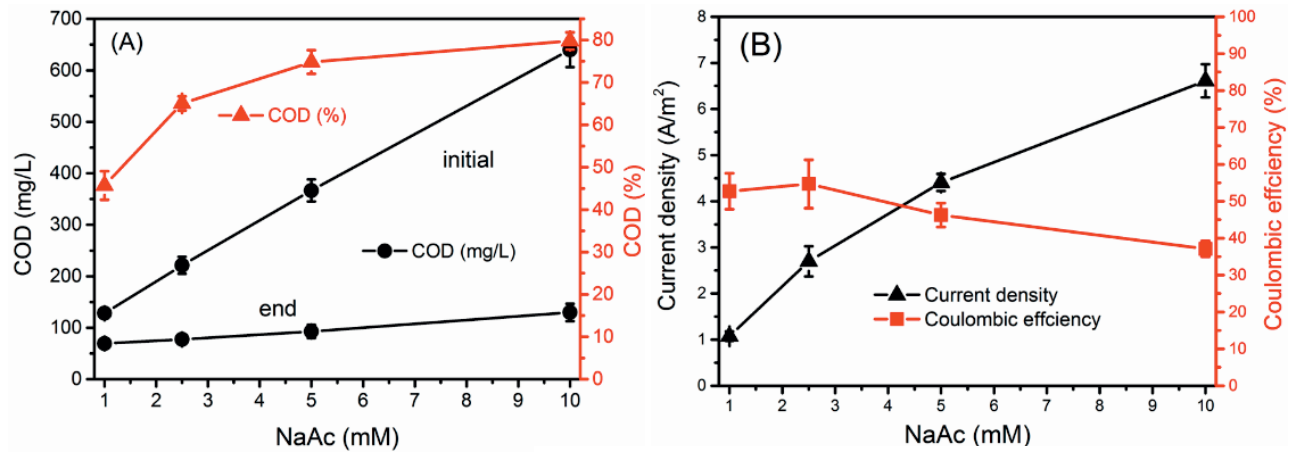

Figure S6.2. (A) Performance of COD conversion in the microbial electrolysis cell, (B) average current density and coulombic efficiency for different sodium acetate (NaAc) concentration. Conditions: bioanode potential $-0.35 \mathrm{~V}$; electrode distance, $1 \mathrm{~cm}$, microbial electrolysis time $24 \mathrm{~h}$. 


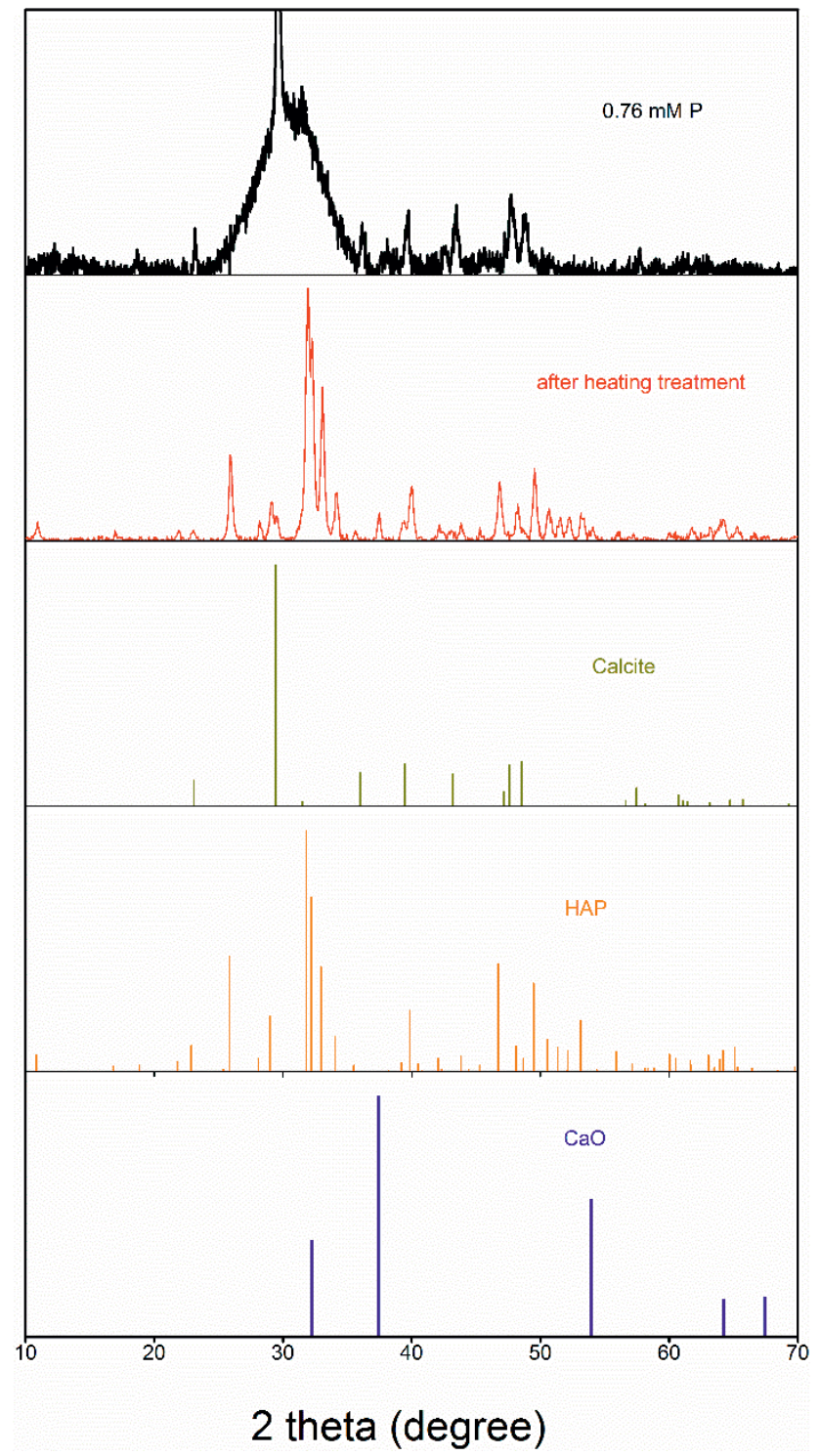

Figure S6.3. XRD pattern of solids collected in the presence of $0.76 \mathrm{mM}$ P before and after heating treatment at $550^{\circ} \mathrm{C}$ for $2 \mathrm{~h}$. 


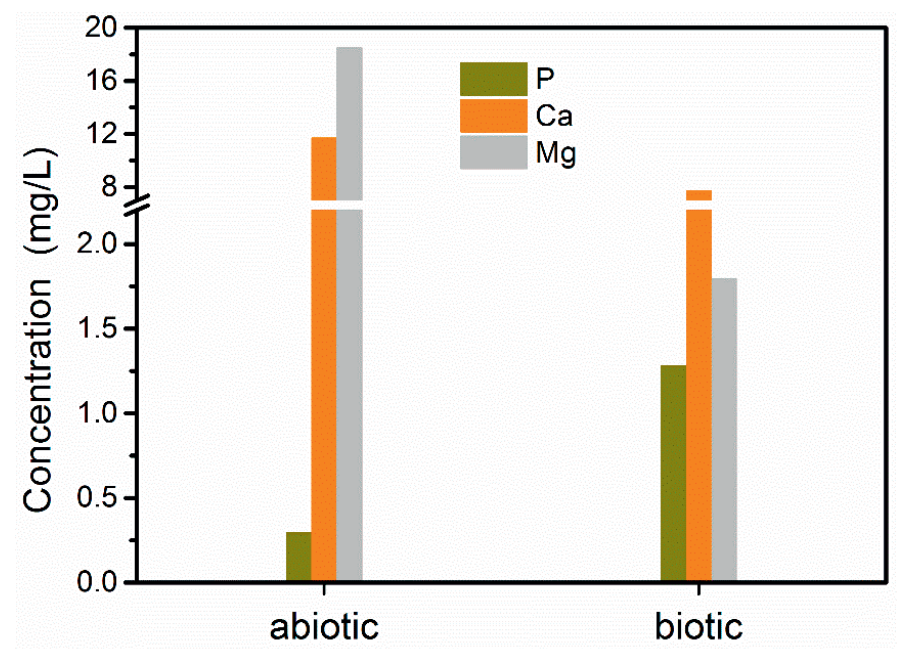

Figure S6.4. Leaching test of abiotic and biotic precipitates. We weighted similar amounts of abiotic precipitates $(0.0212 \mathrm{~g})$ and biotic precipitates $(0.022 \mathrm{~g})$ and mixed these precipitates with $10 \mathrm{~mL}$ deionized water in tubes. The tubes were shaken in a table shaker over three days at $150 \mathrm{rpm}$. Then samples were taken to analyze the soluble $\mathrm{Ca}, \mathrm{Mg}$ and $\mathrm{P}$ concentrations. 
Table S6.1. The main composition of the raw wastewater ${ }^{a}$ (influent) in wastewater treatment plant (Leeuwarden, the Netherlands).

\begin{tabular}{cccc}
\hline parameter & value & standard dev. & unit \\
\hline inorganic carbon & 120.7 & 1.6 & $\mathrm{mg} / \mathrm{L}$ \\
organic carbon & 71.8 & 1.5 & $\mathrm{mg} / \mathrm{L}$ \\
$\mathrm{Ca}^{2+}$ & 81.0 & 1.9 & $\mathrm{mg} / \mathrm{L}$ \\
$\mathrm{Mg}^{2+}$ & 19.5 & 0.5 & $\mathrm{mg} / \mathrm{L}$ \\
$\mathrm{P}^{2 \mathrm{PO}_{4}{ }^{3-}}$ & 7.0 & 0.3 & $\mathrm{mg} / \mathrm{L}$ \\
$\mathrm{NH}_{4}^{+}$ & 51.9 & 0.8 & $\mathrm{mg} / \mathrm{L}$ \\
$\mathrm{K}^{+}$ & 21.3 & 0.1 & $\mathrm{mg} / \mathrm{L}$ \\
$\mathrm{Na}^{+}$ & 249.3 & 15 & $\mathrm{mg} / \mathrm{L}$ \\
$\mathrm{SO}_{4}{ }^{2-}$ & 26.5 & 0.1 & $\mathrm{mg} / \mathrm{L}$ \\
$\mathrm{Cl}^{-}$ & 213 & 8.1 & $\mathrm{mg} / \mathrm{L}$ \\
$\mathrm{COD}^{-}$ & 236 & 2.8 & $\mathrm{mg} / \mathrm{L}$ \\
$\mathrm{pH}^{2}$ & 7.5 & 0.2 & $\mathrm{~N} / \mathrm{A}$ \\
\hline
\end{tabular}

${ }^{a}$ : the sampled wastewater was filtered with a $250 \mu \mathrm{m}$ sieve to remove suspended solids. 


\section{Chapter 7}

\section{Electrochemical removal of phosphate in the presence of calcium at low current density: precipitation or adsorption?}

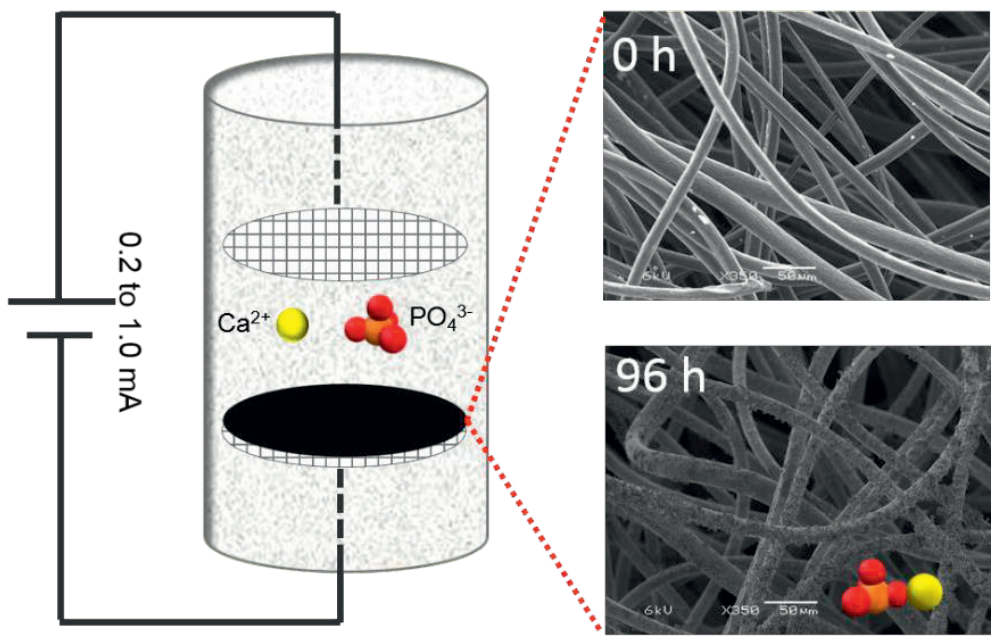

Yang Lei, Emilio Geraets, Michel Saakes, Renata D. van der Weijden and Cees J. N. Buisman

This chapter has been published as:

Lei, Yang, Emilio Geraets, Michel Saakes, Renata D. van der Weijden, and Cees J.N. Buisman. "Electrochemical removal of phosphate in the presence of calcium at low current density: precipitation or adsorption?"

Water Research, 169 (2020): 115207. 


\begin{abstract}
Phosphorus removal and recovery from waste streams are crucial to prevent eutrophication and sustain fertilizer production. As has been shown in our previous papers, electrochemical treatment has the potential to achieve this goal. However, the adoption of electrochemical approach is limited by its high energy consumption. Here, we investigate the possibility of electrochemical phosphorus removal at extremely low current density using graphite felt as the cathode. We found a current density as low as $0.04 \mathrm{~A} / \mathrm{m}^{2}$ can enhance the removal of phosphate in our electrochemical system. The removal of phosphate at extremely low current density resulted from electrochemical induced calcium phosphate precipitation and not by electrochemical adsorption. Electrochemical treatment of real domestic wastewater at 0.2 $\mathrm{A} / \mathrm{m}^{2}$ almost eliminates the precipitation of $\mathrm{Mg}(\mathrm{OH})_{2}$ and limits the formation of $\mathrm{CaCO}_{3}$. The recovered precipitates are dominated by calcium phosphate $(59 \%)$, followed by $35 \% \mathrm{CaCO}_{3}$ and $6 \% \mathrm{Mg}(\mathrm{OH})_{2}$. The specific energy consumption of this newly electrochemical system is between 4.4 and $26.4 \mathrm{kWh} / \mathrm{kg} \mathrm{P}$, which is 2 orders of magnitude lower than our previous system (110 to $2238 \mathrm{kWh} / \mathrm{kg} \mathrm{P}$ ). Key factors for this improvement prove to be enlarged precipitation area and hydroxide flux retardation by graphite felt. Practically, our study offers a potential way to reduce the energy consumption in electrochemical removal of phosphate by using a graphite felt cathode and at a current density below $0.2 \mathrm{~A} / \mathrm{m}^{2}$. Fundamentally, our study contributes to the understanding of adsorption and precipitation in electrochemical removal of phosphate at an extremely low current density and with carbon-based electrodes.
\end{abstract}




\subsection{Introduction}

Phosphorus (P) is a vital nutrient in the global food production chain. Typically, $35.2 \mathrm{~kg}$ of phosphate rock is required to sustain one person per year [16]. Unfortunately, although uncertainty remains in terms of the size and the projected exhaustion date of $\mathrm{P}$ reserves [46], its geographical concerns may cause a potential $\mathrm{P}$ crisis for the majority of countries who heavily depend on importing P fertilizer [10]. This, taken together with the strict legislative target to reduce $\mathrm{P}$ concentration to an ultra-low level to avoid eutrophication, makes it essential to recover and reuse the $\mathrm{P}$ in waste streams [10].

Enhanced biological phosphorus removal, adsorption, and precipitation are well-established methods for P removal $[21,22]$. In most cases, $\mathrm{P}$ is removed from wastewaters by forming insoluble or less soluble phosphate minerals. Among these minerals, calcium phosphate stands out because calcium phosphate precipitation can be achieved without dosing external calcium ions, as most natural and engineered aquatic systems have a favorable stoichiometric ratio for calcium phosphate formation [32]. In addition, calcium phosphate is a preferred raw material for the fertilizer industry [29].

Conventionally, calcium phosphate precipitation in wastewaters can be achieved at increased $\mathrm{pH}(>9)$ and/or increased concentration of calcium ions [124]. In this approach, however, calcium and phosphate ions precipitate as sludge and have inadequate settling performance [150]. Hence, an extra solid-liquid separation process (i.e., centrifugation) is required. Moreover, wastewater $\mathrm{pH}$ needs to be lowered with dosing acid to satisfy the discharge standard $(6<\mathrm{pH}<9)[32]$. To overcome these limitations, an electrochemical precipitation approach was proposed and validated by Lei and coauthors [32, 89]. The principle of this electrochemical approach is that a local high $\mathrm{pH}$ environment is created by water electrolysis close to the cathode [89]. As such, the precipitation of calcium phosphate occurs solely at the cathode surface. Efficient precipitation of calcium phosphate was found in alkaline, neutral and acidic solutions, even in the presence of buffers, thanks to the high local $\mathrm{pH}[89,120]$.

However, the real adoption of this approach is limited by the high energy consumption, which is due to the applied relatively high current density and the low specific surface area of the used titanium plate cathode $[32,151]$. We found that in electrochemical recovery of phosphate from domestic wastewater, it is not only calcium phosphate that forms, calcite $\left(\mathrm{CaCO}_{3}\right)$ and brucite $\left(\mathrm{Mg}(\mathrm{OH})_{2}\right)$ also form as byproducts [32, 147, 151]. Additionally, high 
current density $\left(>20 \mathrm{~A} / \mathrm{m}^{2}\right)$ results in relatively more precipitation of calcite and brucite than calcium phosphate $[147,151]$. In contrast, a larger cathode area favors the selective precipitation of calcium phosphate [32]. Therefore, a possible solution to overcome the low energy efficiency in our electrochemical P recovery is to operate the system with a very low current density and a much larger specific surface area. In this context, carbon-based materials, i.e., graphite felt, which has a large specific surface area [152] seems to be a better alternative than the titanium plate as cathode. Interestingly, the combination of graphite felt and low current density $\left(<0.2 \mathrm{~A} / \mathrm{m}^{2}\right)$ falls in the current density region of capacitive deionization (CDI). CDI is a process where ions are adsorbed either at the cathode or anode depending on their charge when an electric voltage difference is applied between both electrodes [153].

Nonetheless, we do not know yet whether electrochemical P removal can be achieved at a current density below $0.2 \mathrm{~A} / \mathrm{m}^{2}$. The lowest current density we have tested was $1.4 \mathrm{~A} / \mathrm{m}^{2}$ [32]. And if yes, what is the mechanism? Is it precipitation or adsorption, or are both processes involved?

To answer these questions, we performed systematic studies on electrochemical P removal at extremely low current density using a graphite felt cathode and in the presence of calcium ions. This study aims to identify the possibility of electrochemical P removal at extremely low current density with improved cathode configuration and the associated removal mechanisms. The findings in this study may contribute to the development of an energy efficient electrochemical approach for P removal and recovery that uses no chemicals and produce a pure solid product.

\subsection{Material and methods}

\subsubsection{Chemicals}

$\mathrm{Ca}\left(\mathrm{NO}_{3}\right)_{2} \cdot 4 \mathrm{H}_{2} \mathrm{O}$ (as the source of $\mathrm{Ca}^{2+}$ ) was acquired from Merck (Germany). $\mathrm{Na}_{2} \mathrm{HPO}_{4}$ (as the source of phosphate) and $\mathrm{Na}_{2} \mathrm{SO}_{4}$ (as electrolyte) were received from VWR (Belgium). All solutions were prepared with deionized water (Merck Millipore, Germany).

\subsubsection{Setup}

An overview of the schematic of the setup is shown in Figure S7.1. The electrochemical cell is same as the one we used previously [120]. The anode is a platinum $(\mathrm{Pt})$ coated titanium 138 
(Ti) mesh (Ø $\left.8 \mathrm{~cm}, 20 \mathrm{~g} \mathrm{Pt} / \mathrm{m}^{2}\right)$ disk (named as Pt-Ti) to which, a 12-cm Pt-Ti rod $(\varnothing 0.3 \mathrm{~cm})$ was perpendicularly welded. The cathode is a combination of the same material as the anode material with a piece of graphite felt $(\varnothing 8 \mathrm{~cm}$, thickness of $0.3 \mathrm{~cm}$, FMI Composites Ltd., Galashiels, Scotland). The graphite felt was fixed on the Pt-Ti disk by Pt wires. The electrochemical cell was operated in a three-electrode configuration, with the graphite felt combined Pt-Ti disk (named as GF-Pt-Ti) as the working electrode (cathode), Pt-Ti mesh disk as the counter electrode (anode). The electrode distance between the anode and the cathode was $3 \mathrm{~cm}$. A constant current density was applied by a potentiostat (Vertex, Ivium Technologies, The Netherlands). The total solution $(900 \mathrm{~mL})$ in the electrochemical cell was recirculated with a pump (Masterflex L/S digital economy drive, Germany) at a flow rate of $120 \mathrm{~mL} / \mathrm{min}$. All non-specified electrodes were provided by MAGNETO Special Anodes BV (The Netherlands).

\subsubsection{Batch experiments}

In all batch tests, the $\mathrm{P}$ concentration was fixed at $0.6 \mathrm{mM}$. The concentration of Ca changed from $0.5 \mathrm{mM}$ to $2.0 \mathrm{mM}$, and $\mathrm{Na}_{2} \mathrm{SO}_{4}$ concentration varied from $10 \mathrm{mM}$ to $50 \mathrm{mM}$. The applied current density ranged from as low as $0.04 \mathrm{~A} / \mathrm{m}^{2}$ to maximum $0.2 \mathrm{~A} / \mathrm{m}^{2}$. To investigate the removal mechanism, we performed blank experiments in the absence of $\mathrm{Ca}(0 \mathrm{mM})$ or in the absence of an electric field $\left(0 \mathrm{~A} / \mathrm{m}^{2}\right)$. In particular, to understand the role of graphite felt, we also performed experiments with Pt-Ti cathode (without graphite felt). The cell voltage was recorded by the IVIUM software. Lastly, the feasibility of this low current system in real domestic wastewater was evaluated. Typically, all batch tests lasted 4 days and aliquots of solutions were sampled every day. Unless specified, before a next experiment, the electrochemical cell was flushed with deionized water for two days to ensure that no residual ions remained on the cathode surface. All experiments were carried out at least in duplicate. The data are given as the mean and corresponding standard deviation of at least two independent tests.

\subsubsection{Analytical methods}

We analyzed the concentration of Ca and P by ICP-AES (Optima 5300 DV, Perkin Elmer) and $\mathrm{pH}$ (Seven Excellence S470, Mettler Toledo). We examined the morphologies and elements distribution of the fresh and used graphite felt by SEM (JEOL-6480LV, JEOL Ltd., Japan) and EDS (Oxford Instruments), respectively. A small piece $(1 \mathrm{~cm} \mathrm{x} 1 \mathrm{~cm})$ of the fresh 
and used graphite felt was cut and used for SEM-EDS characterization. We obtained the Raman spectra of the deposits on the carbon fiber of the used graphite felt using a LabRAM HR Raman spectrometer (Horiba Jobin Yvon) [89].

\subsubsection{Calculation}

The supersaturation index (SI) of calcium phosphate species was calculated by Visual Minteq (available at https://vminteq.lwr.kth.se/) [89].

$$
\mathrm{SI}=\log \left(\frac{\mathrm{IAP}}{\mathrm{Ksp}}\right)
$$

Here, IAP is the ion activity product of the associated lattice ions of a mineral and $K$ sp is the thermodynamic solubility product.

\subsection{Results and discussion}

\subsubsection{Electrochemical removal of phosphate at low current density is possible}

Figure 7.1 shows phosphate can be removed in the electrochemical system using GF-Pt-Ti cathode by applying a current density as low as $0.04 \mathrm{~A} / \mathrm{m}^{2}$ (Figure 7.1A), which is accompanied by simultaneous removal of $\mathrm{Ca}$ (Figure 7.1B). In open circuit $(0 \mathrm{~mA})$, only $15 \%$ $\mathrm{P}$ and $12 \% \mathrm{Ca}$ were removed from the bulk solution after 4 days' treatment. The removal of $\mathrm{P}$ and $\mathrm{Ca}$ in open circuit is probably a result of spontaneous precipitation [89]. The calculation of SI indicates the solution is indeed supersaturated in terms of both amorphous calcium phosphate $\left(\mathrm{ACP}, \mathrm{SI}_{\mathrm{ACP}}=1.1\right)$ and hydroxyapatite $\left(\mathrm{HAP}, \mathrm{SI}_{\mathrm{HAP}}=9.9\right)$. The relatively low removal efficiency indicates that precipitation is thermodynamically feasible, but kinetically, the spontaneous precipitation of ACP and HAP under our experimental conditions, is slow and has a significant induction time [70].

In a closed electrical circuit, the removal of $\mathrm{P}$ and $\mathrm{Ca}$ was enhanced substantially. The removal efficiency of $\mathrm{P}$ was almost doubled from $15 \%$ in open circuit $\left(0 \mathrm{~A} / \mathrm{m}^{2}\right)$ to $27 \%$ at $0.04 \mathrm{~A} / \mathrm{m}^{2}$ after 4 days of operation. At $0.1 \mathrm{~A} / \mathrm{m}^{2}$, about $53 \% \mathrm{P}$ was removed. At $0.2 \mathrm{~A} / \mathrm{m}^{2}$, this value increased to $62 \%$. The corresponding removal of $\mathrm{Ca}$ increased from $26 \%$ at 0.04 $\mathrm{A} / \mathrm{m}^{2}$ to $46 \pm 3 \%$ at 0.1 and $0.2 \mathrm{~A} / \mathrm{m}^{2}$ (Figure 7.1B). These results demonstrate that electrochemical P removal at extremely low current density $\left(\leq 0.2 \mathrm{~A} / \mathrm{m}^{2}\right)$ is possible. 

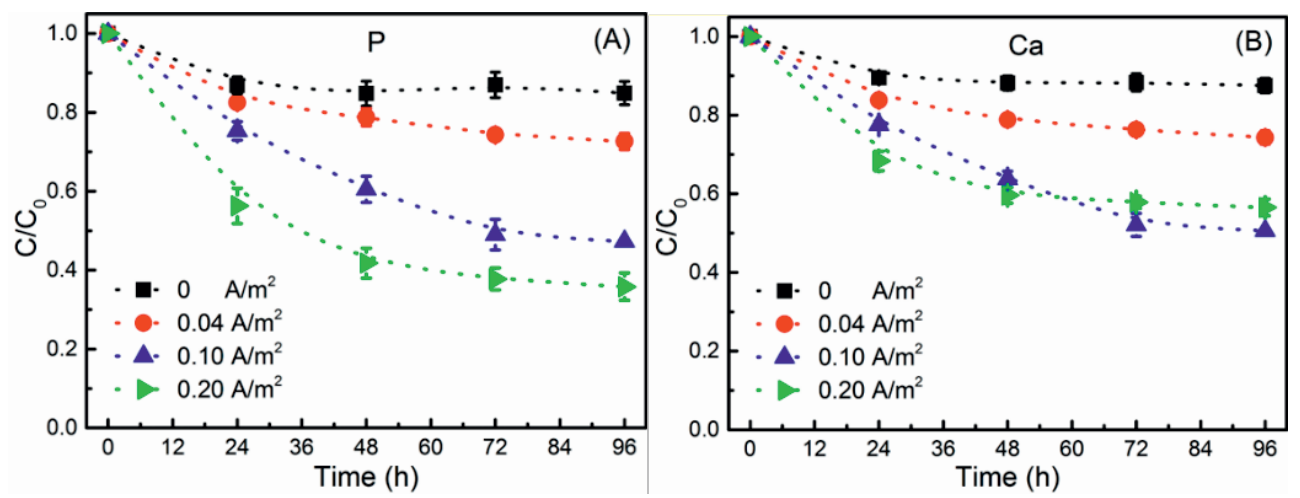

Figure 7.1. Effects of current density on the removal of (A) $\mathrm{PO}_{4}-\mathrm{P}$ and (B) Ca. Conditions: $1.0 \mathrm{mM} \mathrm{Ca}^{2+}, 0.6 \mathrm{mM} \mathrm{PO}_{4}-\mathrm{P}, 10 \mathrm{mM} \mathrm{Na}_{2} \mathrm{SO}_{4}$, Pt-Ti anode and GF-Pt-Ti cathode.
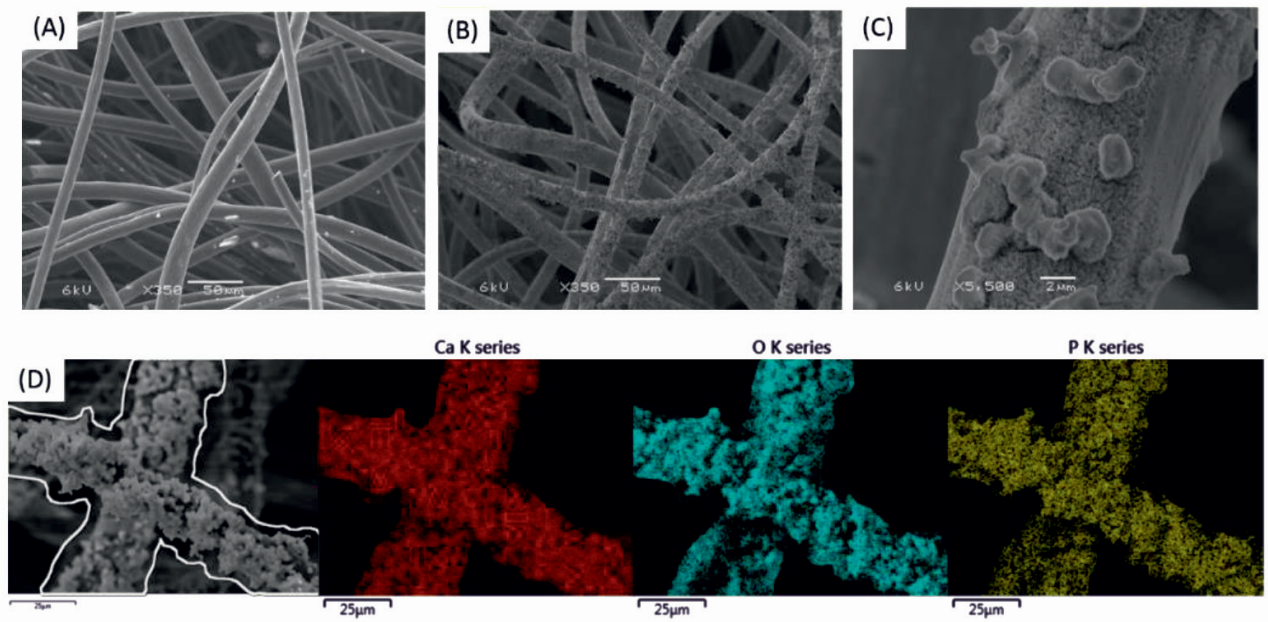

Figure 7.2. SEM image of the (A) fresh (unused) graphite felt and used graphite at a magnification of $(B) \times 350$ and $(C) \times 5500$, (D) element mapping of $\mathrm{Ca}$ (red), oxygen (cyan) and $\mathrm{P}$ (yellow) of a randomly chosen fiber on the used graphite felt.

We further checked the SEM images of used graphite felt and compared it with fresh (unused) felt. The SEM images revealed new morphology and species appeared on the used graphite felt, which is likely connected to the formation of calcium phosphate solids on the graphite felt (Figure 7.2A, 7.2B and 7.2C). This is further confirmed by the EDS data, which shows the element distribution over the fresh and used graphite felt. In the fresh graphite felt, the main element composition is carbon $(>97 \%$, Figure S7.2A). For the used graphite felt, new elements including $\mathrm{Ca}$ and $\mathrm{P}$ were detected (Figure S7.2B). Also, the EDS mapping of a 
randomly chosen spot of the used graphite felt shows a proper distribution of the three elements on the used fiber in the graphite felt (Figure 7.2D), which indicates the strong connection between the presence of $\mathrm{Ca}$ and $\mathrm{PO}_{4}$. The Raman characterization confirms that the new solids on the carbon fibers of the used graphite felt to be crystalline HAP (Figure S7.3). The Raman spectrum displaces four distinguishable characteristic internal $\left(\mathrm{PO}_{4}\right)$ bonds of HAP, including the main $v_{1}\left(\mathrm{PO}_{4}\right)$ peak around $960 \mathrm{~cm}^{-1}$ [75]. Also, from the point of mass balance, the removed $\mathrm{Ca}$ and $\mathrm{P}$ in the molar ratio was calculated to be $1.67 \pm 0.08$, which is close to the theoretical $\mathrm{Ca} / \mathrm{P}$ atomic ratio of HAP (1.67). Therefore, it is confirmed that $\mathrm{Ca}^{2+}$ and $\mathrm{PO}_{4}{ }^{3-}$ form calcium phosphate on the cathode even at such low current density $(\leq$ $\left.0.2 \mathrm{~A} / \mathrm{m}^{2}\right)$.

\subsubsection{Role of graphite felt: adsorption or precipitation?}

Initially, we ascribed the enhanced removal of $\mathrm{P}$ at a current density below $0.2 \mathrm{~A} / \mathrm{m}^{2}$, in comparison with the behavior at open circuit, to electro sorption, as the phenomenon of phosphate removal reported here shows similarities with the CDI process for ion removal. CDI is a process where ions can be adsorbed to capacitive electrodes. While the GF-Pt-Ti cathode is not a typical capacitive electrode, it could still act somehow as a capacitive electrode. The graphite felt is known to have a very large specific surface area with its structure (see SEM images in Figure 7.2).

However, electro-enhanced adsorption mechanism was excluded, based on the experiments we performed with varied electrolyte $\left(\mathrm{Na}_{2} \mathrm{SO}_{4}\right)$ concentrations (Figure S7.4). If the mechanism of CDI played an important role, the increase of background electrolyte concentration would lower the adsorption of $\mathrm{PO}_{4}{ }^{3-}$ and $\mathrm{Ca}^{2+}$, as the introduced $\mathrm{Na}^{+}$and $\mathrm{SO}_{4}{ }^{2-}$ ions would compete with $\mathrm{Ca}^{2+}$ and $\mathrm{PO}_{4}{ }^{3-}$ toward the "capacitive" electrodes [154]. According to the results showed in Figure S7.4, we excluded the involvement of CDI in our process as the influence of electrolyte concentration on the removal of $\mathrm{P}$ and $\mathrm{Ca}$ was found to be small. The slightly decreased removal of $\mathrm{Ca}$ and $\mathrm{P}$ with increased $\mathrm{Na}_{2} \mathrm{SO}_{4}$ concentration is probably connected to the effect of ionic strength on the supersaturation of calcium phosphate, as it decreased with increased ionic strength [36].

The exclusion of CDI mechanism is further supported by the control experiments in the absence of calcium ions. The change in phosphate concentration is insignificant in the absence of calcium ions at a current density of $0.2 \mathrm{~A} / \mathrm{m}^{2}$ (Figure S7.5). This indicates the 
presence of calcium ions is essential for the removal of phosphate, which is unlikely if ion adsorption as in CDI would be the dominant mechanism for the removal of phosphate. In CDI process, the counter cation does not need to be calcium ion, as sodium ion, for example, could be possible as well $[154,155]$. Therefore, electro adsorption of phosphate to the graphite felt is excluded from the mechanism. In fact, the direction of the electrical field is against the diffusion of phosphate (anion) to the cathode, because they both are negatively charged.

To understand which mechanism dominates the removal of phosphate in our electrochemical system, it is necessary to understand the role of graphite felt in this process. To elucidate this, we further performed control experiments in the absence of graphite felt. The results indicated that the combination of graphite felt with Pt-Ti cathode indeed enhanced the removal of P. At $0.2 \mathrm{~A} / \mathrm{m}^{2}$ the removal efficiency of $\mathrm{P}$ with GF-Pt-Ti cathode is $15 \%$ higher than with Pt-Ti cathode (Figure 7.3A). However, it is not clear what is behind the enhancement by the introduction of graphite felt.

$$
\begin{aligned}
& 4 \mathrm{H}_{2} \mathrm{O}+4 \mathrm{e}^{-} \rightarrow 4 \mathrm{OH}^{-}+2 \mathrm{H}_{2} \uparrow(7.2) \\
& 2 \mathrm{H}_{2} \mathrm{O} \rightarrow 4 \mathrm{H}^{+}+\mathrm{O}_{2} \uparrow+4 \mathrm{e}^{-} \\
& \mathrm{H}^{+}+\mathrm{OH}^{-} \rightarrow \mathrm{H}_{2} \mathrm{O}
\end{aligned}
$$
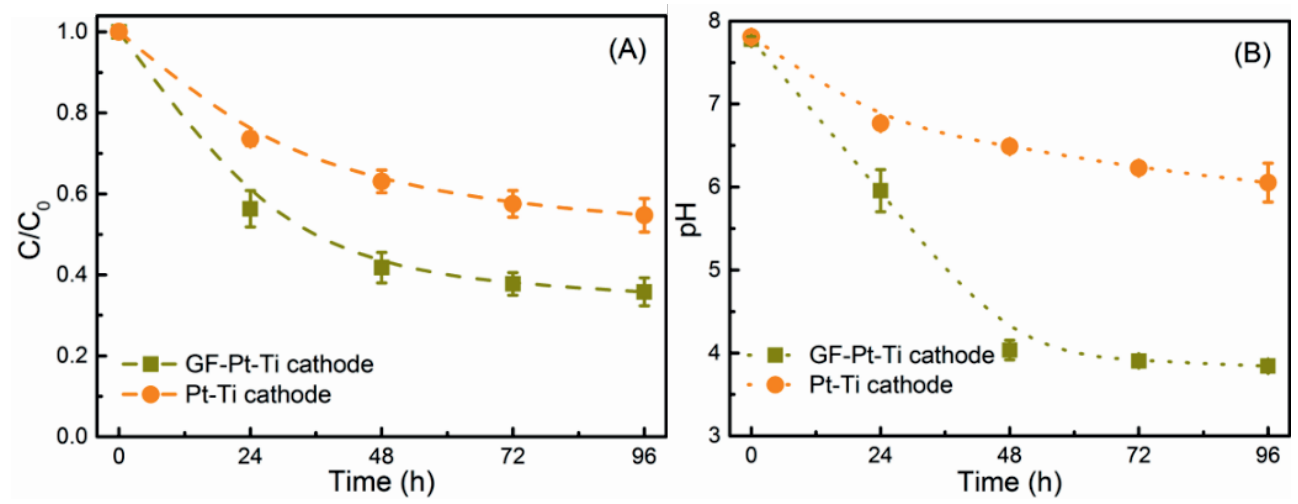

Figure 7.3. Influence of graphite felt (GF) on (A) the removal of phosphate and (B) solution pH. Conditions: $1.0 \mathrm{mM} \mathrm{Ca}^{2+}, 0.6 \mathrm{mM} \mathrm{PO}_{4}-\mathrm{P}, 10 \mathrm{mM} \mathrm{Na}_{2} \mathrm{SO}_{4}, 0.2 \mathrm{~A} / \mathrm{m}^{2}$, Pt-Ti anode, GFPt-Ti or Pt-Ti cathode. 
Looking at the evolution of bulk solution $\mathrm{pH}$, we found that the bulk $\mathrm{pH}$ with graphite felt is much lower than without graphite felt (Figure 7.3B). Therefore, it seems that graphite felt affects the bulk solution $\mathrm{pH}$ as the generated hydroxide ions fluxes are retarded in the porous felt. At the cathode, hydroxide ions $\left(\mathrm{OH}^{-}\right)$were produced by water reduction (eq 7.2) and protons $\left(\mathrm{H}^{+}\right)$were produced at the anode by water oxidation (eq 7.3). Assuming there were no other reactions, the $\mathrm{pH}$ of the bulk solution will not change significantly, as the produced $\mathrm{H}^{+}$will recombine with the produced $\mathrm{OH}^{-}$, forming water again (eq 7.4). In our case, the precipitation of calcium phosphate will consume $\mathrm{OH}^{-}$. As a result, the bulk $\mathrm{pH}$ decreases during the treatment process, due to the accumulation of uncombined $\mathrm{H}^{+}$in the bulk solution, regardless of the presence or absence of graphite felt. However, in the presence of graphite felt, the diffusion of cathode produced $\mathrm{OH}^{-}$toward the bulk solution was limited. As a result, there was more $\mathrm{H}^{+}$accumulation in the bulk solution. This explains why the bulk solution $\mathrm{pH}$ is much lower in the presence of graphite felt than in the absence of graphite felt. Also, due to the limited recombination between $\mathrm{OH}^{-}$and $\mathrm{H}^{+}$, we can imagine that the local $\mathrm{pH}$ at the cathode with graphite felt was much higher than without graphite felt. This probably explains the better phosphate removal performance of using GF-Pt-Ti cathode than with Pt-Ti cathode, giving the fact that negatively charged graphite felt shows no adsorption capacity toward the phosphate anion (Figure S7.5).

Moreover, based on the Raman and SEM-EDS characterization of used graphite felt (Figure 7.2), we confirmed that calcium phosphate precipitates on the carbon fibers of the graphite felt. Therefore, it is likely that a local high $\mathrm{pH}$ environment was also created at the graphite felt. However, it remains unclear if calcium phosphate precipitation occurs on the Pt-Ti part of the GF-Pt-Ti cathode. To check that, we disassembled the used GF-Pt-Ti cathode and used acid to dissolve the solids on the Pt-Ti part. According to the mass balance calculation (Text S7.1), we confirmed that calcium phosphate precipitation occurred both on the graphite felt part and the Pt-Ti part of the GF-Pt-Ti cathode. However, only a small proportion of the removed phosphate precipitated with calcium ions on the Pt-Ti part (15\%) and most of the calcium phosphate precipitates were found on the graphite felt $(85 \%)$. This suggests that the introduction of graphite felt may extend the local high $\mathrm{pH}$ environment from the vicinity of the Pt-Ti part to the graphite felt environment as well. 
To conclude, the enhanced removal of phosphate at extremely low current density with GF$\mathrm{Pt}-\mathrm{Ti}$ cathode is due to the influence of the graphite felt on the local $\mathrm{pH}$ as well as the precipitation area.

\subsubsection{Effect of calcium ions concentration}

Figure S7.5 shows that the removal of phosphate cannot be achieved in the absence of calcium ions. This suggests that the removal of phosphate is linked with calcium ions. Therefore, the removal of $\mathrm{P}$ as a function of $\mathrm{Ca}$ concentration was evaluated.
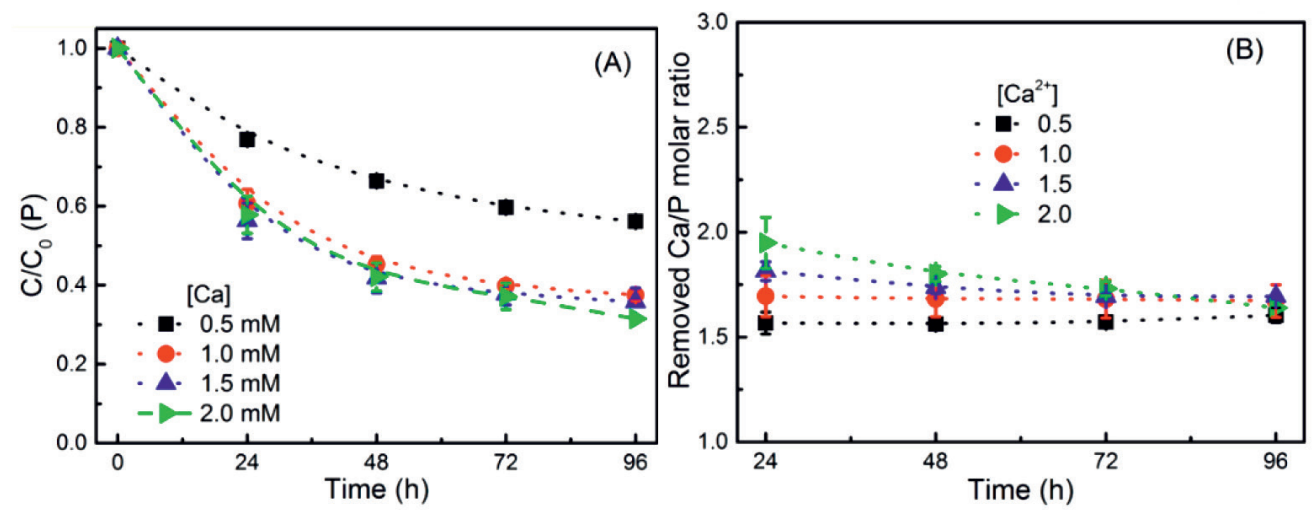

Figure 7.4. (A) Effect of initial Ca concentration on the removal of $\mathrm{PO}_{4}-\mathrm{P}$, (B) and removed $\mathrm{Ca} / \mathrm{P}$ molar ratio as a function of electrolysis time. Conditions: $1.0 \mathrm{mM} \mathrm{Ca}{ }^{2+}, 0.6 \mathrm{mM} \mathrm{PO}_{4}-$ P, $10 \mathrm{mM} \mathrm{Na}_{2} \mathrm{SO}_{4}, 0.2 \mathrm{~A} / \mathrm{m}^{2}$, Pt-Ti anode, GF-Pt-Ti cathode.

As shown in Figure 7.4A, the removal efficiency of $\mathrm{P}$ decreased by $19 \%$ when the $\mathrm{Ca}$ concentration was reduced from $1.0 \mathrm{mM}$ to $0.5 \mathrm{mM}$. However, the increase of $\mathrm{Ca}$ concentration from $1.0 \mathrm{mM}$ to $1.5 \mathrm{mM}$ and further to $2.0 \mathrm{mM}$ does not affect the process very much, as can be seen from the overlapped removal trend of P with 1.0, 1.5, and 2.0 mM Ca. The most stable phase of calcium phosphate species is $\mathrm{HAP}$, which has a $\mathrm{Ca} / \mathrm{P}$ atomic ratio of 1.67 [35]. Theoretically, $1.0 \mathrm{mM} \mathrm{Ca}$ is able to precipitate $0.6 \mathrm{mM}$ P. Therefore, if the initial $\mathrm{Ca} / \mathrm{P}$ molar ratio is higher than 1.67 , the further increase of $\mathrm{Ca} / \mathrm{P}$ molar ratio through increasing $\mathrm{Ca}^{2+}$ concentration will not result in an obvious increase of $\mathrm{P}$ removal, which is because there is enough $\mathrm{Ca}^{2+}$ in the bulk solution for calcium phosphate precipitation. However, if the initial $\mathrm{Ca} / \mathrm{P}$ molar ratio is decreased through decreasing $\mathrm{Ca}^{2+}$ concentration, i.e., at $0.5 \mathrm{mM} \mathrm{Ca}$ (the initial $\mathrm{Ca} / \mathrm{P}$ ratio decreased from 1.67 to 0.83 ), this will not only reduce the driving force for calcium phosphate precipitation but also in terms of stoichiometry, 0.5 
$\mathrm{mM} \mathrm{Ca}$ is not able to precipitate $0.6 \mathrm{mM} \mathrm{PO}_{4}-\mathrm{P}$. As a result, the $\mathrm{P}$ removal efficiency decreased significantly from $63 \%$ with $1.0 \mathrm{mM}$ Ca to $44 \%$ with $0.5 \mathrm{mM} \mathrm{Ca}$.

Looking at the absolute removal of $\mathrm{Ca}$ and $\mathrm{P}$ expressed in $\mathrm{Ca} / \mathrm{P}$ molar ratio (Figure 7.4B), we found that this ratio is stable around $1.64 \pm 0.03$ after 4 days' treatment, regardless of the initial $\mathrm{Ca}$ concentration. This ratio is consistent with the stoichiometric $\mathrm{Ca} / \mathrm{P}$ atomic ratio of HAP (1.67), which indicates that the removed $\mathrm{PO}_{4}{ }^{3-}$ and $\mathrm{Ca}^{2+}$ may end up in the formation of HAP. Interestingly, looking at the evolution of removed $\mathrm{Ca} / \mathrm{P}$ molar ratio over the 4 days' treatment with various $\mathrm{Ca}$ concentration, we can see that this ratio is relatively high when the initial molar ratio of $\mathrm{Ca} / \mathrm{P}$ in the bulk solution is high. For instance, in the first day, the ratio decreased in the order of $2.0 \mathrm{mM} \mathrm{Ca}(1.95)>1.5 \mathrm{mM} \mathrm{Ca}(1.81)>1.0 \mathrm{mM}(1.67)>0.5 \mathrm{mM}$ (1.56). A ratio higher than the stoichiometric ratio (1.67) indicates there might be other mechanisms for the removal of $\mathrm{Ca}$, in addition to its precipitation with phosphate. This phenomenon may be explained by the electrostatic interaction of positive charged $\mathrm{Ca}^{2+}$ with negatively charged graphite felt (cathode), especially at the beginning of operation when both Faradaic and non-Faradaic reactions occur. The non-Faradic reaction might also contribute to the removal of $\mathrm{Ca}$ and thus a ratio over stoichiometric required $\mathrm{Ca} / \mathrm{P}$ ratio for calcium phosphate precipitation is observed at the initial stage. However, the end removal of $\mathrm{Ca}$ is similar when the initial Ca concentration was higher than $1.0 \mathrm{mM}$, with $0.63,0.65$ and 0.67 $\mathrm{mM} \mathrm{Ca}$ being removed at 1.0, 1.5 and $2.0 \mathrm{mM} \mathrm{Ca}$, respectively (Figure S7.6). The independent removal of $\mathrm{Ca}$ in the absolute amount on its concentration after $1.0 \mathrm{mM}$ indicates the removal of $\mathrm{Ca}$ is also connected to the removal of phosphate. Under a certain concentration of phosphate (i.e., $0.6 \mathrm{mM}$ ), the removal of $\mathrm{Ca}$ is also limited, even the $\mathrm{Ca}$ concentration is above the stoichiometric requirement. From the results presented here and above, we concluded that the removal of $\mathrm{P}$ and $\mathrm{Ca}$ is mainly because of calcium phosphate precipitation instead of electro adsorption.

\subsubsection{Efficiency in real wastewater}

The feasibility of the low current density system in real wastewater was confirmed. We dosed extra phosphate to the effluent so that the real wastewater has the same phosphate concentration as the synthetic solutions. The main composition of the wastewater after spiking phosphate is $18.4 \mathrm{mg} / \mathrm{L} \mathrm{P}, 81.8 \mathrm{mg} / \mathrm{L} \mathrm{Ca}$, and $18.6 \mathrm{mg} / \mathrm{L} \mathrm{Mg}$. By applying a low current density of $0.2 \mathrm{~A} / \mathrm{m}^{2}$, the P concentration decreased by $76 \%$ from 18.4 to $4.4 \mathrm{mg} / \mathrm{L}$ 
after 4 days treatment (Figure 7.5), which is accompanied by the removal of $40 \% \mathrm{Ca}$ and $11 \%$ $\mathrm{Mg}$. The removal efficiency of $\mathrm{P}$ in the effluent (76\%) was even higher than its removal in synthetic solutions (68\%, see Figure 7.4) in the presence of $2 \mathrm{mM} \mathrm{Ca}(80 \mathrm{mg} / \mathrm{L})$. These preliminary results indicate that the low current system is also suitable for complicated water matrices. Based on the previously developed calculation approach [147], the recovered precipitates consist of $66 \% \mathrm{Ca}_{5}\left(\mathrm{PO}_{4}\right)_{3} \mathrm{OH}, 29 \% \mathrm{CaCO}_{3}$, and $5 \% \mathrm{Mg}(\mathrm{OH})_{2}$. Therefore, the use of a low current density is a possible way to reduce the co-precipitation of $\mathrm{CaCO}_{3}$ and $\mathrm{Mg}(\mathrm{OH})_{2}$ in electrochemical phosphorus recovery from real wastewater.

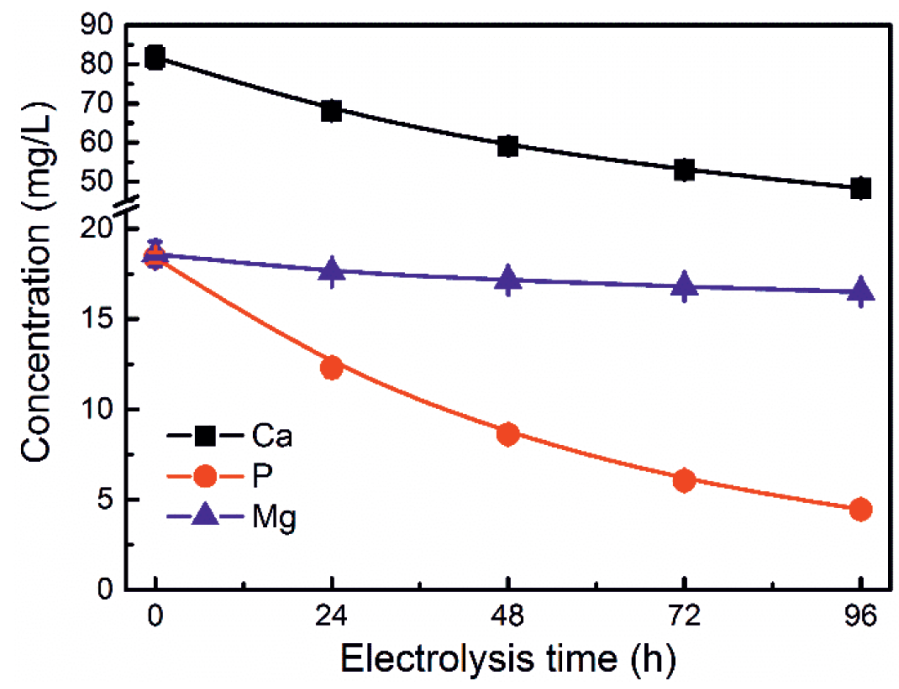

Figure 7.5. Electrochemical removal of $\mathrm{P}, \mathrm{Ca}$ and $\mathrm{Mg}$ from real domestic wastewater. Conditions: $0.2 \mathrm{~A} / \mathrm{m}^{2}$, Pt-Ti anode and GF-Pt-Ti cathode. Extra phosphate was dosed to the wastewater, so it has same P concentration as the synthetic solutions.

\subsection{Saved energy consumption}

The motivation of this research is to reduce the high energy consumption in electrochemical $\mathrm{P}$ recovery in our previous work. Therefore, we calculated the specific energy consumption of electrochemical P recovery at very low current density $\left(\leq 0.2 \mathrm{~A} / \mathrm{m}^{2}\right)$ with and without graphite felt. It was found that the specific energy consumption lies in the range of 4.4 to 24.2 $\mathrm{kWh} / \mathrm{kg} \mathrm{P}$ (Figure S7.7). The energy consumption was reduced by almost half from $24.2 \pm$ 2.1 to $12.2 \pm 0.88 \mathrm{kWh} / \mathrm{kg} \mathrm{P}$, simply by the combination of graphite felt with Pt-Ti cathode. With GF-Pt-Ti cathode, the specific energy consumption decreased with the increase of 
applied current density. The lowest specific energy consumption was as low as $4.4 \mathrm{kWh} / \mathrm{kg}$ $\mathrm{P}$ and was achieved at $0.04 \mathrm{~A} / \mathrm{m}^{2}$. This specific energy consumption is 2 orders of magnitude lower than in our previous system that was operated at relatively high current density and using titanium plate cathode for treating real domestic wastewater (110 to $2238 \mathrm{kWh} / \mathrm{kg} \mathrm{P}$ ) [151]. In comparison with the CDI process, this specific energy consumption is comparable to a previously reported membrane CDI system $(1.5-7.0 \mathrm{kWh} / \mathrm{kg} \mathrm{P})$ where a much higher $\mathrm{P}$ concentration (16.1 mM) was targeted [154] and even lower than a commercial CDI system $(7.0 \mathrm{kWh} / \mathrm{kg} \mathrm{P})$ [155]. We conclude that a simple yet feasible way to construct an energyefficient electrochemically $\mathrm{P}$ recovery system is to use a carbon felt based cathode and operating the system at a very low current density $\left(\leq 0.2 \mathrm{~A} / \mathrm{m}^{2}\right)$. While the performance of such a system in real life and the associated challenges need to be further addressed in future studies, the substantially reduced energy consumption in electrochemical $\mathrm{P}$ removal is a significant step toward its real application. 


\section{Supporting information}

\section{Text S7.1 Mass balance calculation regarding the distribution of removed $P$ on Pt-Ti part and graphite felt part of the GF-Pt-Ti cathode}

The GF-Pt-Ti cathode as used was disassembled in two parts including the graphite felt part and the Pt coated Ti mesh disk (named as Pt-Ti part). We used nitric acid (1 M) to dissolve the solids on the Pt-Ti part and then diluted the acidic solution in a $500 \mathrm{~mL}$ flask with deionized water. The concentrations of $\mathrm{Ca}$ and $\mathrm{P}$ were analyzed by ICP-AES.

The detected $\mathrm{P}$ and $\mathrm{Ca}$ concentrations were 3.12 and $6.37 \mathrm{mg} / \mathrm{L}$. The $\mathrm{P}$ content in the Pt-Ti part was $3.12 \mathrm{mg} / \mathrm{L} \times 500 \mathrm{~mL}=1.56 \mathrm{mg}$.

In the meantime, the removed absolute amount of $\mathrm{P}$, based on the difference of $\mathrm{P}$ concentration before and after treatment, was calculated to be $10.62 \mathrm{mg}$. The percentage of removed $\mathrm{P}$ on the Pt-Ti part was $(1.56 / 10.62)=14.7 \%$. Similarly, the percentage of removed $\mathrm{P}$ on the graphite felt was $((10.62-1.56) / 10.62))=85.3 \%$. 


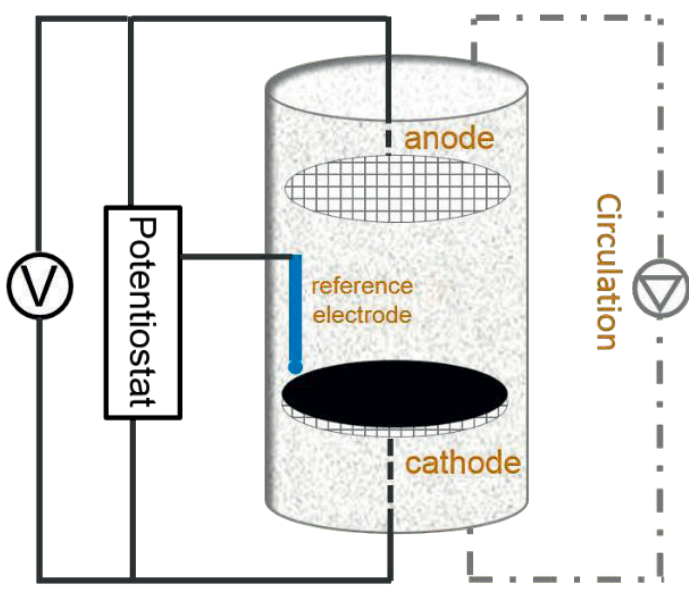

(a)

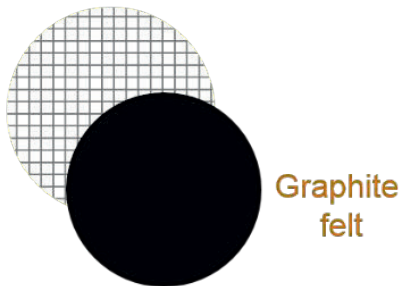

(b)

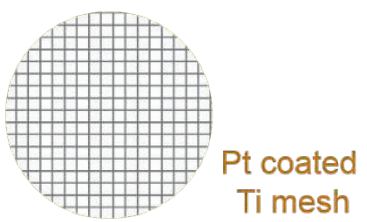

(c)

Figure S7.1. (a) Schematic overview of the electrochemical setup, (b) configuration of the graphite combined Pt-Ti cathode, (c) illustration of the Pt-Ti mesh disk anode.
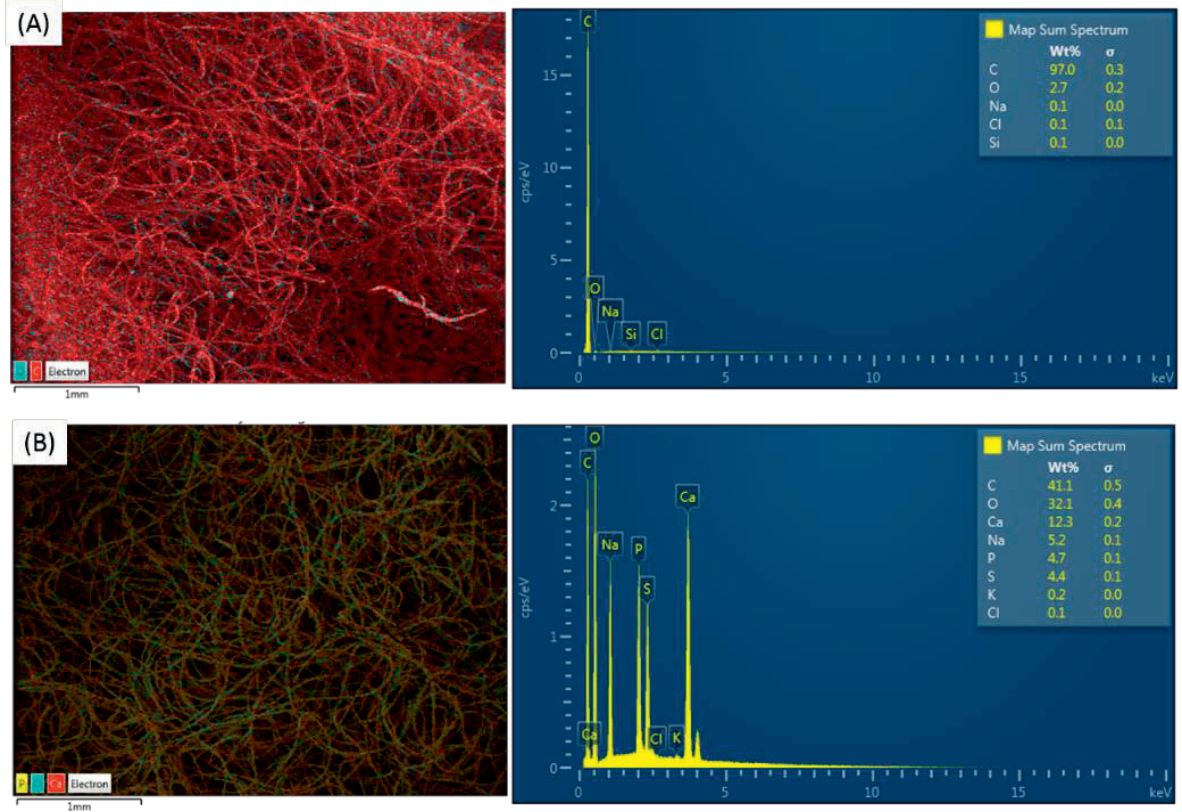

Figure S7.2. Element compositions of the (A) fresh and (B) graphite felt as used, analyzed by element dispersive X-ray spectroscopy (EDS). 


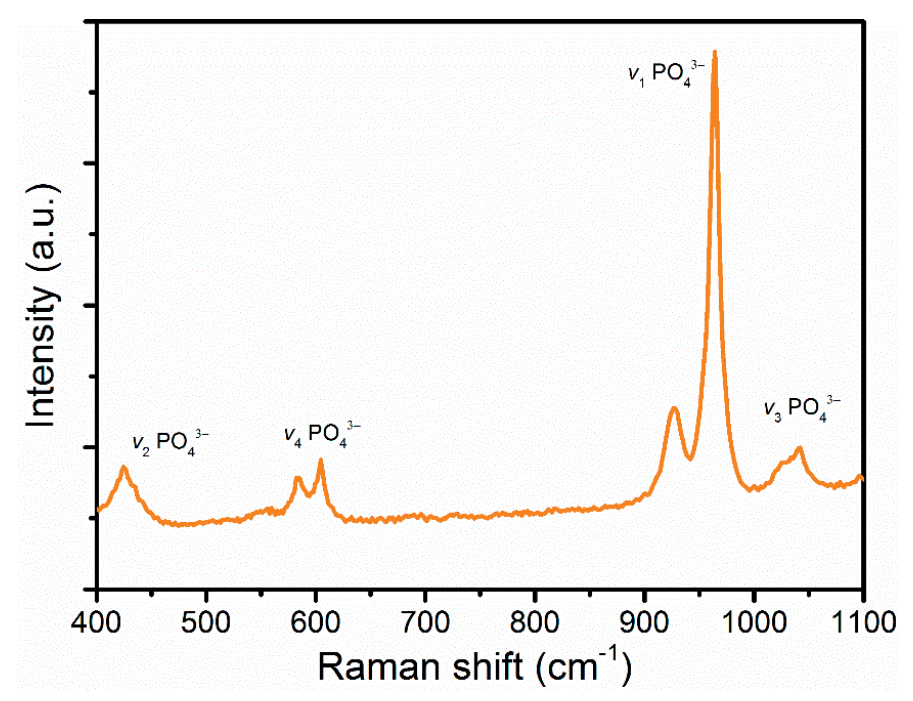

Figure S7.3. Raman spectra of the deposits on the carbon fiber of the used graphite felt. The spectra are in good match with hydroxyapatite.
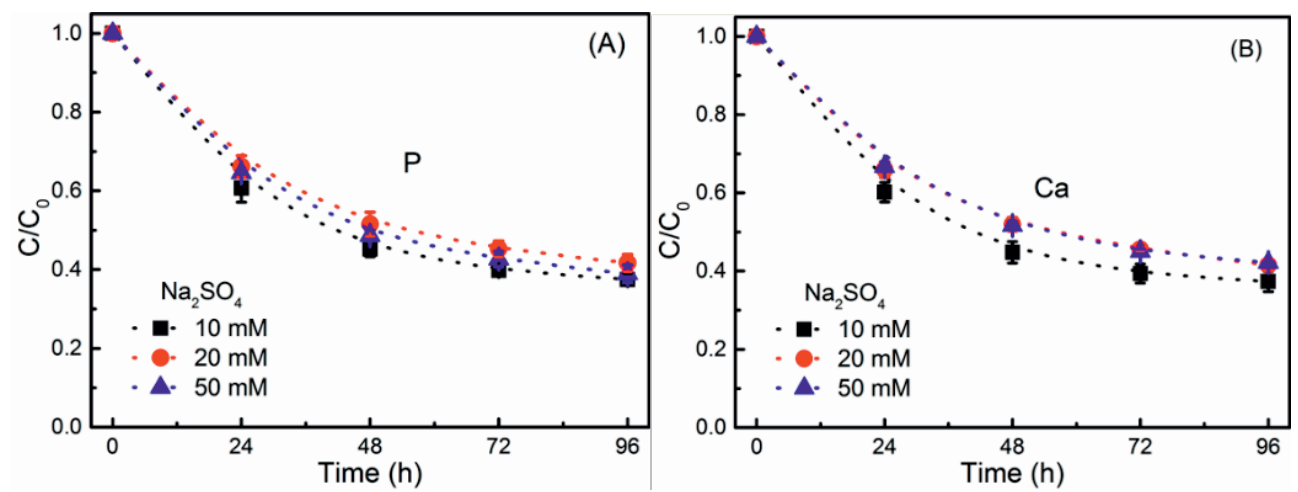

Figure S7.4. Effects of $\mathrm{Na}_{2} \mathrm{SO}_{4}$ concentration on the removal of (A) $\mathrm{PO}_{4}-\mathrm{P}$ and (B) $\mathrm{Ca}$. Conditions: $1.0 \mathrm{mM} \mathrm{Ca}^{2+}, 0.6 \mathrm{mM} \mathrm{PO}_{4}-\mathrm{P}, 0.2 \mathrm{~A} / \mathrm{m}^{2}$, Pt-Ti anode and GF-Pt-Ti cathode. 


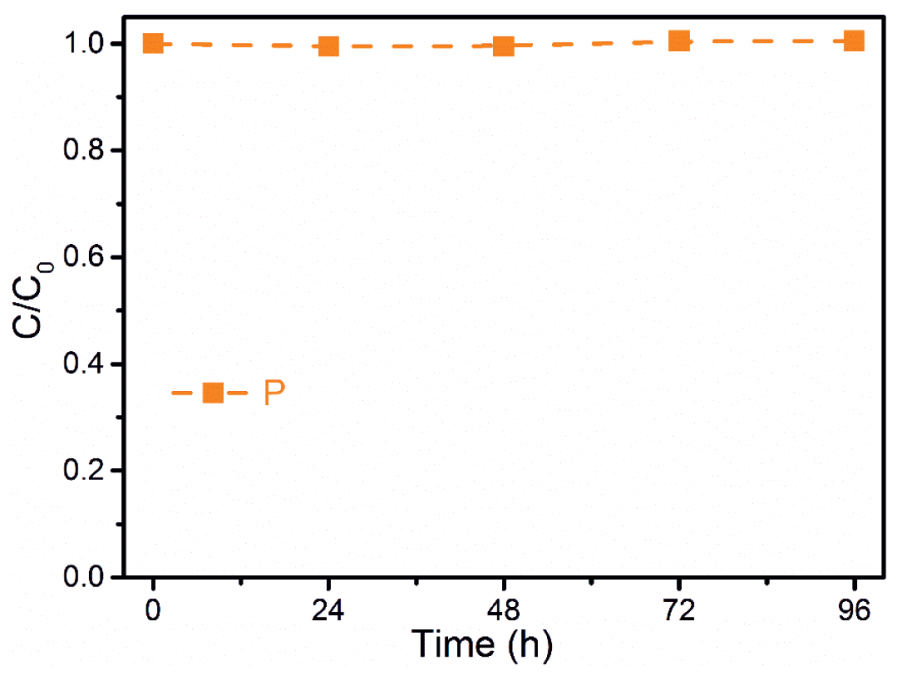

Figure S7.5. Removal of phosphate in the absence of calcium ions. Conditions: $0 \mathrm{mM} \mathrm{Ca}^{2+}$; $0.6 \mathrm{mM} \mathrm{PO}_{4}-\mathrm{P} ; 10 \mathrm{mM} \mathrm{Na}_{2} \mathrm{SO}_{4}, 0.2 \mathrm{~A} / \mathrm{m}^{2}$; Pt-Ti anode and GF-Pt-Ti cathode.

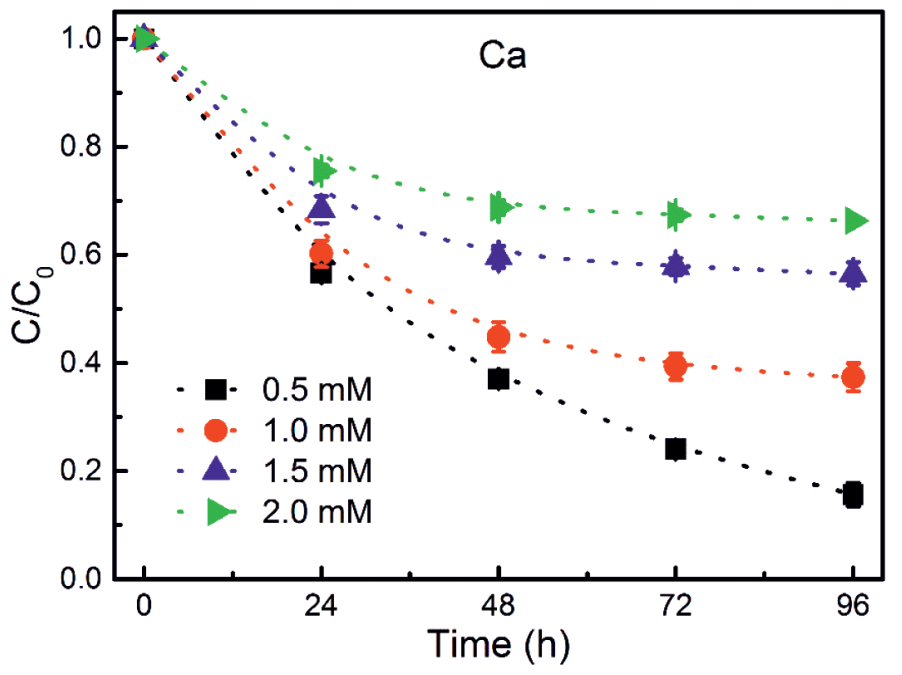

Figure S7.6. Electrochemical removal of $\mathrm{Ca}$ as a function of $\mathrm{Ca}$ concentration. Conditions: $0.6 \mathrm{mM} \mathrm{PO}_{4}-\mathrm{P} ; 10 \mathrm{mM} \mathrm{Na}_{2} \mathrm{SO}_{4} ; 0.2 \mathrm{~A} / \mathrm{m}^{2}$; Pt-Ti anode and GF-Pt-Ti cathode. 


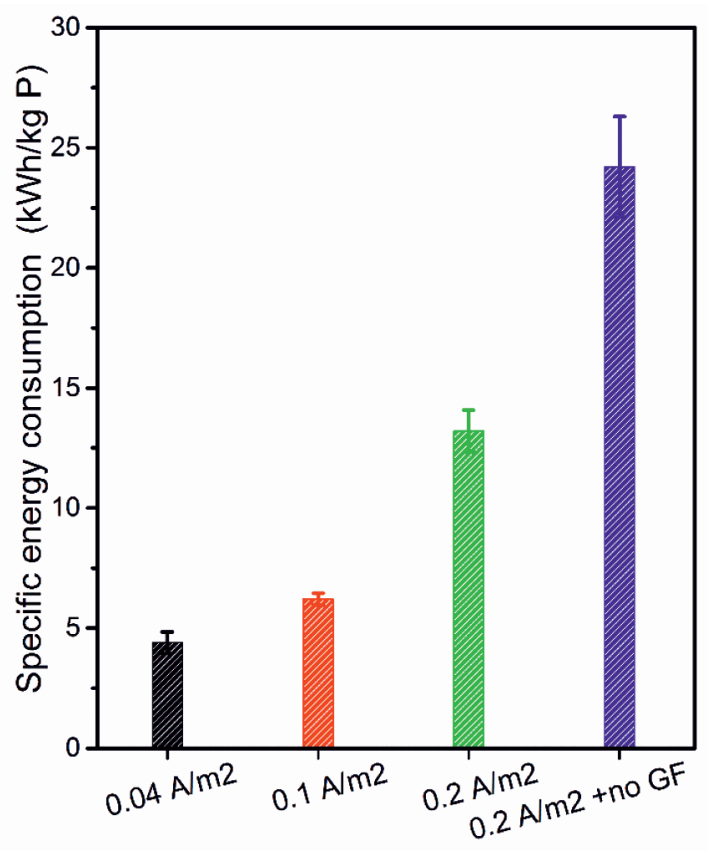

Figure S7.7. Calculated specific energy consumption based on phosphate removal efficiency, applied current and recorded cell voltage (not given in Figure). 


\section{Chapter 8}

\section{Electrochemically mediated calcium phosphate precipitation from phosphonates: implications on phosphorus recovery from non-orthophosphate}

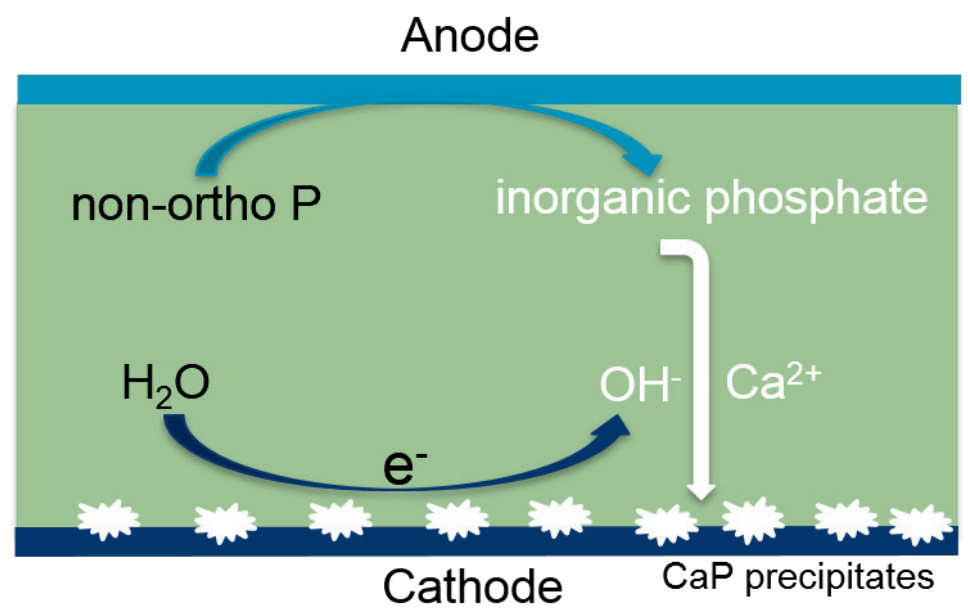

Yang Lei, Michel Saakes, Renata D. van der Weijden, and Cees J. N. Buisman

This chapter has been published as:

Lei, Yang, Michel Saakes, Renata D. van der Weijden,

and Cees J.N. Buisman. "Electrochemically mediated calcium phosphate precipitation from phosphonates: implications on phosphorus recovery from non-orthophosphate" Water Research, 169 (2020): 115206." 


\begin{abstract}
Phosphonates are an important type of phosphorus-containing compounds and have possible eutrophication potential. Therefore, the removal of phosphonates from waste streams is as important as orthophosphate. Herein, we achieved simultaneously removal and recovery of phosphorus from nitrilotris (methylene phosphonic acid) (NTMP) using an electrochemical cell. It was found that the C-N and C-P bonds of NTMP were cleaved at the anode, leading to the formation of orthophosphate and formic acid. Meanwhile, the converted orthophosphate reacted with coexisting calcium ions and precipitated on the cathode as recoverable calcium phosphate solids, due to an electrochemically induced high $\mathrm{pH}$ region near the cathode. Electrochemical removal of NTMP $(30 \mathrm{mg} / \mathrm{L})$ was more efficient when dosed to effluent of a wastewater treatment plant $(89 \%$ in $24 \mathrm{~h})$ than dosed to synthetic solutions of $1.0 \mathrm{mM} \mathrm{Ca}$ and $50 \mathrm{mM} \mathrm{Na}_{2} \mathrm{SO}_{4}(43 \%$ in $168 \mathrm{~h})$ while applying a current density of $28 \mathrm{~A} / \mathrm{m}^{2}$ and using a Pt anode and Ti cathode. The higher removal efficiency of NTMP in real wastewater is due to the presence of chloride ions, which resulted in anodic formation of chlorine. This study establishes a one-step approach for simultaneously phosphorus removal and recovery of calcium phosphate from non-orthophosphates.
\end{abstract}




\subsection{Introduction}

Phosphorus (P) is an essential element for all forms of life, but its reserves are limited on our planet. In particular, modern agricultural industry depends heavily on using $\mathrm{P}$ fertilizer to secure food production for the increasing global population. Unfortunately, phosphate reserves are projected to run out in a few hundred years [1]. Meanwhile, the widespread use of $\mathrm{P}$ fertilizer and many other $\mathrm{P}$ products often result in a load of excess $\mathrm{P}$ in receiving water bodies, causing eutrophication of such aquatic systems [156]. To sustain the use of $\mathrm{P}$ and guarantee food supply, it is necessary to recover and reuse the $\mathrm{P}$ in waste streams $[7,10]$.

While there have been plenty of studies addressing P removal and recovery from wastewaters, the focus was mainly on orthophosphate, which can be relatively easily removed by enhanced biological phosphorus removal, precipitation, or adsorption [22, 23, 157].

However, in terms of non-orthophosphates, we are not aware of any approaches which can achieve simultaneously $\mathrm{P}$ removal and recovery in a single step. A recent review article pointed out that no technique currently has been implemented for the recovery of $\mathrm{P}$ from nonorthophosphates [158].

However, though the relative fractions of non-orthophosphates are widely variable, nonorthophosphates can be one of the main P fractions in many aquatic ecosystems [159]. A recent survey in an eutrophic lake revealed the widespread presence of non-orthophosphates [160]. Non-orthophosphates are also detected in the remote marine environment at unexpectedly high concentrations [161].

Non-orthophosphate compounds are typically characterized by the presence of C-P bond in their molecular structures $[159,162]$. Unlike orthophosphate, the reactivity of nonorthophosphates is relatively low and is generally grouped as nonreactive phosphorus. However, in the last decade, non-orthophosphates were conceived as a potential bioavailable $P$ [163]. Indeed, when subjected to enzymatic degradation or photochemical conversion, the bioavailability of non-orthophosphates to plants, microorganisms, and algae may be enhanced substantially $[158,159,162,164]$. Therefore, non-orthophosphates may be partly responsible for the eutrophication of water bodies.

Nonetheless, non-orthophosphates are not targeted by the existing treatment process in wastewater treatment plants. Instead, they are mainly removed through uncontrolled 
adsorption to sludge $[158,165]$. To prevent eutrophication, many countries set a strict limit for P discharge, for example, as low as $10 \mu \mathrm{g} / \mathrm{L}$ in eco-sensitive areas [166]. The presence of non-orthophosphates makes it difficult to meet the discharge standard [158, 167]. Also, from the point of resource recovery, all forms of $\mathrm{P}$ need to be recovered and reused. Yet, studies on P removal and recovery from non-orthophosphates are rarely reported. This is probably due to the overlooked role of non-orthophosphates on eutrophication and the technical challenge in recovering $\mathrm{P}$ from non-orthophosphates. A few exceptions were the use of advanced oxidation processes as pretreatment to convert non-orthophosphate to orthophosphate [168-170]. However, to our knowledge, there are no approaches which can achieve a one-step P removal and recovery from non-orthophosphates.

Lei et al. established an electrochemical method for the removal and recovery of orthophosphate by electrochemically induced calcium phosphate precipitation $[32,89,119$, 147]. The principle of this method is that a high $\mathrm{pH}$ environment in the vicinity of the cathode was created [89]. Due to the high local $\mathrm{pH}$, calcium ions and phosphate precipitate on the cathode surface. In this electrochemical process, however, the function of the anode has not been explored. Drawn from the knowledge of electrochemical treatment of (micro)organic pollutants $[171,172]$, it may be possible to use the anode to oxidative break down the molecular structure of non-orthophosphate compounds, converting non-orthophosphate to orthophosphate by anodic (-mediated) oxidation. Subsequently, phosphate may precipitate with coexisting calcium ions at the cathode. It should be noted that calcium ions are widely present, both in natural and engineered aquatic systems. Therefore, in practice, the addition of calcium ions is not required.

Nitrilotris (methylene phosphonic acid) (NTMP) is a widely used antiscalant. In 1998, 56,000 ton phosphonic acids were consumed worldwide. In 2012 , this value increased by $70 \%$ to 94,000 ton [165]. Yet, phosphonates are not significantly degraded in wastewater treatment plants. The most common way for the treatment of phosphonates is adsorption [173]. However, the adsorption of phosphonates by adsorbents only achieves the removal of phosphonates but not the recovery of $\mathrm{P}$ from phosphonates.

Here, we chose NTMP as an environmentally relevant non-orthophosphates compound [170], investigated the feasibility and mechanism of $\mathrm{P}$ removal and recovery from phosphonates via a simple electrochemical treatment. Our study established a one-step approach for 
simultaneously P removal and recovery from non-orthophosphate. This may offer new options for treating non-orthophosphate containing waste streams and could be a significant step toward a circular P economy via the recovery of both orthophosphate and nonorthophosphate.

\subsection{Material and methods}

\subsubsection{Setup}

Figure S8.1 gives an overview of the configuration of the electrochemical cell. The electrochemical cell consisted of a single cylindrical glass reactor $(1.0 \mathrm{~L})$. The cathode was placed $3 \mathrm{~cm}$ below the anode and located in the center of the reactor. The solutions in the reactor were mixed by a recirculation pump (Masterflex L/S digital economy drive, Germany) at $150 \mathrm{~mL} / \mathrm{min}$. The electrochemical cell was operated under constant current density (28 $\mathrm{A} / \mathrm{m}^{2}$ ) and the needed cell voltage was provided by a power supply (ES 030-5, Delta elektronics B.V, The Netherlands).

\subsubsection{Electrodes}

The typical anode was a Pt-coated $\left(20 \mathrm{~g} / \mathrm{m}^{2}\right)$ Ti disc (thickness $\left.0.1 \mathrm{~cm}, \varnothing 8 \mathrm{~cm}\right)$. A perpendicular $12 \mathrm{~cm}$ rod $(\varnothing 3 \mathrm{~mm})$ of the same material was welded on the center as current collector. Ru-Ir (10 g/m² $)$ mixed metal oxide (MMO) and Pt-Ir (10 g/m²) MMO were investigated as alternative anode materials. The cathode was an uncoated Ti square plate (grade A, thickness $0.1 \mathrm{~cm}, 6 \times 6 \mathrm{~cm}$ ). All electrodes were provided by MAGNETO Special Anodes BV (Schiedam, The Netherlands).

\subsubsection{Chemicals}

Nitrilotris (methylene phosphonic acid) $\left(\mathrm{N}\left[\mathrm{CH}_{2} \mathrm{PO}(\mathrm{OH})_{2}\right]_{3}\right.$, NTMP) was purchased from Sigma-Aldrich and used as received. $\mathrm{Ca}\left(\mathrm{NO}_{3}\right)_{2} \cdot 4 \mathrm{H}_{2} \mathrm{O}$ and $\mathrm{NaClO}_{4}$ were acquired from Merck (Germany). $\mathrm{Na}_{2} \mathrm{SO}_{4}, \mathrm{NaCl}$ and $\mathrm{NaOH}$ were purchased from VWR (Leuven, Belgium).

\subsubsection{Batch experiments}

We conducted all experiments with $1.0 \mathrm{~L}$ synthetic solutions in the as-described electrochemical cell. The typical synthetic solutions contained $30 \mathrm{mg} / \mathrm{L}$ NTMP (0.3 mM P), $1.0 \mathrm{mM} \mathrm{Ca}{ }^{2+}$ and $50 \mathrm{mM} \mathrm{Na}_{2} \mathrm{SO}_{4}$, prepared by dissolving analytical grade chemicals in deionized water $\left(18.2 \mathrm{M} \Omega \cdot \mathrm{cm}\right.$, Millipore). In some experiments, $\mathrm{NaClO}_{4}$ or $\mathrm{NaCl}_{\text {were }}$ used 
as background electrolyte. In the section of proof of principle, we applied a higher NTMP concentration $(100 \mathrm{mg} / \mathrm{L})$, in order to collect enough precipitates for the subsequent characterization of solids. We also examined the removal of NTMP by conventional chemical precipitation (no current applied). Where necessary, we used concentrated $\mathrm{NaOH}$ to adjust the $\mathrm{pH}$. A typical batch test lasted seven days. After each test, the cathode was cleaned by immersing in acidic solution and then rinsed with deionized water. All experiments were carried out at least in duplicate. The data were expressed as mean and standard deviation of independent tests.

\subsubsection{Analytical methods}

We used ICP-AES (Optima 5300 DV, Perkin Elmer) to quantify the concentrations of P and Ca. The detection limits were $20 \mu \mathrm{g} / \mathrm{L}$ and $50 \mu \mathrm{g} / \mathrm{L}$, respectively. We used two types of cuvettes LCK 349 (0.05 to $5 \mathrm{mg} / \mathrm{L} \mathrm{PO}_{4}-\mathrm{P}$ ) and LCK 350 (2 to $20 \mathrm{mg} / \mathrm{L} \mathrm{PO}_{4}-\mathrm{P}$ ) (Hach) to measure the concentration of ortho-phosphorus $\left(\mathrm{PO}_{4}-\mathrm{P}\right)$. We applied ionic chromatography (Compact IC 761, Metrohm) to check the concentration of $\mathrm{Cl}^{-}$. The ionic chromatography was equipped with a Metrohm Metrosep A Supp 4/5 Guard pre-column, a Metrohm Metrosep A 112 Supp $5(150 / 4.0 \mathrm{~mm})$ column and a conductivity detector. We used ultra-high-pressure liquid chromatography (UHPLC) to quantify the concentration of low molecular weight acids. The UHPLC was equipped with a phenomenex Rezex Organic Acid $\mathrm{H}^{+}(300 \mathrm{x} 7.8 \mathrm{~mm})$ column, an Ultimate 3000 RS Column Compartment column oven and an Ultimate 3000 RS Variable Wavelength Detector. The detection limit for formic acid and acetic acid was 0.5 $\mathrm{mg} / \mathrm{L}$.

\subsubsection{Characterization of solids}

After the electrochemical treatment, the cathode was dried at room temperature for $24 \mathrm{~h}$. Then the solids on the cathode were collected by gentle scraping. The solid precipitates on the cathode were only collected at increased NTMP concentration $(100 \mathrm{mg} / \mathrm{L})$. In this case, enough solids could be collected for solid characterization. We checked the bond information of the solids by Raman Spectroscopy and X-ray diffraction (XRD), examined its morphology by scanning electron microscopy (SEM) and determined its elemental composition with energy dispersive X-Ray spectroscopy (EDS). Details about the instruments can be found elsewhere $[32,89]$. 


\subsection{Results and discussion}

\subsubsection{Proof of principle}

We first investigated the possibility of removing NTMP in the presence of calcium ions by conventional chemical precipitation, which is supposed to be triggered by increasing solution pH. However, as can be seen from Figure S8.2, in the absence of electric current, no NTMP was removed at background $\mathrm{pH}$ of 3.6. Even with an increase of solution $\mathrm{pH}$ to 10 or 12, we did not observe an obvious removal of NTMP. This means that merely adjusting the $\mathrm{pH}$ does not work for the removal of phosphonates. It is worth to mention, however, that this may only be the case for calcium ions. The use of iron or aluminum salts, which could form coagulants at specific pHs, may be able to remove phosphonates to some extent [174]. However, in our approach, we focus on getting phosphonates removed as recyclable calcium phosphate minerals instead of aluminum or iron phosphate, which has low bioavailability for phosphorus uptake by plants.

At $28 \mathrm{~A} / \mathrm{m}^{2}$ applied, the concentrations of $\mathrm{P}$ and $\mathrm{Ca}$ decreased simultaneously over the treatment period (Figure 8.1A). After seven days' treatment, $41.3 \% \mathrm{P}$ and $56.8 \% \mathrm{Ca}$ were removed. The analysis of orthophosphorus $\left(\mathrm{PO}_{4}-\mathrm{P}\right)$ concentration clearly shows the difference between chemical precipitation and electrochemically mediated precipitation. In the chemical precipitation process, the concentration of $\mathrm{PO}_{4}-\mathrm{P}$ is below the detection limit $(50 \mu \mathrm{g} / \mathrm{L})$. This explains why chemical precipitation by adjusting $\mathrm{pH}$ does not work for the non-orthophosphate. As the P in NTMP is connected to carbon (C-P bond), it is not available to $\mathrm{Ca}$.

In contrast, in the electrochemical system, we found an increase of $\mathrm{PO}_{4}-\mathrm{P}$ concentration up to $4.12 \mathrm{mg} / \mathrm{L}$ during the initial two days and then a gradual decrease over the next days. The detection of $\mathrm{PO}_{4}-\mathrm{P}$ indicates the conversion of non-orthophosphate to orthophosphate under electrochemical treatment. The decrease of $\mathrm{PO}_{4}-\mathrm{P}$ concentration afterwards is associated with its precipitation with calcium ions as calcium phosphate on the cathode, which is triggered by the increased local high $\mathrm{pH}$ during water electrolysis process [32, 89]. Indeed, we found white precipitates on the cathode after electrochemical treatment. 

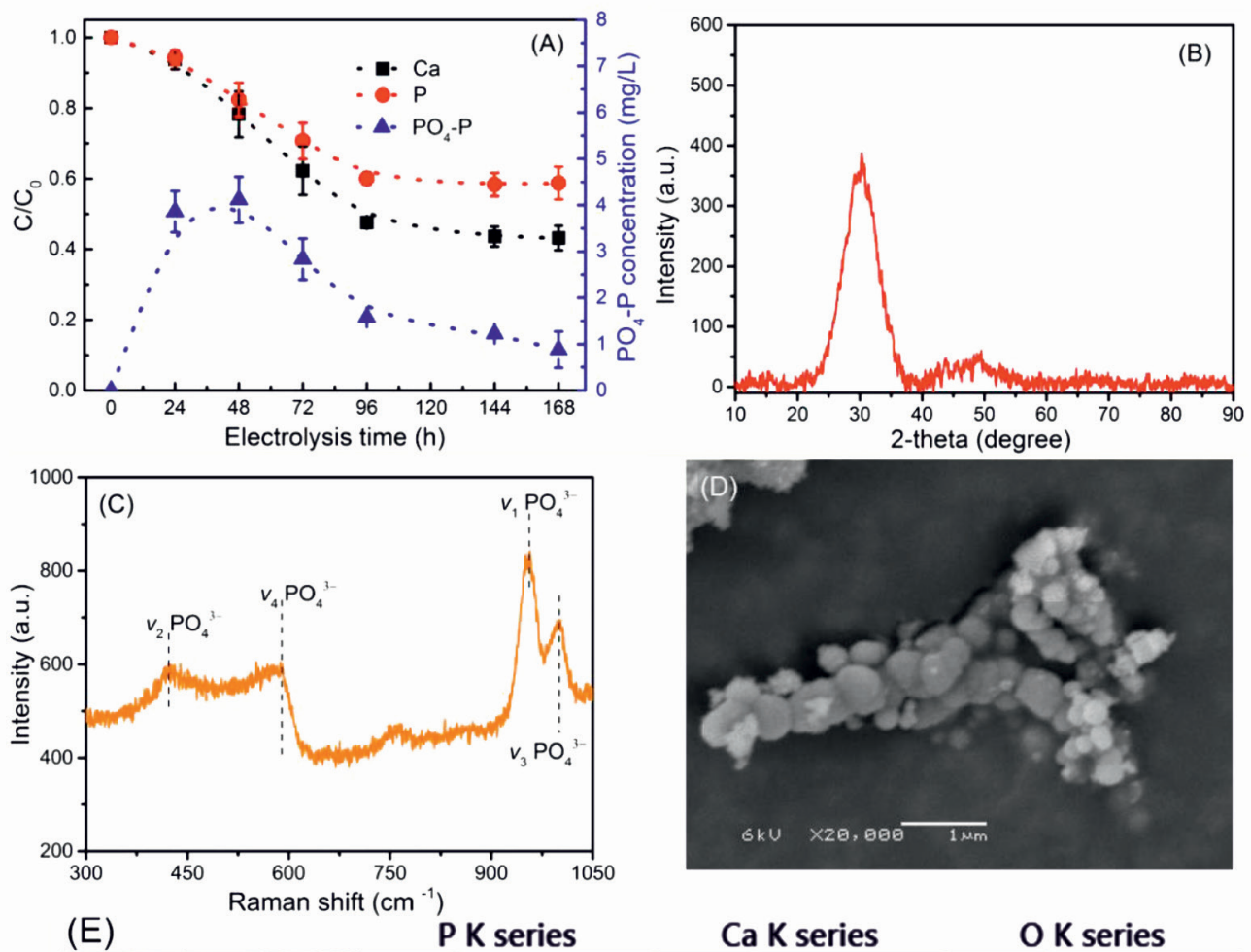

Ca K series O K series

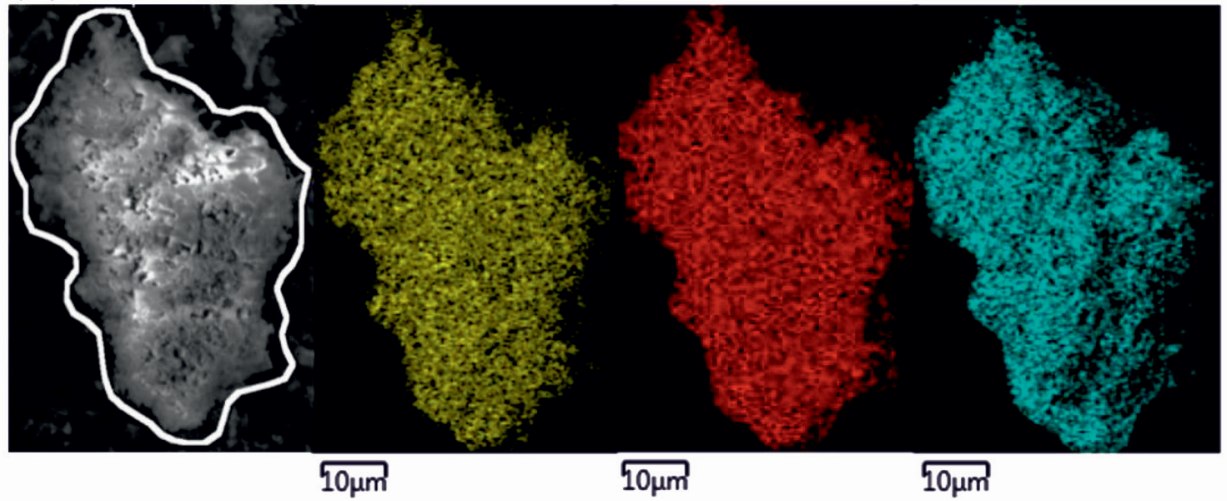

Figure 8.1. (A) Evolution of ortho-phosphorus ( $\left.\mathrm{PO}_{4}-\mathrm{P}\right)$, removal of phosphorus, and calcium in the electrochemical treatment of NTMP. (B) XRD, (C) Raman pattern, (D) SEM image, and (E) element distribution on the collected precipitates. Conditions: $100 \mathrm{mg} / \mathrm{L}$ NTMP, 1.0 $\mathrm{mM} \mathrm{Ca}^{2+}, 50 \mathrm{mM} \mathrm{Na}_{2} \mathrm{SO}_{4}, \mathrm{pH} 03.6$, titanium cathode $\left(36 \mathrm{~cm}^{2}\right)$, platinum coated titanium anode, current density $28 \mathrm{~A} / \mathrm{m}^{2}$.

The XRD pattern of the collected solids shows a broad peak around $2 \theta=30^{\circ}$ (Figure 8.1B), which is likely linked to the amorphous phase of calcium phosphate that we have seen before 
[120]. This assumption is supported by the Raman spectrum (Figure 8.1C), which displays all characteristic internal $\left(\mathrm{PO}_{4}\right)$ bonds information of calcium phosphate including a main $v_{1}$ $\left(\mathrm{PO}_{4}\right)$ peak around $955 \mathrm{~cm}^{-1}[75]$. The observed frequency of the $v_{1}\left(\mathrm{PO}_{4}\right)$ model is deviated from the $v_{1}\left(\mathrm{PO}_{4}\right)$ model of hydroxyapatite $\left(962 \mathrm{~cm}^{-1}\right)$, indicating the precipitates indeed are amorphous calcium phosphate [75]. Moreover, the formation of calcium phosphate is further evidenced by SEM-EDS characterization. From the SEM images (Figure 8.1D), we can see the aggregation of irregular spherical shaped particles, which is typically seen for amorphous calcium phosphate [89]. EDS mapping of the precipitates shows that $\mathrm{P}, \mathrm{Ca}$ and $\mathrm{O}$ atom are well distributed over the collected solids (Figure 8.1E). Furthermore, according to the mass balance calculation, the $\mathrm{Ca} / \mathrm{P}$ atomic ratio in the precipitates is around 1.37 . This is consistent with the EDS result, which indicates a $\mathrm{Ca} / \mathrm{P}$ atomic ratio of 1.32 in the collected precipitates (Figure S8.3). In conclusion, we confirmed that by electrochemical treatment, the nonorthophosphate was converted into orthophosphate and then precipitated with coexisting calcium ions as amorphous calcium phosphate on the cathode.

\subsubsection{Boosting performance}

\subsubsection{Influence of anode material}

In electrochemical systems, the electrode material plays a crucial role in its electrochemical performance [175]. In our system, the anode plays a major role in the anodic conversion of NTMP to orthophosphate. If the non-orthophosphate (NTMP) was not converted to orthophosphate, the cathode, although having a high $\mathrm{pH}$ environment, cannot result in the precipitation of calcium ions with NTMP. The catalytic behavior of the anode material toward oxidation of NTMP is therefore crucial for the performance of the whole system.

We performed experiments with different MMO anodes (Ir-Pt or Ru-Ir) and compared their efficiencies with the $\mathrm{Pt}$ anode, in terms of the evolution of $\mathrm{PO}_{4}-\mathrm{P}$, removal of $\mathrm{P}$ and $\mathrm{Ca}$. Figure 8.2A suggests that the formation of orthophosphate was enhanced substantially using MMO anodes. The maximum detected $\mathrm{PO}_{4}-\mathrm{P}$ concentration increased from $1.6 \mathrm{mg} / \mathrm{L}$ with $\mathrm{Pt}$ anode to $1.8 \mathrm{mg} / \mathrm{L}$ with MMO Ir-Pt anode and further to $3.5 \mathrm{mg} / \mathrm{L}$ with MMO Ru-Ir anode. 

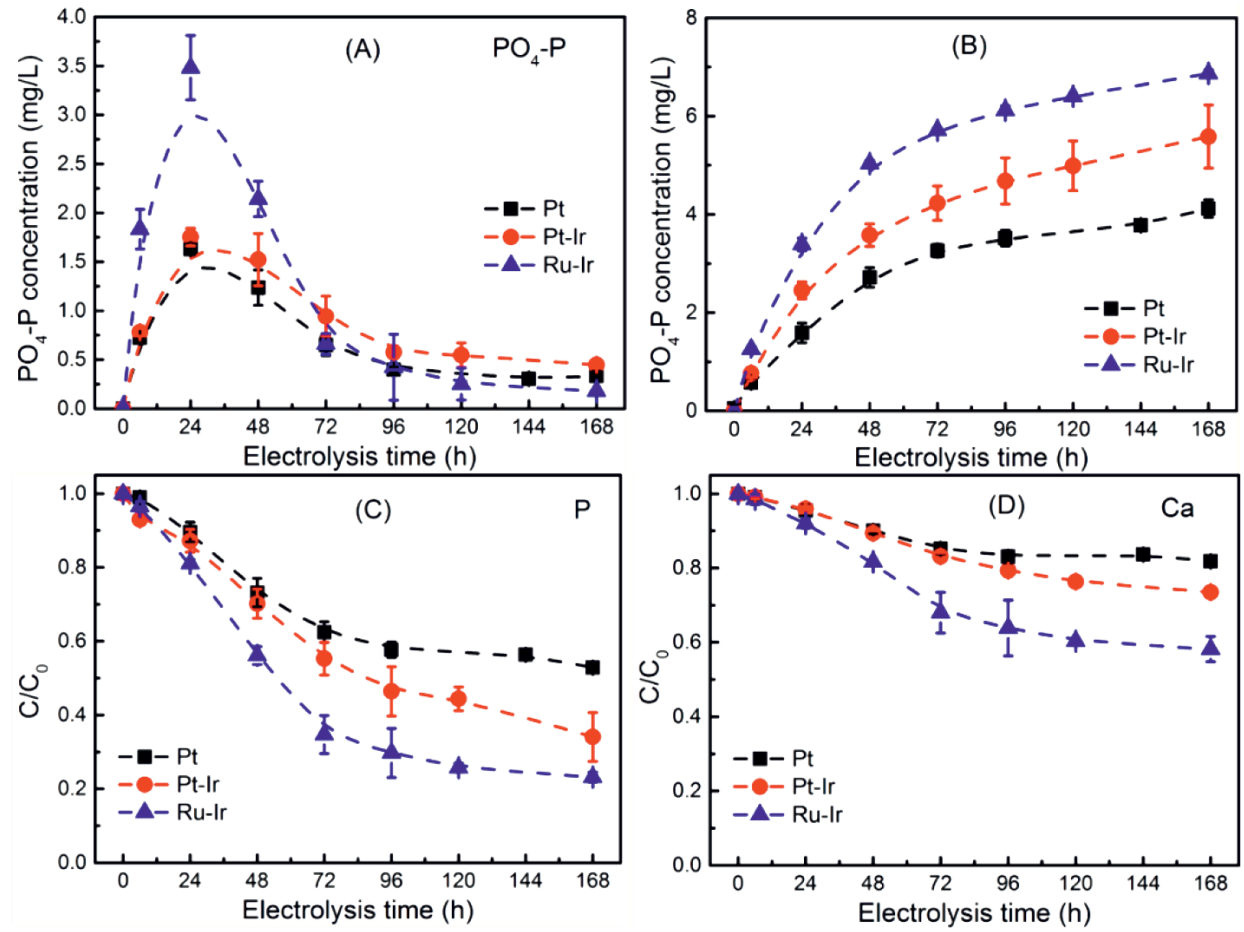

Figure 8.2. Influence of anode material on the evolution of $\mathrm{PO}_{4}-\mathrm{P}$ in the (A) presence and (B) absence of calcium ions, the removal of (C) $\mathrm{P}$, and (D) Ca in electrochemical treatment of NTMP. Conditions: $30 \mathrm{mg} / \mathrm{L}$ NTMP; $1.0 \mathrm{mM} \mathrm{Ca}{ }^{2+} ; 50 \mathrm{mM} \mathrm{Na}_{2} \mathrm{SO}_{4} ; \mathrm{pH}_{0}$ 4.0. titanium cathode $\left(36 \mathrm{~cm}^{2}\right)$; current density $28 \mathrm{~A} / \mathrm{m}^{2}$.

In the absence of calcium ions, the difference in the evolution of orthophosphate is even more obvious (Figure 8.2B). This is because the converted orthophosphate from NTMP will not be removed by calcium phosphate precipitation which happens in the presence of calcium ions. The maximum $\mathrm{PO}_{4}-\mathrm{P}$ concentration was in the order of $\mathrm{Ru}-\mathrm{Ir}(6.9 \mathrm{mg} / \mathrm{L})>\mathrm{Ir}-\mathrm{Pt}(5.6$ $\mathrm{mg} / \mathrm{L})>\operatorname{Pt}(4.1 \mathrm{mg} / \mathrm{L})$. The converted phosphate from NTMP corresponds to a conversion efficiency of non-orthophosphate to orthophosphate of $73.6 \%$ with $\mathrm{MMO} \mathrm{Ru}-\mathrm{Ir}$ anode, followed by MMO Ir-Pt anode (57.6\%) and Pt anode (43.5\%). Due to the improved formation of $\mathrm{PO}_{4}-\mathrm{P}$, the accompanied calcium phosphate precipitation was also enhanced. According to the kinetic modeling (Figure S8.4), the apparent rate constant of electrochemical removal of P from NTMP decreased in the order of Ru-Ir $\left(0.00592 \mathrm{~h}^{-1}\right)>\operatorname{Ir}-\mathrm{Pt}\left(0.00360 \mathrm{~h}^{-1}\right)>\mathrm{Pt}$ $\left(0.00264 \mathrm{~h}^{-1}\right)$. The overall removal of P reached $47.8 \%$ with $\mathrm{Pt}$ anode, $65.9 \%$ with Ir-Pt anode and $76.8 \%$ with Ru-Ir anode (Figure 8.2C). Similarly, as shown in Figure 8.2D, the removal efficiency of $\mathrm{Ca}$ increased from $19.2 \%(\mathrm{Pt})$ to $26.5 \%$ (Ir-Pt) and further to $41.8 \%$ (Ru-Ir). 
We conclude that the performance of the three different anode materials decreases in the order of Ru-Ir $>$ Ir-Pt $>$ Pt. The same trend was observed in the electrochemical conversion of micro-organic pollutants where the same electrodes were employed [176]. The difference in performance in the conversion of non-orthophosphate to orthophosphate, removal of $\mathrm{P}$, and $\mathrm{Ca}$ of the three employed anode materials is probably connected to their anodic oxidation mechanisms or anodic-mediated oxidation ability toward NTMP. In the electrochemical system, oxygen evolution will compete with NTMP oxidation at the anode surface. Pt is a well known material that has a low overpotential toward oxygen evolution. As such, Pt anode shows a poor oxidation toward NTMP. However, the use of MMO anodes may result in the formation of chemical or even physical adsorbed hydroxyl radicals $\left({ }^{\circ} \mathrm{OH}\right)$ [172], which are a very powerful oxidant. Hence, the performance of electrochemical destruction of NTMP and the associated $\mathrm{P}$ recovery as calcium phosphate were enhanced dramatically by using $\mathrm{Ru}-\mathrm{Ir}$ anode.

\subsubsection{Influence of electrolyte}

Given the fact that non-orthophosphates may be present in different water matrices, the performance of electrochemical $\mathrm{P}$ recovery from NTMP was evaluated in various background electrolytes (Figure 8.3). We found that in the presence of $\mathrm{NaCl}$, the removal efficiency of $\mathrm{P}$ (Figure 8.3A), the formation of $\mathrm{PO}_{4}-\mathrm{P}$ (Figure 8.3B) and the associated removal of $\mathrm{Ca}$ (Figure 8.3C) were boosted. The apparent rate constant of $\mathrm{P}$ removal in with $50 \mathrm{mM} \mathrm{NaCl}$ is $0.01577 \mathrm{~h}^{-1}$, which is even three times faster than with $\mathrm{Ru}-\mathrm{Ir}$ anode in $\mathrm{Na}_{2} \mathrm{SO}_{4}$ electrolyte (Figure S8.4 and Table S8.1). In just two days, $60.7 \%$ P of NTMP and $35.0 \% \mathrm{Ca}$ were removed and precipitated as solid calcium phosphate on the cathode. After four days' treatment, the removal of $\mathrm{P}$ and $\mathrm{Ca}$ reached $96.7 \%$ and $56.6 \%$, respectively. The substantially enhanced removal of $\mathrm{P}$ in the presence of $\mathrm{NaCl}$ is probably due to the role of chloride anion. Chloride can be oxidized at the anode, forming $\mathrm{Cl}_{2}$. In parallel, a series of chain reactions may result in the formation of other reactive chlorine species, i.e., $\mathrm{ClO}^{-}$[172]. These active chlorine species are known as strong oxidants and could oxidize NTMP molecules, converting non-orthophosphate to orthophosphate. In the case of $\mathrm{NaClO}_{4}$, no reactive chlorine species can be formed. Then the conversion of non-orthophosphate to orthophosphate will completely rely on direct electron transfer from NTMP to the anode and/or surface bounded radicals, although the later mechanism is likely to be limited. The Pt 
anode is not a good candidate for producing surface-bounded free radicals, due to its low overpotential for oxygen evolution [177]. Therefore, the oxygen evolution reaction competes with the oxidation of NTMP by Pt anode. As a result, the lowest removal efficiency was found within inert $\mathrm{NaClO}_{4}$ electrolyte. In the case of $\mathrm{Na}_{2} \mathrm{SO}_{4}$, although previous research suggested that persulfate and subsequent $\mathrm{H}_{2} \mathrm{O}_{2}$ could be formed [178], the contribution of such oxidants to the conversion of non-orthophosphate should be negligible, based on the fact that there is no significant difference between $\mathrm{Na}_{2} \mathrm{SO}_{4}$ and $\mathrm{NaClO}_{4}$.
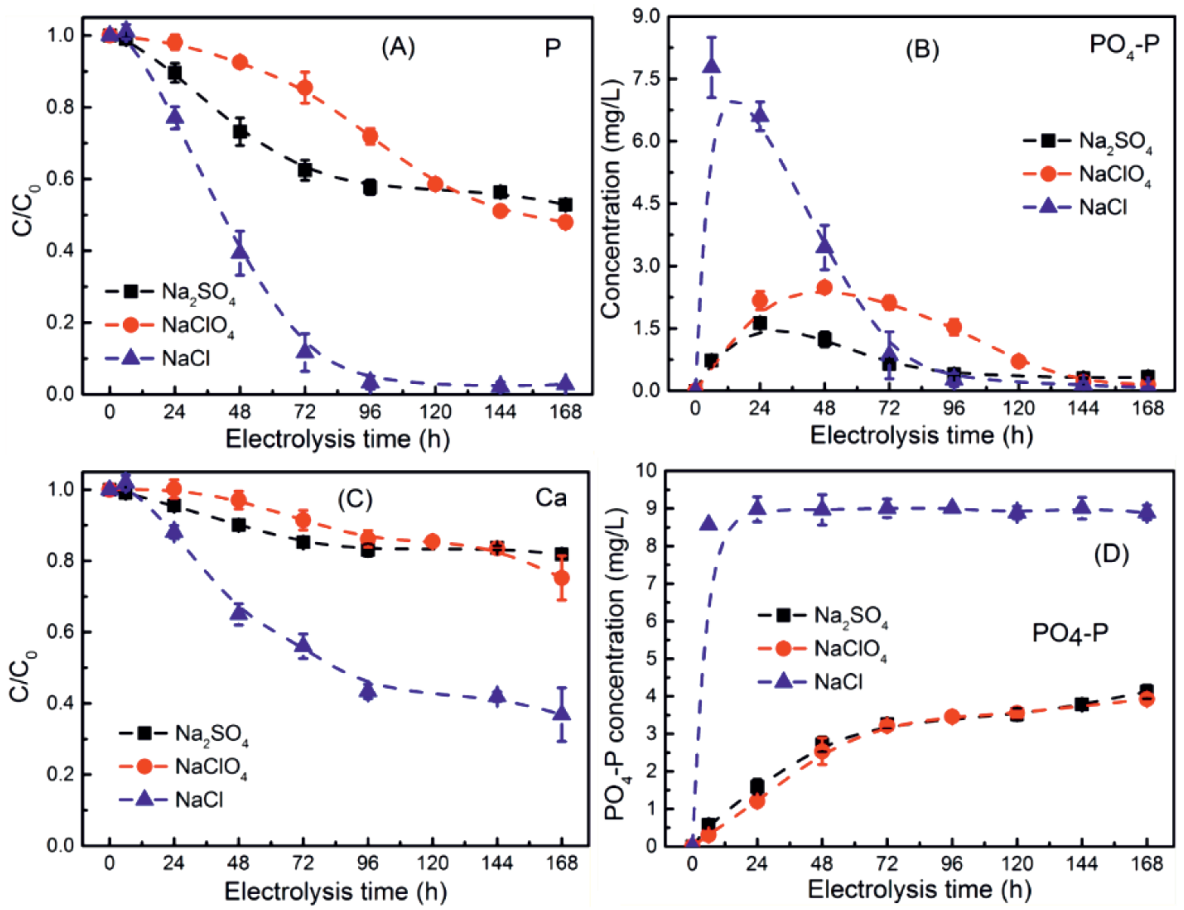

Figure 8.3. Influence of electrolyte on the removal of (A) P and (C) $\mathrm{Ca}$, and evolution of $\mathrm{PO}_{4}-\mathrm{P}$ in the (B) presence and (D) absence of calcium ions in electrochemical treatment of NTMP. Conditions: 30 mg/L NTMP; $1.0 \mathrm{mM} \mathrm{Ca}^{2+} ; 50$ mM Na $2 \mathrm{SO}_{4}$ or $\mathrm{NaClO}_{4}$ or NaCl; $\mathrm{pH}_{0}$ 4.0; titanium cathode $\left(36 \mathrm{~cm}^{2}\right)$; platinum coated titanium anode; current density $28 \mathrm{~A} / \mathrm{m}^{2}$.

We further confirmed the function of $\mathrm{Cl}^{-}$by looking at the evolution of $\mathrm{PO}_{4}-\mathrm{P}$ in the absence of calcium ions (Figure 8.3D). While the formation of $\mathrm{PO}_{4}-\mathrm{P}$ in the cases of $\mathrm{NaClO}_{4}$ and $\mathrm{Na}_{2} \mathrm{SO}_{4}$ is slow and incomplete, the conversion efficiency of non-orthophosphate to orthophosphate in the presence of $\mathrm{NaCl}$ is much higher. In six hours, the $\mathrm{PO}_{4}-\mathrm{P}$ concentration reached $8.6 \mathrm{mg} / \mathrm{L}$, which corresponds to a conversion efficiency of non-orthophosphate to 
orthophosphate of about $91.9 \%$. This efficiency is almost three times higher than with $\mathrm{NaClO}_{4}$ or $\mathrm{Na}_{2} \mathrm{SO}_{4}$ electrolyte. The overlapping $\mathrm{PO}_{4}-\mathrm{P}$ evolution trend between $\mathrm{NaClO}_{4}$ and $\mathrm{Na}_{2} \mathrm{SO}_{4}$ excludes the potential contribution of $\mathrm{SO}_{4}{ }^{2-}$ induced reactive oxidants (i.e., persulfate) in NTMP degradation. While not being tested, we can imagine that the performance could be further boosted if we combine the use of Ru-Ir anode with $\mathrm{NaCl}$ electrolyte.

\subsection{Mechanistic study}

The conversion of phosphonate to orthophosphate was not caused by radicals in the bulk solution. We examined this by adding methanol. Methanol is a well-known quenching agent for free radicals (i.e., ${ }^{\circ} \mathrm{OH}$ ) in bulk solutions [179]. However, the addition of $100 \mathrm{mM}$ methanol has no significant influence on the evolution of $\mathrm{PO}_{4}-\mathrm{P}$ and removal of $\mathrm{P}$ (Figure 8.4A), indicating that the conversion of NTMP to $\mathrm{PO}_{4}-\mathrm{P}$ is a surface-based reaction between anode and NTMP $[177,179]$. In addition, free radicals (i.e., $\left.{ }^{\circ} \mathrm{OH}\right)$ are not the main oxidant species for the conversion of NTMP to orthophosphate.
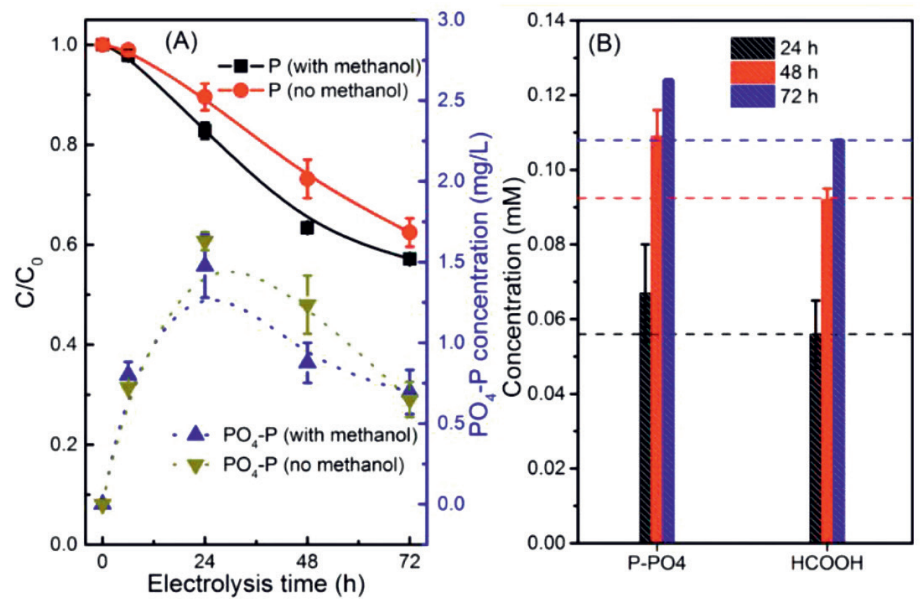

Figure 8.4. (A) Influence of methanol on the evolution of ortho-phosphorus $\left(\mathrm{PO}_{4}-\mathrm{P}\right)$ and removal of $\mathrm{P}$ in electrochemical treatment of NTMP. (B) Evolution of $\mathrm{PO}_{4}-\mathrm{P}$ and $\mathrm{HCOOH}$ in the absence of calcium ions in the presence of ethanol. Conditions: $30 \mathrm{mg} / \mathrm{L} \mathrm{NTMP}, 0 \mathrm{mM}$ $\mathrm{Ca}^{2+} ; 50 \mathrm{mM} \mathrm{Na} 2 \mathrm{SO}_{4} ; 100 \mathrm{mM}$ methanol or ethanol; $\mathrm{pH}_{0} 4.0$; titanium cathode $\left(36 \mathrm{~cm}^{2}\right)$; platinum coated titanium anode; current density $28 \mathrm{~A} / \mathrm{m}^{2}$. 
Instead, the conversion of NTMP is likely to happen via an electrochemical mediated electron transfer from NTMP to the anode. The evolution of orthophosphate indicates the cleavage of the C-P bond of NTMP molecules. We monitored the evolution of low molecular weight organic acids. It was found that formic acid $(\mathrm{HCOOH})$ was formed. The formation of formic acid indicates the breakdown of both $\mathrm{C}-\mathrm{P}$ and $\mathrm{C}-\mathrm{N}$ bonds. The cleavage of the two bonds was also observed in manganese catalyzed degradation of NTMP [180] and also in iron mineral induced degradation of other phosphonate compounds [181]. However, it is not clear which bond is broken first. It should be noted that the cleavage of $\mathrm{C}-\mathrm{N}$ bond alone will not generate phosphate and formic acid. Assuming the two bonds were cleaved at the same time, the generated mole concentration of phosphate and formic acid should be same, providing that the subsequent conversion of formic acid to $\mathrm{CO}_{2}$ and precipitation of phosphate with calcium ions were prevented. Therefore, we did control experiments by adding ethanol to the system in the absence of calcium ions. Without calcium ions, the converted $\mathrm{PO}_{4}-\mathrm{P}$ will not be consumed. The presence of ethanol will result in the formation of acetic acid $\left(\mathrm{CH}_{3} \mathrm{COOH}\right)$ instead of formic acid. Therefore, we can correlate the formation of formic acid and the oxidation of NTMP (Figure S8.5). More importantly, the addition of a high concentration of ethanol will inhibit the conversion of formic acid to $\mathrm{CO}_{2}$. In this case, the comparison of ortho-phosphorus concentration (mM) with formic acid will be able to reveal the cleavage of $\mathrm{C}-\mathrm{P}$ and $\mathrm{C}-\mathrm{N}$ bonds. As shown in Figure 8.4B, the formed $\mathrm{PO}_{4}-\mathrm{P}$ concentration is higher than $\mathrm{HCOOH}$ concentration in the whole process. Therefore, it is likely that the C-P bond was attacked first and then the $\mathrm{C}-\mathrm{N}$ bond. This could also be explained by the relevant bond energies. Theoretically, the C-N bond has a higher bond energy than the C-P bond, 305 $\mathrm{kJ} / \mathrm{mol}$ vs. $264 \mathrm{~kJ} / \mathrm{mol}$.

Based on the above discussion, a schematic diagram of proposed reaction pathways coupling oxidation and precipitation is illustrated in Figure 8.5. Firstly, NTMP is partly converted to phosphate by direct anodic oxidation (i.e., electron transfer) or through anodic-mediated oxidation (i.e., via $\mathrm{Cl}_{2}$ ) at the anode, depending on the background electrolyte and the catalytic nature of the anode material. Meanwhile, due to the reduction of water molecules at the cathode, which generates $\mathrm{H}_{2}$ and hydroxide ions $\left(\mathrm{OH}^{-}\right)$, a local high $\mathrm{pH}$ environment is established in the vicinity of the cathode. Secondly, the converted orthophosphate reacts with coexisting calcium ions, forming calcium phosphate solids on the cathode surface, driven by the local high $\mathrm{pH}$. In this way, the conversion of non-orthophosphate to orthophosphate and 
its subsequent recovery as recyclable calcium phosphate solids were achieved simultaneously by combining the functions of both electrodes.

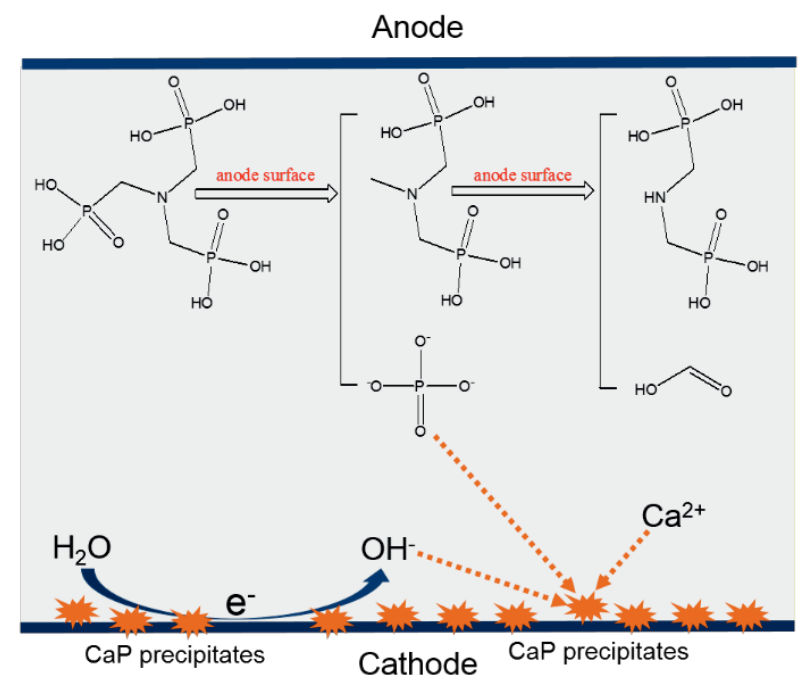

Figure 8.5. Electrochemically mediated calcium phosphate precipitation from phosphonate is coupled with the conversion of non-orthophosphate to orthophosphate and its subsequent precipitation with calcium ions on the cathode.

\subsection{Environmental implications}

We further investigated the efficiency of this system in a complicated environment by adding NTMP to the effluent of the local wastewater treatment plant. The total soluble P concentration in the effluent increased from less than $0.5 \mathrm{mg} / \mathrm{L}$ to $9.3 \mathrm{mg} / \mathrm{L}$ after adding 30 mg/L NTMP. As shown in Figure S8.6, by electrochemical treatment, the total P concentration decreased from $9.3 \pm 0.2$ to $3.5 \pm 0.3 \mathrm{mg} / \mathrm{L}$ in $24 \mathrm{~h}$ and to $1.0 \pm 0.1 \mathrm{mg} / \mathrm{L}$ in 48 $\mathrm{h}$, which corresponds to a removal efficiency of $63 \%$ in $24 \mathrm{~h}$ and $85 \%$ in $48 \mathrm{~h}$. Meanwhile, the Ca concentration in the effluent decreased from $49 \pm 1.2$ to $15 \pm 1.3 \mathrm{mg} / \mathrm{L}$ in $24 \mathrm{~h}$ and to $7.2 \pm 3.3 \mathrm{mg} / \mathrm{L}$ in $48 \mathrm{~h}$. The removal of the phosphonate in the real environment (Figure S8.6) is even faster than in synthetic solutions which do not contain chloride ions. This is probably due to the presence of $\mathrm{Cl}^{-}$in the real environment that results in the formation of chlorine and/or other potential active chlorine species, which could oxidize NTMP molecules, converting phosphonates to orthophosphate. The decrease of $\mathrm{Cl}^{-}$concentration in the wastewater supports the formation of $\mathrm{Cl}_{2}$ gas in this process (Figure S8.6). It should be noted 
that no external $\mathrm{Ca}$ source was dosed. The preliminary results in real wastewater highlight the promising feasibility of removing non-orthophosphate from complicated water matrices by a simple electrochemical treatment. The non-orthophosphate (i.e., phosphonates) could be converted to orthophosphate and then precipitated with coexisting calcium ions on the cathode in the form of calcium phosphate solids. The calcium phosphate solids could be collected and then used as a raw material for producing $\mathrm{P}$ fertilizer. In this way, the removal of non-orthophosphates and the recovery of $\mathrm{P}$ from non-orthophosphates were achieved in a single reactor by a simple electrochemical treatment. The findings in this study may be applied to other organic phosphorus-containing compounds as well like 1-hydroxyethylidene diphosphonic acid and diethylenetraiamine penta (methylene phosphonic acid) as used in household cleaning products, personal care products, industrial cleaning process, and as water treatment additives in various applications. While the feasibility of this system in real wastewaters needs to be further addressed in future studies in terms of efficiency and energy consumption, the proof of principle of this electrochemical approach may offer a simple yet efficient solution for addressing the possible eutrophication potential of non-orthophosphates. Moreover, the electrochemical recovery of $\mathrm{P}$ from non-orthophosphates may contribute to a circular P economy via the recovery of not only inorganic phosphate but also other groups of phosphorus-containing compounds (i.e., phosphonates).

\subsection{Conclusions}

Here, we demonstrated that electrochemical treatment of non-orthophosphate compounds could result in one-step phosphorus recovery in the form of calcium phosphate. At the anode, the non-orthophosphate was converted to inorganic orthophosphate. At the cathode, due to water reduction, a local high $\mathrm{pH}$ was established. Then the converted inorganic phosphate reacted with coexisting calcium ions and precipitated as calcium phosphate solids on the cathode. The performance of the electrochemical approach was affected by the catalytic nature of the anode material and the background electrolyte. The use of Ru-Ir anode or the presence of $\mathrm{Cl}^{-}$ions can boost the performance of the electrochemical approach. 


\section{Supporting information}

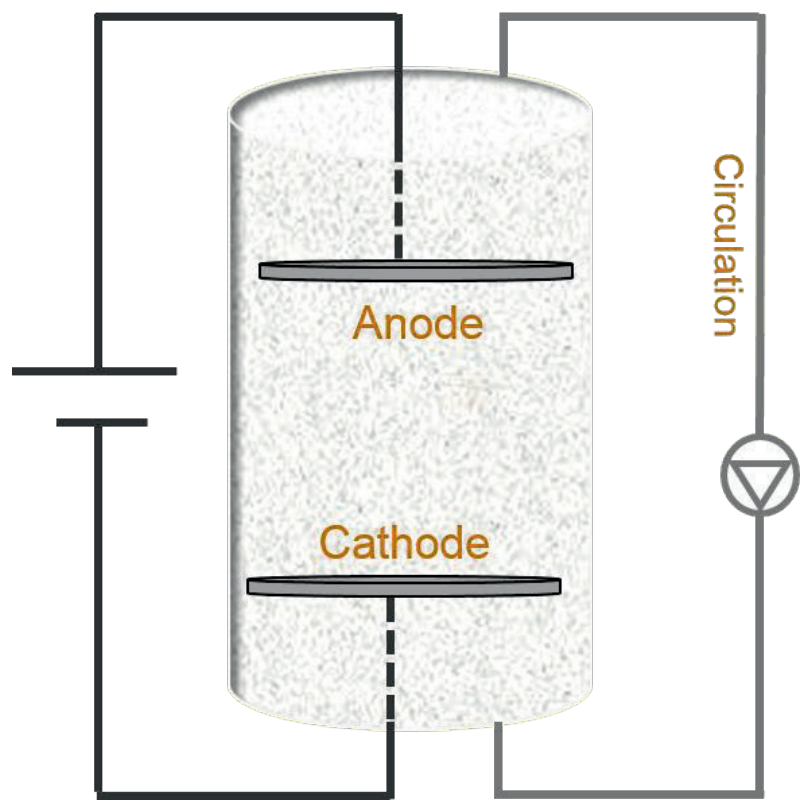

Figure S8.1. Schematic view of the electrochemical cell. The cathode was located below the anode. A pump was used to mixing the solutions inside the reactor. 


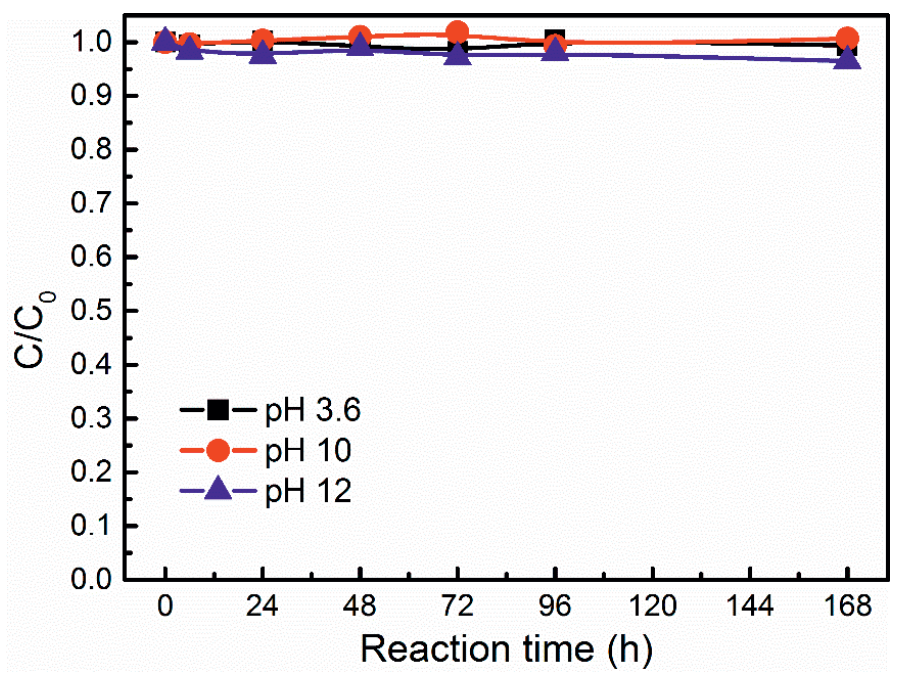

Figure S8.2. Removal profile of $\mathrm{P}$ in the absence of current by chemical precipitation, $\mathrm{pH}$ was adjusted by concentrated $\mathrm{NaOH}$. Almost no removal of $\mathrm{P}$ can be seen in chemical precipitation process. Conditions: $100 \mathrm{mg} / \mathrm{L}$ NTMP; $1.0 \mathrm{mM} \mathrm{Ca}^{2+} ; 50 \mathrm{mM} \mathrm{Na} \mathrm{SO}_{4}$.

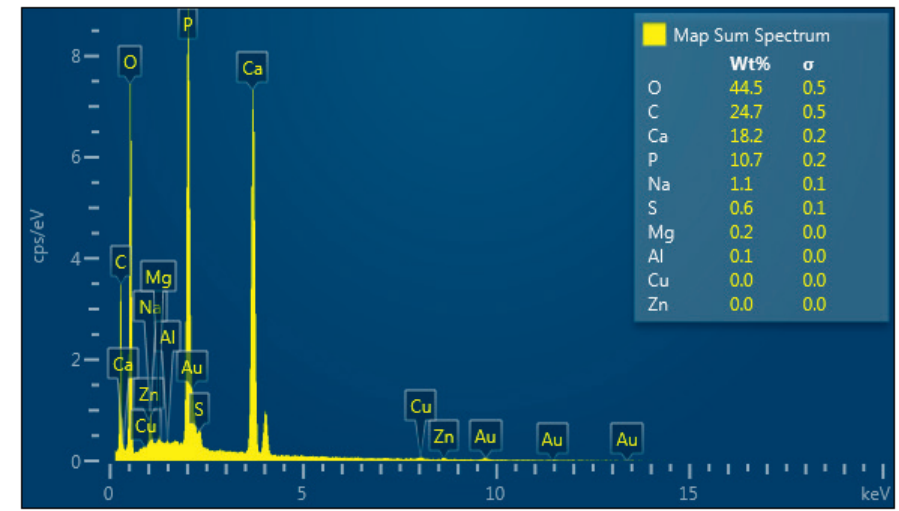

Figure S8.3. Element composition of the collected solids detected by energy dispersive Xray spectroscopy. The $\mathrm{Ca} / \mathrm{P}$ atomic ratio of the solids was determined to be 1.32 . 


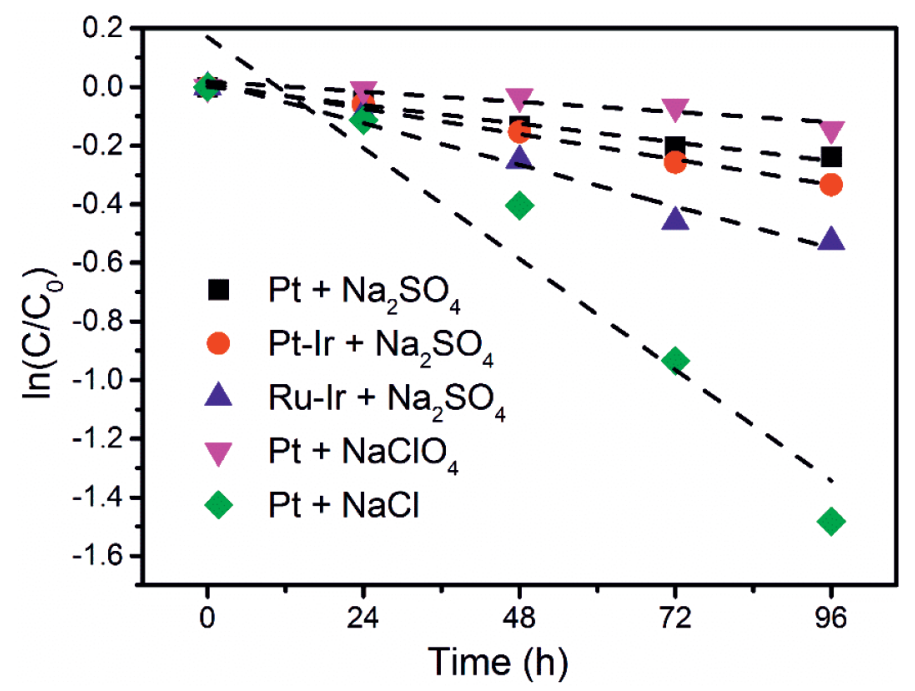

Figure S8.4. Influence of anode material and electrolyte on the removal of organic phosphorus in the electrochemical system. Conditions: $30 \mathrm{mg} / \mathrm{L}$ NTMP; $1.0 \mathrm{mM} \mathrm{Ca}{ }^{2+}$; titanium cathode $\left(36 \mathrm{~cm}^{2}\right)$; current $100 \mathrm{~mA}$.

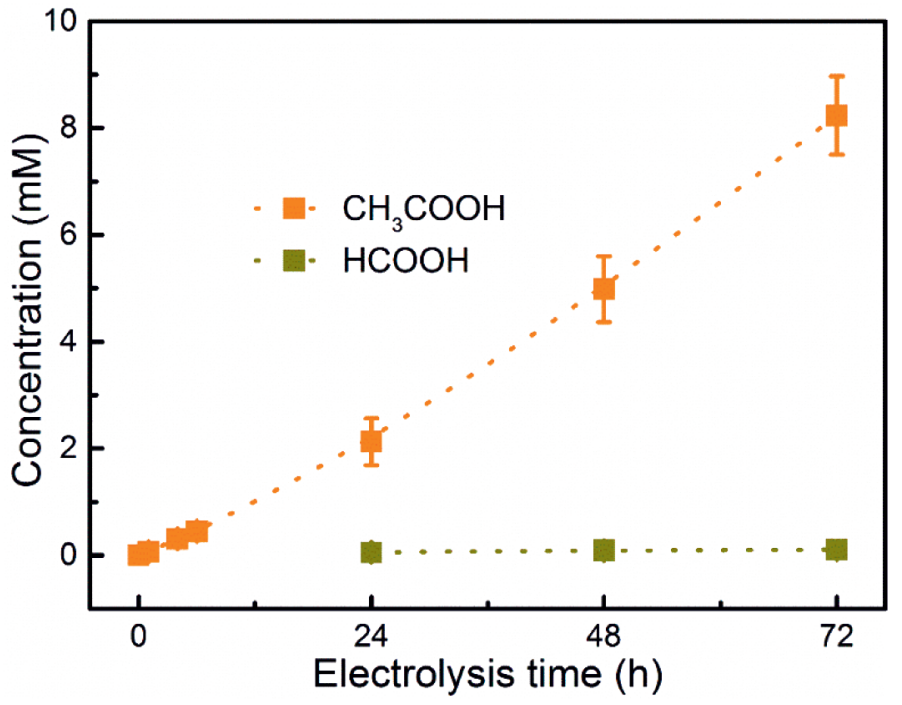

Figure S8.5. Formation of acetic acid and formic acid in electrochemical recovery of phosphorus from NTMP. Conditions: $30 \mathrm{mg} / \mathrm{L}$ NTMP; $1.0 \mathrm{mM} \mathrm{Ca}^{2+} ; 50 \mathrm{mM} \mathrm{Na}_{2} \mathrm{SO}_{4} ; 100$ $\mathrm{mM} \mathrm{CH} \mathrm{CH}_{2} \mathrm{OH}$; titanium cathode $\left(36 \mathrm{~cm}^{2}\right)$; platinum coated titanium anode; current 100 mA. 


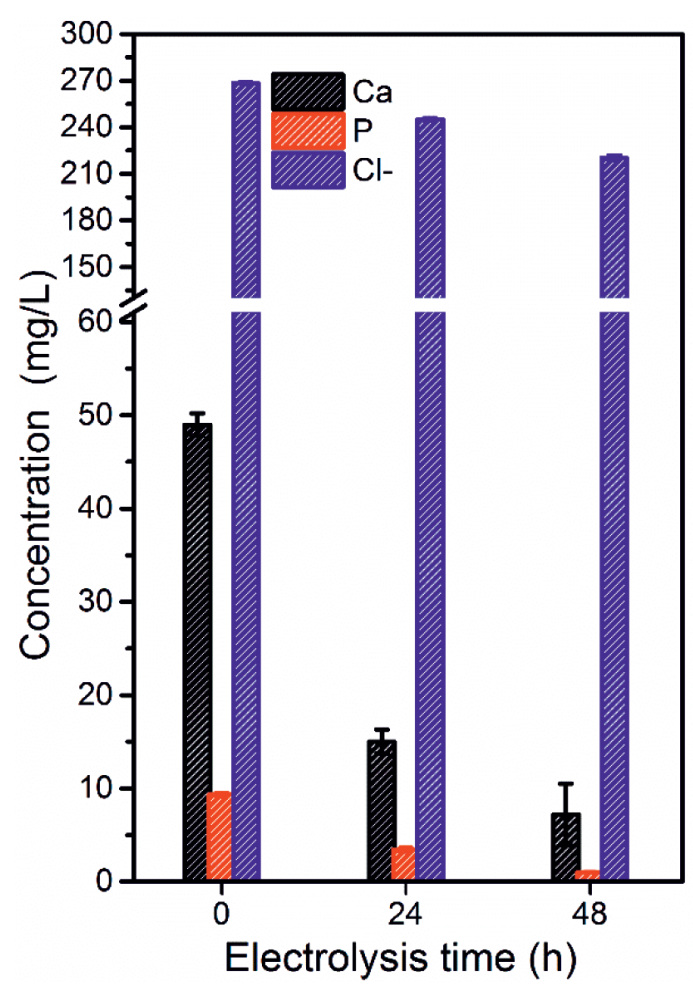

Figure S8.6. Change of $\mathrm{P}, \mathrm{Ca}$, and $\mathrm{Cl}^{-}$in electrochemical treatment of NTMP in real wastewater, $30 \mathrm{mg} / \mathrm{L}$ NTMP was added to the effluent from the local wastewater treatment plant. Conditions: titanium cathode $\left(36 \mathrm{~cm}^{2}\right)$; platinum coated titanium anode; current 100 $\mathrm{mA}$. 
Table S8.1. Apparent rate constant of electrochemical removal of organic phosphorus under various operating conditions $(\mathrm{NTMP}=30 \mathrm{mg} / \mathrm{L})$.

\begin{tabular}{llll}
\hline Anode material & Electrolyte $(50 \mathrm{mM})$ & $k\left(\mathrm{~h}^{-1}\right)$ & $\mathrm{R}^{2}$ \\
\hline $\mathrm{Pt}$ & $\mathrm{Na}_{2} \mathrm{SO}_{4}$ & 0.00264 & 0.976 \\
$\mathrm{Pt}$ & $\mathrm{NaClO}_{4}$ & 0.00144 & 0.848 \\
$\mathrm{Pt}$ & $\mathrm{NaCl}$ & 0.01577 & 0.920 \\
$\mathrm{Pt}-\mathrm{Ir}$ & $\mathrm{Na}_{2} \mathrm{SO}_{4}$ & 0.00360 & 0.991 \\
& $\mathrm{Na}_{2} \mathrm{SO}_{4}$ & 0.00592 & 0.969 \\
$\mathrm{Ru}-\mathrm{Ir}$ & & & \\
\hline
\end{tabular}




\section{Chapter 9}

\section{Calcium carbonate packed electrochemical precipitation column: new concept of phosphate removal and recovery}

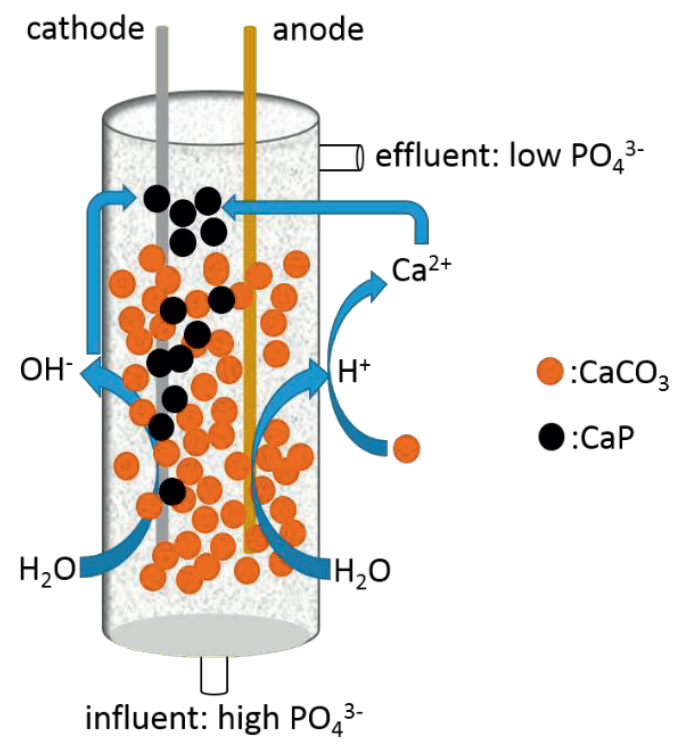

Yang Lei, Santosh Narsing, Michel Saakes, Renata D. van der Weijden, and Cees J. N. Buisman

This chapter has been published as:

Lei, Yang, Santosh Narsing, Michel Saakes, Renata D. van der Weijden, and Cees J. N. Buisman. "Calcium carbonate packed electrochemical precipitation column: new concept of phosphate removal and recovery"

Environmental Science \& Technology, 53, no. 18 (2019): 10774-10780. 


\begin{abstract}
Phosphorus (P) is a vital micronutrient element for all life forms. Typically, $\mathrm{P}$ can be extracted from phosphate rock. Unfortunately, the phosphate rock is a nonrenewable resource with a limited reserve on the earth. High levels of $\mathrm{P}$ discharged to waterbodies lead to eutrophication. Therefore, $\mathrm{P}$ needs to be removed and is preferably recovered as an additional $\mathrm{P}$ source. A possible way to achieve this goal is by electrochemically induced phosphate precipitation with coexisting calcium ions. Here, we report a new concept of phosphate removal and recovery, namely a $\mathrm{CaCO}_{3}$ packed electrochemical precipitation column, which achieved improved removal efficiency, shortened hydraulic retention time and substantially enhanced stability, compared with our previous electrochemical system. The concept is based on the introduction of $\mathrm{CaCO}_{3}$ particles, which facilitates calcium phosphate precipitation by buffering the formed $\mathrm{H}^{+}$at the anode, releases $\mathrm{Ca}^{2+}$, acts as seeds, and establishes a high $\mathrm{pH}$ environment in the bulk solution in addition to that in the vicinity of the cathode. It was found that the applied current, the $\mathrm{CaCO}_{3}$ particle size, and the feed rate affect the removal of phosphate. Under optimized conditions (particle size, $<0.5 \mathrm{~mm}$; feed rate, $0.4 \mathrm{~L} / \mathrm{d}$, current, 5 $\mathrm{mA}$ ), in a continuous flow system, the $\mathrm{CaCO}_{3}$ packed electrochemical precipitation column achieved $90 \pm 5 \%$ removal of phosphate in 40 days and $>50 \%$ removal over 125 days with little maintenance. The specific energy consumptions of this system lie between 29 and 61 $\mathrm{kWh} / \mathrm{kg}$ P. The experimental results demonstrate the promising potential of the $\mathrm{CaCO}_{3}$ packed electrochemical precipitation column for $\mathrm{P}$ removal and recovery from $\mathrm{P}$-containing streams.
\end{abstract}




\subsection{Introduction}

The ability to feed 10 billion people is one of the main challenges of the 21 st century. In any case, the use of phosphorus (P) fertilizer is crucial. $\mathrm{P}$, as an essential element for all living organisms, accounts for $2-4 \%$ weight of most dried cells and plays a vital role in fundamental biochemical reactions (i.e., gene expression) [2]. Typically, one adult consumes $35.2 \mathrm{~kg}$ of phosphate rock per year [3]. In general, P fertilizer can be processed from mined phosphate rock. Unfortunately, phosphate rock, as a finite resource, will be subject to exhaustion in a few hundred years with the current mining and usage rate [1]. The use of P fertilizer and other $\mathrm{P}$ products have brought much $\mathrm{P}$ to water bodies, leading to a worldwide environmental problem, namely, eutrophication $[7,10]$.

We need to address issues about $\mathrm{P}$ being scare as a resource (fertilizer) yet abundant as a pollutant (eutrophication) by recycling the $\mathrm{P}$ in waste streams [7, 10]. Pioneers have recognized the importance of $\mathrm{P}$ recycling and developed many approaches for achieving this goal $[21,22]$. While each approach has its merits and drawbacks, the principle is the same: the conversion of $\mathrm{P}$ from a soluble form to a solid phase, which can then be separated from waste streams for potential reuse.

In the realm of $\mathrm{P}$ recovery, struvite process is a well-developed method [27]. This method has the advantage that phosphate $\left(\mathrm{PO}_{4}-\mathrm{P}\right)$ and ammonium $\left(\mathrm{NH}_{4}-\mathrm{N}\right)$ are removed simultaneously. Also, the recovered product can be used as a slow release fertilizer. However, the struvite process needs well-controlled solution conditions [52], which typically means a high phosphate concentration, a $\mathrm{Mg} / \mathrm{NH}_{4} / \mathrm{PO}_{4}$ molar ratio close to $1: 1: 1$, and $\mathrm{pH}$ between 8 and 9 [28]. As such, due to the low $\mathrm{Mg}^{2+}$ concentration relative to $\mathrm{PO}_{4}{ }^{3-}$ and $\mathrm{NH}_{4}{ }^{+}$in most nutrient-rich waste streams, the dosing of a Mg source is required [28]. The struvite process is used in practice but is not widely adopted. Furthermore, calcium phosphate has also recently been shown to be an effective fertilizer when compared to conventional fertilizers and struvite [182].

Alternatively, P removal and recovery as calcium phosphate was proposed [29]. This process has the advantage that the addition of $\mathrm{Ca}$ is usually not necessary, as $\mathrm{Ca}^{2+}$ is an abundant ion in most waste streams $[31,32]$. It is worth mentioning that even when $\mathrm{Ca}$ addition is required, the cost of dosing $\mathrm{Ca}$ is cheaper than dosing $\mathrm{Mg}[33,34]$. Moreover, calcium phosphate is 
the key component of mined phosphate rock and therefore, it can be used directly as a raw material for producing $\mathrm{P}$ fertilizer in the existing production process [31].

Electrochemical processes have gained increasing interest as next-generation wastewater treatment technologies in the last decades [44, 62]. On top of wastewater treatment, electrochemical methods also show excellent potential in resource recovery from waste streams $[45,183]$. Lei and coauthors established and validated an electrochemical approach for P removal and recovery [32, 147, 151]. This approach showed advantages: there was no need to dose a calcium source, adjust the $\mathrm{pH}$ of wastewater, or require a solid-liquid separation process $[32,147,151]$. Moreover, it is a membrane-free system. However, the P removal efficiency in this system is low, and the retention time is long. For example, to reach $50 \%$ removal efficiency, a run-time of about $24 \mathrm{~h}$ at $20 \mathrm{~mA}$ (current density of $4.0 \mathrm{~A} / \mathrm{m}^{2}$ ) is needed [89].

One of the critical reasons for the low removal efficiency and long retention time in this membrane-free electrochemical approach is the recombination of anode produced protons $\left(\mathrm{H}^{+}\right)$with cathode generated hydroxide ions $\left(\mathrm{OH}^{-}\right)$. While the $\mathrm{H}^{+}-\mathrm{OH}^{-}$recombination can be avoided by using ion exchange membranes, the introduction of membranes will bring other problems, such as a complex configuration, the fouling of membranes, the associated maintenance effort, and the increased operating cost.

Here, in this paper, we propose a simple yet highly efficient approach to overcome direct $\mathrm{H}^{+}-$ $\mathrm{OH}^{-}$recombination. In our approach, we fill a column-shaped electrochemical precipitation reactor with calcium carbonate $\left(\mathrm{CaCO}_{3}\right)$ particles. The $\mathrm{CaCO}_{3}$ particles, which are in contact with/or close to the anode, react with electrochemically produced $\mathrm{H}^{+}$[126], and thus limit the neutralization between $\mathrm{H}^{+}$and $\mathrm{OH}^{-}$. Additionally, two extra benefits are achieved. Along with the consumption of $\mathrm{H}^{+}$by $\mathrm{CaCO}_{3}$ particles, $\mathrm{Ca}^{2+}$ ions are released into the bulk solution. Meanwhile, the electrochemically generated $\mathrm{OH}^{-}$ions are accumulated in the bulk solution. As a result, a high $\mathrm{pH}$ environment can be established in the bulk solution as well as in the vicinity of the cathode [126]. Therefore, homogeneous precipitation of calcium phosphate may occur in the bulk solution, in addition to its precipitation on the cathode surface. Furthermore, the $\mathrm{CaCO}_{3}$ particles may work as crystallization seeds, allowing calcium phosphate nucleation and growth on their surface at a much lower driving force and induction time [184]. 
The goal of this research is to identify the possibility, the efficiency, and the mechanism of the $\mathrm{CaCO}_{3}$ particle packed electrochemical precipitation column toward phosphate removal and recovery. We first looked at the possibility of electrochemically splitting of $\mathrm{CaCO}_{3}$ particles. We then explored the effects of particle size, feed rate, and electrical current on the removal of phosphate in this system. Additionally, we examined the feasibility of this system to treat low P-containing streams and real domestic wastewater and further evaluated the stability of this system for long-term operation. The $\mathrm{CaCO}_{3}$ packed electrochemical precipitation column may offer a robust yet efficient approach toward $\mathrm{P}$ removal and recovery from various wastewaters.

\subsection{Materials and methods}

\subsubsection{Materials}

$\mathrm{Na}_{2} \mathrm{HPO}_{4} \cdot 2 \mathrm{H}_{2} \mathrm{O}, \mathrm{NaOH}$, and $\mathrm{Na}_{2} \mathrm{SO}_{4}$ were purchased from VWR chemicals (Belgium). $\mathrm{Ca}\left(\mathrm{NO}_{3}\right)_{2} \cdot 4 \mathrm{H}_{2} \mathrm{O}$ was received from Merck (Germany). The $\mathrm{CaCO}_{3}$ particles were supplied by a drinking water company where $\mathrm{CaCO}_{3}$ solids were produced from the water softening process. These particles were fractioned through mesh sieves: diameters $<0.5 \mathrm{~mm}, 0.5-1 \mathrm{~mm}$, 1-2 $\mathrm{mm}$, and 2-3 mm diameter. The domestic wastewater was obtained from the influent of a local wastewater treatment plant (Leeuwarden, The Netherlands), further prefiltered with a $100-\mu \mathrm{m}$ sieve, and stored in a $4^{\circ} \mathrm{C}$ fridge. The electrodes were provided by MAGNETO Special Anodes BV (Schiedam, The Netherlands).

\subsubsection{Setup}

Figure 9.1 shows the configuration of the electrochemical precipitation column with real images. The column was made of polypropylene material with a diameter of $6 \mathrm{~cm}$ and a length of $16 \mathrm{~cm}$ and had an empty bed volume of about $70 \mathrm{~mL}$. The column was filled with glass beads at the bottom to prevent clogging of the tubes with fine $\mathrm{CaCO}_{3}$ particles and to have an equal distribution of feed solution inside the column. There was about $85 \mathrm{~g}$ of a predetermined size (1-2 mm) of $\mathrm{CaCO}_{3}$ particles on top of the glass beads, giving a bed height of $12-13 \mathrm{~cm}$. The column contained two rod-shaped electrodes, a platinum-coated titanium anode, and a pure A-grade titanium cathode. Both electrodes had diameters of $3 \mathrm{~mm}$ and lengths of about $20 \mathrm{~cm}$ each. However, only the electrode length that was below the liquid level was considered for the calculation of current density. Thus, the length was about 
$15 \mathrm{~cm}$ for both electrodes. Therefore, the surface area of both electrodes was approximately $0.0014 \mathrm{~m}^{2}$. The distance between the electrodes was about $1 \mathrm{~cm}$. The electrochemical precipitation column was operated under constant current mode, and the needed cell voltage was provided by a power supply (ES 030-5, Delta Electronics B.V, The Netherlands). All experiments were conducted at room temperature $\left(T=23 \pm 1^{\circ} \mathrm{C}\right)$.

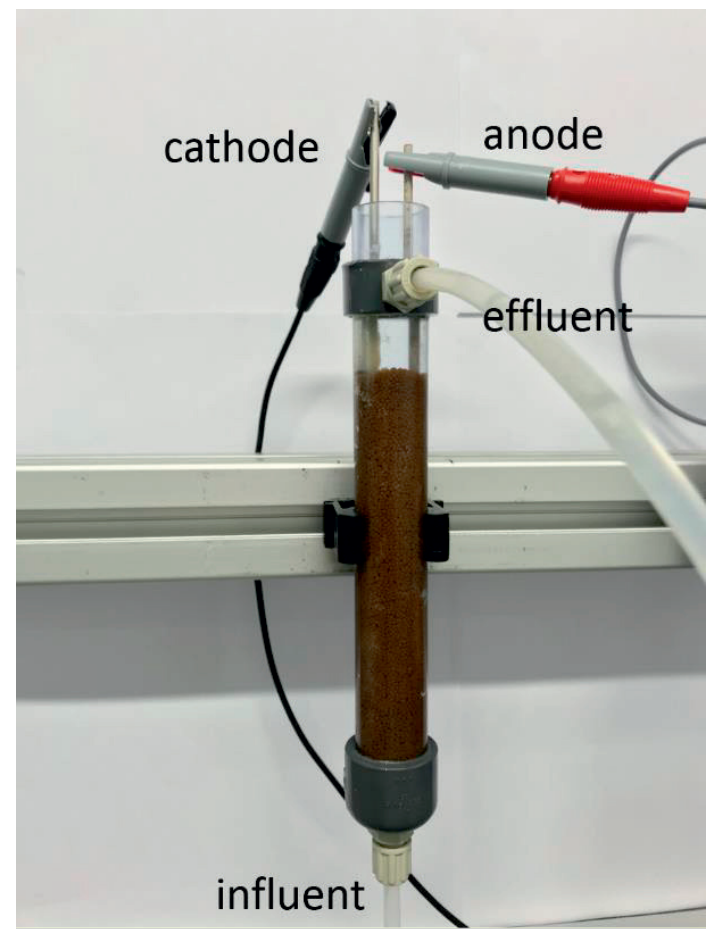

Figure 9.1. Schematic diagram of the setup. The cathode is A-grade titanium rod; the anode is platinum coated titanium rod. $\mathrm{CaCO}_{3}$ particles are packed in the column-shaped electrochemical cell. At the bottom of the column, glass beads are used.

\subsubsection{Experimental design}

We first conducted experiments with synthetic solutions in the as-described electrochemical precipitation column. The typical synthetic solutions contained $0.6 \mathrm{mM} \mathrm{PO}-\mathrm{P}$ and $10 \mathrm{mM}$ $\mathrm{Na}_{2} \mathrm{SO}_{4}$, which were prepared by dissolving analytical grade chemicals in deionized water (18.2 $\mathrm{M} \Omega \cdot \mathrm{cm}$, Millipore). We studied the influence of particle size $(<0.5 \mathrm{~mm}, 0.5-1 \mathrm{~mm}$, 1-2 mm, 2-3 mm), applied current $(5,10,20 \mathrm{~mA})$, and feed rate $(0.4,0.8,1.2,2.4 \mathrm{~L} / \mathrm{d})$ on the performance of the electrochemical precipitation column with synthetic solutions. In the 
section of proof of principle, the feed solutions only contained $10 \mathrm{mM} \mathrm{Na}_{2} \mathrm{SO}_{4}$ and the $\mathrm{pH}$ was adjusted to 7.5 , which was the same as the phosphate present in the feed solution. In some experiments, we reduced the phosphate concentration to as low as $0.032 \mathrm{mM}(\sim 1.0$ $\left.\mathrm{mg} / \mathrm{L}_{4}-\mathrm{P}\right)$ in order to determine the feasibility of this system to treat low phosphatecontaining solutions. We then evaluated the efficiency of this system toward real domestic wastewater. To identify the function of the $\mathrm{CaCO}_{3}$ particles, we also examined the removal of $\mathrm{PO}_{4}-\mathrm{P}$ in the absence of $\mathrm{CaCO}_{3}$ particles, by supplying $1.0 \mathrm{mM} \mathrm{Ca}^{2+}(40 \mathrm{mg} / \mathrm{L})$ to the feed solution, and the adsorption of phosphate by $\mathrm{CaCO}_{3}$ particles in the absence of current. For each independent test, the column was run in a continuous up-flow way under predetermined conditions for at least 1 week. The data are given as the mean and standard deviations of the samples collected each day over the independent testing period. After each test, both electrodes were cleaned by immersion in acidic solutions $\left(1 \mathrm{M} \mathrm{HNO}_{3}\right)$ and then rinsed with deionized water. The new and used $\mathrm{CaCO}_{3}$ granule compositions were examined by dissolution in strong acid $\left(69 \% \mathrm{HNO}_{3}, 20 \mathrm{~mL}\right)$. The composition of these acidic solutions was analyzed to identify the possible precipitates on both electrodes and $\mathrm{CaCO}_{3}$ particles. Lastly, we tested the performance of the electrochemical precipitation column for phosphate removal under the recognized best parameters for a long period (125 days) in order to verify the stability of this system for long-term operation.

\subsubsection{Analytical methods}

We applied ICP-AES (Optima $5300 \mathrm{DV}$, PerkinElmer) to quantify the concentrations of P and $\mathrm{Ca}$, with the detection limits for $\mathrm{P}$ and being 20 and $50 \mu \mathrm{g} / \mathrm{L}$, respectively. Total organic carbon (TOC) was measured by a TOC-LCPH analyzer equipped with an ASI-L autosampler (Shimadzu) with $1.0 \mathrm{mg} / \mathrm{L}$ detection limit. We identified the phases of the fresh (unused) and used $\mathrm{CaCO}_{3}$ granules by X-ray diffraction (XRD) and determined their elemental compositions with acid digestion. Details about the instruments can be referred elsewhere $[32,89]$.

\subsection{Results and discussion}

\subsubsection{Proof of principle: electrochemically splitting of $\mathrm{CaCO}_{3}$ particles}

We first show that calcium ions can be released from electrochemically induced dissolution of $\mathrm{CaCO}_{3}$ particles (see solid characterization in Text S9.1, Figure S9.1, and Table S9.1). 
In this case, the feed solution only contained $\mathrm{Na}^{+}$and $\mathrm{SO}_{4}{ }^{2-}$ (no $\mathrm{PO}_{4}{ }^{3-}$ ). As shown in Figure 9.2, in the absence of current, the effluent $\mathrm{Ca}$ concentration was $8.7 \mathrm{mg} / \mathrm{L}$ and $\mathrm{pH}$ was 8.3 . In the presence of $5 \mathrm{~mA}$ (current density of $3.5 \mathrm{~A} / \mathrm{m}^{2}$ ), the effluent Ca concentration and $\mathrm{pH}$ increased to $28.0 \mathrm{mg} / \mathrm{L}$ and 9.9, respectively. This reveals that the combination of $\mathrm{CaCO}_{3}$ particles with electric current not only provides calcium ions but also creates a high $\mathrm{pH}$ environment in the entire bulk solution. In a typical electrochemical system, at the anode, water molecules are oxidized, producing $\mathrm{H}^{+}$and oxygen (eq 9.1). At the cathode, water molecules are reduced, forming $\mathrm{OH}^{-}$and hydrogen (eq 9.2).

$$
\begin{aligned}
& \text { Anode: } 2 \mathrm{H}_{2} \mathrm{O} \rightarrow 4 \mathrm{H}^{+}+\mathrm{O}_{2} \uparrow+4 \mathrm{e}^{-} \\
& \text {Cathode: } 4 \mathrm{H}_{2} \mathrm{O}+4 \mathrm{e}^{-} \rightarrow 4 \mathrm{OH}^{-}+2 \mathrm{H}_{2} \uparrow \\
& \text { Bulk solution: } \mathrm{H}^{+}+\mathrm{OH}^{-} \rightarrow \mathrm{H}_{2} \mathrm{O} \\
& \mathrm{CaCO}_{3}+2 \mathrm{H}^{+} \rightarrow \mathrm{Ca}^{2+}+\mathrm{H}_{2} \mathrm{CO}_{3}
\end{aligned}
$$
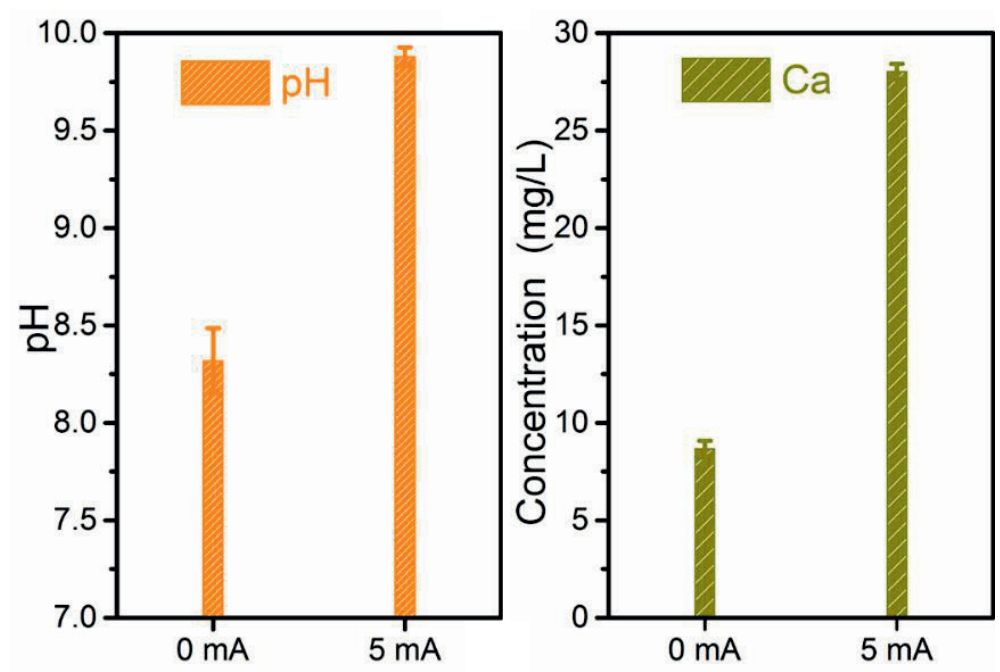

Figure 9.2. Proof of principle. Conditions: feed solutions contain only $10 \mathrm{mM} \mathrm{Na}_{2} \mathrm{SO}_{4}$, and no phosphate. Initial $\mathrm{pH}$ of feed solution was adjusted to 7.5 , which is similar to when phosphate is present.

As a result, a local high $\mathrm{pH}$ and low $\mathrm{pH}$ will be established at the cathode and anode, respectively. The bulk solution $\mathrm{pH}$, however, will not change significantly, due to the neutralization of $\mathrm{H}^{+}$with $\mathrm{OH}^{-}$(eq 9.3). In the presence of $\mathrm{CaCO}_{3}$ particles, the $\mathrm{CaCO}_{3}$ solids 
which face the anode will be dissolved to some extent by the anodically produced acidity (eq 9.4) [126]. Along with the reaction of $\mathrm{H}^{+}$with $\mathrm{CaCO}_{3}$, the cathodically produced $\mathrm{OH}^{-}$ions will accumulate in the bulk solution, increasing the $\mathrm{pH}$ of the bulk solution [126]. As a result, we found an increased $\mathrm{Ca}$ concentration and $\mathrm{pH}$ in the effluent (Figure 9.2). In the case of a feed solution containing phosphate, the phosphate will be removed by calcium phosphate precipitation, either on the cathode surface which has a local high $\mathrm{pH}$ or on the surface of $\mathrm{CaCO}_{3}$ particles (heterogeneous precipitation) and/or even in the bulk solution by homogeneous precipitation. It may be argued that $\mathrm{CaCO}_{3}$ granules can directly result in the removal of phosphate by adsorption. However, according to the control experiments in the absence of current, the removal of phosphate is negligible, and the effluent calcium concentration and $\mathrm{pH}$ are also much lower than those with current (Figure 9.3).

\subsubsection{Effect of current}

We further studied the influence of current (density) on the performance of the electrochemical precipitation column. Figure 9.3 shows that the removal of phosphate strongly depends on the applied current.
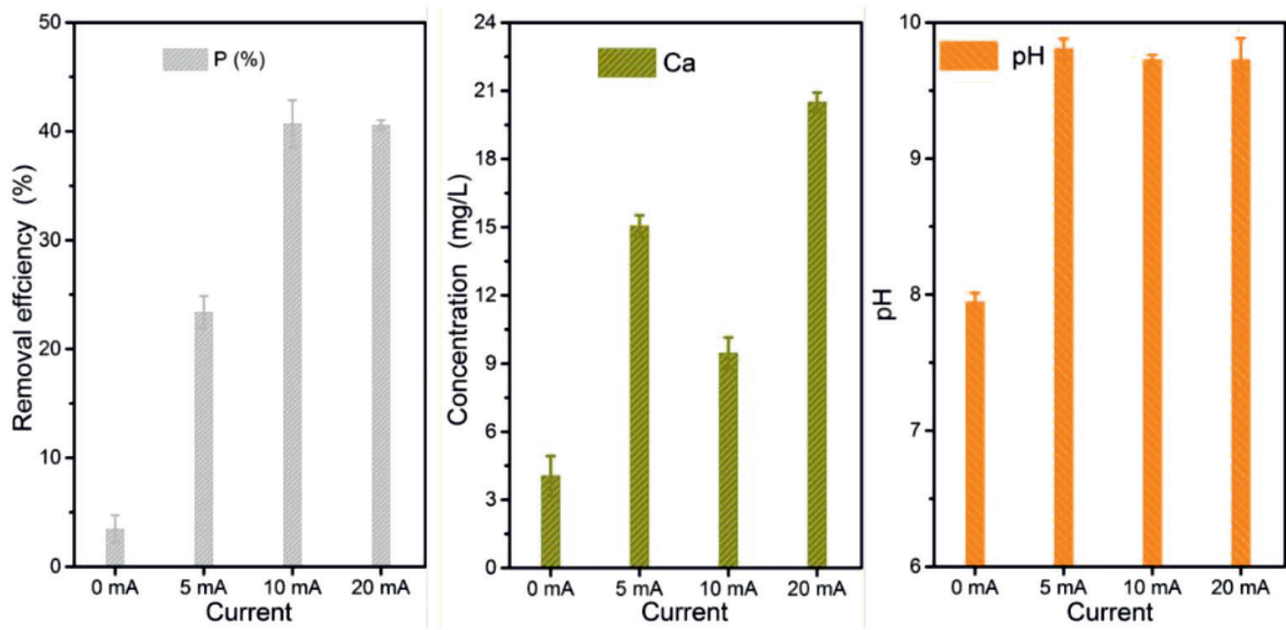

Figure 9.3. Effects of current on the removal of $\mathrm{PO}_{4}-\mathrm{P}$, the effluent $\mathrm{Ca}$ concentration and $\mathrm{pH}$. Conditions: particle size, $1-2 \mathrm{~mm}$; feed rate, $2.4 \mathrm{~L} / \mathrm{d}$. Feed solution contains $10 \mathrm{mM} \mathrm{Na}_{2} \mathrm{SO}_{4}$ and $0.6 \mathrm{mM} \mathrm{PO}_{4}-\mathrm{P}$ with an initial $\mathrm{pH}$ of 7.5.

Specifically, in an open circuit ( $0 \mathrm{~mA})$, only $4 \%$ of phosphate was removed. The phosphate removal efficiency reached $23 \%$ at a current of $5 \mathrm{~mA}\left(3.5 \mathrm{~A} / \mathrm{m}^{2}\right)$ and $40 \%$ at $10 \mathrm{~mA}(7.0$ 
$\left.\mathrm{A} / \mathrm{m}^{2}\right)$. However, a further increase of the applied current to $20 \mathrm{~mA}\left(14 \mathrm{~A} / \mathrm{m}^{2}\right)$ did not promote the removal of phosphate anymore. This may be due to the competition between the precipitation of $\mathrm{CaCO}_{3}$ and calcium phosphate. In our previous study, we found that in the presence of (bi)carbonate, a high current resulted in a greater precipitation of $\mathrm{CaCO}_{3}$ than calcium phosphate [32].

The effluent $\mathrm{Ca}$ concentration is not always positively related to the applied current. At 10 $\mathrm{mA}$, the effluent Ca concentration $(9.5 \mathrm{mg} / \mathrm{L})$ was lower than that at $5 \mathrm{~mA}(15.1 \mathrm{mg} / \mathrm{L})$, which was not expected. This might result from the simultaneous release and consumption of $\mathrm{Ca}^{2+}$. While a high current means a high production of $\mathrm{H}^{+}$possibly resulting in a greater release of $\mathrm{Ca}^{2+}$ from $\mathrm{CaCO}_{3}$ particles, a high current also means a high removal of $\mathrm{P}$ and thus the removal of released $\mathrm{Ca}^{2+}$. More importantly, it should be noted that the calcium ions could precipitate with carbonate again by forming calcium carbonate (eq 9.5).

$$
\mathrm{Ca}^{2+}+\mathrm{CO}_{3}^{2-} \rightarrow \mathrm{CaCO}_{3}
$$

This is because the dissolution of $\mathrm{CaCO}_{3}$ solids will release both calcium ions and carbonic acid [126]. The carbonic acid may quickly dissociate to bicarbonate and/or carbonate, depending on the bulk solution $\mathrm{pH}$ before it would escape as $\mathrm{CO}_{2}$ through the bulk solution. As the local $\mathrm{pH}$ close to the cathode is much higher than that in the bulk solution [89], part of the inorganic carbon around the cathode may be in the form of $\mathrm{CO}_{3}{ }^{2-}$, which may react with $\mathrm{Ca}^{2+}$, forming solid calcium carbonate. These factors together may explain the trend of effluent $\mathrm{Ca}$ concentration as a function of current.

The effluent $\mathrm{pH}$ was relatively stable around 9.7 in closed circuit, regardless of the applied current. As explained, the increase of effluent $\mathrm{pH}$ is due to the consumption of $\mathrm{H}^{+}$(anode) by $\mathrm{CaCO}_{3}$ particles and the accumulation of $\mathrm{OH}^{-}$(cathode). The relatively stable effluent $\mathrm{pH}$ is due to the formation of (bi)carbonate resulting from the electrochemically induced dissolution of $\mathrm{CaCO}_{3}$ granules, which work as buffer.

\subsubsection{Effect of $\mathrm{CaCO}_{3}$ particle size}

A prerequisite for the electrochemical precipitation of calcium phosphate in the $\mathrm{CaCO}_{3}$ packed column is the release of calcium ions. As such, the $\mathrm{CaCO}_{3}$ particle size is expected to affect the performance. In general, the smaller the particle size, the larger the surface area. Therefore, more release of calcium ions is expected when using smaller particles, as is $\mathrm{P}$ 
removal efficiency. Indeed, as shown in Figure S9.2, the removal of P follows the theory that a smaller particle size results in a higher removal efficiency, except for the case of particles with sizes from 2 to $3 \mathrm{~mm}$. The $2-3 \mathrm{~mm} \mathrm{CaCO}_{3}$ particles are believed to have a lower surface area compared with smaller particles.

Nonetheless, we achieved the second highest removal efficiency (35\%) with using $2-3 \mathrm{~mm}$ $\mathrm{CaCO}_{3}$ particles, which was not expected. This might be explained by large pores between the stacked $\mathrm{CaCO}_{3}$ particles with the use of bigger particles, which facilitates the diffusion of released $\mathrm{Ca}^{2+}$, and its interaction with phosphate and $\mathrm{CaCO}_{3}$ solids. Due to the presence of (bi)carbonate (buffer), the $\mathrm{pH}$ in the column should be similar to the effluent $\mathrm{pH}$, which lies between 9 and 10. The high $\mathrm{pH}$ may result in homogeneous precipitation of calcium phosphate in the bulk solution inside the column and the associated settling on the $\mathrm{CaCO}_{3}$ particles. Thus, a higher removal percentage of phosphate was observed with $2-3 \mathrm{~mm}$ particles $(35 \%)$ than that with the use of $1-2 \mathrm{~mm}$ particles $(21 \%)$. Additionally, the use of large particles may bring practical benefits by reducing the clogging risk of the column in the treatment of real wastewater which would result in a longer run-time.

\subsubsection{Effect of feed rate}

Figure 9.4 shows that the removal efficiency of phosphate decreased with the increase of flow rate. At $0.4 \mathrm{~L} / \mathrm{d}$, the phosphate removal efficiency reached $87 \%$. The removal efficiency slightly decreased to $79 \%$ at $0.8 \mathrm{~L} / \mathrm{d}$, to $61 \%$ at $1.2 \mathrm{~L} / \mathrm{d}$ and down to $28 \%$ at $2.4 \mathrm{~L} / \mathrm{d}$. With a lower feed rate, the feed solution has a longer hydraulic retention time (HRT) in the electrochemical precipitation column, resulting in a high calcium concentration in the reactor solution. The electrolysis current and time determine the electrochemical release of calcium ions from $\mathrm{CaCO}_{3}$ particles. As a result, a higher removal of phosphate is expected with a lower feed rate. 

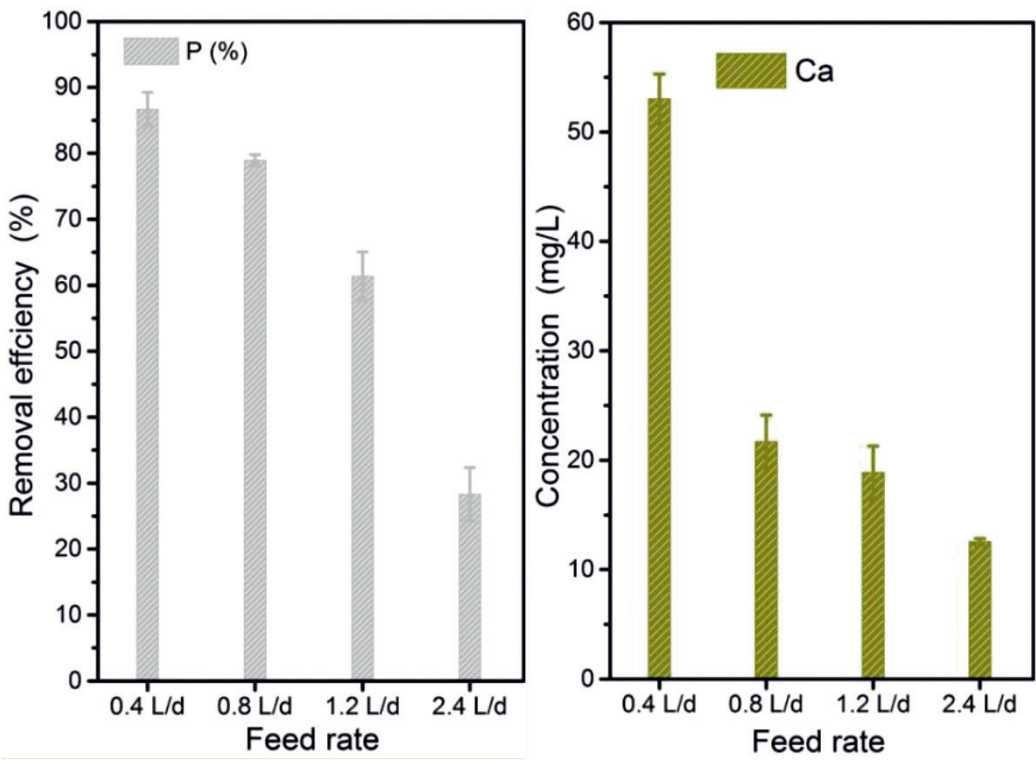

Figure 9.4. Effects of feed rate on the removal of $\mathrm{P}$ and the effluent $\mathrm{Ca}$ concentration. Conditions: particle size, 1-2 mm; current, $5 \mathrm{~mA}$ (current density $3.5 \mathrm{~A} / \mathrm{m}^{2}$ ). Feed solution contains $10 \mathrm{mM} \mathrm{Na}_{2} \mathrm{SO}_{4}$ and $0.6 \mathrm{mM} \mathrm{PO}_{4}-\mathrm{P}$ with an initial $\mathrm{pH}$ of 7.5.

The effluent $\mathrm{Ca}$ concentration confirms the effect of feed rate. We can see from Figure 9.4 that the effluent $\mathrm{Ca}$ concentration at $0.4 \mathrm{~L} / \mathrm{d}(53 \mathrm{mg} / \mathrm{L})$ was significantly higher than that $0.8 \mathrm{~L} / \mathrm{d}(22 \mathrm{mg} / \mathrm{L})$. For the highest feed rate $(2.4 \mathrm{~L} / \mathrm{d})$ we tested, the effluent calcium concentration was $13 \mathrm{mg} / \mathrm{L}$, which is indeed lower than that at $1.2 \mathrm{~L} / \mathrm{d}(19 \mathrm{mg} / \mathrm{L})$. However, the effluent $\mathrm{Ca}$ concentrations at $1.2 \mathrm{~L} / \mathrm{d}$ and $0.8 \mathrm{~L} / \mathrm{d}(22 \mathrm{mg} / \mathrm{L})$ were similar, which points out the interactive effects of feed rate on the release of $\mathrm{Ca}^{2+}$ and the consumption of released $\mathrm{Ca}^{2+}$. On the one hand, a lower feed rate results in more release of $\mathrm{Ca}^{2+}$. On the other hand, a lower feed rate results in enhanced precipitation of released $\mathrm{Ca}^{2+}$ with phosphate and carbonate due to increased retention time.

The normalized specific energy consumption was comparable ( $31 \pm 2 \mathrm{kWh} / \mathrm{kg} \mathrm{P})$ among the feed rates of 2.4, 1.2 and $0.8 \mathrm{~L} / \mathrm{d}$. For the lowest feed rate $(0.4 \mathrm{~L} / \mathrm{d})$, the specific energy consumption was $61 \mathrm{kWh} / \mathrm{kg}$ P. In practical applications, we need to create a balance between the removal efficiency and the feed rate. A lower rate means a higher removal efficiency but a longer HRT, whereas a higher feed rate means a shorter treatment time but relatively lower removal efficiency. Nonetheless, the needed retention time in the current system is relatively low, compared with a previous electrochemical system without the use of $\mathrm{CaCO}_{3}$ particles 
[89]: $0.7-4.2 \mathrm{~h}$ vs $\sim 24 \mathrm{~h}$, yet the phosphate removal efficiency was comparable and even higher. We suggest a feed rate of $1.2 \mathrm{~L} / \mathrm{d}$ for real applications as a satisfactory removal efficiency (61\%), a low HRT (2.1 h), and a low energy consumption (29 kWh/kg P) were achieved at this feed rate.

\subsubsection{Calcium ions instead of $\mathrm{CaCO}_{3}$ particles (no bed)}

To further check the function of the packed $\mathrm{CaCO}_{3}$ bed, we performed control experiments without using $\mathrm{CaCO}_{3}$ particles. Alternatively, calcium ions were supplied in the feed solution. While we provided the feed solution with a high calcium concentration (40 mg/L), which was even higher than the released calcium ions $(28 \mathrm{mg} / \mathrm{L})$ in the absence of phosphate under standard conditions (Figure 9.2), the removal of phosphate was much lower than that with $\mathrm{CaCO}_{3}$ particles fully packed in the column (Figure S9.3). In the absence of $\mathrm{CaCO}_{3}$ particles, the removal of phosphate will depend on its precipitation with calcium ions mainly on the cathode surface, as reported in electrochemical $\mathrm{P}$ removal without the use of $\mathrm{CaCO}_{3}$ solids [89]. In the bulk solution, due to the recombination of anodically produced $\mathrm{H}^{+}$with cathodically formed $\mathrm{OH}^{-}$(eq 9.3) and the consumption of $\mathrm{OH}^{-}$by calcium phosphate precipitation, the solution $\mathrm{pH}$ will decrease [89]. Indeed, the effluent $\mathrm{pH}$ in the absence of $\mathrm{CaCO}_{3}$ particles ( $\mathrm{pH} 7.3$ ) is much lower than that with $\mathrm{CaCO}_{3}$ solids packed in the column ( $\mathrm{pH}$ 9.8). When the feed rate was reduced and the applied current was increased, the $\mathrm{P}$ removal efficiency increased from $13 \%$ to $33 \%$, yet it was still much lower than the $\mathrm{CaCO}_{3}$ packed column under similar conditions ( $\left.90 \%\right)$, as was the effluent $\mathrm{pH}$ (7.1). Again, the results confirmed the multi-function of the packed $\mathrm{CaCO}_{3}$ granules: (1) provide $\mathrm{Ca}^{2+}$, (2) limit the recombination of $\mathrm{H}^{+}$with $\mathrm{OH}^{-}$, (3) enhance calcium phosphate precipitation, and (4) retain precipitates.

\subsubsection{Efficiency for low phosphate-containing solutions and real domestic wastewater}

We further investigated the performance of the electrochemical precipitation column for low $\mathrm{P}$ streams, as an application of this process toward post-treatment. The typical effluent $\mathrm{P}$ concentration in the wastewater treatment plant is around $1.0 \mathrm{mg} / \mathrm{L}$. Due to strict legislation requirements, some wastewater treatment plants may need to update their process. We found that the $\mathrm{CaCO}_{3}$ packed electrochemical precipitation column is also suitable for low $\mathrm{P}$ streams. Still, this is not caused by adsorption, because the removal of phosphate is negligible in an open circuit. The precipitation potential of a specific mineral is affected by the 
concentration of the associated lattice ion, temperature, and solution $\mathrm{pH}$, which can be evaluated through the calculation of the saturation index (SI) [36]. The low P concentration might make it difficult to have $\mathrm{P}$ removed by precipitation. However, the low phosphatecontaining solution is still highly saturated with respect to hydroxyapatite $\left(\mathrm{HAP}, \mathrm{SI}_{\mathrm{HAP}}=13\right)$ in the precipitation column (Text S9.2) thanks to the release of $\mathrm{Ca}^{2+}$ and the increase of $\mathrm{pH}$. In addition, the $\mathrm{CaCO}_{3}$ particles assist calcium phosphate precipitation by lowering the induction time for precipitation [185]. As a result, the P removal efficiency reached $22 \%$ even though the initial concentration was just $1.0 \mathrm{mg} / \mathrm{L}$ (Figure 9.5). The P removal efficiency could be further enhanced by lowering the feed rate and increasing the applied current. About $53 \%$ of the phosphate was removed at $10 \mathrm{~mA}$ with a feed rate of $0.4 \mathrm{~L} / \mathrm{d}$. We also noticed that the effluent $\mathrm{Ca}$ concentration was higher when treating the low $\mathrm{P}$ streams $(27 \mathrm{mg} / \mathrm{L}$, Figure 9.5) than that when treating a higher P concentration stream (15 mg/L, Figure 9.3) under standard conditions $(5 \mathrm{~mA}, 2.4 \mathrm{~L} / \mathrm{d})$, which is due to the reduced consumption of released calcium ions that leaves more calcium ions in the effluent. The effluent $\mathrm{pH}$ was 9.9 under standard conditions $(5 \mathrm{~mA}, 2.4 \mathrm{~L} / \mathrm{d})$ and was increased to 10.7 at an increased current $(10 \mathrm{~mA})$ with a lower feed rate $(0.4 \mathrm{~L} / \mathrm{d})$.
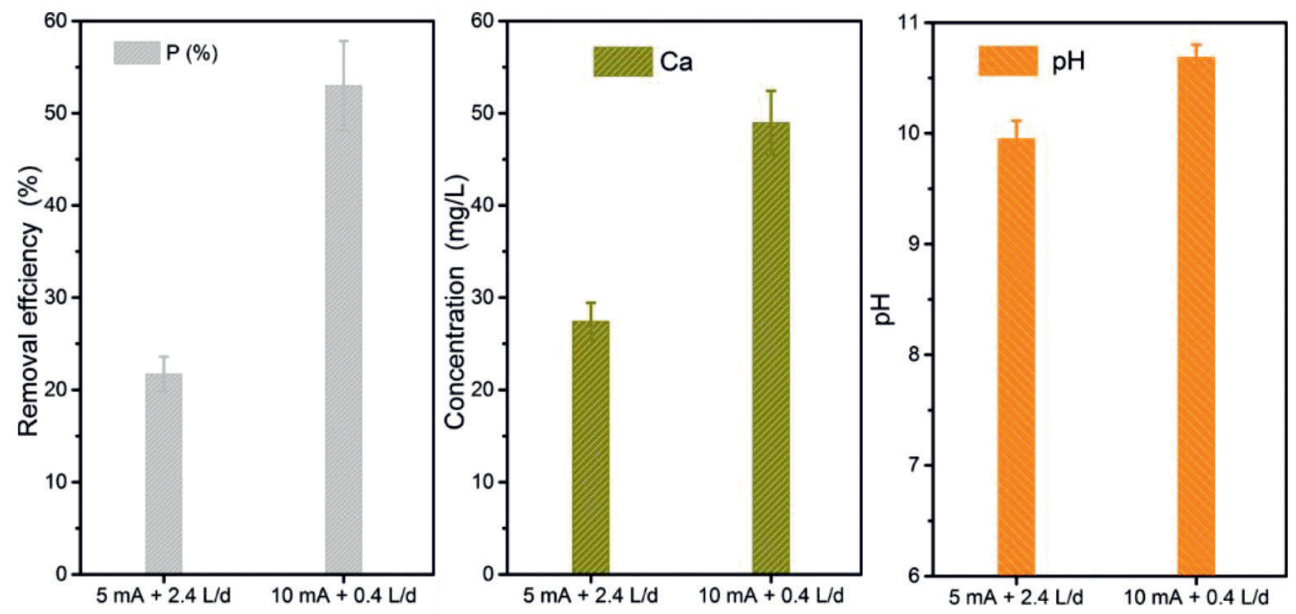

Figure 9.5. Efficiency of the $\mathrm{CaCO}_{3}$ packed electrochemical precipitation toward low phosphate-containing solutions. Conditions: particle size, 1-2 $\mathrm{mm}$. The feed solution were synthetic solutions containing $10 \mathrm{mM} \mathrm{Na}_{2} \mathrm{SO}_{4}$ and $1.0 \mathrm{mg} / \mathrm{L} \mathrm{PO}_{4}-\mathrm{P}$.

We then treated real wastewater with the electrochemical precipitation column. The initial P concentration in the wastewater was about $3 \mathrm{mg} / \mathrm{L}$, which was lower than the wastewater we 190 
sampled previously [32]. This was probably due to the frequent rain in the local area before sampling was conducted. Still, as shown in Figure S9.4, about $16 \%$ of the P was removed under standard conditions, and 43\% $\mathrm{P}$ was removed at optimized conditions $(10 \mathrm{~mA}, 0.4 \mathrm{~L} / \mathrm{d})$. The $\mathrm{pH}$ of the wastewater increased from 7.7 to 8.5 after treatment. The lower increase in solution $\mathrm{pH}$ in real wastewater than that in synthetic solutions is probably due to the buffers presented in the domestic wastewater. This is an advantage in the real application as the $\mathrm{pH}$ of treated wastewater should not be higher than 9.0. This preliminary result demonstrates the feasibility of applying this system for complicated real wastewater.

\subsubsection{Long-term performance.}

We further performed a long-term evaluation of this electrochemical precipitation column in view of its potential application. We ran the system for 125 days under optimized conditions based on the investigation of different parameters that we have discussed here. The results are summarized in Figure 9.6.

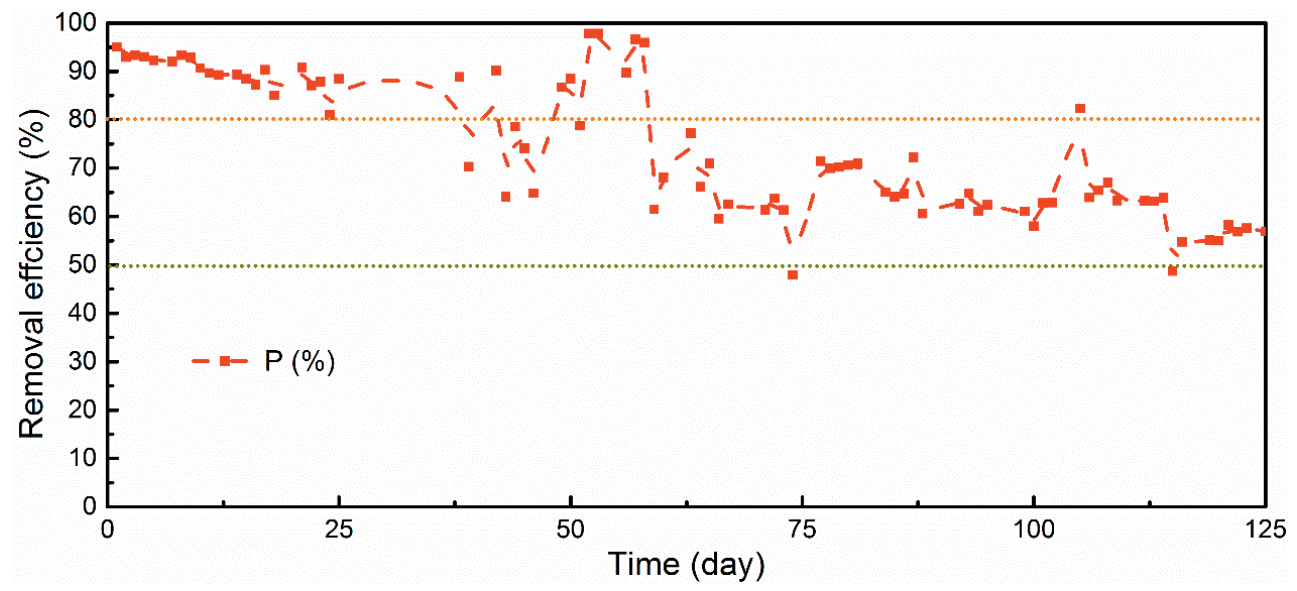

Figure 9.6. $\mathrm{P}$ removal efficiency of the $\mathrm{CaCO}_{3}$ packed electrochemical precipitation in longterm operation. Conditions: particle size, $<0.5 \mathrm{~mm}$; current, $5 \mathrm{~mA}$ (current density $3.5 \mathrm{~A} / \mathrm{m}^{2}$ ); feed rate, $0.4 \mathrm{~L} /$ d. Feed solution contains $10 \mathrm{mM} \mathrm{Na}_{2} \mathrm{SO}_{4}$ and $0.6 \mathrm{mM} \mathrm{PO}_{4}-\mathrm{P}$ with an initial $\mathrm{pH}$ of 7.5 .

It was found that in the initial 40 days, the P removal efficiency was maintained at $90 \pm 5 \%$. Thereafter, the removal efficiency decreased slightly but was still around $60 \%$ untill around the 110th day. Even after more than 125 days of operation, the column still achieved a P removal efficiency of more than $50 \%$. These results confirmed that the system could work 
quite well in long-term operation with little maintenance (cleaning or replacing the effluent tube).

\subsubsection{Calcium phosphate is present both on the cathode and the $\mathrm{CaCO}_{3}$ particles.}

To understand where calcium phosphate precipitates, we analyzed the precipitates on the $\mathrm{CaCO}_{3}$ solids and the electrodes by considering the experiments performed under standard conditions (1-2 mm particle size; $12-13 \mathrm{~cm}$ bed, $5 \mathrm{~mA}, 2.4 \mathrm{~L} / \mathrm{d}$ ) as examples. The analysis of the elemental composition of the $\mathrm{CaCO}_{3}$ particles showed $\mathrm{P}$ to be present on the used particles (Table S9.1). The detection of $\mathrm{P}$ on the used $\mathrm{CaCO}_{3}$ particles indicates that part of the $\mathrm{P}$ in the feed solution is removed by (heterogeneous) precipitation on the $\mathrm{CaCO}_{3}$ particles. We then used acid $\left(20 \mathrm{~mL}, 1 \mathrm{M} \mathrm{HNO}_{3}\right)$ to dissolve the precipitates on the electrodes and analyzed the compositions of the acidic solutions. The $\mathrm{Ca}$ and $\mathrm{P}$ concentrations detected in the acidic solution from the cathode were 170 and 42 times higher than those in the acidic solution used for the anode, respectively (Table S9.2). This confirms the precipitation of calcium phosphate on the cathode but not on the anode, due to local high $\mathrm{pH}$ and low $\mathrm{pH}$, respectively. In conclusion, in the $\mathrm{CaCO}_{3}$ packed electrochemical precipitation column, calcium phosphate precipitates both on the cathode and on the $\mathrm{CaCO}_{3}$ particles.

\subsection{Outlook}

We experimentally investigated the principle, demonstrated the efficiency and the stability of the $\mathrm{CaCO}_{3}$ packed electrochemical precipitation column toward phosphate removal. One unaddressed question that remains is how can the removed phosphate be reused? Indeed, unlike previously reported systems where we can collect calcium phosphate solids from the cathode, in the current system, the calcium phosphate precipitates are mixed with packed calcium carbonate particles. This makes the collection of calcium phosphate difficult. However, we may not need to separate the calcium phosphate solids from the mixture. Given the fact that $\mathrm{CaCO}_{3}$ solids, in general, are more soluble than calcium phosphate solids, it may be possible to convert most of the $\mathrm{CaCO}_{3}$ in the column to calcium phosphate. Thus we can collect the whole solids from the precipitation column and replace them with new $\mathrm{CaCO}_{3}$ solids. The collected solids may be used either in the production of $\mathrm{P}$ fertilizer or directly as fertilizer. Alternatively, the separation of calcium phosphate precipitates with the packed $\mathrm{CaCO}_{3}$ solids could be enhanced by an improved cell configuration, for instance, by putting the anode in a porous $\mathrm{CaCO}_{3}$ container. In this design, the reaction of $\mathrm{H}^{+}$with the $\mathrm{CaCO}_{3}$ 
particles is physically separated from the calcium phosphate precipitation on the cathode and in the bulk solution. Hopefully, this design can be made into reality in our future studies. Given the relatively low energy consumption $(29-61 \mathrm{kWh} / \mathrm{kg} \mathrm{P})$ and the fact that calcium carbonate is a cheap material (here, it is a byproduct from a water softening process), the $\mathrm{CaCO}_{3}$ packed electrochemical precipitation column may offer a robust yet highly stable and efficient system to deal with $\mathrm{P}$ containing streams at various concentrations.

\section{Supporting information}

\section{Text S9.1. Solid characterization}

The XRD characterization (Figure S9.1) together with the acid-digestion analysis (Table S9.1) confirmed the speciation and the main elemental composition of the solids. The used solids are calcite $\left(\mathrm{CaCO}_{3}\right)$, and the main elemental composition of the particles is $\mathrm{Ca}$, followed by some trace amounts of $\mathrm{Mg}, \mathrm{Na}$ and $\mathrm{S}$. The Ca content in the solids was $38.9 \%$, which is close to the theoretical value $(40 \%)$, indicates the high purity of the $\mathrm{CaCO}_{3}$ solids. The TOC analysis of the acid-digestion solution indicated that the $\mathrm{CaCO}_{3}$ solids contain $0.78 \%$ (mass weight) organic carbon, which explains the brown color of the solids. The missing part of the solids is inorganic carbon, which is converted to $\mathrm{CO}_{2}$ during the acid digestion process.

\section{Text S9.2. Calculation of supersaturation index for a low phosphate-containing solution under experimentally relevant conditions}

We applied Visual MINTEQ 3.1 (available at https://vminteq.lwr.kth.se/download/) to calculate the saturation index (SI) of hydroxyapatite (HAP) in the $\mathrm{CaCO}_{3}$ packed precipitation column. The $\mathrm{Ca}^{2+}$ concentration and $\mathrm{pH}$ in the column were based on the control experiments in the absence of phosphate (see Figure 9.2), where the effluent Ca was $28 \mathrm{mg} / \mathrm{L}$ and $\mathrm{pH}$ was 9.9. The other input was $10 \mathrm{mM} \mathrm{Na}_{2} \mathrm{SO}_{4}, 1.0 \mathrm{mg} / \mathrm{L} \mathrm{PO}_{4}-\mathrm{P}$. 


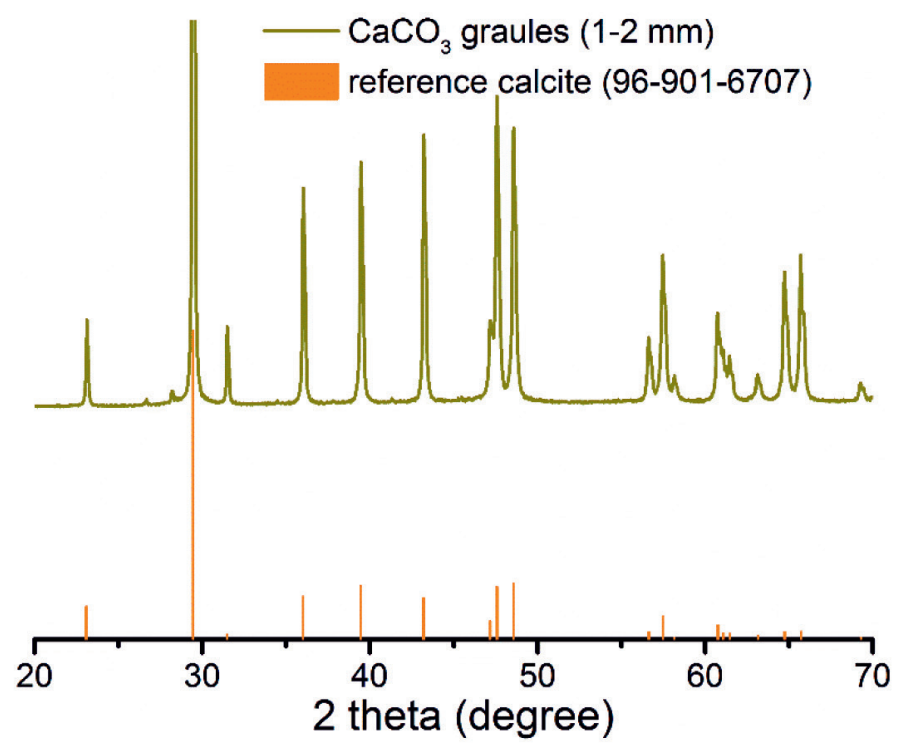

Figure S9.1. XRD pattern of $\mathrm{CaCO}_{3}$ particles (1-2 mm). The XRD pattern matches well with reference calcite spectrum.
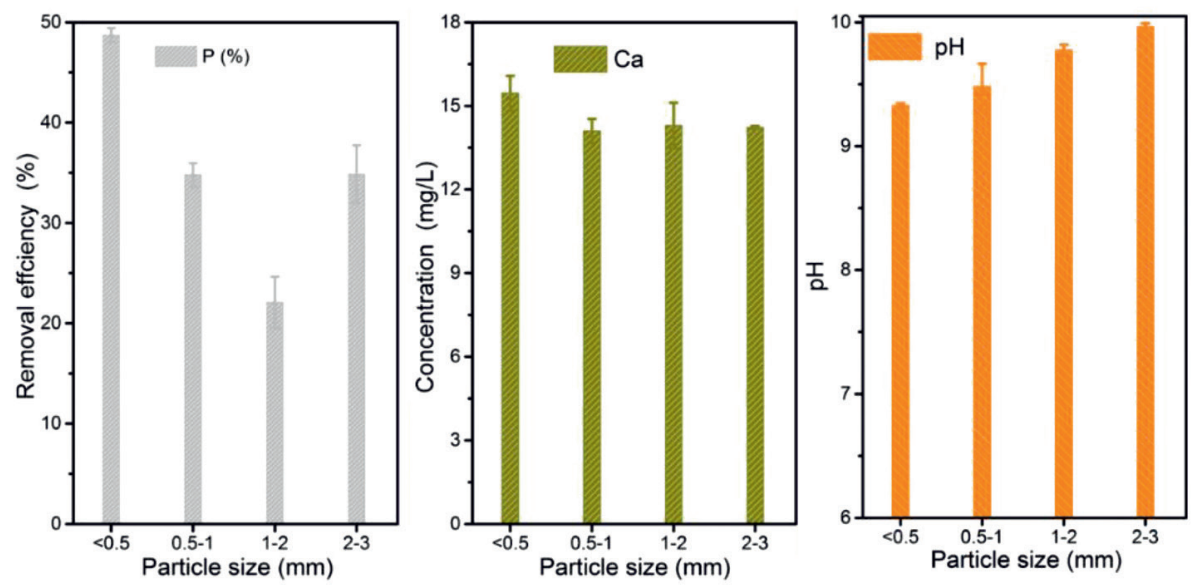

Figure S9.2. Effects of particle size of $\mathrm{CaCO}_{3}$ solids on the removal of $\mathrm{P}$, the effluent $\mathrm{Ca}$ concentration and $\mathrm{pH}$. Conditions: current, $5 \mathrm{~mA}$ (current density $3.5 \mathrm{~A} / \mathrm{m}^{2}$ ); bed height, $12-13 \mathrm{~cm}$; feed rate, $2.4 \mathrm{~L} / \mathrm{d}$. Feed solution contains $10 \mathrm{mM} \mathrm{Na}_{2} \mathrm{SO}_{4}$ and $0.6 \mathrm{mM} \mathrm{PO}_{4}-\mathrm{P}$ with an initial $\mathrm{pH}$ of 7.5 . 

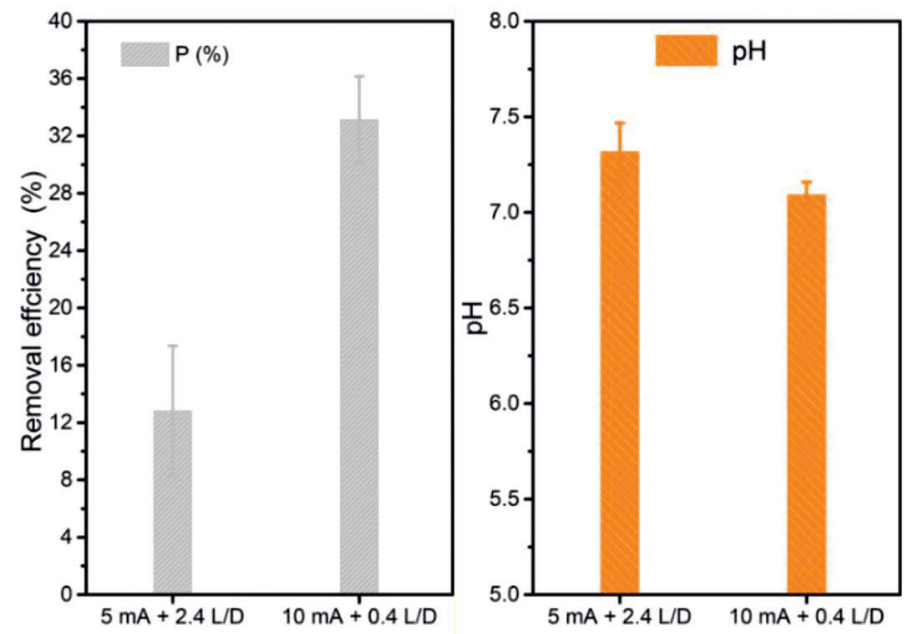

Figure S9.3. $\mathrm{No} \mathrm{CaCO}_{3}$ solids, calcium ions were supplied in the feed solution. Conditions: current $5 \mathrm{~mA}$ (current density $3.5 \mathrm{~A} / \mathrm{m}^{2}$ ) and feed rate $2.4 \mathrm{~L} / \mathrm{d}$ or current $10 \mathrm{~mA}$ (current density $7.0 \mathrm{~A} / \mathrm{m}^{2}$ ) and feed rate $0.4 \mathrm{~L} / \mathrm{d}$. Feed solution contains $10 \mathrm{mM} \mathrm{Na}_{2} \mathrm{SO}_{4}, 1.0 \mathrm{mM} \mathrm{Ca}^{2+}$, and $0.6 \mathrm{mM} \mathrm{PO}_{4}-\mathrm{P}$ with an initial $\mathrm{pH}$ of 7.5.
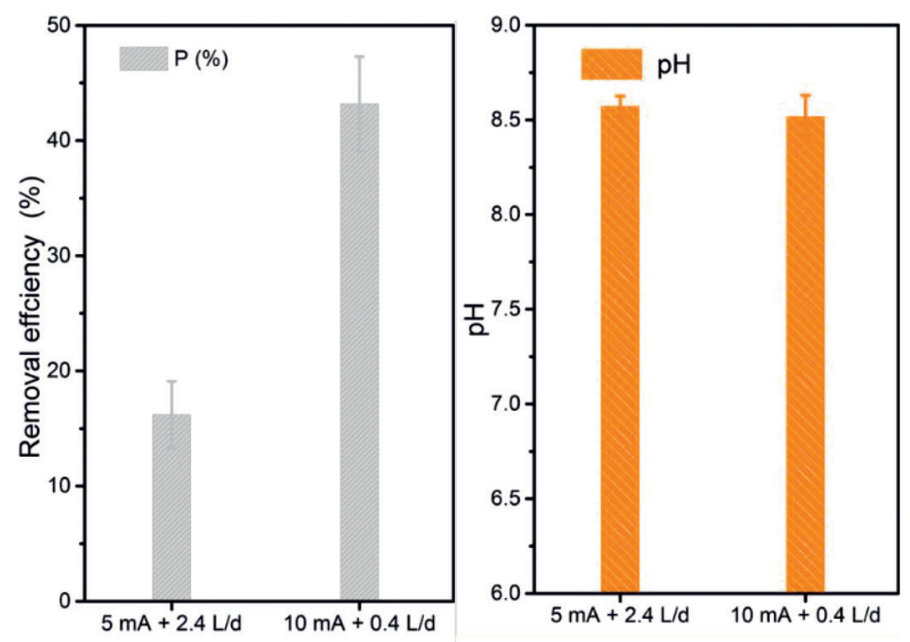

Figure S9.4. Efficiency of the $\mathrm{CaCO}_{3}$ packed electrochemical precipitation toward real wastewater from the local wastewater treatment plant (influent). Conditions: particle size, $1-2 \mathrm{~mm}$, bed height, $12-13 \mathrm{~cm}$, initial wastewater $\mathrm{pH}$ is $7.7 \pm 0.2$. 
Table S9.1. The elemental composition of fresh (unused) and used $\mathrm{CaCO}_{3}$ particles under standard conditions (1-2 mm particle size, $12-13 \mathrm{~cm}$ bed height, $5.0 \mathrm{~mA}, 2.4 \mathrm{~L} / \mathrm{D}$ feed rate)

\begin{tabular}{ccccccc}
\hline $\begin{array}{c}\mathrm{CaCO}_{3} \\
\text { solids }\end{array}$ & $\mathrm{Ca}(\mathrm{g} / \mathrm{kg})$ & $\begin{array}{c}\text { Organic } \\
\mathrm{C}^{a}(\mathrm{~g} / \mathrm{kg})\end{array}$ & $\mathrm{Mg}(\mathrm{g} / \mathrm{kg})$ & $\mathrm{Na}(\mathrm{g} / \mathrm{kg})$ & $\mathrm{P}(\mathrm{g} / \mathrm{kg})$ & $\mathrm{S}(\mathrm{g} / \mathrm{kg})$ \\
\hline fresh & 388.9 & 7.797 & 2.281 & 0.803 & $\mathrm{~N}^{2} .^{b}$ & 0.435 \\
used & 387.6 & 5.914 & 2.257 & 1.127 & 1.186 & 0.557 \\
\hline
\end{tabular}

${ }^{a}$ Detected by TOC; ${ }^{b}$ Not Detected

Table S9.2. $\mathrm{Ca}, \mathrm{Mg}$ and $\mathrm{P}$ concentration in the acidic solution used for dissolving the precipitates on the electrodes

\begin{tabular}{cccc}
\hline electrode & $\mathrm{Ca}(\mathrm{mg} / \mathrm{L})$ & $\mathrm{Mg}(\mathrm{mg} / \mathrm{L})$ & $\mathrm{P}(\mathrm{mg} / \mathrm{L})$ \\
\hline cathode & 922 & 5.64 & 36.8 \\
anode & 5.42 & 0.0297 & 0.875 \\
\hline
\end{tabular}




\section{Chapter 10}

General discussion \& outlook 


\subsection{Introduction}

Along with the increase of the global population, the demand for food has increased significantly, as also the need for phosphorus fertilizer [1]. The main source of phosphorus fertilizer is mined phosphate rock. However, phosphate rock is a finite resource. The worldwide phosphate rock reserves are projected to run out in a few hundred years [1, 22]. On the other hand, eutrophication, which is caused by the discharge of phosphorus-containing streams, is a great concern in many surface waters in many countries. The most obvious way to address the two issues is to remove and reuse phosphorus from waste streams $[7,10]$.

Although phosphorus removal and recovery are well-justified as to prevent eutrophication and the potential phosphorus shortage, this is often not done in practice. A key reason is due to the imbalance between the efforts in recovering phosphorus and the market price of commercial phosphorus fertilizer processed from phosphate rock [10]. The cost associated with phosphorus recovery is way higher than the price of phosphorus fertilizer. Therefore, there is little interest in recovered phosphate.

Hence, a prerequisite condition for potential large-scale application of a new system is to consider the economic feasibility. In this Chapter, we summarize the energy (electricity) consumption of electrochemical phosphorus removal and recovery from a variety of waste streams, either synthetic or real wastewaters. We also discuss the associated limitations and possible improvements within the electrochemical approach.

\subsection{Specific electricity consumption $(\mathrm{kWh} / \mathrm{kg} \mathrm{P})$}

In this thesis, a variety of solutions, synthetic and real wastewater have been targeted for electrochemical phosphorus removal and recovery. Table $\mathbf{1 0 . 1}$ summaries the specific energy consumption $(\mathrm{kWh} / \mathrm{kg} \mathrm{P})$ in electrochemical treatment of various wastewaters under different operational conditions.

According to Table 10.1, it is apparent that the electrochemical approach cannot offer energy-efficient solutions for all kinds of wastewater. As shown in Table 10.1, it is clear that for domestic wastewater, energy consumption is too high. Depending on the applied current density, the specific energy consumption lies between 110 and $2238 \mathrm{kWh} / \mathrm{kg} \mathrm{P}$ for electrochemical phosphorus recovery from domestic wastewater $(0.23 \mathrm{mM} \mathrm{P})$. The energy consumption associated with phosphorus recovery from domestic wastewater can be lowered 
using a bio-anode via shifting the anode reaction from abiotic water splitting to bacterial catalyzed degradation of organic substances. However, this energy consumption remains high for treating low phosphorus-containing municipal wastewater $(0.23 \mathrm{mM})$, namely 224 $\mathrm{kWh} / \mathrm{kg} \mathrm{P}$. In addition, for the bioelectrochemical system, an external carbon source (i.e., acetic acid) was required, due to the low bioavailable chemical oxygen demand (COD) in the domestic wastewater. This makes the application of bioelectrochemical systems less attractive.

The high-energy consumption found with electrochemical $\mathrm{P}$ recovery from real domestic wastewater was due to the low phosphorus concentration in the influent (about $0.23 \mathrm{mM} \mathrm{PO}_{4}$ P). The energy consumption can be reduced significantly when the phosphorus concentration in the wastewater was increased. With $1.15 \mathrm{mM} \mathrm{P}$, the specific energy consumption decreased from 785 to $142 \mathrm{kWh} / \mathrm{kg}$ P. For the bioelectrochemcial systems; the energy consumption decreased by four times from 224 to $56 \mathrm{kWh} / \mathrm{kg} \mathrm{P}$ when the P concentration was increased from $0.23 \mathrm{mM}$ to $0.76 \mathrm{mM}$. Even more encouraging, it was found that energy consumption could be further reduced by operating the system at a low current density. The lowest specific energy consumption was found to be $6.2 \mathrm{kWh} / \mathrm{kg}$ P for treating synthetic solutions $(0.6 \mathrm{mM})$ at $0.1 \mathrm{~A} / \mathrm{m}^{2}$ in combination with a high surface area graphite felt cathode. For the real wastewater spiked with extra phosphate (about $0.6 \mathrm{mM} \mathrm{P}$ ), the specific energy consumption was $14.9 \mathrm{kWh} / \mathrm{kg} \mathrm{P}$, which was slightly higher than for synthetic solutions (11.2 $\mathrm{kWh} / \mathrm{kg} \mathrm{P}$ ) with the same $\mathrm{P}$ concentration. Therefore, the combination of low current densities with high surface area cathodes is the best way to achieve energy-efficient phosphorus recovery. However, the drawback of this system is the need for longer treatment time. This can affect the adoption of this system for real life applications.

Nonetheless, it is clear that the electrochemical system could only be energy-efficient in treating a type of wastewater that has relatively high phosphorus concentration $(>10 \mathrm{mg} / \mathrm{L})$. 


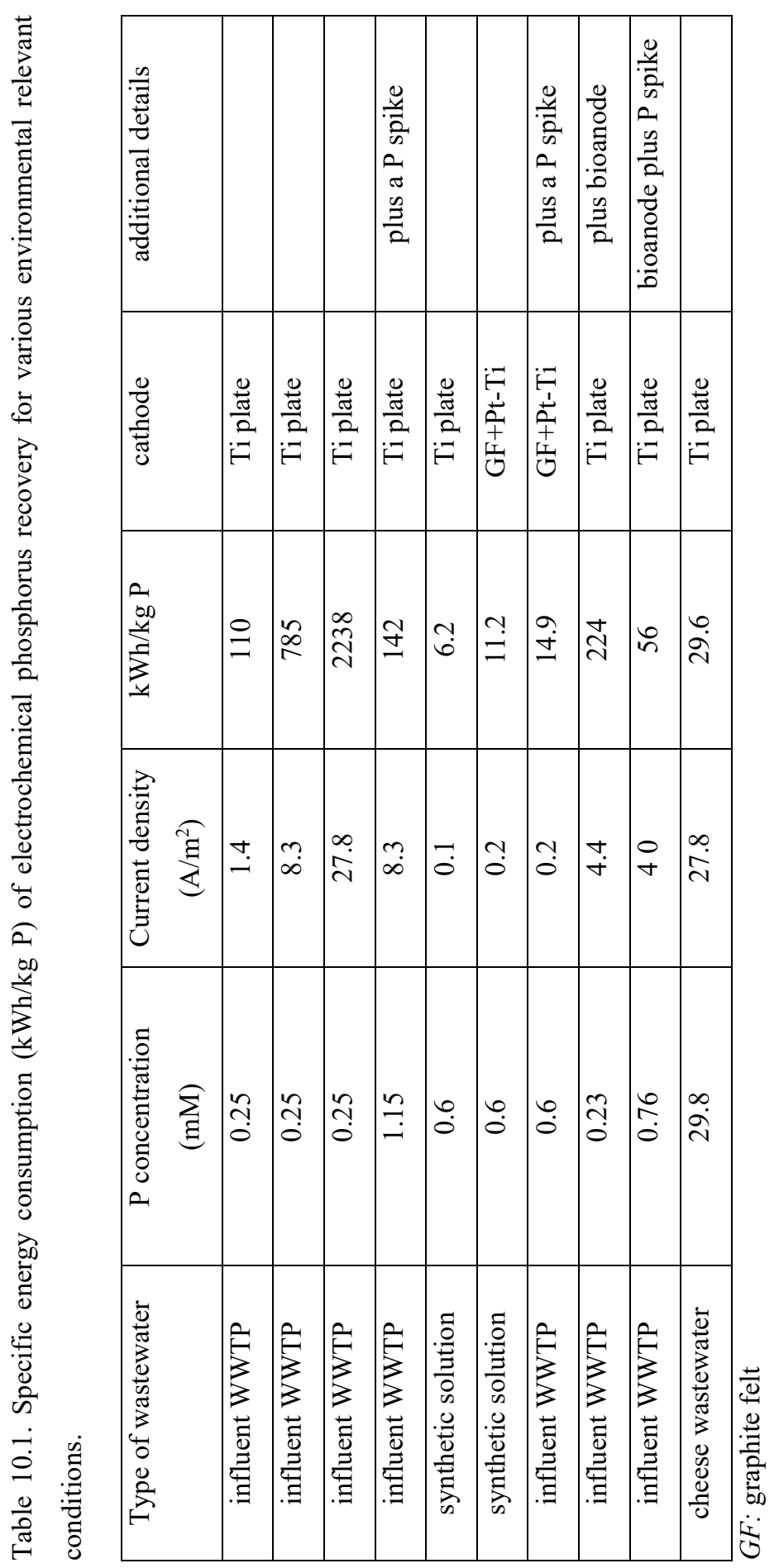




\subsection{Use of electrochemically produced $\mathrm{H}_{2}$ and $\mathrm{O}_{2}$ for biological wastewater treatment}

Electrochemically mediated calcium phosphate precipitation depends on the locally produced base (hydroxide) at the cathode. In Chapter 9, we showed that $\mathrm{CaCO}_{3}$ particles could be dissolved by the electrochemically produced acidity at the anode. Yet, the associated production of gases $\left(\mathrm{H}_{2}\right.$ at the cathode, $\mathrm{O}_{2}$ at the anode) were not utilized.

In comparison to biological and chemical precipitation process, the developed electrochemical technique seems not that attractive for treating low phosphorus-containing wastewater, i.e., domestic wastewater. However, if we take the produced $\mathrm{O}_{2}$ and $\mathrm{H}_{2}$ into account, the electrochemical technique could be very promising.

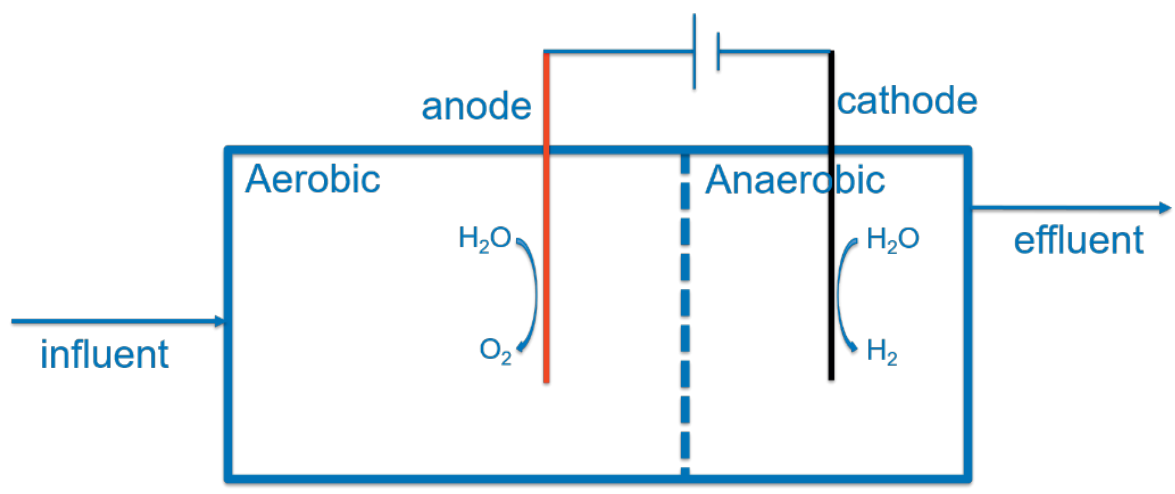

Figure 10.1. Integration of electrochemical phosphorus recovery system with the conventional biological process. This allows usage (recovery) of anodically produced $\mathrm{O}_{2}$ and cathodically produced $\mathrm{H}_{2}$.

Our idea is to integrate the electrochemical system with a conventional biological process, which typically includes anaerobic and aerobic processes (Figure 10.1). The electrochemically produced $\mathrm{O}_{2}$ can be collected and used for aerobic removal of COD and nitrification. The electrochemically produced $\mathrm{H}_{2}$ can be used as biogas enhanced by converting $\mathrm{CO}_{2}$ to $\mathrm{CH}_{4}$ or directly used as the electron donor for denitrification. In this way, a large part of the energy consumption can be compensated by utilizing of the $\mathrm{O}_{2}$ and $\mathrm{H}_{2}$. Further research could deal with the challenge on how to collect/transport the produced gas to the bioreactors. 


\subsection{Selective calcium phosphate precipitation}

Wastewaters are characterized by complicated water matrices, including organic and inorganic compounds. In terms of phosphorus recovery from real wastewaters, it was found that not only calcium phosphate, but also other products formed.

The research question is: can calcium phosphate be selectively precipitated?

The answer is no and yes.

We have shown in Chapter 4 that $\mathrm{CaCO}_{3}$ and $\mathrm{Mg}(\mathrm{OH})_{2}$ co-precipitates with calcium phosphate in electrochemical $\mathrm{P}$ recovery from the domestic wastewater. Based on the color of the harvested precipitates, it appears that organic substances in the wastewater also coprecipitate with the inorganic precipitates. Although the co-precipitation of organics is not specifically discussed in the case of real wastewater, we have shown in Chapter 3 that natural organic matters could co-precipitate with calcium phosphate in the electrochemical system.

The co-precipitation of $\mathrm{CaCO}_{3}$ and $\mathrm{Mg}(\mathrm{OH})_{2}$ has several negative effects. First of all, the coprecipitation of $\mathrm{CaCO}_{3}$ and $\mathrm{Mg}(\mathrm{OH})_{2}$ will lower the relatively amount of calcium phosphate in the recovered precipitates, and as a result, the value of the recovered product as a raw material or fertilizer. Second and more importantly, the precipitation of $\mathrm{CaCO}_{3}$ and $\mathrm{Mg}(\mathrm{OH})_{2}$ will cover part of the cathode surface and thus reduces the active sites for calcium phosphate precipitation. In real applications, this will result in a more frequent collection of precipitates at the cathode and increased energy use, which is not desirable.

Therefore, it is desirable to avoid or limit the co-precipitation of $\mathrm{CaCO}_{3}$ and $\mathrm{Mg}(\mathrm{OH})_{2}$. Based on the thermodynamic evaluation in Chapter 5 , it is theoretically possible to avoid the precipitation of $\mathrm{CaCO}_{3}$ and $\mathrm{Mg}(\mathrm{OH})_{2}$, as calcium phosphate precipitation thermodynamically has the highest driving force and calcium phosphate is less soluble than $\mathrm{CaCO}_{3}$ and $\mathrm{Mg}(\mathrm{OH})_{2}$. The experimental results show that while it is not possible to completely avoid the precipitation of $\mathrm{CaCO}_{3}$ and $\mathrm{Mg}(\mathrm{OH})_{2}$ it is possible to selectively precipitate more calcium phosphate. Pre-acidification was shown to be a possible way to reduce the formation of $\mathrm{CaCO}_{3}$ as the inorganic carbon concentration was reduced (Chapter 4). Yet, in practice, it seems not economically feasible to acidify the wastewater. Promisingly, we have shown in Chapter 5 that by operating the electrochemical phosphorus recovery system at a low current density, relatively more precipitation of amorphous calcium phosphate occurs than $\mathrm{CaCO}_{3}$ 
and $\mathrm{Mg}(\mathrm{OH})_{2}$. Furthermore, we have shown in Chapter 7 that electrochemical P removal at a current density as low as $0.04 \mathrm{~A} / \mathrm{m}^{2}$ is possible and can be enhanced by employing a graphite felt at the cathode. Given the low energy consumption, the performance, the adaptability and the optimization of electrochemical phosphorus recovery at a low current (density) with a large surface area cathode deserve further research. We propose future research on shortening the required retention time in the low current density system through improved cell and cathode configuration. For instance, novel materials, i.e., porous graphene, could be applied as an alternative for the graphite felt.

\subsection{Target application}

The unique advantage of the electrochemical approach is that calcium phosphate precipitation could be achieved even in acidic $\mathrm{pH}$ environments without having to add a base to increase the entire $\mathrm{pH}$ of the bulk solution. Therefore, a potential candidate for this system is acidic wastewater that has a high phosphorus concentration $(>10 \mathrm{mg} / \mathrm{L} \mathrm{P})$.

Is there a type of wastewater that fits all these characteristics? I.e. wastewater at low $\mathrm{pH}$ and high phosphorus concentration?

The Netherlands is one of the most prominent cheese producing countries in the world. Along with the production of cheese, wastewater is generated, which has an acidic $\mathrm{pH}$ and a high phosphate concentration. Furthermore, it is characterized by high COD, high salinity, and high calcium concentration. The high salinity is crucial for lowering the ohmic resistance of the electrochemical cell and in turn the energy consumption. Altogether, cheese wastewater seems to be suitable for electrochemical treatment. Yet, the low $\mathrm{pH}$ might hinder calcium phosphate precipitation. 


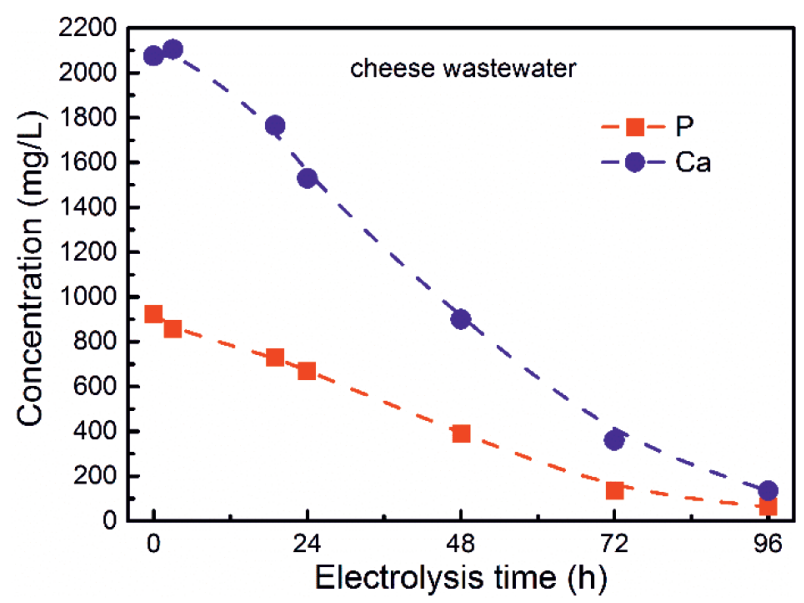

Figure 10.2 Change of phosphorus and calcium concentration in cheese wastewater under electrochemical treatment. Conditions: $100 \mathrm{~mA}, 36 \mathrm{~cm}^{2}$ titanium plate cathode, platinum coated titanium disk anode, electrode distance $3 \mathrm{~cm}$, initial $\mathrm{pH} 4.0$.

Surprisingly, the electrochemical system works well, even for the acidic cheese wastewater ( $\mathrm{pH}$ 4.0). As shown in Figure 10.2, the $\mathrm{P}$ and $\mathrm{Ca}$ concentration of the cheese wastewater decreased significantly when a current was applied. The P concentration decreased from 925 $\mathrm{mg} / \mathrm{L}$ to around $60 \mathrm{mg} / \mathrm{L}$, which corresponds to a removal efficiency larger than $90 \%$. The specific energy consumption was low $(29.6 \mathrm{kWh} / \mathrm{kg} \mathrm{P})$, due to the high conductivity and high phosphorus concentration of the cheese wastewater. Considering an electricity price of 0.09 euro/kWh, the specific electric energy consumption is just 2.7 euro $/ \mathrm{kg} P$. This value is already close to the market price of phosphorus fertilizer mined from phosphate rock, which is between 1 and 2 euro/kg P. It is worth mentioning that phosphorus mining from phosphate rocks produces toxic phosphogypsum byproducts (5 tons associated with 1 ton process phosphate), which is not an environmentally friendly process and harms our environment [1]. In addition to energy consumption, electrochemical phosphorus recovery from the cheese wastewater also produces high-quality calcium phosphate solids. Due to the acidic $\mathrm{pH}$, the inorganic carbon concentration was low in the cheese wastewater. The $\mathrm{Mg}$ concentration $(134 \mathrm{mg} / \mathrm{L})$ of the cheese wastewater is about 20 times lower than the Ca concentration (2075 $\mathrm{mg} / \mathrm{L}$ ). As a result, the co-precipitation of $\mathrm{CaCO}_{3}$ and $\mathrm{Mg}(\mathrm{OH})_{2}$, which was an issue to consider in the case of domestic wastewater, was not an issue in this case. Consequently, 
electrochemical phosphorus recovery from cheese wastewater is promising, as it recovers a high purity product in an energy-efficient way.

Few phosphorus removal/recovery methods can be justified by economy benefits at this moment when the price of commercial phosphorus fertilizer is very low [186, 187]. However, by this approach, it is possible to achieve this. Electrochemical phosphorus recovery from the cheese wastewater in the form of calcium phosphate was shown to be energy efficient. The recovered product already justifies the electricity consumption, in comparison to the price of commercial phosphorus fertilizer, yet the positive environmental effects of phosphorus removal from the cheese wastewater have not been included in our consideration. While we should not exclude the potential application of the electrochemical approach for other types of wastewater, the cheese wastewater is an ideal target. The cheese wastewater tests warrant further study of the anodic process, since chloride is being oxidized to chlorine and hypochlorite. A possible solution to overcome the formation of chlorine at the anode is to recycle the formed hydrogen gas formed at the cathode and use it at the anode. The anodic process would become then the oxidation of hydrogen gas to protons. This also will lower to a great extent the required cell voltage and lower the specific energy consumption of the formed calcium phosphate.

\subsection{The challenge: collection of precipitates}

In this thesis, we studied the fundamentals of electrochemical phosphorus removal and recovery. To our knowledge, this is the first systematic study focusing on electrochemical phosphorus removal and recovery. While the feasibility of this system toward a variety of wastewaters has been proven, there are still some challenges that need to be addressed.

An important consideration is the collection of precipitates from the cathode. In the lab-scale tests, the precipitates on the cathode were physically scraped off. In a large-scale application, automatically collection equipment may be installed together with the electrochemical system. We also presented a new idea for cleaning and collecting precipitates on the cathode. The idea is to suddenly increase the applied current density to a very high value, in this way, a lot of hydrogen gas will be created at the cathode, which pressure would remove the precipitates from the electrode. The removed precipitates would fall into the collection tank located close to the electrochemical cell (Figure 10.3). A vertical orientation of electrodes 
would be beneficial for collecting the precipitates. The precipitates can be collected at the bottom of the electrochemical cell.

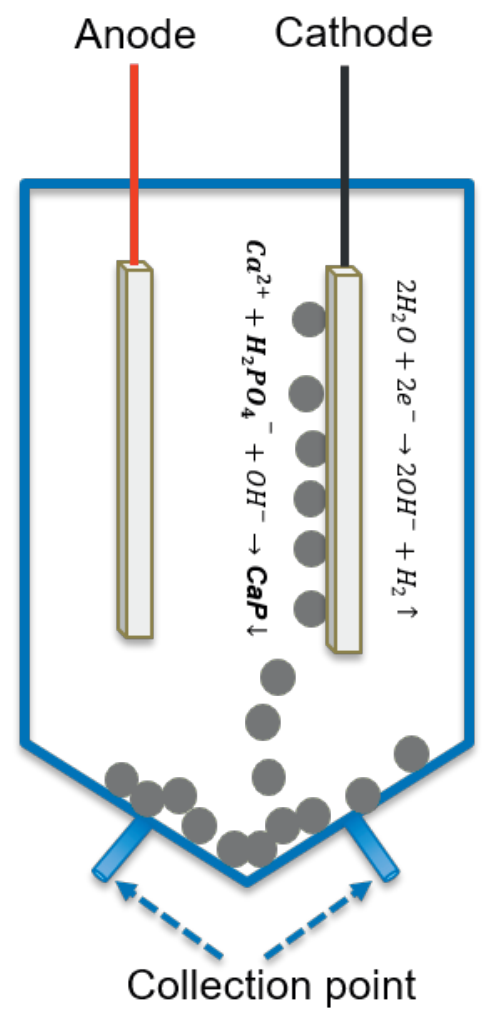

Figure 10.3. Vertical location of two electrodes. 


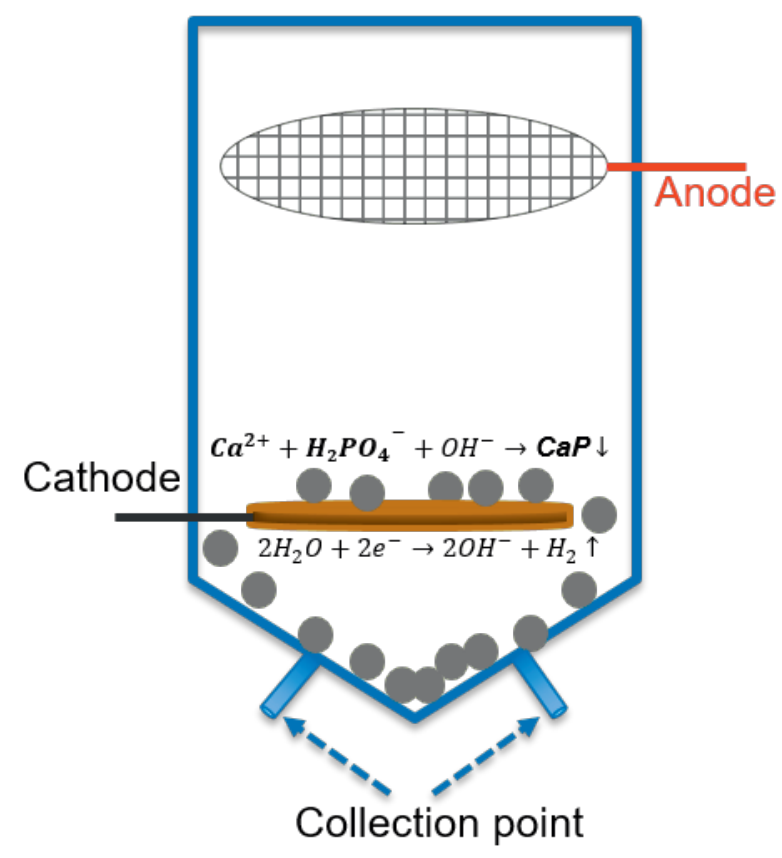

Figure 10.4. Horizontal location of electrodes.

Alternatively, the horizontal location of electrodes is another an option (Figure 10.4). In this configuration, the cathode is preferably located at the bottom of the anode, so once the precipitates fall off from the cathode, they will enter into the collection tank. Nonetheless, both the efficiency of the two configurations and their suitability for precipitate collection need to be evaluated before up scaling of the technology.

\subsection{Perspectives on future improvements}

\subsubsection{Multi-layer structure cathode}

Luan et al. proposed a novel cathode configuration for electrochemical removal of hardness [188], which shares the same principle of electrochemically mediated calcium phosphate precipitation. In the study of Luan et al., the multi-layer cathode was a simple combination of a few pieces of stainless-steel which has different mesh numbers [188]. It was shown that these stainless-steel with different mesh numbers play different functions in the removal of hardness. The 50-mesh layer generated alkalinity and the 8-mesh layer provided pathway for the diffusion of ions. The 20- and 12-mesh layers works as the deposition layers where mineral precipitation mainly take place. The multi-configuration allows the production of 
alkalinity and the precipitation of minerals happen in a different region of the coupled cathode. The same concept could be applied in electrochemical removal and recovery of phosphorus from real wastewater. Part of the cathode is used for producing alkalinity. This alkalinity then diffuses to the other part of the cathode and induce calcium phosphate precipitation there. In this design, the precipitation of calcium phosphate will not compete with the production of hydroxide ions, as they take place in a different region of the multi-layer cathode.

Actually, in Chapter 8, we have proposed a similar concept, where we put a piece of graphite felt on the platinum-coated titanium mesh cathode. The graphite felt serves as the precipitation area whereas the Pt-Ti mesh disk serves as the real cathode, where hydroxide ions were produced. The mass balance calculation indicates $85 \%$ of the removed phosphate appears on the graphite felt. Therefore, the coupling of the real cathode with some extra materials which could provide a large surface area for calcium phosphate deposition may be an excellent way for achieving electrochemical phosphorus recovery and collection of recovered products. This needs to be studied in further detail. For example, we do not know yet if this extra surface material needs to be conductive or not. In any case, a cheaper material needs to be selected to make this process economically feasible.

\subsubsection{Minerals assisted electrochemically calcium phosphate precipitation}

Electrochemically mediated calcium phosphate precipitation on the cathode shows many advantages over a classical chemical precipitation approach, yet the efficiency of this system is limited by the precipitation area (restricted to the cathode). While the precipitation area can be enlarged from the cathode to the catholyte solution when ion exchange membranes are used, the drawbacks of using membranes are the increased complexity in cell configuration, material costs, and the associated maintenance issues of membranes [189]. Enlarging the precipitation area without using membranes would be a great step toward up scaling of the technology. In Chapter 9, we have shown that the function of membranes can be achieved by using $\mathrm{CaCO}_{3}$ particles. In the $\mathrm{CaCO}_{3}$ packed electrochemical precipitation column, the $\mathrm{CaCO}_{3}$ solids consumed the anode-produced acidity. As a result, a high pH environment was created inside the column in addition to the vicinity of the cathode.

Moreover, $\mathrm{CaCO}_{3}$ solids could work as seed materials, assisting calcium phosphate precipitation. In this way, the precipitation of calcium phosphate was expanded from the cathode surface to the $\mathrm{CaCO}_{3}$ surface and even in the bulk solution. Due to the enlarged 
precipitation area and the presence of seed materials, the kinetics of calcium phosphate formation and precipitation was enhanced. Long-term evaluation has shown that the new system achieved more than 50\% removal efficiency during 125 days of operation with little maintenance.

The $\mathrm{CaCO}_{3}$ packed electrochemical precipitation column is a new concept toward the continuous operation of electrochemical phosphorus recovery. While we have explained the basic concept of this system in Chapter 9, we believe future improvements of the $\mathrm{CaCO}_{3}$ (and other minerals) packed column would make this concept even more promising. In addition to $\mathrm{CaCO}_{3}$ solids, the suitability and performance of other minerals (i.e., biochar or construction waste) in assisting calcium phosphate precipitation is worth investigating.

This thesis presents a new application of electrochemistry toward energy-efficient phosphorus recovery. The fundamentals, efficiency, challenges, and potential applications have been addressed. As we have shown in this thesis, the electrochemical technique offers a promising way for phosphorus removal and recovery from a variety of wastewater and shows many advantages over classical approaches, such as no need for dosing chemicals. It is advised to keep working on enhancing the removal performance, lowering the energy consumption, and further exploring the benefits in a pilot-scale evaluation of electrochemical phosphorus removal and recovery. 


\section{Summary}

In this thesis, we propose an innovative membrane-free electrochemical system, which can potentially achieve the removal and recovery of phosphorus from wastewaters in the form of recoverable calcium phosphate. Electrochemically induced calcium phosphate precipitation can be applied for a range of wastewater $\mathrm{pHs,} \mathrm{also} \mathrm{for} \mathrm{a} \mathrm{more} \mathrm{acidic} \mathrm{pH}$. In real wastewaters (i.e., sewage), the dosing of an external calcium source is not necessary, as enough calcium ions are already present. Additionally, no dosing of chemicals is needed. This dissertation is a first systematic study on electrochemical phosphorus removal and recovery with main findings summarized below. The insights gained present a significant step toward the potential application of this new method.

\section{Electrochemically induced calcium phosphate precipitation depends on the local pH}

\section{(Chapter 2)}

In Chapter 2, we investigated the removal of phosphate in a wide range of $\mathrm{pH}$ values in the electrochemical system, from acidic conditions $(\mathrm{pH} 4)$ to more neutral environment $(\mathrm{pH} 8)$ and basic solutions ( $\mathrm{pH} \mathrm{10).} \mathrm{It} \mathrm{was} \mathrm{found} \mathrm{that} \mathrm{the} \mathrm{system} \mathrm{was} \mathrm{not} \mathrm{that} \mathrm{sensitive} \mathrm{to} \mathrm{the} \mathrm{bulk}$ solution and works in a wide range of $\mathrm{pHs}$. The precipitation of calcium phosphate was not expected at $\mathrm{pH} \mathrm{4}$, as at this $\mathrm{pH}$, the solutions are undersaturated. This pointed out the importance of local $\mathrm{pH}$ near the cathode in electrochemically induced calcium phosphate precipitation. This unique $\mathrm{pH}$ difference allows calcium phosphate precipitation in acidic solutions. We also found that both the morphology and the phase of calcium phosphate change during the electrolysis time. The solids on the cathode eventually re-crystallized from amorphous calcium phosphate to hydroxyapatite, which is the most stable phase of calcium phosphate.

\section{Natural organic matters did not block electrochemically induced calcium phosphate precipitation (Chapter 3)}

In Chapter 3, we studied the behavior of natural organic matter (NOM) and its effect on calcium phosphate $(\mathrm{CaP})$ precipitation in the electrochemical P recovery system. In contrast to studies where NOM hindered CaP precipitation, our results showed that the interaction of NOM with CaP improved the removal of $\mathrm{P}$, and the enhancement was independent of the types of NOM. The P removal increased from $43.8 \pm 4.9 \%$ to $58.5 \pm 1.2 \%$ in the presence of 
$1.0 \mathrm{mg} / \mathrm{L}$ NOM and based on the yellow color of the CaP product; NOM was co-precipitated. The bulk solution $\mathrm{pH}$ with and without buffers had different effects on the precipitation process. Without a buffer, CaP precipitated on the cathode surface in a wide $\mathrm{pH}$ range $\mathrm{pH}$ 4-10). However, the precipitation process was completely inhibited when the bulk solution was buffered at $\mathrm{pH} 4.0$ and 6.0. This is due to the neutralization of hydroxide ions by the buffers, so a high local $\mathrm{pH}$ could not be established. Regardless of the presence or absence of NOM and solution $\mathrm{pH}$, the recovered products were mainly amorphous $\mathrm{CaP}$ unless the electrolysis time was increased to seven days with $4.0 \mathrm{~A} / \mathrm{m}^{2}$, at which crystalline $\mathrm{CaP}$ formed.

Calcium carbonate $\left(\mathrm{CaCO}_{3}\right)$ and brucite $\left(\mathrm{Mg}(\mathrm{OH})_{2}\right)$ co-precipitates with calcium phosphate (Chapter 4)

In Chapter 4, we clarified the electrochemical interaction of phosphate and coexisting calcium $(\mathrm{Ca})$, magnesium $(\mathrm{Mg})$ and inorganic carbon via pre-acidifying the wastewater and altering the applied current density. The removal of $\mathrm{P}$ was attributed to amorphous calcium phosphate (ACP) formation, whereas the removal of bicarbonate was mainly due to calcite $\left(\mathrm{CaCO}_{3}\right)$ formation and acid-base neutralization. While both ACP and calcite formation resulted in Ca removal, Ca predominantly ended up in calcite. $\mathrm{Mg}$ was exclusively removed as brucite $\left(\mathrm{Mg}(\mathrm{OH})_{2}\right)$. Regardless of acidification (from $\mathrm{pH} 7.5$ to 3.8 ), $53 \pm 2 \% \mathrm{P}$ and $32 \pm 1 \%$ $\mathrm{Mg}$ were removed in $24 \mathrm{~h}$ at $8.3 \mathrm{~A} / \mathrm{m}^{2}$. By contrast, in response to the acidification, the removal of $\mathrm{Ca}$ dropped from $42 \%$ to $19 \%$. The removal of $\mathrm{Mg}$ depended on the current density, with less than $5 \%$ removed at $1.4 \mathrm{~A} / \mathrm{m}^{2}$ and $70 \%$ at $27.8 \mathrm{~A} / \mathrm{m}^{2}$ in $24 \mathrm{~h}$. Based on the precipitation mechanisms, the formation of calcite and brucite was reduced by acidification and operating at a relatively low current density, respectively. Accordingly, the lowest $\mathrm{Ca} / \mathrm{P}$ molar ratio (1.8) and the highest relative abundance of ACP in the precipitates (75\%) were achieved when the wastewater was acidified to $\mathrm{pH} 3.8$ and treated with a current density of $1.4 \mathrm{~A} / \mathrm{m}^{2}$.

Low current density, large area cathode and high phosphorus concentration enable selectively precipitate calcium phosphate (Chapter 5)

In Chapter 5, we explored the precipitation sequence among calcium phosphate, calcite $\left(\mathrm{CaCO}_{3}\right)$ and brucite $\left(\mathrm{Mg}(\mathrm{OH})_{2}\right)$ in electrochemical phosphorus recovery from domestic wastewater. Theoretically, as calcium phosphate (i.e., hydroxyapatite) has the lowest thermodynamic solubility product and highest saturation index in the wastewater, it has the 
potential to precipitate first. Experimentally, this was not observed in electrochemical phosphate recovery from raw wastewater. This is probably caused by the very high $\mathrm{Ca} / \mathrm{P}$ molar ratio (7.5) and high bicarbonate concentration in the wastewater resulting in the formation of calcite. In case of a decreased $\mathrm{Ca} / \mathrm{P}$ molar ratio (1.77) by spiking with extra phosphate, most of the removed $\mathrm{Ca}$ in the wastewater was used for calcium phosphate formation instead of calcite. The formation of brucite, however, was only affected when the current density was decreased, or the size of cathode was changed. Overall, the removal of $\mathrm{Ca}$ and $\mathrm{Mg}$ was much more affected by the current density than by the surface area of cathode, whereas for P removal, the reverse was true. Because of these dependencies, though there was no definite precipitation sequence among ACP, calcite and brucite, it is still possible to influence the precipitation degree of these species by relatively low current density and high surface area cathode or by targeting phosphorus-rich wastewaters.

\section{Bioelectrochemical system allows calcium phosphate precipitation at a relatively low energy consumption (Chapter 6)}

In Chapter 6, from the consideration of energy saving, we upgraded the previously developed abiotic electrochemical $\mathrm{P}$ recovery systems to a bioelectrochemical system. The anode was inoculated with electroactive bacterial (electricigens) which are capable of oxidizing soluble organic substrates and releasing electrons. These electrons were used for the reduction of $\mathrm{H}_{2} \mathrm{O}$ at the cathode, resulting in an increase of $\mathrm{pH}$ close to the cathode. Hence, phosphate was removed with coexisting calcium ions as calcium phosphate at the surface of the cathode at a much lower energy input. Depending on the available substrate (sodium acetate) concentration, an average current density from $1.1 \pm 0.1$ to $6.6 \pm 0.4 \mathrm{~A} / \mathrm{m}^{2}$ was achieved. This resulted in a P removal of $20.1 \pm 1.5 \%$ to $73.9 \pm 3.7 \%$, a Ca removal of 10.5 $\pm 0.6 \%$ to $44.3 \pm 1.7 \%$ and a $\mathrm{Mg}$ removal of $2.7 \pm 1.9 \%$ to $16.3 \pm 3.0 \%$. The specific energy consumption and the purity of the solids were limited by the relative low P concentration $(0.23 \mathrm{mM})$ in the domestic wastewater. The relative abundance of calcium phosphate in the recovered product increased from $23 \%$ to $66 \%$ and the energy consumption for recovery was decreased from $224 \pm 7 \mathrm{kWh} / \mathrm{kg}$ P to just $56 \pm 6 \mathrm{kWh} / \mathrm{kg}$ P when treating wastewater with higher $\mathrm{P}$ concentration $(0.76 \mathrm{mM})$. Even lower energy demand of $21 \pm 2 \mathrm{kWh} / \mathrm{kg} \mathrm{P}$ was obtained with a platinized cathode. 
A very low current density combined with graphite felt enables energy-efficient phosphorus recovery (Chapter 7)

Chapter 7 investigated the possibility of electrochemical phosphorus removal at low current density using graphite felt as the cathode. We found a current density as low as $0.04 \mathrm{~A} / \mathrm{m}^{2}$ could enhance the removal of phosphate in our electrochemical system. The removal of phosphate at these low current densities resulted from electrochemical induced calcium phosphate precipitation and not from electrochemical adsorption. More importantly, the application of the low current density reduced the co-precipitation of calcium carbonate and magnesium hydroxide. The specific energy consumption of this newly electrochemical system was between 4.4 and $13.2 \mathrm{kWh} / \mathrm{kg}$ P. This was 2 orders of magnitude lower than our previous system (110-2238 $\mathrm{kWh} / \mathrm{kg} \mathrm{P})$ and even comparable to the capacitive deionization process $(1.5-7.0 \mathrm{kWh} / \mathrm{kg}$ P). Key factors for this improvement were shown to be the enlarged precipitation area and lowered hydroxide flux by graphite felt.

Electrochemical treatment allows phosphorus recovery from non-orthophosphate compounds (Chapter 8)

In Chapter 8, we expanded the application of electrochemical phosphorus recovery system from orthophosphate to non-orthophosphate using nitrilotris (methylene phosphonic acid) (NTMP) as a model compound. It was found that the C-N and C-P bonds of NTMP were broken at the anode, leading to the formation of orthophosphate and formic acid. Meanwhile, the converted orthophosphate reacted with coexisting calcium ions and precipitated on the cathode as recoverable calcium phosphate solid, due to an electrochemically induced high $\mathrm{pH}$ region near the cathode. Electrochemical removal of NTMP (at $30 \mathrm{mg} / \mathrm{L}$ ) was more efficient when dosed to effluent of a wastewater treatment plant (89\% in $24 \mathrm{~h})$ than dosed to synthetic solutions of $1.0 \mathrm{mM} \mathrm{Ca}$ and $50 \mathrm{mM} \mathrm{Na}_{2} \mathrm{SO}_{4}(43 \%$ in $168 \mathrm{~h})$ while applying a current density of $28 \mathrm{~A} / \mathrm{m} 2$ and using a Pt anode and Ti cathode. The higher removal efficiency of NTMP in real wastewater was due to the presence of chloride ions, which resulted in anodic formation of reactive chlorine species.

Use of $\mathrm{CaCO}_{3}$ granules reduce the neutralization of cathodically produced $\mathrm{OH}^{-}$with anodically produced $\mathrm{H}^{+}$(Chapter 9)

Chapter 9 presented a new concept of phosphate removal and recovery, namely a $\mathrm{CaCO}_{3}$ packed electrochemical precipitation column, which achieved improved removal efficiency, 
shortened hydraulic retention time and substantially enhanced stability, compared with the previous electrochemical system. The concept was based on the introduction of $\mathrm{CaCO}_{3}$ particles, which facilitated calcium phosphate precipitation by buffering the formed $\mathrm{H}^{+}$at the anode, releasing $\mathrm{Ca}^{2+}$, acting as seed materials, and establishing a high $\mathrm{pH}$ environment in the bulk solution in addition to the vicinity of the cathode. It was found that the applied current density, the $\mathrm{CaCO}_{3}$ particle size, and the feed rate affected the removal of phosphate. Under optimized conditions (particle size: $<0.5 \mathrm{~mm}$; feed rate: $0.4 \mathrm{~L} / \mathrm{d}$, current: $5 \mathrm{~mA}$ ), in a continuous flow system, the $\mathrm{CaCO}_{3}$ packed electrochemical precipitation column achieved $90 \pm 5 \%$ removal of phosphate over 40 days and $>50 \%$ removal over 125 days with little maintenance. 


\section{References}

[1] D. Cordell, J.-O. Drangert, S. White, The story of phosphorus: Global food security and food for thought, Global Environmental Change, 19 (2009) 292-305.

[2] D.M. Karl, Aquatic ecology: Phosphorus, the staff of life, Nature, 406 (2000) 31.

[3] S.M. Jasinski, Phosphate rock. In Mineral Commodity Summaries; United States Geological Survey, (2018).

[4] M. Chen, T.E. Graedel, A half-century of global phosphorus flows, stocks, production, consumption, recycling, and environmental impacts, Global Environmental Change, 36 (2016) 139-152.

[5] C. Grant, D. Flaten, D. Tomasiewicz, S. Sheppard, The importance of early season phosphorus nutrition, Canadian Journal of Plant Science, 81 (2001) 211-224.

[6] D.E.C. Corbridge, Phosphorus. An outline of its chemistry, biochemistry, and technology, Elsevier Scientific Co., 1980.

[7] J. Elser, E. Bennett, Phosphorus cycle: a broken biogeochemical cycle, Nature, 478 (2011) 29-31.

[8] World Population: https://www.worldometers.info/world-population/, in, 2019.

[9] H.C.J. Godfray, J.R. Beddington, I.R. Crute, L. Haddad, D. Lawrence, J.F. Muir, J. Pretty, S. Robinson, S.M. Thomas, C. Toulmin, Food security: the challenge of feeding 9 billion people, Science, 327 (2010) 812-818.

[10] B.K. Mayer, L.A. Baker, T.H. Boyer, P. Drechsel, M. Gifford, M.A. Hanjra, P. Parameswaran, J. Stoltzfus, P. Westerhoff, B.E. Rittmann, Total value of phosphorus recovery, Environmental Science \& Technology, 50 (2016) 6606-6620.

[11] B. Geissler, M.C. Mew, G. Steiner, Phosphate supply security for importing countries: Developments and the current situation, Science of the Total Environment, 677 (2019) 511 523.

[12] D. Harper, What is eutrophication?, in: Eutrophication of Freshwaters, Springer, 1992, pp. 1-28.

[13] S.R. Carpenter, Phosphorus control is critical to mitigating eutrophication, Proceedings of the National Academy of Sciences, 105 (2008) 11039-11040. 
[14] W.K. Dodds, W.W. Bouska, J.L. Eitzmann, T.J. Pilger, K.L. Pitts, A.J. Riley, J.T. Schloesser, D.J. Thornbrugh, Eutrophication of U.S. Freshwaters: Analysis of Potential Economic Damages, Environmental Science \& Technology, 43 (2009) 12-19.

[15] M.F. Chislock, E. Doster, R.A. Zitomer, A. Wilson, Eutrophication: causes, consequences, and controls in aquatic ecosystems, Nature Education Knowledge, 4 (2013) 10.

[16] K.A. Macintosh, B.K. Mayer, R.W. McDowell, S.M. Powers, L.A. Baker, T.H. Boyer, B.E. Rittmann, Managing diffuse phosphorus at the source versus at the sink, Environmental science \& technology, 52 (2018) 11995-12009.

[17] R.J. Diaz, R. Rosenberg, Spreading dead zones and consequences for marine ecosystems, Science, 321 (2008) 926-929.

[18] D. Cordell, A. Rosemarin, J.J. Schroder, A.L. Smit, Toward global phosphorus security: a systems framework for phosphorus recovery and reuse options, Chemosphere, 84 (2011) 747-758.

[19] Z. Yuan, S. Pratt, D.J. Batstone, Phosphorus recovery from wastewater through microbial processes, Current Opinion in Biotechnology, 23 (2012) 878-883.

[20] Y. Ye, H.H. Ngo, W. Guo, Y. Liu, X. Zhang, J. Guo, B.J. Ni, S.W. Chang, D.D. Nguyen, Insight into biological phosphate recovery from sewage, Bioresoure Technology, 218 (2016) 874-881.

[21] G. Morse, S. Brett, J. Guy, J. Lester, Phosphorus removal and recovery technologies, Science of the Total Environment, 212 (1998) 69-81.

[22] E. Desmidt, K. Ghyselbrecht, Y. Zhang, L. Pinoy, B. Van der Bruggen, W. Verstraete, K. Rabaey, B. Meesschaert, Global Phosphorus Scarcity and Full-Scale P-Recovery Techniques: A Review, Critical Reviews in Environmental Science and Technology, 45 (2015) 336-384.

[23] Y. Ye, H.H. Ngo, W. Guo, Y. Liu, J. Li, Y. Liu, X. Zhang, H. Jia, Insight into chemical phosphate recovery from municipal wastewater, Science of the Total Environment, 576 (2017) 159-171.

[24] S. Yeoman, T. Stephenson, J. Lester, R. Perry, The removal of phosphorus during wastewater treatment: a review, Environmental Pollution, 49 (1988) 183-233.

[25] P.K. Wilfert, Phosphate recovery from sewage sludge containing iron phosphate, in, Delft University of Technology, 2018. 
[26] P. Suresh Kumar, L. Korving, M. van Loosdrecht, G. Witkamp, Adsorption as a technology to achieve ultra-low concentrations of phosphate: Research gaps and economic analysis, Water Research X, 4 (2019).

[27] K.S. Le Corre, E. Valsami-Jones, P. Hobbs, S.A. Parsons, Phosphorus recovery from wastewater by struvite crystallization: A review, Critical Reviews in Environmental Science and Technology, 39 (2009) 433-477.

[28] J. Hovelmann, C.V. Putnis, In situ nanoscale imaging of struvite formation during the dissolution of natural brucite: implications for phosphorus recovery from wastewaters, Environmental Science \& Technology, 50 (2016) 13032-13041.

[29] X. Hao, C. Wang, M.C. van Loosdrecht, Y. Hu, Looking beyond struvite for P-recovery, Environmental Science \& Technology, 47 (2013) 4965-4966.

[30] K.P. Law, K.R. Pagilla, Phosphorus recovery by methods beyond struvite precipitation, Water Environment Research, 90 (2018) 840-850.

[31] T. Tervahauta, R.D. van der Weijden, R.L. Flemming, L. Hernandez Leal, G. Zeeman, C.J. Buisman, Calcium phosphate granulation in anaerobic treatment of black water: a new approach to phosphorus recovery, Water Research, 48 (2014) 632-642.

[32] Y. Lei, J. Remmers, R.D. van der Weijden, M. Saakes, C.J. Buisman, Is there a precipitation sequence in municipal wastewater induced by electrolysis? , Environmental Science \& Technology, 52 (2018) 8399-8407.

[33] D.G. Randall, M. Krähenbühl, I. Köpping, T.A. Larsen, K.M. Udert, A novel approach for stabilizing fresh urine by calcium hydroxide addition, Water Research, 95 (2016) 361369.

[34] A. Bouzas, N. Martí, S. Grau, R. Barat, D. Mangin, L. Pastor, Implementation of a global P-recovery system in urban wastewater treatment plants, Journal of Cleaner Production, 227 (2019) 130-140.

[35] L. Wang, G.H. Nancollas, Calcium orthophosphates: crystallization and dissolution, Chemical Reviews, 108 (2008) 4628-4669.

[36] Y. Song, H.H. Hahn, E. Hoffmann, Effects of solution conditions on the precipitation of phosphate for recovery: A thermodynamic evaluation, Chemosphere, 48 (2002) 1029-1034. [37] Y. Jaffer, T. Clark, P. Pearce, S. Parsons, Potential phosphorus recovery by struvite formation, Water Research, 36 (2002) 1834-1842. 
[38] G. Tchobanoglous, H.D. Stensel, R. Tsuchihashi, F. Burton, M. Abu-Orf, G. Bowden, W. Pfrang, Wastewater Engineering: Treatment and Resource Recovery, ; Metcalf \& Eddy I AECOM, in, McGraw-Hill Book Company: New York, NY, USA, 2014.

[39] R.D. Cusick, B.E. Logan, Phosphate recovery as struvite within a single chamber microbial electrolysis cell, Bioresoure Technology, 107 (2012) 110-115.

[40] P. Yuan, Y. Kim, Increasing phosphorus recovery from dewatering centrate in microbial electrolysis cells, Biotechnology for Biofuels, 10 (2017) 70.

[41] D. Hasson, G. Sidorenko, R. Semiat, Calcium carbonate hardness removal by a novel electrochemical seeds system, Desalination, 263 (2010) 285-289.

[42] T.H. Sleutels, H.V. Hamelers, C.J. Buisman, Reduction of $\mathrm{pH}$ buffer requirement in bioelectrochemical systems, Environment Science \& Technology, 44 (2010) 8259-8263.

[43] H. Zöllig, C. Fritzsche, E. Morgenroth, K.M. Udert, Direct electrochemical oxidation of ammonia on graphite as a treatment option for stored source-separated urine, Water Research, 69 (2015) 284-294.

[44] J. Radjenovic, D.L. Sedlak, Challenges and opportunities for electrochemical processes as next-generation technologies for the treatment of contaminated water, Environmental Science \& Technology, 49 (2015) 11292-11302.

[45] M.E.R. Christiaens, S. Gildemyn, S. Matassa, T. Ysebaert, J. De Vrieze, K. Rabaey, Electrochemical ammonia recovery from source-separated urine for microbial protein production, Environmental Science \& Technology, 51 (2017) 13143-13150.

[46] Z. Bradford-Hartke, J. Lane, P. Lant, G. Leslie, Environmental Benefits and Burdens of Phosphorus Recovery from Municipal Wastewater, Environmental Science \& Technology, 49 (2015) 8611-8622.

[47] A.K. Venkatesan, A.H. Hamdan, V.M. Chavez, J.D. Brown, R.U. Halden, Mass balance model for sustainable phosphorus recovery in a US wastewater treatment plant, Journal of Environmental Quality, 45 (2016) 84-89.

[48] S. Hukari, L. Hermann, A. Nattorp, From wastewater to fertilisers--Technical overview and critical review of European legislation governing phosphorus recycling, Science of the Total Environment, 542 (2016) 1127-1135.

[49] Y. Zhang, E. Desmidt, A. Van Looveren, L. Pinoy, B. Meesschaert, B. Van der Bruggen, Phosphate separation and recovery from wastewater by novel electrodialysis, Environmental Science \& Technology, 47 (2013) 5888-5895. 
[50] J. Wu, D. Franzén, M.E. Malmström, Anthropogenic phosphorus flows under different scenarios for the city of Stockholm, Sweden, Science of the Total Environment, 542 (2016) 1094-1105.

[51] Y. Zhang, B. Pan, C. Shan, X. Gao, Enhanced Phosphate Removal by Nanosized Hydrated La(III) Oxide Confined in Cross-linked Polystyrene Networks, Environmental Science \& Technology, 50 (2016) 1447-1454.

[52] X.D. Hao, C.C. Wang, L. Lan, M.C. van Loosdrecht, Struvite formation, analytical methods and effects of $\mathrm{pH}$ and $\mathrm{Ca}^{2+}$, Water Science and Technology, 58 (2008) 1687-1692. [53] N. Marti, L. Pastor, A. Bouzas, J. Ferrer, A. Seco, Phosphorus recovery by struvite crystallization in WWTPs: influence of the sludge treatment line operation, Water Research, 44 (2010) 2371-2379.

[54] A. Hug, K.M. Udert, Struvite precipitation from urine with electrochemical magnesium dosage, Water Research, 47 (2013) 289-299.

[55] M. Xie, L.D. Nghiem, W.E. Price, M. Elimelech, Toward Resource Recovery from Wastewater: Extraction of Phosphorus from Digested Sludge Using a Hybrid Forward Osmosis-Membrane Distillation Process, Environmental Science \& Technology Letters, 1 (2014) 191-195.

[56] G. Qiu, Y.M. Law, S. Das, Y.P. Ting, Direct and complete phosphorus recovery from municipal wastewater using a hybrid microfiltration-forward osmosis membrane bioreactor process with seawater brine as draw solution, Environmental Science \& Technology, 49 (2015) 6156-6163.

[57] V.S. Mehta, F. Maillot, Z. Wang, J.G. Catalano, D.E. Giammar, Effect of Reaction Pathway on the Extent and Mechanism of Uranium(VI) Immobilization with Calcium and Phosphate, Environmental Science \& Technology, 50 (2016) 3128-3136.

[58] X. Chen, H. Kong, D. Wu, X. Wang, Y. Lin, Phosphate removal and recovery through crystallization of hydroxyapatite using xonotlite as seed crystal, Journal of Environmental Sciences, 21 (2009) 575-580.

[59] R. Barat, T. Montoya, A. Seco, J. Ferrer, Modelling biological and chemically induced precipitation of calcium phosphate in enhanced biological phosphorus removal systems, Water Research, 45 (2011) 3744-3752. 
[60] H. Zou, Y. Wang, Phosphorus removal and recovery from domestic wastewater in a novel process of enhanced biological phosphorus removal coupled with crystallization, Bioresoure Technology, 211 (2016) 87-92.

[61] P.T. Kelly, Z. He, Nutrients removal and recovery in bioelectrochemical systems: a review, Bioresoure Technology, 153 (2014) 351-360.

[62] E. Brillas, I. Sirés, M.A. Oturan, Electro-Fenton process and related electrochemical technologies based on Fenton's reaction chemistry, Chemical reviews, 109 (2009) 6570-6631. [63] A.T. Heijne, F. Liu, R.v.d. Weijden, J. Weijma, C.J. Buisman, H.V. Hamelers, Copper recovery combined with electricity production in a microbial fuel cell, Environmental Science \& Technology, 44 (2010) 4376-4381.

[64] C.C. Wang, X.D. Hao, G.S. Guo, M.C.M. van Loosdrecht, Formation of pure struvite at neutral pH by electrochemical deposition, Chemical Engineering Journal, 159 (2010) 280 283.

[65] R.D. Cusick, B.E. Logan, Phosphate recovery as struvite within a single chamber microbial electrolysis cell, Bioresource Technology, 107 (2012) 110-115.

[66] R.D. Cusick, M.L. Ullery, B.A. Dempsey, B.E. Logan, Electrochemical struvite precipitation from digestate with a fluidized bed cathode microbial electrolysis cell, Water Research, 54 (2014) 297-306.

[67] J. Zhang, C. Lin, Z. Feng, Z. Tian, Mechanistic studies of electrodeposition for bioceramic coatings of calcium phosphates by an in situ $\mathrm{pH}$-microsensor technique, Journal of Electroanalytical Chemistry, 452 (1998) 235-240.

[68] T. Honda, K. Murase, T. Hirato, Y. Awakura, $\mathrm{pH}$ measurement in the vicinity of a cathode evolving hydrogen gas using an antimony microelectrode, Journal of Applied Electrochemistry, 28 (1998) 617-622.

[69] C. Kappel, K. Yasadi, H. Temmink, S.J. Metz, A.J.B. Kemperman, K. Nijmeijer, A. Zwijnenburg, G.J. Witkamp, H.H.M. Rijnaarts, Electrochemical phosphate recovery from nanofiltration concentrates, Separation and Purification Technology, 120 (2013) 437-444.

[70] W. House, The physico-chemical conditions for the precipitation of phosphate with calcium, Environmental Technology, 20 (1999) 727-733.

[71] J. Gustafsson, Visual MINTEQ ver. 3.0, Department of Land and Water Resources Engineering, Royal Institute of Technology: Stokholm, Sweden, (2011). 
[72] I. Puigdomènech, Chemical equilibrium software Hydra and Medusa, Inorganic Chemistry Department, Technology Institute, Stockholm, Sweden, (2001).

[73] W. Ostwald, Studien über die Bildung und Umwandlung fester Körper, Z. phys. Chem, 22 (1897) 289-330.

[74] A. Akiva, M. Kerschnitzki, I. Pinkas, W. Wagermaier, K. Yaniv, P. Fratzl, L. Addadi, S. Weiner, Mineral formation in the larval zebrafish tail bone occurs via an acidic disordered calcium phosphate phase, Journal of the American Chemical Society, 138 (2016) 1448114487.

[75] H.-J. Ensikat, T. Geisler, M. Weigend, A first report of hydroxylated apatite as structural biomineral in Loasaceae-plants' teeth against herbivores, Scientific Reports, 6 (2016) 26073. [76] A. Ter Heijne, D.P. Strik, H.V. Hamelers, C.J. Buisman, Cathode potential and mass transfer determine performance of oxygen reducing biocathodes in microbial fuel cells, Environmental Science \& Technology, 44 (2010) 7151-7156.

[77] H.-T. Chen, M.-C. Wang, K.-M. Chang, S.-H. Wang, W.-J. Shih, W.-L. Li, Phase transformation and morphology of calcium phosphate prepared by electrochemical deposition process through alkali treatment and calcination, Metallurgical and Materials Transactions A, 45 (2013) 2260-2269.

[78] F. Betts, A. Posner, An X-ray radial distribution study of amorphous calcium phosphate, Materials Research Bulletin, 9 (1974) 353-360.

[79] X. Lu, Z. Zhao, Y. Leng, Calcium phosphate crystal growth under controlled atmosphere in electrochemical deposition, Journal of Crystal Growth, 284 (2005) 506-516.

[80] M. Arifin, P.J. Swedlund, Y. Hemar, I.R. McKinnon, Calcium phosphates in Ca2+fortified milk: Phase identification and quantification by Raman spectroscopy, Journal of Agricultural and Food Chemistry, 62 (2014) 12223-12228.

[81] M. Ronteltap, M. Maurer, W. Gujer, The behaviour of pharmaceuticals and heavy metals during struvite precipitation in urine, Water Research, 41 (2007) 1859-1868.

[82] M. Munir, B. Li, I. Boiarkina, S. Baroutian, W. Yu, B.R. Young, Phosphate recovery from hydrothermally treated sewage sludge using struvite precipitation, Bioresource Technology, 239 (2017) 171-179.

[83] L. Reijnders, Phosphorus resources, their depletion and conservation, a review, Resources, Conservation and Recycling, 93 (2014) 32-49. 
[84] J.R. Cunha, C. Schott, R.D. van der Weijden, L.H. Leal, G. Zeeman, C. Buisman, Calcium addition to increase the production of phosphate granules in anaerobic treatment of black water, Water Research, 130 (2018) 333-342.

[85] P.S. Kumar, T. Prot, L. Korving, K.J. Keesman, I. Dugulan, M.C. van Loosdrecht, G.-J. Witkamp, Effect of pore size distribution on iron oxide coated granular activated carbons for phosphate adsorption-Importance of mesopores, Chemical Engineering Journal, 326 (2017) 231-239.

[86] Y.-J. Shih, R.R.M. Abarca, M.D.G. de Luna, Y.-H. Huang, M.-C. Lu, Recovery of phosphorus from synthetic wastewaters by struvite crystallization in a fluidized-bed reactor: Effects of $\mathrm{pH}$, phosphate concentration and coexisting ions, Chemosphere, 173 (2017) 466473.

[87] S. Yang, P. Jin, X. Wang, Q. Zhang, X. Chen, Phosphate recovery through adsorption assisted precipitation using novel precipitation material developed from building waste: Behavior and mechanism, Chemical Engineering Journal, 292 (2016) 246-254.

[88] C. Barca, S. Troesch, D. Meyer, P. Drissen, Y. Andres, F. Chazarenc, Steel slag filters to upgrade phosphorus removal in constructed wetlands: two years of field experiments, Environmental Science \& Technology, 47 (2012) 549-556.

[89] Y. Lei, B. Song, R.D. van der Weijden, M. Saakes, C.J. Buisman, Electrochemical induced calcium phosphate precipitation: Importance of local $\mathrm{pH}$, Environmental Science \& Technology, 51 (2017) 11156-11164.

[90] X. Cao, W. Harris, Carbonate and magnesium interactive effect on calcium phosphate precipitation, Environmental Science \& Technology, 42 (2007) 436-442.

[91] M. Hermassi, C. Valderrama, J. Dosta, J. Cortina, N. Batis, Detrimental effects of magnesium (II) on hydroxyapatite precipitation from synthetic industrial brines, Chemical Engineering Journal, 283 (2016) 572-581.

[92] J. Cunha, T. Tervahauta, R. Van Der Weijden, L.H. Leal, G. Zeeman, C. Buisman, Simultaneous recovery of calcium phosphate granules and methane in anaerobic treatment of black water: Effect of bicarbonate and calcium fluctuations, Journal of Environmental Management, (2017).

[93] Y.-h. Song, H.H. Hahn, E. Hoffmann, P.G. Weidler, Effect of humic substances on the precipitation of calcium phosphate, Journal of Environmental Sciences, 18 (2006) 852-857. 
[94] X. Cao, W.G. Harris, M.S. Josan, V.D. Nair, Inhibition of calcium phosphate precipitation under environmentally-relevant conditions, Science of the Total Environment, 383 (2007) 205-215.

[95] H.R. Sindelar, M.T. Brown, T.H. Boyer, Effects of natural organic matter on calcium and phosphorus co-precipitation, Chemosphere, 138 (2015) 218-224.

[96] A. Matilainen, M. Vepsäläinen, M. Sillanpää, Natural organic matter removal by coagulation during drinking water treatment: a review, Advances in Colloid and Interface Science, 159 (2010) 189-197.

[97] R. Hahn, C. Hein, J.M. Sander, R. Kautenburger, Complexation of europium and uranium with natural organic matter (NOM) in highly saline water matrices analysed by ultrafiltration and inductively coupled plasma mass spectrometry (ICP-MS), Applied Geochemistry, (2017).

[98] S. Semitsoglou-Tsiapou, A. Mous, M.R. Templeton, N.J. Graham, L. Hernandez Leal, J.C. Kruithof, The role of natural organic matter in nitrite formation by $\mathrm{LP}-\mathrm{UV} / \mathrm{H}_{2} \mathrm{O}_{2}$ treatment of nitrate-rich water, Water Research, 106 (2016) 312-319.

[99] J.D. Ritchie, E.M. Perdue, Proton-binding study of standard and reference fulvic acids, humic acids, and natural organic matter, Geochimica et Cosmochimica Acta, 67 (2003) 8596.

[100] L. Rajic, N. Fallahpour, R. Nazari, A.N. Alshawabkeh, Influence of humic substances on electrochemical degradation of trichloroethylene in limestone aquifers, Electrochimica Acta, 181 (2015) 123-129.

[101] I. Perassi, L. Borgnino, Adsorption and surface precipitation of phosphate onto $\mathrm{CaCO}_{3}-$ montmorillonite: effect of $\mathrm{pH}$, ionic strength and competition with humic acid, Geoderma, 232 (2014) 600-608.

[102] R. Alvarez, L.A. Evans, P.J. Milham, M.A. Wilson, Effects of humic material on the precipitation of calcium phosphate, Geoderma, 118 (2004) 245-260.

[103] A. Delgado, A. Madrid, S. Kassem, L. Andreu, M. del Carmen del Campillo, Phosphorus fertilizer recovery from calcareous soils amended with humic and fulvic acids, Plant and Soil, 245 (2002) 277-286.

[104] Z. Zhou, D. Hu, W. Ren, Y. Zhao, L.M. Jiang, L. Wang, Effect of humic substances on phosphorus removal by struvite precipitation, Chemosphere, 141 (2015) 94-99. 
[105] A.S. Al-Amoudi, Factors affecting natural organic matter (NOM) and scaling fouling in NF membranes: a review, Desalination, 259 (2010) 1-10.

[106] A.W. Jeremiasse, H.V. Hamelers, J.M. Kleijn, C.J. Buisman, Use of biocompatible buffers to reduce the concentration overpotential for hydrogen evolution, Environmental Science \& Technology, 43 (2009) 6882-6887.

[107] H. Dai, X. Lu, Y. Peng, H. Zou, J. Shi, An efficient approach for phosphorus recovery from wastewater using series-coupled air-agitated crystallization reactors, Chemosphere, 165 (2016) 211-220.

[108] T. Yan, Y. Ye, H. Ma, Y. Zhang, W. Guo, B. Du, Q. Wei, D. Wei, H.H. Ngo, A critical review on membrane hybrid system for nutrient recovery from wastewater, Chemical Engineering Journal, (2018).

[109] C. Tarayre, L. De Clercq, R. Charlier, E. Michels, E. Meers, M. Camargo-Valero, F. Delvigne, New perspectives for the design of sustainable bioprocesses for phosphorus recovery from waste, Bioresource Technology, 206 (2016) 264-274.

[110] C.m.A. Cid, J.T. Jasper, M.R. Hoffmann, Phosphate recovery from human waste via the formation of hydroxyapatite during electrochemical wastewater treatment, ACS Sustainable Chemistry \& Engineering, 6 (2018) 3135-3142.

[111] O. Nir, R. Sengpiel, M. Wessling, Closing the cycle: Phosphorus removal and recovery from diluted effluents using acid resistive membranes, Chemical Engineering Journal, 346 (2018) 640-648.

[112] L. Peng, H. Dai, Y. Wu, Y. Peng, X. Lu, A comprehensive review of phosphorus recovery from wastewater by crystallization processes, Chemosphere, 197 (2018) 768-781. [113] P.M. Melia, A.B. Cundy, S.P. Sohi, P.S. Hooda, R. Busquets, Trends in the recovery of phosphorus in bioavailable forms from wastewater, Chemosphere, 186 (2017) 381-395.

[114] A. Monballiu, K. Ghyselbrecht, X. Crabeels, B. Meesschaert, Calcium phosphate precipitation in nitrified wastewater from the potato-processing industry, Environmental Technology, (2018) 1-17.

[115] Y. Feng, L. Yang, J. Liu, B.E. Logan, Electrochemical technologies for wastewater treatment and resource reclamation, Environmental Science: Water Research \& Technology, 2 (2016) 800-831. 
[116] H. Huang, D. Zhang, G. Guo, Y. Jiang, M. Wang, P. Zhang, J. Li, Dolomite application for the removal of nutrients from synthetic swine wastewater by a novel combined electrochemical process, Chemical Engineering Journal, 335 (2018) 665-675.

[117] A. Kuhn, C. Chan, pH changes at near-electrode surfaces, Journal of Applied Electrochemistry, 13 (1983) 189-207.

[118] K. Zeppenfeld, Electrochemical removal of calcium and magnesium ions from aqueous solutions, Desalination, 277 (2011) 99-105.

[119] Y. Lei, M. Saakes, R.D. van der Weijden, C.J. Buisman, Effects of current density, bicarbonate and humic acid on electrochemical induced calcium phosphate precipitation, Chemical Engineering Journal, 342 (2018) 350-356.

[120] Y. Lei, B. Song, R.D. van der Weijden, M. Saakes, C.J. Buisman, Interaction of calcium, phosphorus and natural organic matter in electrochemical recovery of phosphate, Water Research, 142 (2018) 10-17.

[121] R.E. Zeebe, D.A. Wolf-Gladrow, $\mathrm{CO}_{2}$ in seawater: equilibrium, kinetics, isotopes, Gulf Professional Publishing, 2001.

[122] S. Arabi, G. Nakhla, Impact of calcium on the membrane fouling in membrane bioreactors, Journal of Membrane Science, 314 (2008) 134-142.

[123] P. Yuan, Y. Kim, Increasing phosphorus recovery from dewatering centrate in microbial electrolysis cells, Biotechnology for Biofuels, 10 (2017) 70.

[124] E. Diamadopoulos, A. Benedek, The precipitation of phosphorus from wastewater through $\mathrm{pH}$ variation in the presence and absence of coagulants, Water Research, 18 (1984) 1175-1179.

[125] Y. Yuan, S. Zhou, J. Tang, In situ investigation of cathode and local biofilm microenvironments reveals important roles of $\mathrm{OH}-$ and oxygen transport in microbial fuel cells, Environmental Science \& Technology, 47 (2013) 4911-4917.

[126] G.H. Rau, Electrochemical splitting of calcium carbonate to increase solution alkalinity: Implications for mitigation of carbon dioxide and ocean acidity, Environmental Science \& Technology, 42 (2008) 8935-8940.

[127] I. Buljan Meić, J. Kontrec, D. Domazet Jurašin, B. Njegić Džakula, L. Štajner, D.M. Lyons, M. Dutour Sikirić, D. Kralj, Comparative study of calcium carbonates and calcium phosphates precipitation in model systems mimicking the inorganic environment for biomineralization, Crystal Growth \& Design, 17 (2017) 1103-1117. 
[128] H. Wang, V. Alfredsson, J. Tropsch, R. Ettl, T. Nylander, Formation of $\mathrm{CaCO}_{3}$ Deposits on Hard Surfaces-Effect of Bulk Solution Conditions and Surface Properties, ACS applied materials \& interfaces, 5 (2013) 4035-4045.

[129] J.T. Jasper, Y. Yang, M.R. Hoffmann, Toxic byproduct formation during electrochemical treatment of latrine wastewater, Environmental Science \& Technology, 51 (2017) 7111-7119.

[130] Y. Vanlangendonck, D. Corbisier, A. Van Lierde, Influence of operating conditions on the ammonia electro-oxidation rate in wastewaters from power plants (ELONITA ${ }^{\mathrm{TM}}$ technique), Water Research, 39 (2005) 3028-3034.

[131] A.T.K. Tran, Y. Zhang, D. De Corte, J.-B. Hannes, W. Ye, P. Mondal, N. Jullok, B. Meesschaert, L. Pinoy, B. Van der Bruggen, P-recovery as calcium phosphate from wastewater using an integrated selectrodialysis/crystallization process, Journal of Cleaner Production, 77 (2014) 140-151.

[132] R. Angel, Removal of Phosphate from Sewage as Amorphous Calcium Phosphate, Environmental Technology, 20 (1999) 709-720.

[133] R.A. Rozendal, H.V. Hamelers, K. Rabaey, J. Keller, C.J. Buisman, Toward practical implementation of bioelectrochemical wastewater treatment, Trends in Biotechnology, 26 (2008) 450-459.

[134] B.E. Logan, B. Hamelers, R. Rozendal, U. Schröder, J. Keller, S. Freguia, P. Aelterman, W. Verstraete, K. Rabaey, Microbial fuel cells: methodology and technology, Environmental Science \& Technology, 40 (2006) 5181-5192.

[135] B.E. Logan, D. Call, S. Cheng, H.V. Hamelers, T.H. Sleutels, A.W. Jeremiasse, R.A. Rozendal, Microbial electrolysis cells for high yield hydrogen gas production from organic matter, Environmental Science \& Technology, 42 (2008) 8630-8640.

[136] O. Ichihashi, K. Hirooka, Removal and recovery of phosphorus as struvite from swine wastewater using microbial fuel cell, Bioresoure Technology, 114 (2012) 303-307.

[137] K. Hirooka, O. Ichihashi, Phosphorus recovery from artificial wastewater by microbial fuel cell and its effect on power generation, Bioresoure Technology, 137 (2013) 368-375. [138] Y. Yuan, S. Zhou, J. Tang, In situ investigation of cathode and local biofilm microenvironments reveals important roles of $\mathrm{OH}-$ and oxygen transport in microbial fuel cells, Environmental Science Technology, 47 (2013) 4911-4917. 
[139] L. Lu, N.B. Williams, J.A. Turner, P.-C. Maness, J. Gu, Z.J. Ren, Microbial photoelectrosynthesis for self-sustaining hydrogen generation, Environmental Science \& Technology, 51 (2017) 13494-13501.

[140] J.T. Jasper, Y. Yang, M.R. Hoffmann, Toxic Byproduct Formation during Electrochemical Treatment of Latrine Wastewater, Environmental Science \& Technology, (2017).

[141] W.-W. Li, H.-Q. Yu, Z. He, Toward sustainable wastewater treatment by using microbial fuel cells-centered technologies, Energy \& Environmental Science, 7 (2014) 911 924.

[142] B.E. Logan, K. Rabaey, Conversion of wastes into bioelectricity and chemicals by using microbial electrochemical technologies, Science, 337 (2012) 686-690.

[143] T.H. Sleutels, S.D. Molenaar, A.T. Heijne, C.J. Buisman, Low substrate loading limits methanogenesis and leads to high coulombic efficiency in bioelectrochemical systems, Microorganisms, 4 (2016) 7.

[144] A.J. Zehnder, B.A. Huser, T.D. Brock, K. Wuhrmann, Characterization of an acetatedecarboxylating, non-hydrogen-oxidizing methane bacterium, Archives of Microbiology, 124 (1980) 1-11.

[145] S.D. Molenaar, A.R. Mol, T.H. Sleutels, A. Ter Heijne, C.J. Buisman, Microbial rechargeable battery: energy storage and recovery through acetate, Environmental Science \& Technology Letters, 3 (2016) 144-149.

[146] T.H. Sleutels, L. Darus, H.V. Hamelers, C.J. Buisman, Effect of operational parameters on Coulombic efficiency in bioelectrochemical systems, Bioresource Technology, 102 (2011) 11172-11176.

[147] Y. Lei, I. Hidayat, R.D. van der Weijden, M. Saakes, C.J. Buisman, Fate of calcium, magnesium and inorganic carbon in electrochemical phosphorus recovery from domestic wastewater Chemical Engineering Journal, 362 (2019) 453-459.

[148] Y.-P. Lin, P.C. Singer, G.R. Aiken, Inhibition of calcite precipitation by natural organic material: kinetics, mechanism, and thermodynamics, Environmental Science \& Technology, 39 (2005) 6420-6428.

[149] Rock phosphate monthly price, in, https://www.indexmundi.com/commodities/?commodity=rock-phosphate\&months=12, 2019. 
[150] J. Van Dijk, H. Braakensiek, Phosphate removal by crystallization in a fluidized bed, Water Science and Technology, 17 (1985) 133-142.

[151] Y. Lei, J.C. Remmers, M. Saakes, R.D. van der Weijden, C.J.N. Buisman, Influence of cell configuration and long-term operation on electrochemical phosphorus recovery from domestic wastewater, ACS Sustainable Chemistry \& Engineering, 7 (2019) 7362-7368.

[152] L.L. Zhang, X. Zhao, Carbon-based materials as supercapacitor electrodes, Chemical Society reviews, 38 (2009) 2520-2531.

[153] M. Suss, S. Porada, X. Sun, P. Biesheuvel, J. Yoon, V. Presser, Water desalination via capacitive deionization: what is it and what can we expect from it?, Energy \& Environmental Science, 8 (2015) 2296-2319.

[154] X. Huang, D. He, W. Tang, P. Kovalsky, T.D. Waite, Investigation of pH-dependent phosphate removal from wastewaters by membrane capacitive deionization (MCDI), Environmental Science: Water Research \& Technology, 3 (2017) 875-882.

[155] G.-H. Huang, T.-C. Chen, S.-F. Hsu, Y.-H. Huang, S.-H. Chuang, Capacitive deionization (CDI) for removal of phosphate from aqueous solution, Desalination and Water Treatment, 52 (2014) 759-765.

[156] D.J. Conley, H.W. Paerl, R.W. Howarth, D.F. Boesch, S.P. Seitzinger, K.E. Havens, C. Lancelot, G.E. Likens, Controlling eutrophication: nitrogen and phosphorus, Science, 323 (2009) 1014-1015.

[157] A. Oehmen, P.C. Lemos, G. Carvalho, Z. Yuan, J. Keller, L.L. Blackall, M.A. Reis, Advances in enhanced biological phosphorus removal: from micro to macro scale, Water Research, 41 (2007) 2271-2300.

[158] K. Venkiteshwaran, P.J. McNamara, B.K. Mayer, Meta-analysis of non-reactive phosphorus in water, wastewater, and sludge, and strategies to convert it for enhanced phosphorus removal and recovery, Science of the Total Environment, 644 (2018) 661-674.

[159] D.S. Baldwin, Organic phosphorus in the aquatic environment, Environmental Chemistry, 10 (2013) 439.

[160] M.R. Brooker, K. Longnecker, E.B. Kujawinski, M.H. Evert, P.J. Mouser, Discrete organic phosphorus signatures are evident in pollutant sources within a Lake Erie tributary, Environmental Science \& Technology, 52 (2018) 6771-6779.

[161] C.A. McDonough, A.O. De Silva, C. Sun, A. Cabrerizo, D. Adelman, T. Soltwedel, E. Bauerfeind, D.C.G. Muir, R. Lohmann, Dissolved organophosphate esters and 
polybrominated diphenyl ethers in remote marine environments: arctic surface water distributions and net transport through fram strait, Environmental Science \& Technology, 52 (2018) 6208-6216.

[162] B. Nowack, Environmental chemistry of phosphonates, Water Research, 37 (2003) 2533-2546.

[163] S. Dyhrman, P. Chappell, S. Haley, J. Moffett, E. Orchard, J. Waterbury, E. Webb, Phosphonate utilization by the globally important marine diazotroph Trichodesmium, Nature, 439 (2006) 68.

[164] X. Zhang, J. Li, W.-Y. Fan, G.-P. Sheng, Photomineralization of effluent organic phosphorus to orthophosphate under simulated light illumination, Environmental Science \& Technology, 53 (2019) 4997-5004.

[165] E. Rott, H. Steinmetz, J.W. Metzger, Organophosphonates: A review on environmental relevance, biodegradability and removal in wastewater treatment plants, Science of the Total Environment, 615 (2018) 1176-1191.

[166] USEPA, Quality Criteria for Water, United States Environ. Prot. Agency, Off. Water Regul. Stand., 395 (1986).

[167] B.K. Mayer, D. Gerrity, B.E. Rittmann, D. Reisinger, S. Brandt-Williams, Innovative Strategies to Achieve Low Total Phosphorus Concentrations in High Water Flows, Critical Reviews in Environmental Science and Technology, 43 (2013) 409-441.

[168] H.R. Sindelar, J. Lloyd, M.T. Brown, T.H. Boyer, Transformation of dissolved organic phosphorus to phosphate using $\mathrm{UV} / \mathrm{H}_{2} \mathrm{O}_{2}$, Environmental Progress \& Sustainable Energy, 35 (2016) 680-691.

[169] E. Rott, R. Minke, U. Bali, H. Steinmetz, Removal of phosphonates from industrial wastewater with UV/Fe(II), Fenton and UV/Fenton treatment, Water Research, 122 (2017) 345-354.

[170] S. Sun, S. Wang, Y. Ye, B. Pan, Highly efficient removal of phosphonates from water by a combined Fe (III)/UV/co-precipitation process, Water Research, 153 (2019) 21-28.

[171] C.A. Martínez-Huitle, M.A. Rodrigo, I. Sirés, O. Scialdone, Single and coupled electrochemical processes and reactors for the abatement of organic water pollutants: a critical review, Chemical Reviews, 115 (2015) 13362-13407. 
[172] C.A. Martinez-Huitle, S. Ferro, Electrochemical oxidation of organic pollutants for the wastewater treatment: direct and indirect processes, Chemical Society Reviews, 35 (2006) 1324-1340.

[173] L. Boels, K.J. Keesman, G.J. Witkamp, Adsorption of phosphonate antiscalant from reverse osmosis membrane concentrate onto granular ferric hydroxide, Environmental Science \& Technology, 46 (2012) 9638-9645.

[174] E. Rott, R. Minke, H. Steinmetz, Removal of phosphorus from phosphonate-loaded industrial wastewaters via precipitation/flocculation, Journal of Water Process Engineering, 17 (2017) 188-196.

[175] N. Oturan, J. Wu, H. Zhang, V.K. Sharma, M.A. Oturan, Electrocatalytic destruction of the antibiotic tetracycline in aqueous medium by electrochemical advanced oxidation processes: Effect of electrode materials, Applied Catalysis B: Environmental, 140-141 (2013) 92-97.

[176] A. Butkovskyi, A.W. Jeremiasse, L. Hernandez Leal, T. van der Zande, H. Rijnaarts, G. Zeeman, Electrochemical conversion of micropollutants in gray water, Environmental Science \& Technology, 48 (2014) 1893-1901.

[177] H. Song, L. Yan, J. Ma, J. Jiang, G. Cai, W. Zhang, Z. Zhang, J. Zhang, T. Yang, Nonradical oxidation from electrochemical activation of peroxydisulfate at $\mathrm{Ti} / \mathrm{Pt}$ anode: Efficiency, mechanism and influencing factors, Water Research, 116 (2017) 182-193.

[178] A. Farhat, J. Keller, S. Tait, J. Radjenovic, Removal of persistent organic contaminants by electrochemically activated sulfate, Environmental Science \& Technology, 49 (2015) 14326-14333.

[179] Y. Lei, C.-S. Chen, Y.-J. Tu, Y.-H. Huang, H. Zhang, Heterogeneous degradation of organic pollutants by persulfate activated by $\mathrm{CuO}-\mathrm{Fe}_{3} \mathrm{O}_{4}$ : mechanism, stability, and effects of $\mathrm{pH}$ and bicarbonate ions, Environmental Science \& Technology, 49 (2015) 6838-6845. [180] B. Nowack, A.T. Stone, Degradation of nitrilotris (methylenephosphonic acid) and related (amino) phosphonate chelating agents in the presence of manganese and molecular oxygen, Environmental Science \& Technology, 34 (2000) 4759-4765.

[181] L. Zhang, Y.S. Jun, The role of Fe-bearing phyllosilicates in DTPMP degradation under high-temperature and high-pressure conditions, Environmental Science \& Technology, 52 (2018) 9522-9530. 
[182] G. Meyer, E. Frossard, P. Mäder, S. Nanzer, D.G. Randall, K.M. Udert, A. Oberson, Water soluble phosphate fertilizers for crops grown in calcareous soils-an outdated paradigm for recycled phosphorus fertilizers?, Plant and soil, 424 (2018) 367-388.

[183] W.A. Tarpeh, J.M. Barazesh, T.Y. Cath, K.L. Nelson, Electrochemical stripping to recover nitrogen from source-separated urine, Environmental Science \& Technology, 52 (2018) 1453-1460.

[184] L. Wang, E. Ruiz-Agudo, C.V. Putnis, M. Menneken, A. Putnis, Kinetics of Calcium Phosphate Nucleation and Growth on Calcite: Implications for Predicting the Fate of Dissolved Phosphate Species in Alkaline Soils, Environmental Science \& Technology, 46 (2012) 834-842.

[185] Y. Song, P.G. Weidler, U. Berg, R. Nuesch, D. Donnert, Calcite-seeded crystallization of calcium phosphate for phosphorus recovery, Chemosphere, 63 (2006) 236-243.

[186] P. Cornel, C. Schaum, Phosphorus recovery from wastewater: needs, technologies and costs, Water Science and Technology, 59 (2009) 1069-1076.

[187] M. Molinos-Senante, F. Hernández-Sancho, R. Sala-Garrido, M. Garrido-Baserba, Economic feasibility study for phosphorus recovery processes, Ambio, 40 (2011) 408-416. [188] J. Luan, L. Wang, W. Sun, X. Li, T. Zhu, Y. Zhou, H. Deng, S. Chen, S. He, G. Liu, Multi-meshes coupled cathodes enhanced performance of electrochemical water softening system, Separation and Purification Technology, 217 (2019) 128-136.

[189] W. Su, R. Pan, Y. Xiao, X. Chen, Membrane-free electrodeionization for high purity water production, Desalination, 329 (2013) 86-92. 


\section{Acknowledgements}

What a wonderful time to look back on the past four years.

It was an adventure for me at the beginning, but soon it became a pleasant trip. That is impossible without you girls and guys. That is the reason why I want to thank you at the end of this book. Please forgive my omission in naming all the names. I believe the real interaction we had is more important than being acknowledged in this dissertation.

My first appreciation goes to my supervision team: Cees, Michel, and Renata. It is a real pleasure to be part of your team. Renata, you are the first person that I got in contact. I still remember the day before I had the interview with Cees, you sent me an email, explaining the project and kindly remind me of the pronunciation of "Cees" (case). I truly like the way you talk, behave and treat others. I appreciate your critical comments on our papers even sometimes it takes time to take them. I am grateful for your tremendous guidance and support. And so many things.... Thank you!

Cees, the first time we met was during the recruitment challenge. Thank you for offering me the opportunity to pursue my PhD in Wetsus and Wageningen University. Thank you for your trust, support, and guidance. Thank you for providing me the freedom to explore my interest while also being an excellent mentor to me, including your critical reflection on the direction of our project. I am genuinely impressed by your leadership and your vision of combining scientific excellence and commercial relevance in water technology. It is a valuable experience for me to have the luck to work with you and learn from you. I believe this will be reflected in my career in the future.

Michel, what a great person you are. You are probably the most positive and passionate person that I know. I am delighted that you are my daily supervisor. You are always there when I need you. I couldn't thank you more for the trust and patience you have shown to me, the intelligence you have shared, the passion you have shown on our project, and the endless support you have expressed to me. You made my work in Wetsus easier and more efficient. Thank you!

Philipp K., although you are not my official supervisor, you are more than a supervisor to me. You are easy-going. I feel comfortable to ask for your help, to talk, and to share my work and life with you. Thank you for being so supportive. I believe our cooperation will continue. 
My thanks also go to all my students: Bingnan, Jorrit, Mengyi, Ipan, Emilio, and Santosh. I am grateful for your dedication and contribution to my work. The supervision experience I had with you is true wealth for my academic career.

This dissertation would not be possible without strong support from the support team of Wetsus. I want to thank the secretaries (Anke, Linda, Trienke, Nynke, Willy) for all administrative arrangements. I want to thank the canteen people (Gerben, Riet) for the nice food, smiles and all the "GOOD MORNING" to me (sometimes to Yin). I want to thank our amazing technicians. Wim, thank you for managing all the facilities in Wetsus. Jan Tuinstra, thank you for cutting and welding the titanium electrodes. John, thank you for helping with the auto sampling machine. Ernst, as my chief technician, you are always there, ready to help and made all my ideas into reality. More than that, I enjoyed our talk about family. Gerrit, a big thank to you for all the purchase you did for me, and our open talks about personal life. Rienk, thank you for helping with all my IT requests/problems. Marianne, Mieke, Janneke, Jan-Willem, Ton, Lisette and Jelmer, a big thank to you for the tremendous analysis you have done for me. Jelmer, I appreciate your help in SEM-EDS and BET analysis, and especially, let me get in Wetsus on Saturday afternoon (to get the key of my house). Ton, because of my wrong pronunciation, you became the first person to guide me on my arrival day in Wetsus. Thank you for being so kind. More than that, I want to thank you for helping with Raman analysis in the darkroom, the same thank to Jan-Willem. For all Wetsus support team members, I sincerely appreciate your help and the way how you react to my questions and requests. A big "thank you" to all of you.

To my officemates, it has been a pleasure to be part of the office, because of you. Natasha, I remember the day you walked with me and introduced me to all colleagues on my arrival day in Wetsus, office by office. Thank you! Fabian, we were officemate in both downstairs and upstairs. Thank you for all the funny things you have shared with me. Raquel, you are probably the most organized person I know. Sandra, I am jealous of your social and language skills. Casper $G$., you are quiet in the office as me. I enjoyed all the conversions we had in the office, in borrels, and on the train. Evelyn, I am glad to meet you in the office before I move to upstairs, and I wish you the best for your $\mathrm{PhD}$. Qingdian, as both officemate and housemate, I am sure our friendship with continue.

Hakan \& Gijs, my lovely paranymphs. Having two shooting men on my side is absolutely the right decision. Hakan, I lost interest in playing Ping-Pong, as it is getting hard to beat you. Gijs, how can I forget you. It is incredible to have your friendship (to hear about informal 
Wetsus development-Gossips). I love to see that you are with Catarina.

I want to extend my thanks to some of my colleagues out of my office. Gaofeng, Zexin, Yujia, Xiaoxia, Ruizhe, and Li, my lovely Chinese friends in Wetsus, thank you for being around and occasionally our chat in Chinese. This made me less homesick. Ricardo, how nice it is to do all calcium phosphate stuff with you. Prashanth, for all the horror movies we watched together and the chat we had, they are memorable. Roel, thank you for coaching me on grant application at the last stage of my PhD. Bert, I think I never get your humor, but you have my full respect. Johannes, I do understand your jokes and you have my full respect too. Yin, it is a great pleasure to have shared the house with you for almost three years. You made my stay in the Netherlands much more comfortable. Thank you also for the cooking lessons. My special thanks go to Antoine, Ilse, Suyash, Victor, Enas, Paulina, Hector, Diego, Carlo, Doekle, Michel, Jan G., for all the nice chats we had. It has always been a pleasure to talk to you.

I want to thank Jan M., Jouke, Tom, Annemiek, Adam, Maarten, Hardy, Bert, and anyone else who have shared their wisdom with me.

I want to thank the Wetsuits team (Henk, Jannie, Shuyana, Lisette, Emad). It has been a pleasure to do Wetsuits with you.

I thank Prof Bitter, Prof. Falk, Dr. Philipp, and Dr. Perry, for your efforts to examine my thesis. I hope you had some fun, but I know it was not an easy task.

I want to thank the "Resource Recovery" theme members for all the fruitful discussions and financial support. I like a lot the open, respect and friendly atmosphere in this theme. Specifically, I want to thank Pau, Monir, Sam, Casper B., Steffen, Gaofeng, Marianna(s), and Sebastian for your accompany in "Resource Recovery" theme. Casper B, Steffen, and Marianna, I miss the gather together we had just before theme meetings.

I want to thank the people who work at WWTP Leeuwarden for their generous help in wastewater sampling.

To (bio)crystallization people (Jan Weima, Ricardo, Annemerel, Adrian, Silvia, Cris, and Bingnan), it is always lovely to share my work and learn yours in this small group.

I also want to thank the organizers and participants of our $\mathrm{PhD}$ trip to Chile. Karine, Steffen, Paulina, Tania, I want to thank you in particular for your accompany, as a group from Wetsus in this PhD trip.

I would also like to thank my Wageningen friends and colleagues. Although I am stationed in 
Leeuwarden, I never feel disconnected from our department because of you. Vinnie and Ilse, I appreciate your help on XRD characterization. Liesbeth, for all your secretary's work, it is much appreciated. I always feel comfortable to contact you. $\mathrm{Hub}$, it is nice to hear from you about ETE developments in China. Dandan, Momo, Shuwen, Yu, Shiyang, Shengle and Bingnan, my Chinese-speaking friends in Wageningen, because of you, I always feel motivated to visit Wageningen and I love to hear your developments and stories.

最后的最后, 我想感谢我的家人。你们给予的无私的爱与关怀, 让我能够一直勇敢 前行！感谢我的妻子袁晗, 感谢你一直以来的爱与陪伴。我能想到的最美好的事, 就是与你一起, 走过春夏秋冬, 海角天涯。谢谢你, 我爱你!

Yang Lei

October 30, 2019

Leeuwarden 


\section{About the author}

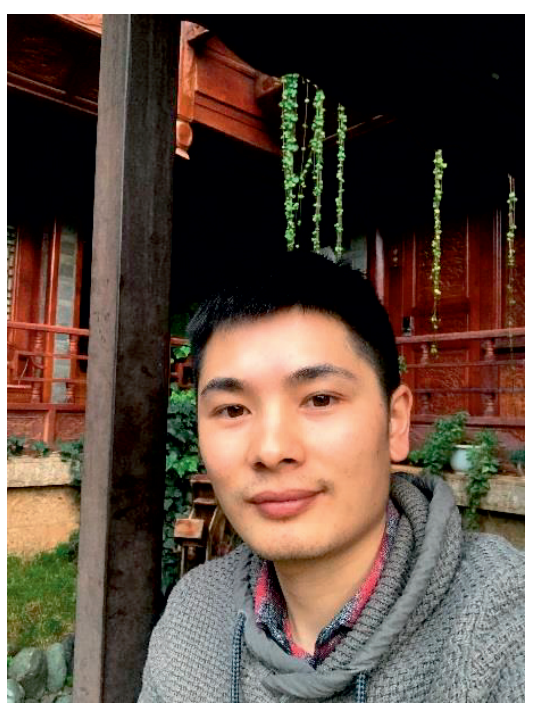

Yang Lei was born on Mar 7, 1989 in Tongcheng, China. In 2012, he obtained bachelor's degree from Hunan University of Science and Technology (HNUST). His bachelor thesis entitled "Remediation of oily wastewater by magnetic assisted porous ceramics" was awarded an excellent thesis of HNUST. From 2012 until 2015, he did a three-year master program in Wuhan University, under the supervision of Professor Zhang. In this period, he visited National Cheng Kung University and stayed in Professor Huang's group as an exchange student over five months. He received a couple of prizes in master studies, like the Graduate Student Academic Innovation Award and Outstanding Graduates of Wuhan University. His master thesis entitled "Activation of persulfate by novel ways: implications to the destruction of organic pollutants" was awarded Outstanding Master Thesis of Hubei Province, China. From 2016 on Yang started working at Wetsus on a PhD project "electrochemical phosphorus removal and recovery". Meanwhile, he is a Marie Sklodowska-Curie fellow and a $\mathrm{PhD}$ candidate in the department of Environmental Technology, Wageningen University. In 2018, he received the prestigious "Chinese Government Award for Outstanding Self-financed Students Abroad". In 2019, he received the prestigious Marcel Mulder Prize. 


\section{List of publications}

1. Lei, Yang, Emilio Geraets, Michel Saakes, Renata D. van der Weijden, and Cees J.N. Buisman. "Electrochemical removal of phosphate in the presence of calcium at low current density: precipitation or adsorption?" Water Research, 169 (2020): 115207.

2. Lei, Yang, Michel Saakes, Renata D. van der Weijden, and Cees J.N. Buisman. "Electrochemically mediated calcium phosphate precipitation from phosphonates: implications on phosphorus recovery from non-orthophosphate". Water Research, 169 (2020): 115206.

3. Lei, Yang, Santosh Narsing, Michel Saakes, Renata D. van der Weijden, and Cees J.N. Buisman. "Calcium carbonate packed electrochemical precipitation column: new concept of phosphate removal and recovery” Environmental Science \& Technology, 53, no. 18 (2019): 10774-10780.

4. Lei, Yang, Mengyi Du, Philipp Kuntke Michel Saakes, Renata D. van der Weijden, and Cees J.N. Buisman. "Energy efficient phosphorus recovery by microbial electrolysis cell induced calcium phosphate precipitation" ACS Sustainable Chemistry \& Engineering, 7, no. 9 (2019): 8860-8867.

5. Lei, Yang, Jorrit Christiaan Remmers, Michel Saakes, Renata D. van der Weijden, and Cees J.N. Buisman. "Influence of cell configuration and long-term operation on electrochemical phosphorus recovery from domestic wastewater." ACS Sustainable Chemistry \& Engineering 7, no. 7 (2019): 7362-7368.

6. Lei, Yang, Ipan Hidayat, Michel Saakes, Renata D. van der Weijden, and Cees J.N. Buisman. "Fate of calcium, magnesium and inorganic carbon in electrochemical phosphorus recovery from domestic wastewater." Chemical Engineering Journal 362 (2019): 453-459.

7. Lei, Yang, Bingnan Song, Michel Saakes, Renata D. van der Weijden, and Cees J.N. Buisman. "Interaction of calcium, phosphorus and natural organic matter in electrochemical recovery of phosphate." Water Research 142 (2018): 10-17.

8. Lei, Yang, Jorrit Christiaan Remmers, Michel Saakes, Renata D. van der Weijden, and Cees J.N. Buisman. "Is there a precipitation sequence in municipal wastewater induced by electrolysis?"Environmental Science \& Technology 52, no. 15 (2018): 8399-8407.

9. Lei, Yang, Michel Saakes, Renata D. van der Weijden, and Cees J.N. Buisman. "Effects of current density, bicarbonate and humic acid on electrochemical induced calcium phosphate precipitation." Chemical Engineering Journal 342 (2018): 350-356.

10. Lei, Yang, Bingnan Song, Renata D. van der Weijden, Michel Saakes, and Cees J.N. Buisman. "Electrochemical induced calcium phosphate precipitation: importance of local pH."Environmental Science \& Technology 51, no. 19 (2017): 11156-11164. 


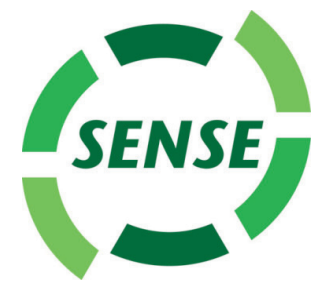

Netherlands Research School for the

Socio-Economic and Natural Sciences of the Environment

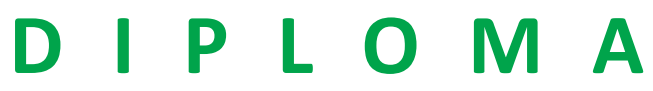

for specialised PhD training

The Netherlands research school for the Socio-Economic and Natural Sciences of the Environment

(SENSE) declares that

\section{Yang Lei}

born on 7 March 1989 in Tongcheng, China

has successfully fulfilled all requirements of the educational PhD programme of SENSE.

Wageningen, 6 December 2019
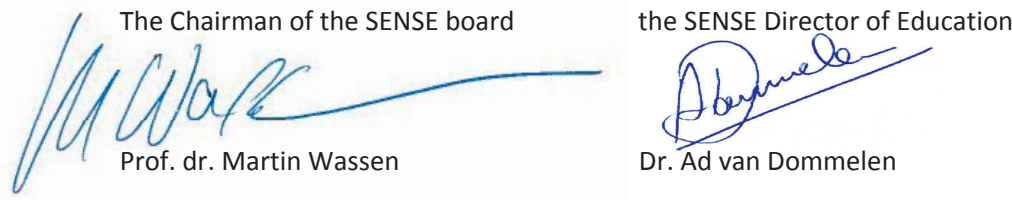

The SENSE Research School has been accredited by the Royal Netherlands Academy of Arts and Sciences (KNAW)

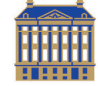

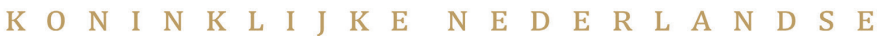

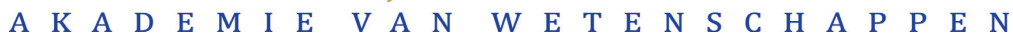




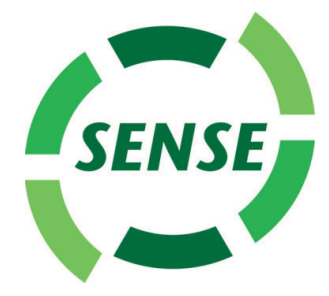

The SENSE Research School declares that Yang Lei has successfully fulfilled all requirements of the educational PhD programme of SENSE with a work load of $43.8 \mathrm{EC}$, including the following activities:

\section{$\underline{\text { SENSE PhD Courses }}$}

- Environmental research in context (2016)

- Research in context activity: 'Organizing the 6th biocrystallization workshop, Leeuwarden 2018'

- Model training for scenario analyses: river export of nutrients from land to sea (2018)

- Speciation and bioavailability of metals, organics and nanoparticles (2019)

\section{Other PhD and Advanced MSc Courses}

- Anaerobic wastewater treatment, IHE Delft (2016)

Presentation skills, Wetsus (2016)

Communication styles, Wetsus (2016)

Image processing for scientists: Adobe illustrator \& Design, Wetsus (2017)

- Talents, Wetsus (2017)

- How to supervise BSc/MSc students, Wetsus (2017)

- Grant application, BCF Career (2019)

\section{External training}

- Introduction course on pattern fitting for TOPAS, Bruker, The Netherlands (2017)

\section{Management and Didactic Skills Training}

- Supervising 6 MSc student with thesis entitled (2017-2019)

- Editor of Wetsuits, The internal journal of Wetsus (2018-2019)

\section{$\underline{\text { Selection of Oral Presentations }}$}

- Effects of natural organic matters on electrochemical induced calcium phosphate precipitation. The IWA 2017 Conference on Sustainable Wastewater Treatment and Resource Recovery: Research, Planning, Design and Operation, 7-10 November, Chongqing, China

- Influence of cell configuration and long-term operation on electrochemical phosphorus recovery. DACG annual meeting, 3 October 2018, Wageningen, The Netherlands

- Energy efficient phosphorus recovery by microbial electrolysis cell induced calcium phosphate precipitation. The 12th Environmental Conference for Doctoral Students, 811 October 2018, Beijing, China

- Electrochemical Phosphorus Removal and Recovery. Technological approaches for future (waste)water treatment and resource recovery, 6 March 2019, Santiago, Chile

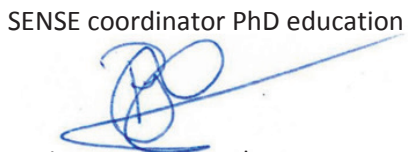

Dr. ir. Peter Vermeulen 
This work was performed in the cooperation framework of Wetsus, European Centre of Excellence for Sustainable Water Technology (www.wetsus.eu). Wetsus is co-funded by the Dutch Ministry of Economic Affairs and Ministry of Infrastructure and Environment, the Province of Fryslân, and the Northern Netherlands Provinces. The author would like to thank the participants of the research theme "Resource Recovery" for the fruitful discussions and their financial support.

Cover painting by Yujia Luo and Xin Liao. 